\title{
Investigation Into the Feasibility of Alternative Plutonium Shipping Forms
}

Prepared by J. Mishima, C. G. Lindsey

Pacific Northwest Laboratory Operated by

Battelle Memorial Institute

Prepared for

U.S. Nuclear Regulatory

Commission 


\section{NOTICE}

This report was prepared as an account of work sponsored by an agency of the United States Government. Neither the United States Government nor any agency thereof, or any of their employees, makes any warranty, expressed or implied, or assumes any legal liability of responsibility for any third party's use, or the results of such use, of any information, apparatus, product or process disclosed in this report, or represents that its use by such third party would not infringe privately owned rights.

\section{Availability of Reference Materials Cited in NRC Publications}

Most documents cited in NRC publications will be available from one of the following sources:

1. The NRC Public Document Room, 1717 H Street, N.W. Washington, DC 20555

2. The NRC/GPO Sales Program, U.S. Nuclear Regulatory Commission, Washington, DC 20555

3. The National Technical Information Service, Springfield, VA 22161

Although the listing that follows represents the majority of documents cited in NRC publications, it is not intended to be exhaustive.

Referenced documents available for inspection and copying for a fee from the NRC Public Document Room include NAC correspondence and irternal NRC memoranda; NRC Office of Inspection and Enforcement bulletins, circulars, information notices, inspection and investigation notices; Licensee Event Reports; vendor reports and correspondence; Commission papers; and applicant and licensee documents and correspondence.

The following documents in the NUREG series are available for purchase from the NAC/GPO Sales Program: formal NRC staff and contractor reports, NRC-sponsored conference proceedings, and NRC booklets and brochures. Also available are Regulatory Guides, NRC regulations in the Code of Federal Regulations, and Nuclear Regulatory Commission Issuances.

Documents available from the National Technical Information Service include NUREG series reports and technical reports prepared by other federal agencies and reports prepared by the Atomic Energy Commission, forerunner agency to the Nuclear Regulatory Commission.

Documents available from public and special technical libraries include ail open literature items, such as books, journal and periodical articles, and transactions. Federal Register notices, federal and state legislation, and congressional reports can usually be obtained from these libraries.

Documents such as theses, dissertations, foreign reports and translations, and non-NAC conference proceedings are available for purchase from the organization sponsoring the publication cited.

Single copies of NAC draft reports are available free upon written request to the Division of Technical Information and Document Control, U.S. Nuclear Regulatory Commission, Washington, DC 20555.

Copies of industry codes and standards used in a substantive manner in the NRC regulatory process are maintained at the NRC Library, 7920 Norfolk Avenue, Bethesda, Maryland, and are available there for reference use by the public. Codes and standards are usually copyrighted and may be purchased from the originating organization or, if they are American National Standards, from the American National Standards Institute, 1430 Broadway, New York, NY 10018. 
NUREG/CR-3007

PNL-4507

RT

\section{Investigation Into the Feasibility of Alternative Plutonium Shipping Forms}

Manuscript Completed: April 1983

Date Published: June 1928

Prepared by

J. Mishima, C. G. Lindsey

Pacific Northwest Laboratory

Richland, WA 99352

Prepared for

Division of Risk Analysis

Office of Nuclear Regulatory Research

U.S. Nuclear Regulatory Commission

Washington, D.C. 20555

NRC FIN B2424 


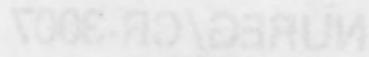

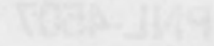

T月

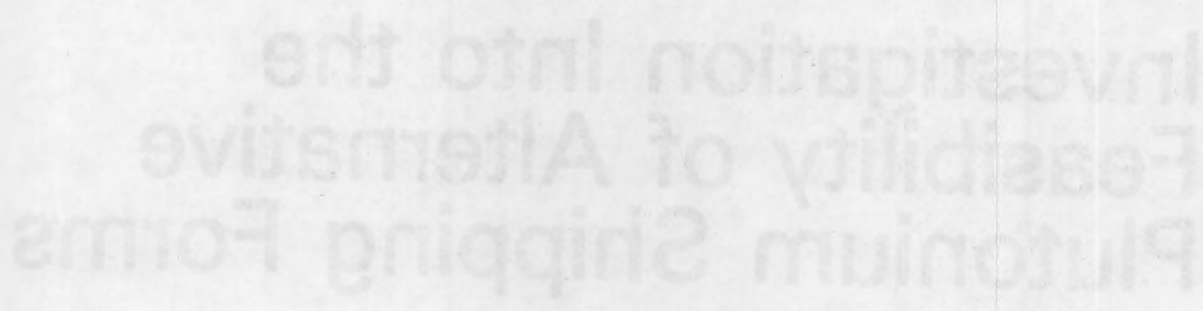

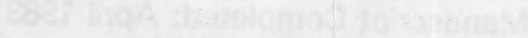

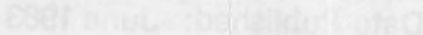

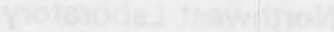

thas

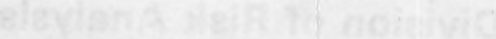

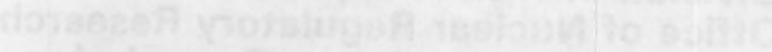

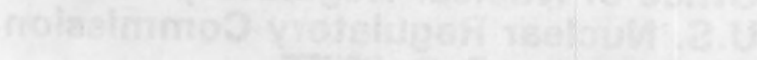

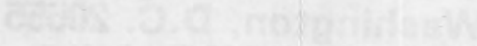

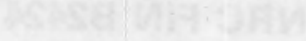




\section{ABSTRACT}

Pacific Northwest Laboratory (PNL), operated for the Department of Energy by the Battelle Memorial Institute, is conducting a study for the Nuclear Regulatory Commission on the feasibility of altering current plutonium shipping forms to reduce or eliminate the airborne dispersibility of $\mathrm{PuO}_{2}$ which might occur during a shipping accident. Plutonium used for fuel fabrication is currently shipped as a $\mathrm{PuO}_{2}$ powder with a significant fraction in the respirable size range. If the high-strength container is breached due to stresses imposed during a transportation accident, the $\mathrm{PuO}_{2}$ powder could be subject to airborne dispersion. The available information indicated that a potential accident involving fire accompanied by crush/impact forces would lead to failure of current surface shipping containers (no assumptions were made on the possibility of such a severe accident). Criteria were defined for an alternate shipping form to mitigate the effects of such an accident. Candidate techniques and materials were evaluated as alternate shipping forms by a task team consisting of personnel from PNL and Rockwell Hanford Operations (RHO). At this time, the most promising candidate for an alternate plutonium shipping form appears to be pressing $\mathrm{PuO}_{2}$ into unsintered ("green") pellets. These "green" pellets satisfy the criteria for a less dispersible form without requiring significant process changes. Discussions of all candidates considered are contained in a series of appendices. Recommendations for further investigations of the applicability of "green" pellets as an alternate shipping form are given, including the need for a cost-benefit study. 


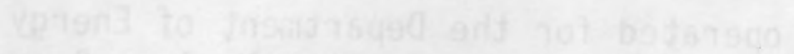

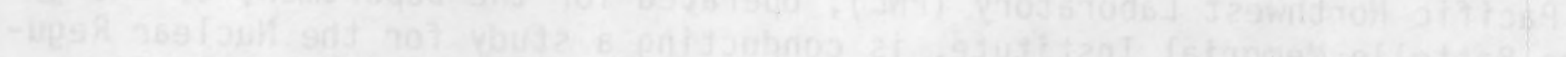

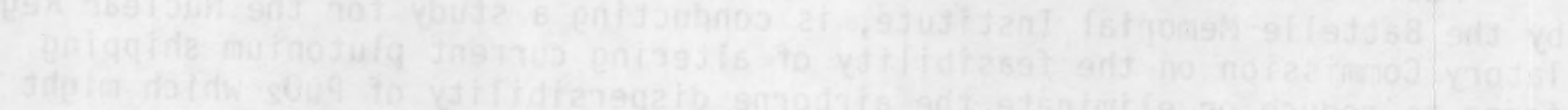

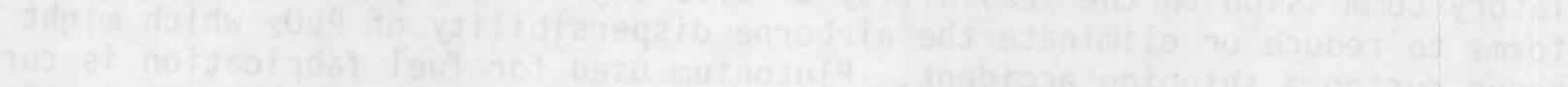

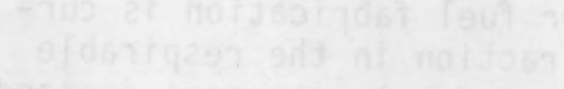
- $6 \mathbf{x}^{2}$ 


\section{ACKNOWLEDGMENTS}

This report culminates the efforts of a task team led by the authors to investigate alternative plutonium shipping forms. The authors wish to acknowledge their indebtedness and gratitude to the team members: A. L. Franklin, B. W. Mercer, and L. R. Bunnell of Pacific Northwest Laboratory; and J. V. Panesko and T. D. Cooper of Rockwell Hanford Operations. We also wish to thank S. F. Liebetrau for her fine job as our technical editor. Mr. D. 0. Nellis served as the NRC project manager, and we thank him for his assistance, guidance, and encouragement. 


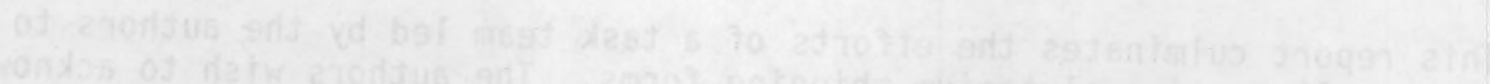

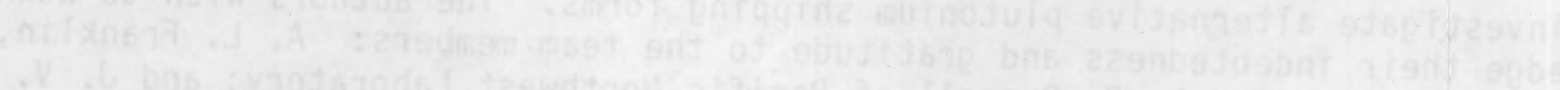

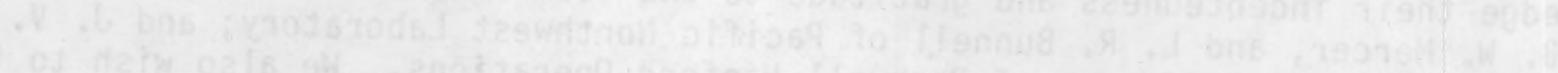

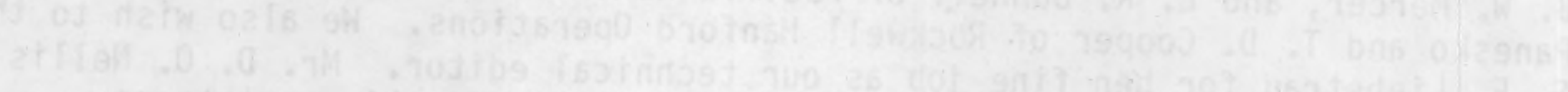

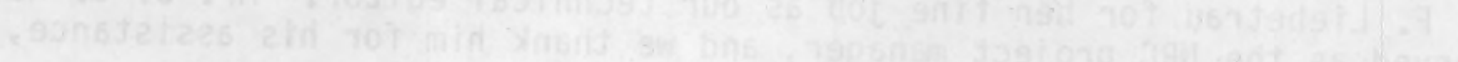

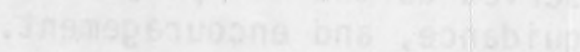




\section{CONTENTS}

ABSTRACT

ii

ACKNOWLEDGMENTS $\ldots \ldots \ldots \ldots \ldots \ldots \ldots \ldots \ldots \ldots \ldots \ldots \ldots \ldots \ldots \ldots \ldots \ldots \ldots \ldots \ldots$

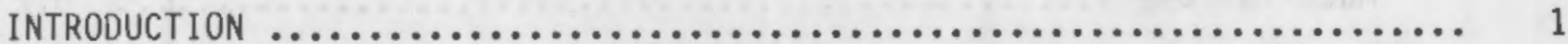

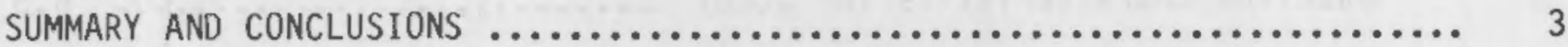

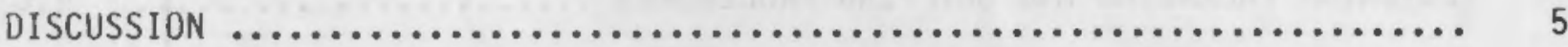

CURRENT SHIPPING PRACTICES AND PROCEDURES $\ldots \ldots \ldots \ldots \ldots \ldots \ldots \ldots \ldots \ldots . \ldots$

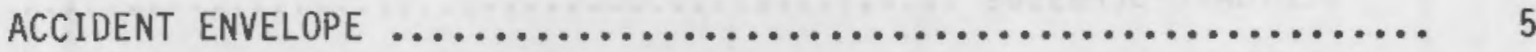

SELECTION CRITERIA AND CANDIDATE TECHNIQUES $\ldots \ldots \ldots \ldots \ldots \ldots \ldots \ldots \ldots$

EVALUATION OF CANDIDATE MATERIALS $\ldots \ldots \ldots \ldots \ldots \ldots \ldots \ldots \ldots \ldots \ldots \ldots \ldots$

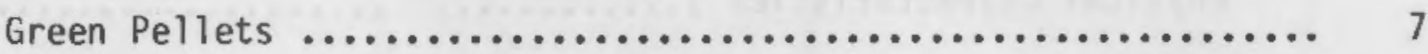

Sol-Gel Microspheres $\ldots \ldots \ldots \ldots \ldots \ldots \ldots \ldots \ldots \ldots \ldots \ldots \ldots \ldots \ldots . \ldots$

Inorganic Ion Exchangers $\ldots \ldots \ldots \ldots \ldots \ldots \ldots \ldots \ldots \ldots \ldots \ldots \ldots . \ldots \ldots$

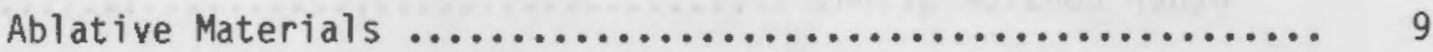

Alternative Packaging Materials ...................... 9

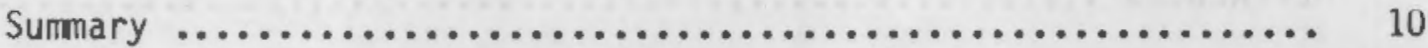

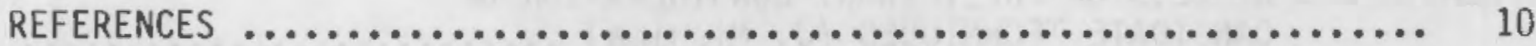

APPENDIX A - TRANSPORTATION ACCIDENT CHARACTERIZATION

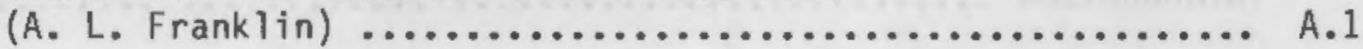

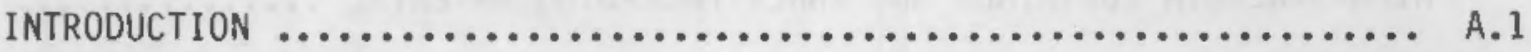

PLUTONIUM TRANSPORT PACKAGING $\ldots \ldots \ldots \ldots \ldots \ldots \ldots \ldots \ldots \ldots \ldots \ldots \ldots \ldots \ldots \ldots \ldots \ldots$

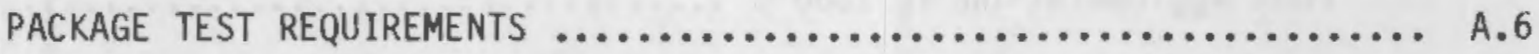

HOSTILE ENVIRONMENTS ANTICIPATED FOR PACKAGES $\ldots \ldots \ldots \ldots \ldots \ldots \ldots \ldots \ldots$

PACKAGE CONTENT ENVIRONMENT: TEST RESULTS $\ldots \ldots \ldots \ldots \ldots \ldots \ldots \ldots \ldots \ldots . \ldots \ldots$

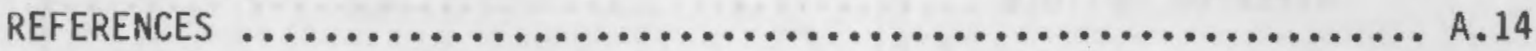


APPENDIX B - CRITERIA FOR SELECTION OF ALTERNATIVE PLUTONIUM SHIPPING FORMS (J. Mishima and C. G. Lindsey) ............ B.1

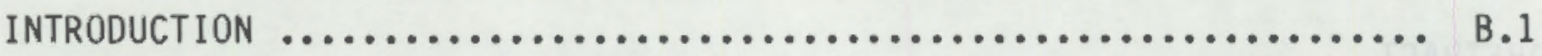

CHARACTERISTICS OF PLUTONIUM DIOXIDE SHIPPED $\ldots \ldots \ldots \ldots \ldots \ldots \ldots \ldots \ldots \ldots \ldots \ldots, 2$

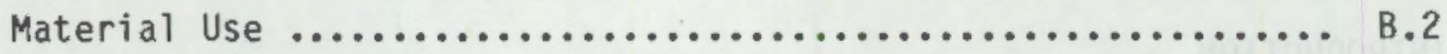

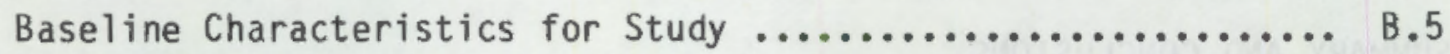

PLUTONIUM PACKAGING AND SHIPPING PROCEDURES $\ldots \ldots \ldots \ldots \ldots \ldots \ldots \ldots \ldots \ldots$

Inner Packaging Considerations $\ldots \ldots \ldots \ldots \ldots \ldots \ldots \ldots \ldots \ldots \ldots \ldots \ldots$, B.7

Accident Stresses $\ldots \ldots \ldots \ldots \ldots \ldots \ldots \ldots \ldots \ldots \ldots \ldots \ldots \ldots \ldots \ldots \ldots \ldots$, B.7

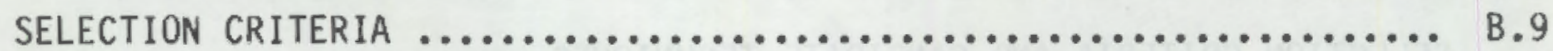

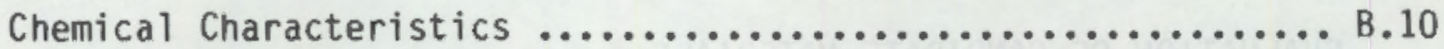

Physical Characteristics ............................... B.10

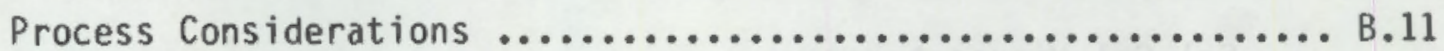

Transport Considerations $\ldots \ldots \ldots \ldots \ldots \ldots \ldots \ldots \ldots \ldots \ldots \ldots \ldots \ldots \ldots$, B.11

Other Considerations $\ldots \ldots \ldots \ldots \ldots \ldots \ldots \ldots \ldots \ldots \ldots \ldots \ldots \ldots \ldots$, B.11

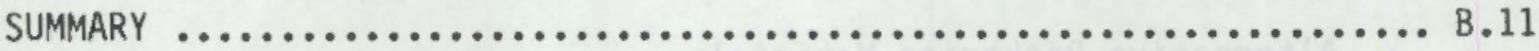

REFERENCES $\ldots \ldots \ldots \ldots \ldots \ldots \ldots \ldots \ldots \ldots \ldots \ldots \ldots \ldots \ldots \ldots \ldots \ldots \ldots \ldots \ldots \ldots, 12$

$\begin{aligned} \text { APPENDIX } C & - \text { RESULTS OF PRELIMINARY CONSIDERATION OF } \\ \text { CANDIDATE TECHNIQUES }(\text { J. Mishima) } \ldots \ldots \ldots \ldots \ldots \ldots \ldots \ldots \ldots \ldots & \ldots \ldots \ldots \ldots\end{aligned}$

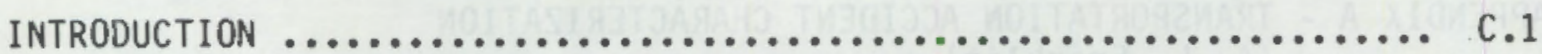

HIGH-STRENGTH CONTAINER AND INNER PACKAGING MATERIAL $\ldots \ldots \ldots \ldots \ldots c .2$

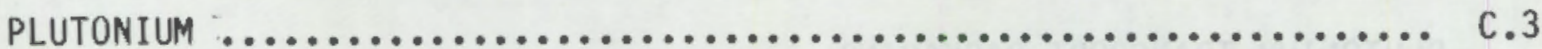

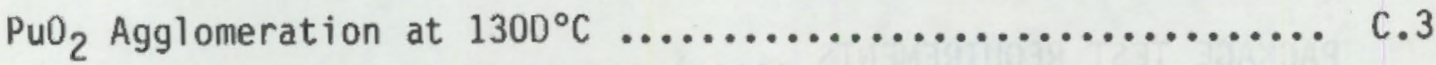

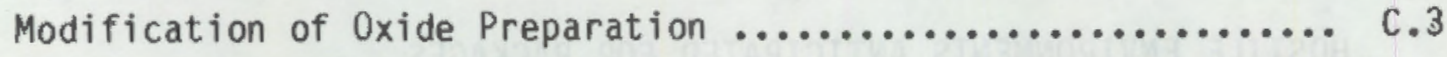

Green Pressing Pellets ............................... C.4

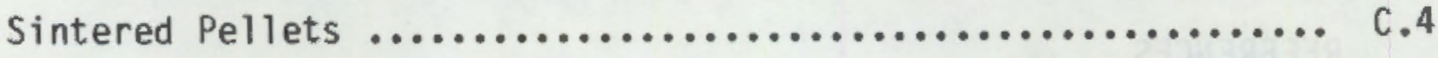


Sol-Gel Production of Plutonium 0xide Microspheres ........... C.4

Freeze-Dry Processing $\ldots \ldots \ldots \ldots \ldots \ldots \ldots \ldots \ldots \ldots \ldots \ldots \ldots \ldots \ldots . . \ldots$

Immobilization of $\mathrm{PuO}_{2}$ in Metal Lattice ................. C.5

Immobilization of $\mathrm{Pu}_{2}$ in Ceramic/Salt Lattice $\ldots \ldots \ldots \ldots \ldots \ldots$... 5

Change in the Chemical Form of Plutonium $\ldots \ldots \ldots \ldots \ldots \ldots \ldots \ldots$...

Use of Inorganic Ion Exchangers $\ldots \ldots \ldots \ldots \ldots \ldots \ldots \ldots \ldots \ldots \ldots$. 5

CONCLUSIONS $\ldots \ldots \ldots \ldots \ldots \ldots \ldots \ldots \ldots \ldots \ldots \ldots \ldots \ldots \ldots \ldots \ldots \ldots \ldots \ldots \ldots$

REFERENCES $\ldots \ldots \ldots \ldots \ldots \ldots \ldots \ldots \ldots \ldots \ldots \ldots \ldots \ldots \ldots \ldots \ldots \ldots \ldots \ldots \ldots \ldots \ldots \ldots$

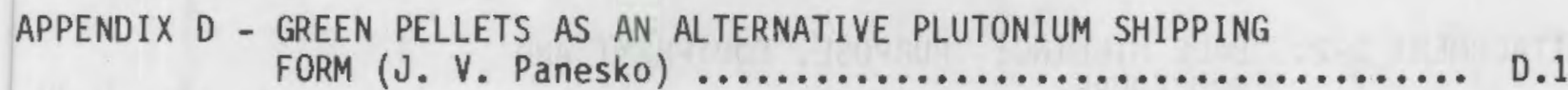

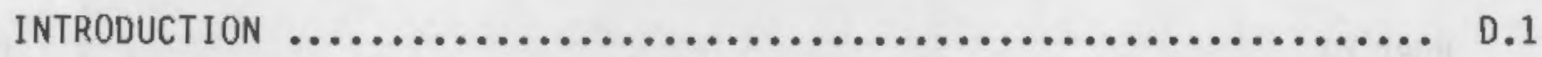

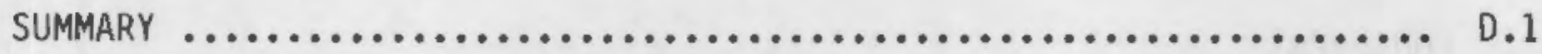

Advantages of Green Pellet Shipping Form ................ D.1

Disadvantages of Green Pellet Shipping Form .............. D.2

Need for Future Work $\ldots \ldots \ldots \ldots \ldots \ldots \ldots \ldots \ldots \ldots \ldots \ldots \ldots \ldots . \ldots . \ldots \ldots \ldots$

PROGRAMS THAT USED GREEN PELLETS $\ldots \ldots \ldots \ldots \ldots \ldots \ldots \ldots \ldots \ldots \ldots \ldots \ldots \ldots . \ldots \ldots$

Plutonium-Metal Fuel Forms $\ldots \ldots \ldots \ldots \ldots \ldots \ldots \ldots \ldots \ldots \ldots \ldots . \ldots \ldots$

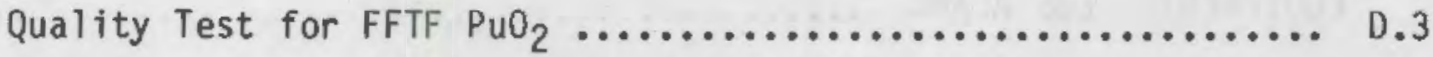

Plutonium Fuel for Nuclear Power Systems ............... D.4

PREPARATION FOR GREEN PELLETS $\ldots \ldots \ldots \ldots \ldots \ldots \ldots \ldots \ldots \ldots \ldots \ldots \ldots \ldots \ldots . \ldots . . . . . \ldots$

Source Materials $\ldots \ldots \ldots \ldots \ldots \ldots \ldots \ldots \ldots \ldots \ldots \ldots \ldots \ldots \ldots \ldots \ldots . \ldots . . \ldots$

Pretreatment of Oxide Before Pressing ................. D.9

Pressing Green Pellets ............................ D.12

BEHAVIOR OF GREEN PELLETS IN ACCIDENT CONDITIONS $\ldots \ldots \ldots \ldots \ldots \ldots \ldots \ldots . . \ldots$

Stability in Fire $\ldots \ldots \ldots \ldots \ldots \ldots \ldots \ldots \ldots \ldots \ldots \ldots \ldots \ldots \ldots \ldots . . \ldots . . \ldots \ldots$

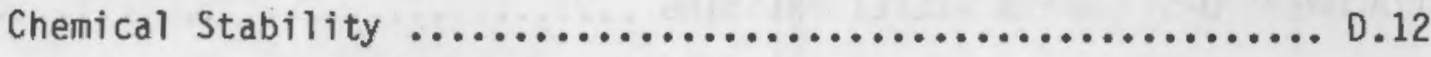


Reaction with Extinguishing Agents ..................... D. 13

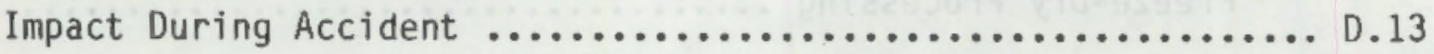

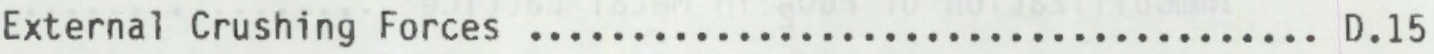

Environmental Studies of Pellets and Fragments .............. D.18

Conversion of Green Pellets to 0xide ..................... D.21

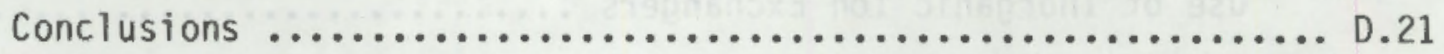

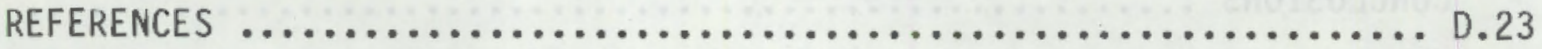

ATTACHMENT D-1: CRITERIA FOR ALTERNATIVE SHIPPING FORMS ............. D.29

ATTACHMENT D-2: BALL MILLING: PURPOSE, EQUIPMENT AND

PROCEDURE .................................. D. 30

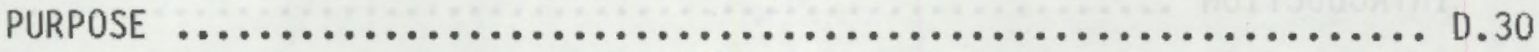

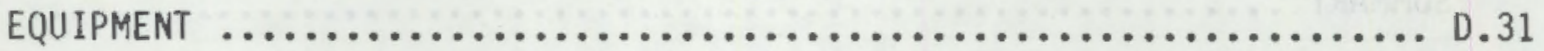

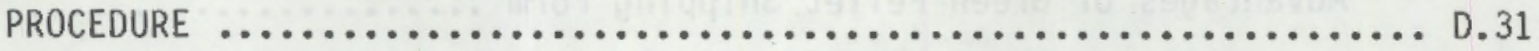

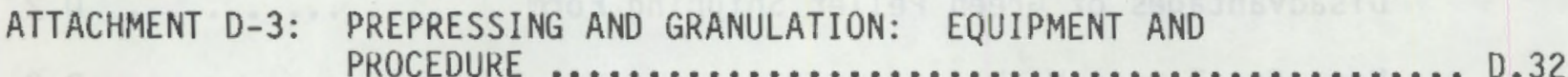

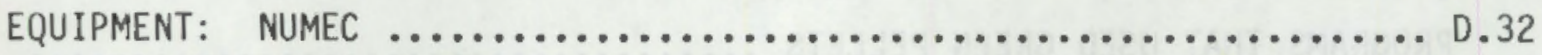

EQUIPMENT: WESTINGHOUSE HANFORD $\ldots \ldots \ldots \ldots \ldots \ldots \ldots \ldots \ldots \ldots \ldots \ldots \ldots \ldots \ldots \ldots \ldots, 32$

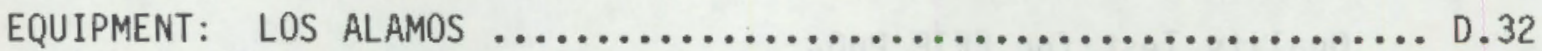

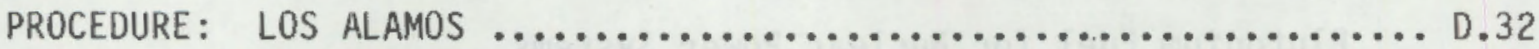

ATTACHMENT D-4: ADDITION OF BINDER TO STRENGTHEN GREEN PELLETS $\ldots \ldots \ldots . . .2 .34$

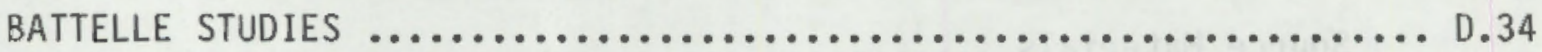

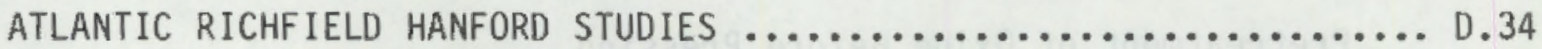

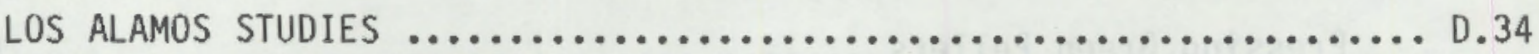

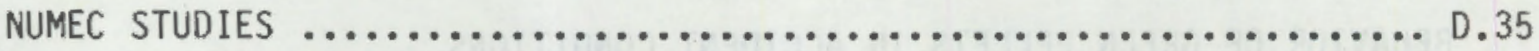

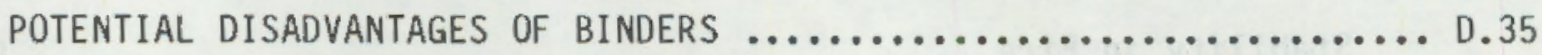

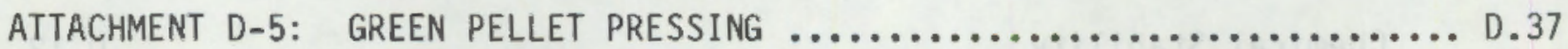


Early Studies at Hanford $\ldots \ldots \ldots \ldots \ldots \ldots \ldots \ldots \ldots \ldots \ldots \ldots, 0.38$

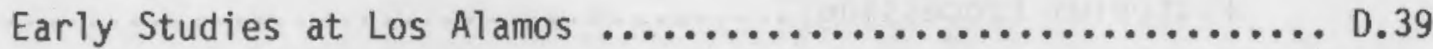

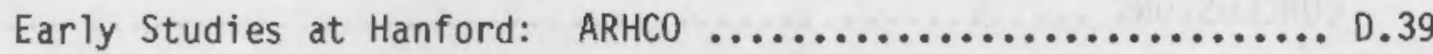

Later Studies at Hanford: Pacific Northwest Laboratory ...... D.40

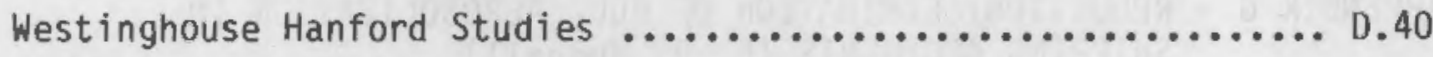

Summary of Presses Used in Green Pellet Studies ............ D.40 APPENDIX E - SHIPPING CHARACTERISTICS OF SOL-GEL MICROSPHERES

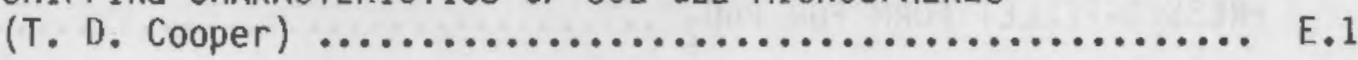

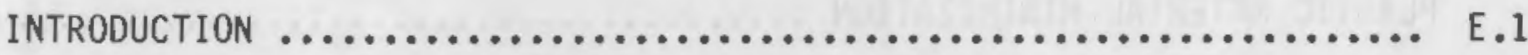

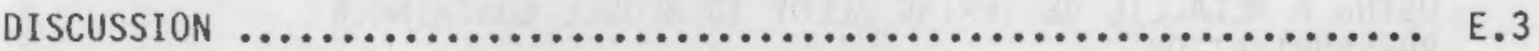

Sol-Gel Applications..$\ldots \ldots \ldots \ldots \ldots \ldots \ldots \ldots \ldots \ldots \ldots \ldots \ldots$, E.3

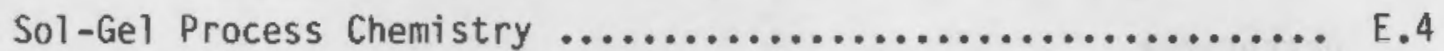

Sol-Gel Processes Development...$\ldots \ldots \ldots \ldots \ldots \ldots \ldots \ldots \ldots \ldots$, E -6

Physical and Chemical Particle Characteristics ............... E.14

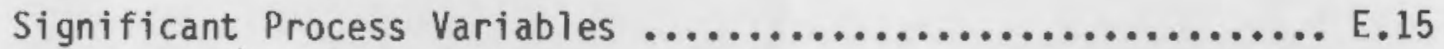

Impact on Shipping Procedures and Equipment $\ldots \ldots \ldots \ldots \ldots \ldots \ldots . .16$

Impact on Plutonium Recovery and Fuel Fabrication ............ E.17

Sol-Gel Particles in Accident Envelope Conditions ............. E.17

Future Trends in Plutonium Technology ..................... E.17

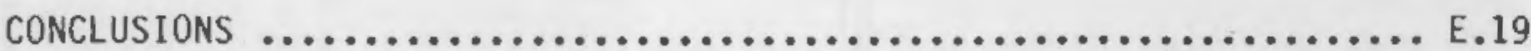

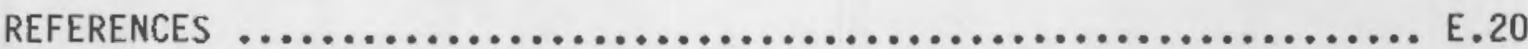

APPENDIX $F$ - EVALUATION OF INORGANIC ION EXCHANGERS AS AN ALTERNATE
SHIPPING FORM FOR PLUTONIUM (B. W. Mercer) $\ldots \ldots \ldots \ldots \ldots \ldots, \ldots .1$

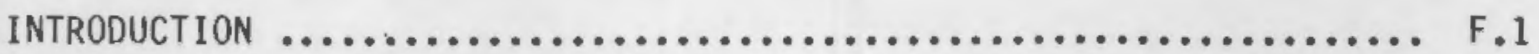

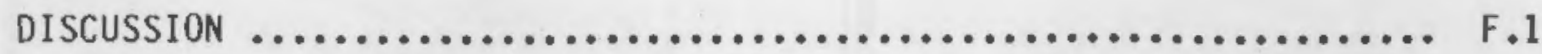




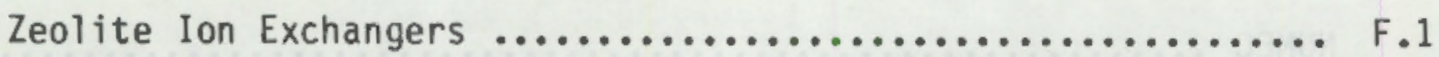

Inorganic Exchangers $\ldots \ldots \ldots \ldots \ldots \ldots \ldots \ldots \ldots \ldots \ldots \ldots \ldots \ldots, \ldots \ldots \ldots, 14$

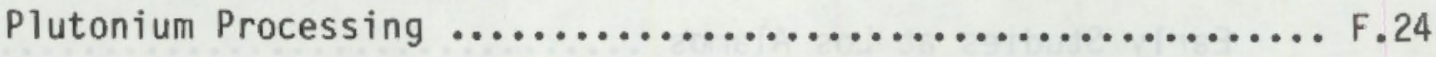

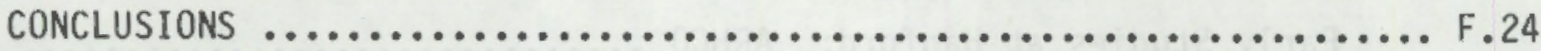

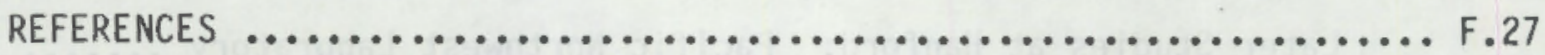

APPENDIX G - REDUCTION/ELIMINATION OF PUO 2 AEROSOLIZATION IN SHIPPING ACCIUENTS (L. R. Bunne11) .................... G.1

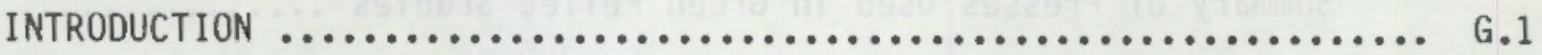

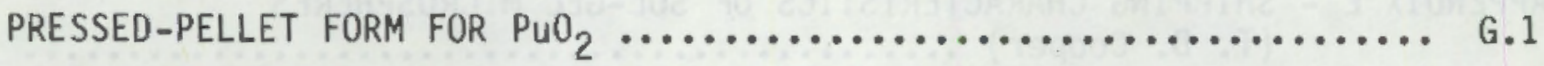

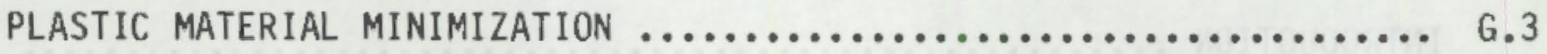

USING A METALLIC GETTERING ALLOY TO REDUCE CONTAINMENT

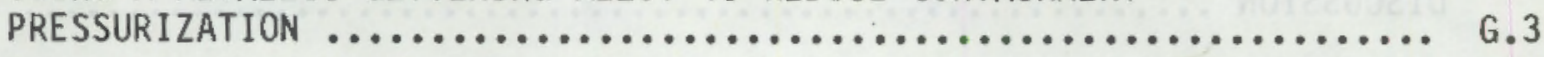

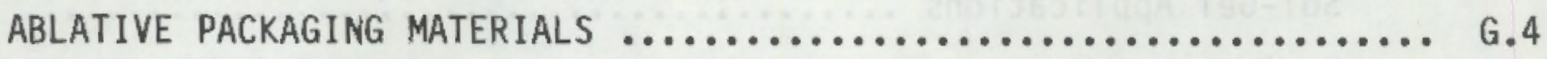

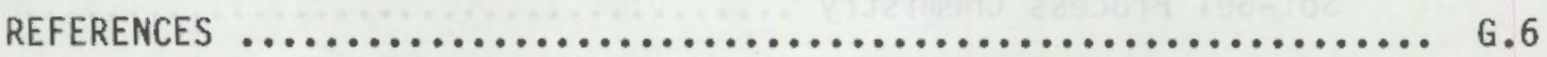




\section{FIGURES}

A-1. L-10 Container $\ldots \ldots \ldots \ldots \ldots \ldots \ldots \ldots \ldots \ldots \ldots \ldots \ldots \ldots \ldots \ldots \ldots \ldots \ldots \ldots \ldots \ldots \ldots \ldots$, A.2

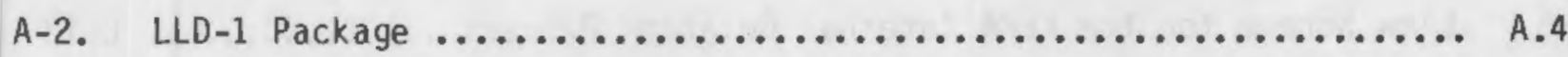

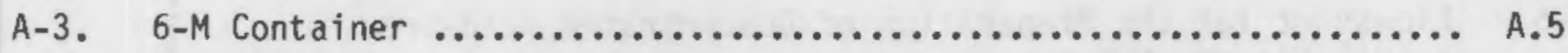

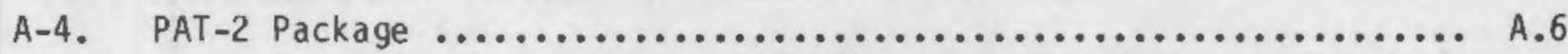

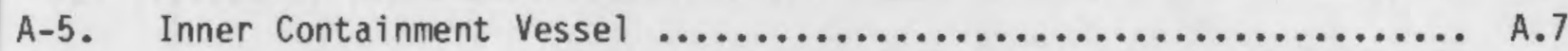

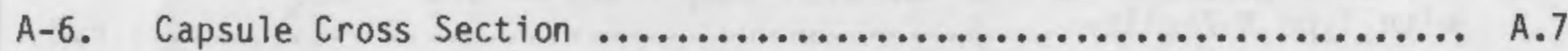

B-1. "Respirable Fraction" of Airborne Particles $\ldots \ldots \ldots \ldots \ldots \ldots \ldots \ldots$ B.2

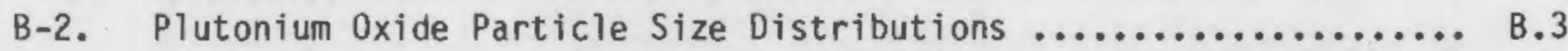

B-3. Nominal $\mathrm{PuO}_{2}$ Particle Size Distributions $\ldots \ldots \ldots \ldots \ldots \ldots \ldots \ldots \ldots \ldots \ldots \ldots \ldots \ldots$

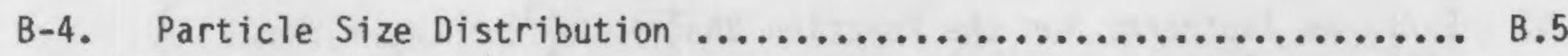

B-5. Plutonium Air Transportable Package $\ldots \ldots \ldots \ldots \ldots \ldots \ldots \ldots \ldots \ldots \ldots$ B. 6

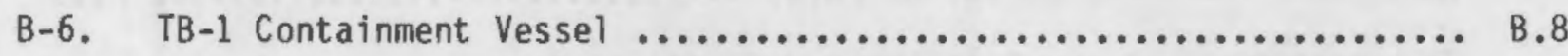

D-1. Green Pellet Density Versus Composition $\mathrm{UO}_{2}-\mathrm{PuO}_{2}$ Compacted

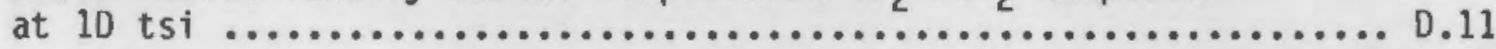

D-2. $\quad \mathrm{Pu}(238)_{2} \mathrm{O}_{2}$ Compressive U1timate Stress Versus Test Temperatures.... D.16

D-3. $\mathrm{Pu}(238) \mathrm{O}_{2}$ Compressive Ultimate Stress Versus Percent

Theoretical Pellet Density at Various Test Temperatures ......... D.17

D-4. $\quad \mathrm{Pu}(238) \mathrm{O}_{2}$ Compressive U1timate Stress Versus Grain Size at

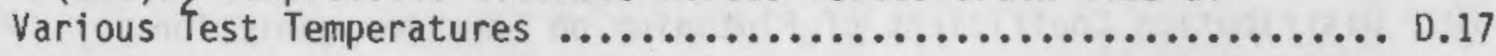

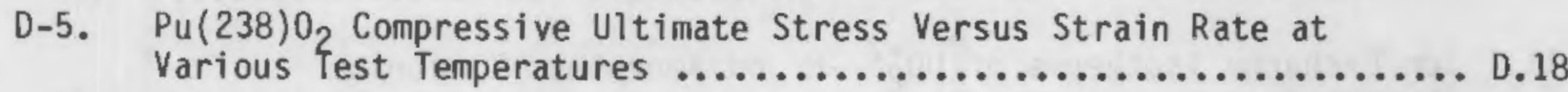

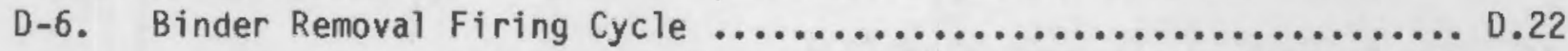

D-7. Effect of Pressing Pressure on Green Pellet Density ........... 0.39

E-1. ORNL Flow Sheet for the Preparation of $\mathrm{PuO}_{2}$ Sol $\ldots \ldots \ldots \ldots \ldots . . . . . . . .6$

E-2. ORNL-Modified APEX Process for the Preparation of Low-Nitrate
Plutonia Sol $\ldots \ldots \ldots \ldots \ldots \ldots \ldots \ldots \ldots \ldots \ldots \ldots \ldots \ldots \ldots \ldots \ldots \ldots \ldots \ldots \ldots \ldots \ldots \ldots$ 
E-3. Preparation Schemes for Urania and Plutonia Sols, CNEN Process ... E.10

E-4. Block Diagram of the SNAM Process for Preparation of $\mathrm{UO}_{2}, \mathrm{ThO}_{2}$

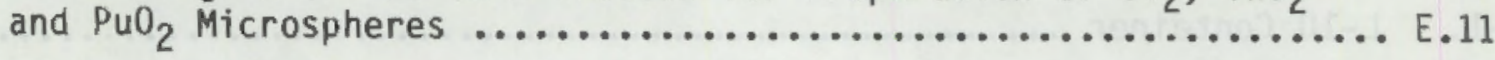

E-5. Flow Scheme for the KEMA Internal Gelation Process ................ 13

E-6. Flowsheet for the Preparation of Concentrated Acid-Free

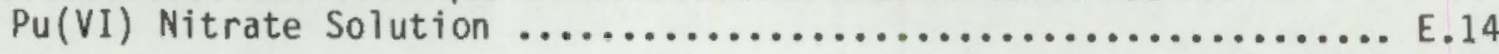

F-1. Temperature and Pressure Drop History $\ldots \ldots \ldots \ldots \ldots \ldots \ldots \ldots \ldots \ldots, \ldots$

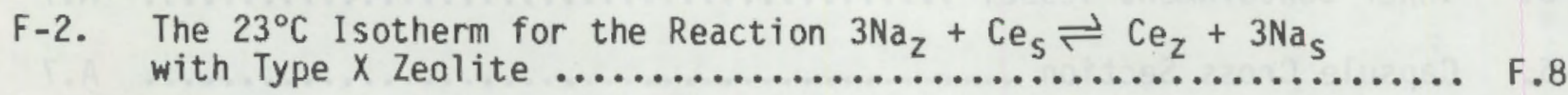

F-3. The $70^{\circ} \mathrm{C}$ Isotherm for the Reaction $3 \mathrm{Na}_{z}+\mathrm{Ce}_{s} \rightleftharpoons \mathrm{Ce}_{z}+3 \mathrm{Na}_{\mathrm{s}}$

with Type X Zeolite ..................................... F.9

F-4. The $25^{\circ} \mathrm{C}$ Isotherm for the Reaction $3 \mathrm{Na}_{2}+Y_{S} \rightleftharpoons Y_{Z}+3 \mathrm{Na}_{5}$

with Type $x$ Zeolite ..................................... F.9

F-5. Exchange Is otherms for the Reaction $3 \mathrm{Na}_{z}^{+}+\mathrm{La}_{s}^{+3} \rightleftharpoons \mathrm{La}_{z}+3 \mathrm{Na}_{s}$

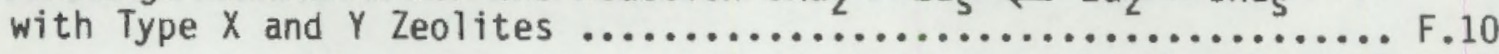

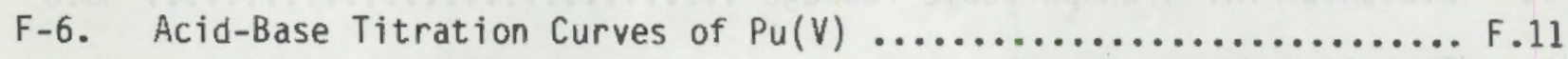

F-7. The Dependence of the Distribution Coefficients on the

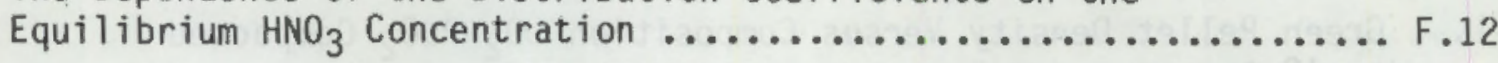

F-8. Change in the Distribution Coefficient of Zirconium Phosphate

with Nitric Acid Concentrate at $75^{\circ} \mathrm{C}$ and Equilibrium Time of

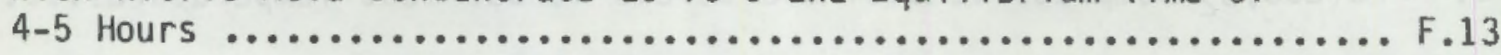

F-9. Distribution Coefficients of Certain Lanthanides and Actinides

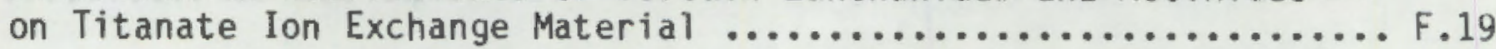

F-10. Distribution Coefficient of Plutonium on Some Inorganic Ion

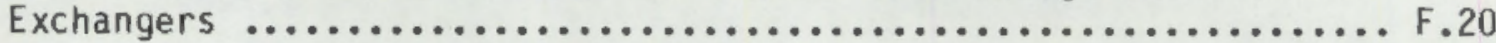

$\mathrm{F}-11$. I on Exchange Isotherms of $\mathrm{UO}_{2}^{+2}--\mathrm{H}+$ on Amorphous Zirconium

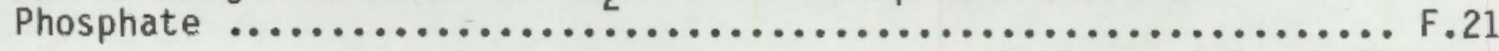

$\mathrm{F}-12$. Ion Exchange Isotherms of $\mathrm{UO}_{2}^{+2}--\mathrm{H}+$ on Semicrystalline

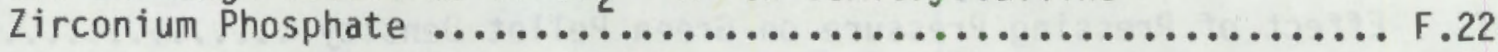

F-13. I In Exchange Isotherms of $\mathrm{UO}_{2}^{+2}--\mathrm{H}+$ on Crystalline

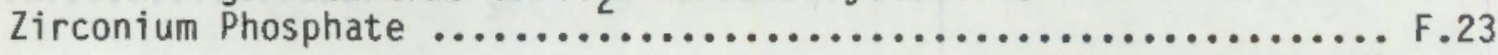

G-1. Conceptual Drawing of an Isostatic Pressing Arrangement which

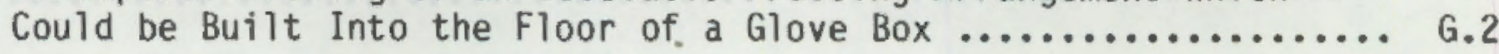




\section{TABLES}

A-1. Free Drop Distances $\ldots \ldots \ldots \ldots \ldots \ldots \ldots \ldots \ldots \ldots \ldots \ldots \ldots \ldots \ldots \ldots \ldots$, A.8

A-2. Accident Envelope Descriptions $\ldots \ldots \ldots \ldots \ldots \ldots \ldots \ldots \ldots \ldots \ldots \ldots \ldots \ldots . . .11$

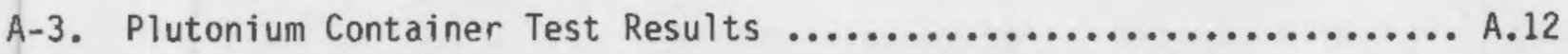

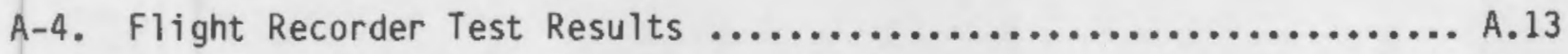

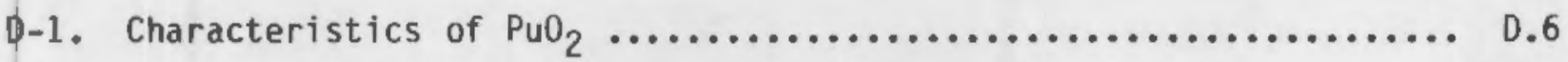

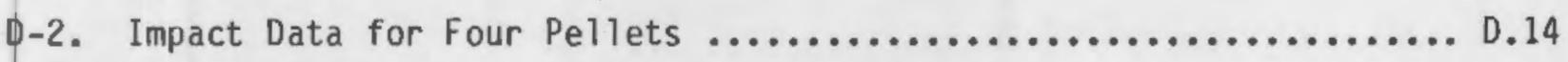

D-3. Fractional Distribution for Four Pellets $\ldots \ldots \ldots \ldots \ldots \ldots \ldots \ldots \ldots .14$

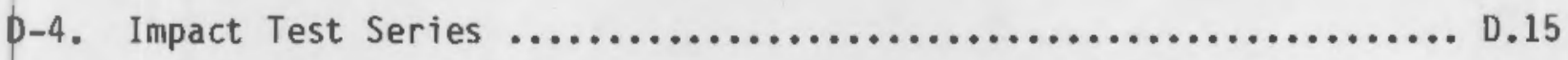

D-5. Plutonium-238 Removed by Rain Water from Pellet Fragments ....... D.20

p-6. Transport of Plutonium Through Soil $\ldots \ldots \ldots \ldots \ldots \ldots \ldots \ldots \ldots \ldots \ldots . . . \ldots \ldots$

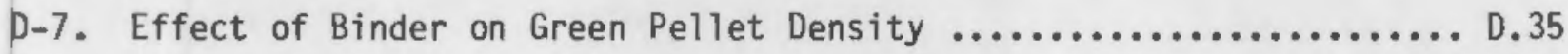

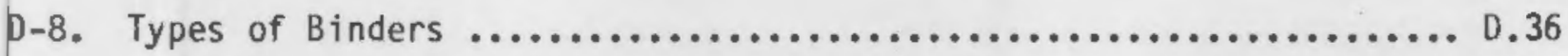

D-9. Effect of Pellet Length on Density ....................... D. 38

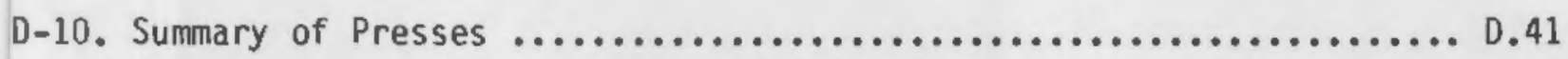

E-1. Assumed Maximum Credible Accident Conditions $\ldots \ldots \ldots \ldots \ldots \ldots \ldots . . .2$

F-1. Zeolite Types in Commercial Applications $\ldots \ldots \ldots \ldots \ldots \ldots \ldots \ldots$. F.2

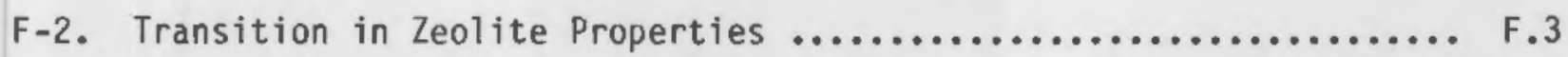

F-3. Properties of Selected Commercial Zeolites $\ldots \ldots \ldots \ldots \ldots \ldots \ldots \ldots$. F.4

F-4. Dust Loading and Particle Size Distribution $\ldots \ldots \ldots \ldots \ldots \ldots \ldots \ldots$ F.7

F-5. Properties of Selected Inorganic Ion Exchangers $\ldots \ldots \ldots \ldots \ldots \ldots \ldots$ F.16

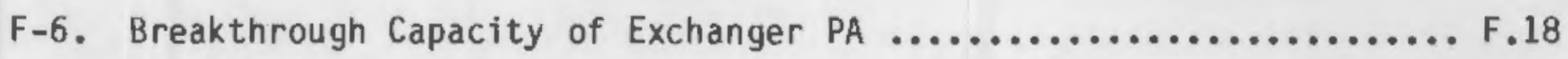

F-7. Characteristics of Zirconium Phosphate Samples $\ldots \ldots \ldots \ldots \ldots \ldots \ldots$. F.23

F-8. Qualitative Summary of Exchanger Properties $\ldots \ldots \ldots \ldots \ldots \ldots \ldots \ldots$ F.26 
G-1. Gettering Rates at $100^{\circ} \mathrm{C}$ and $400^{\circ} \mathrm{C}$ and at a Gas Pressure of $3 \times$ $10^{-6}$ torr for $1 \mathrm{~cm}^{2}$ of St 101 Alloy Getters, and After a Gas Exposure of $3 \times 10^{-5}$ torr-min 
INTRODUCTION

Plutonium is one of many radiotoxic materials whose transport is regulated. The responsibility for regulating shipments in the United States is shared by the Department of Transportation and the Nuclear Regulatory Commission. Under a Memorandum of Understanding between the Department of Transportation and Nuclear Regulatory Comrnission, dated 7/2/79, "The NRC develops safety standards for design and performance of packages for fissile materials and for quantities of other radioactive materials (other than low-specific-activity materials) exceeding Type A quantities" for specified features (44 FR 38690 1979). One of the findings of an NRC re-evaluation of its present regulations on air and other modes of transport of radioactive materials (NRC 1977) was that "large decreases in accident risks result in insignificant changes in the total (accident plus normal) risk." However, that study goes on to conclude that if significant social and/or economic benefits will accrue as a result of change in transportation procedures; then, regardless of the level of reduced risk, better alternatives should be sought.

The example given was the reduction in risk from potential accidents in which plutonium and polonium are the radioactive materials involved, accomplished by altering the materials to less dispersible physical forms. The level of information was deemed inadequate to permit an evaluation of this approach. The Transportation and Materials Risk Branch, U.S. Nuclear Regulatory Comission, is sponsoring an effort at the Pacific Northwest Laboratory to investigate the feasibility of alternative plutonium shipping forms. This report covers the evaluation of various candidate techniques and materials, based upon the information in the published literature, to reduce the radiological hazard of potential airborne releases of plutonium during shipping accidents. The report summarizes the detailed information (found in the appendices) for the various elements of the study. This form of presentation is used so that the reader can rapidly ascertain the conclusions of the study and find the documentation of greatest interest for particular needs. 


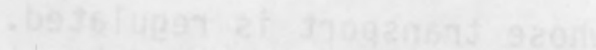

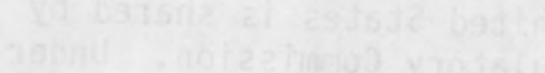

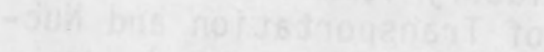

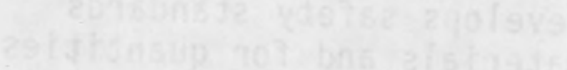

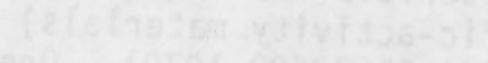

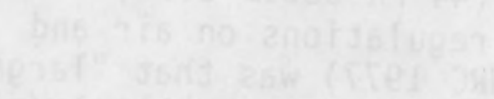

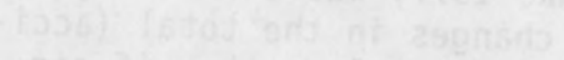

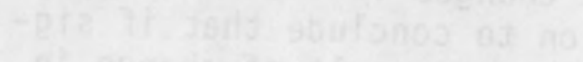

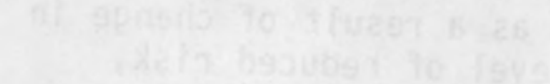

(2) 3 
In order to evaluate the feasibility of various techniques and materials for reducing the potential airborne dispersion of plutonium during transportation accidents, it is necessary to understand the conditions of imposed stresses which lead to failure of the high-strength container (and of its effectiveness as a barrier) and dispersion of the contained material. Two sources for the plutonium are considered--for fuel fabrication and as waste. The special characteristics of the $\mathrm{PuO}_{2}$ used for fuel fabrication are covered in Appendix B. It is assumed that plutonium generated as waste from uranium recovery can have two forms. For facilities designed to handle plutonium as waste, the plutonium is assumed to be in an immobilized, nondispersible form; then, the objectives of this study, providing a less-vulnerable shipping form, would be realized. Thus, this case is not considered. If plutonium is generated as a waste in facilities equipped to convert it into a dioxide powder, the existing process could be used to generate a coarser size distribution by adjusting process parameters, making it the same as handling the $\mathrm{PuO}_{2}$ powder for fuel fabrication. The latter case is addressed in this study. The current plutonium shipping packages and procedures and postulated accident envelope are discussed (Appendix A). Based upon available information, fire appears to be the condition most likely to lead to container failure and to conditions provoking the airborne release of plutonium dioxide powder. Criteria were defined to aid in selecting candidate techniques and materials (Appendix B), with the intent of reducing the airborne release from, at minimum, fires. However, candidates which do not eliminate all airborne release but reduce dispersibility can still be considered. Unstated criteria, at this stage, are the direct and indirect costs of proposed changes in process, handling, and shipping. Of the various techniques considered (discussed in Appendix C), four were chosen for further study: pelletization of the $\mathrm{PuO}_{2}$ powder (Appendix 0 ), production of Sol-Gel microspheres of $\mathrm{PuO}_{2}$ on mixed oxide (Appendix E), adsorption of plutonium on inorganic ion exchangers (Appendix F), and reduction of the pressures resulting from fires by the use of ablative materials or alternative (noncarbonaceous) packing materials (Appendix G).

Based upon currently available information, pelletization of $\mathrm{Pu}_{2}$ powders appears to be the most promising technique. Plutonium dioxide is chemically stable under the conditions postulated for fires and does not appear to react unfavorably under these conditions with fire-fighting materials currently in use. Subjecting the pellets to elevated temperatures is the accepted way to harden them, and pellets would be less friable in fires. The procedures and equipment needed to pelletize and reconstitute the powder are currently in use in the nuclear industry, so use of such a technique would minimize development time. Pelletizing increases the density of the material transported, providing the opportunity to increase the quantity per shipment or to include ablative materials without altering the container size.

As for the remaining alternatives, shipment of microspheres of $\mathrm{PuO}_{2}$ or the mixed (uranium and plutonium) oxide appears to of fer many advantages but would require a radical change in process, resulting in costly equipment changes and 
development. The information currently available on inorganic ion exchanges is too limited to make a good evaluation but indicates considerable development costs. No useful ablative or alternative packaging materials were identified, but the survey was necessarily limited by the time and funds available.

Our recommendations include a limited cost-benefit study on the use of unsintered ("green") $\mathrm{PuO}_{2}$ pellets and the outlining of a study plan to substantiate their effectiveness in reducing the airborne release of plutonium under shipping accident conditions. Potential requalification costs would be covered in such a study. 
DISCUSSION

The alternate plutonium shipping forms (AlPuf) study was organized in a chronological sequence of investigations which are reported in Appendices A through G. The first task was to identify current shipping practices and the stresses arising during a transportation accident which could lead to failure of the high-strength container and subsequent release of the $\mathrm{PuO}_{2}$. This information is presented in Appendix A. The second step was to define a set of desirable criteria for a new shipping form which would mitigate the accident envelope conditions and reduce or eliminate the dispersibility of the container contents. These criteria are given in Appendix $B$. The third step was to examine various candidate techniques which would satisfy these criteria, and in turn define a set of candidate materials which warranted further investigation. To accomplish this task, a team of experts was formed, and their suggestions for candidate techniques are summarized in Appendix $C$.

At the conclusion of the third step, four candidate materials were selected for evaluation. The final task was initiated whereby each candidate was evaluated for its effectiveness as an alternate plutonium shipping form in light of the criteria for a new form. Appendices $D$ through $G$ are the reports, prepared by the task team members, which discuss each candidate material.

The following section briefly summarizes the findings of each phase of the A]Puf investigations, and presents our recommendations for a potential alternate shipping form. The reader may refer to the appendices for the detailed discussions of each step in the investigation and the candidate materials investigated.

\section{CURRENT SHIPPING PRACTICES AND PROCEDURES}

Current U.S. regulations only allow the shipment of significant quantities of solid-form plutonium in containers designed and tested to withstand most of the anticipated accident stresses (10 CFR 71.42). Two packages, the LLD-1 and $6-M$, have been used extensively and have been the subject of studies. Only the 6-M has been approved for use by the NRC. Recently, two containers, the PAT-1 and 2 (Plutonium Air Transportable) have been approved for use in air transport. The details of these packages are presented in Appendix A.

All package types must be qualified by surviving (without failure) a sequential series of tests representing significant stress levels for that mode of transport. The requirements for packages for 1 and and water use and air transport are also shown in Appendix $A$. As anticipated, the requirements for air transport are the most stringent.

\section{ACCIDENT ENVELOPE}

The maximum accident environments anticipated for the various modes of transport were tabulated to provide an envelope of conditions to which the high-strength containers and their contents could be subjected. Again, the 
environment anticipated for air transport was the most rigorous (see

Table A-2). The responses of the various high-strength containers to the range of conditions in this accident envelope were tabulated to arrive at the range of test conditions to which the contents may be subjected (Tables A-3 and A-4). Both air-transportable containers maintained their integrities under the most stringent conditions and were dropped from consideration. Both remaining containers (6-M and LLD-1) survived all tests in the Flight Recorder Test sequence until the $2000^{\circ} \mathrm{F}, 30$ min fire, at which point both lost their integrities--the thread sealant charred on the 6-M, and the $0-$ ring was lost on the LLD-1. Fire also raises the temperature of the container and its contents, resulting in higher internal pressures from the generation of vapors (organic and water) and volume expansion, thus providing a force to expel the container contents. Fire was chosen as the accident condition which, at minimum, must be mitigated.

SELECTION CRITERIA AND CANDIDATE TECHNIQUES

Based upon the above and other considerations, selection criteria for candidate techniques to provide the desired mitigation were outlined and are discussed in Appendix B, "Selection Criteria." The criteria for possible candidate techniques fall into three categories:

- additions to the high-strength container (i.e., pressure relief without particle release; a liner of low-melting material which would wet and incorporate the $\mathrm{PuO}_{2}$ powder in the event of a fire; etc.)

- changes in inner packaging (i.e., a substitute for plastic wrapping that does not generate vapors in the event of a fire; an improved can which holds powder; ablative materials to reduce temperature increase; etc.)

- plutonium form (i.e., a coarser, harder form; incorporation of plutonium in a matrix material resistant to accident conditions; an additive which ties up the plutonium during an accident; etc.)

After discussion and preliminary evaluation by the participants of the program (see Appendix C), four techniques that appeared to have the greatest promise were chosen for further study:

- pelletization of $\mathrm{PuO}_{2}$ powder

- sol-gel plutonium or mixed oxide microspheres

- inorganic ion exchange materials

- ablative and alternative wrapping materials. 
The evaluation of various candidate materials for the proposed techniques are presented in Appendices D through G. Based upon the information available, several observations can be made.

\section{Green Pellets}

Green pellets of $\mathrm{PuO}_{2}$ (see Appendix D) appear to be the most promising of the candidate materials evaluated. No changes in chemical processing are required since the plutonium compound used remains the same. The mechanical processes required to pelletize the $\mathrm{PuO}_{2}$ and recover it at its destination are currently in use in another segment of the fuel cycle (fuel fabrication), although some modifications may be required to optimize performance for this specific application. Use of green pellets likely would not require additional shipments or container redesign since the volume of material handled is reduced. Consideration could be given to the use of additional materials (to mitigate the effects of accidents) in the space made available in the container by use of this $\mathrm{PuO}_{2}$ form rather than the powder. Shipments of green pellets would reduce the susceptibility of airborne dispersion and transport by accident-generated forces due to their coarser, denser composition. Some of the imposed forces would be absorbed in deagglomerating the compacted material. Steindler and Seefeldt (1981) report that, for explosive events, the degree of deagglomeration of uncompacted powder and liquid (size of the particles made airborne) is a function of the force applied per unit mass. Data are lacking on the subdivision of green pellets subjected to crush and impact forces. Data on the subdivision of sintered pellets subjected to such forces indicate that a substantial reduction in the fraction of small particles (less than $10 \mu \mathrm{m}$ AED) is possible. Subjecting the green pellets to elevated temperatures appears to harden them, enhancing their resistance to crush and impact forces. Their response over the entire anticipated temperature range needs experimental verification. There do not appear to be any hazardous reactions between $\mathrm{PuO}_{2}$ green pellets and fire-extinguishing materials (1ike water, carbon dioxide, and Halon although no specific documentation addressing the subject was found. Since the plutonium compound used remains the same, the only additional concern would be possible chemical reactions resulting from the change in form (e.g., trace iron impurities from pressing equipment, or trace organics from binding) under accident conditions. Effects of such reactions should be checked experimentally.

Some, but not necessarily all, of the additional information required to validate the applicability of the use of green $\mathrm{PuO}_{2}$ pellets as an alternative shipping form is outlined below:

- process parameters (e.g., size and density of pellets, press pressure, binder) to obtain pellets which are most resistant to accident force without creating undue difficulties in regenerating a usable powder for fuel fabrication.

- Registered trademark of Davies Nitrate Company, Inc., Metuchen, New Jersey. 
- subdivision of the final pellet configuration, due to various levels of crush and impact forces.

- response of green pellets to elevated temperatures and to fireextinguishing materials applied to heated pellets.

Sol-Gel Microspheres

The Sol-Gel process produces sintered microspheres of pure $\mathrm{PuO}_{2}$ or mixed oxide $(P U-U)$. Particle size distribution is readily control?ed, with a nominal diameter of $100 \mu \mathrm{m}$ being most common. Sol-Gel microspheres possess many attractive characteristics which would make them an ideal shipping form. They can be produced as either pure $\mathrm{PuO}_{2}$ or as mixed oxide for fuel fabrication, they are not easily dispersed under the criteria accident conditions, and they have many of the same space-saving attributes as the green pellets. However, the Sol-Gel process is still an immature technology. Adopting this process would require major revisions to current fuel-processing and fabrication procedures. At this time, substantial costs would be incurred if the microspheres were adopted as the alternative plutonium shipping form.

Quantitative data on responses of Sol-Gel microspheres to the criteria accident conditions (fire, crush, impact, etc.) are not available. Hence, further investigations would be needed to describe their behavior. Because of the process change requirements, associated costs, and need for additional development, the Sol-Gel technology is not considered a viable option for an alternative plutonium shipping form at this time.

Inorganic Ion Exchangers

Incorporating plutonium on inorganic ion exchangers such as zeolites appears to show some promise as an alternative plutonium shipping form, but lack of usable information on various facets makes the viability of this concept uncertain (see Appendix F). Many of the inorganic ion exchange materials are not available in commercial quantities, and much of the information required for this evaluation has not been developed. Zeolites are available commercially. Some of the conclusions detailed in Appendix $F$ are as follows:

- Feed preparation requirements appear to be minimal for loading Pu (III) on type $X$ and $Y$ zeolites, as long as the plutonium can be easily maintained in the III state. Acid concentration must be controlled to avoid degradation of the zeolite. Pu (III) is readily oxidized to $\mathrm{Pu}$ (IV) and, if oxidized, would precipitate in the zeolite, making recovery difficult.

- The highest theoretical loading computed for a zeolite was $0.7 \mathrm{~kg}$ $\mathrm{Pu}(\mathrm{V}) / \mathrm{kg}$ of $\mathrm{Na}$-type $\mathrm{X}$ zeolite. (Although the capacity of the exchanger may be adequate, so as not to require additional volume in the container, the features required for the loading and eluting of the exchanger would still dictate redesigning the container.) 
Control of the $\mathrm{HNO}_{3}: \mathrm{Pu}$ ratio in the feed solution would be required to attain adequate loadings of $\mathrm{Pu}$ (III) and $\mathrm{Pu}$ (IV).

- Inorganic ion exchangers require some "structural water" (interstitial) to maintain their ion exchange capacity. The quantity of moisture allowable in containers needs to be resolved, as well as the behavior of the plutonium on dehydrated exchangers, during loading, transport, and elution.

- More information is needed on Pu (V) and Pu (VI) ion exchange characteristics with both the zeolites and other inorganic ion exchangers.

- Information on the response of the inorganic ion exchangers to crush impact forces is not available and must be developed.

Most of the inorganic ion exchange materials evaluated are incapable of resisting the temperature extremes in the accident envelope without serious alterations of their characteristics. Such alterations, however, are not necessarily indicative of increased susceptibility to airborne release. Many alterations (e.g., glassification of zeolites) could result in stronger binding of the radioactive material to the matrix material, thereby reducing the susceptibility of the radioactive material to airborne release.

Ablative Materials

The use of ablative materials within the high-strength container to mitigate the effects of impact and temperature does not appear to have promise as a technique in and of itself, although specific materials were not identified (see Appendix G). An ablative material is one which absorbs significant quantities of thermal energy. The classes of materials identified (plastic and wood) generate vapors and gases as a result of the combustion; thus, if used in the high-strength container, they increase the capacity to disperse its contents in the event of failure. If energy-absorbing materials that do not result in such detrimental conditions can be identified, the use of ablative materials should be re-evaluated.

Alternative Packaging Materials

Use of alternative packaging materials other than plastic also does not show promise by itself (see Appendix F). Plastics are currently used to hold the $\mathrm{PuO}_{2}$ powder because they can withstand the rigors of handling (folding, bending, and crushing without cracking, tearing or puncturing) and can be effectively sealed. A substitute wrapping material with the desired characteristics which does not generate vapor was not identified. Metal foils (e.g., aluminum) with the desired flexibility do not appear to have the required strength. Also, metal foils present additional sealing problems. Reducing the quantity of plastic used would reduce internal pressures in the event of a fire. Use of thinner sheets or plastic-backed foils may serve the purpose, but a testing program to identify the specific candidates may be required. 
Summary

Of the candidate techniques and materials surveyed, pelletization of $\mathrm{PuO}_{2}$ powders (pressing into green pellets) appears by far the most promising candidate. Additional data, in the form of a cost-benefit analysis, should be obtained to aid in assessing the viability of the technique. Available information on various process parameters and behavior of green pellets in the presence of elevated temperatures and crush-impact forces has been identified, and its cost-benefit implications (reduction of risk of dispersion and associated airborne radiological hazard) need to be quantified. Equipment and process costs must be developed to evaluate the cost impact. Transportation considerations would remain the same, since the quantity of material shipped is based upon other than space considerations; therefore, transportation equipment and practices should tend to remain unchanged. The costs of any such investigation do not appear prohibitive.

\section{REFERENCES}

10 CFR 71.42. Code of Federal Regulations. Title 10, Atomic Energy. Part 71, Packaging of Radioactive Material for Transport and Transportation of Radioactive Material Under Certain Conditions, Paragraph 71.42, "Special Requirements for Plutonium Shipments After June 17, 1978.

44 FR 38690. 1979. "Transportation of Radioactive Materials," Memoranda of Understanding, Department of Transportation, Nuclear Regulatory Commission, Washington, D.C.

NRC 1977. Final Environmental Statement on the Transportation of Radioactive Material by Air and Other Modes, Vol. 1. NUREG-0170, U.S. Nuclear Regulatory Commission, Washington, D.C.

Steindler, M. J., and W. B. Seefeldt. 1981. "A Method for Estimating the Challenge to an Air Cleaning System Resulting from an Accidental Explosive Event." In 16th DOE Nuclear Air Cleaning Conference (M. W. First, ed), U.S. Department of Energy/The Harvard Air Cleaning Laboratory, Cambridge, Massachusetts. 


\author{
APPENDIX A \\ TRANSPORTATION ACCIDENT CHARACTERIZATION
}

A. L. Franklin 
APPENDIX A

TRANSPORTATION ACCIDENT CHARACTERIZATION

INTRODUCTION

This appendix provides a quantitative description of the potentially hostile transportation environments encountered by a radioactive material package during shipment. Its purpose is to aid in establishing criteria for determining the relative merits of transporting plutonium in various forms.

The information contained herein has been gathered through a review of existing literature on related topics. While every attempt has been made to use the most current literature available, it is conceivable that more recent data does exist. No attempt has been made to substantiate the results of the material used as reference for this report. Also, no attempt was made to perform original research to fill in the gaps where information of interest could not be found.

Three modes of transportation are discussed: cargo aircraft, truck, and rail. There is a brief discussion of packagings available for the transportation of plutonium. Another section addresses the qualifying criteria which packages must meet prior to being certified for radioactive material transport. This section has been included to provide some indication of the minimum conditions which a radioactive material package is anticipated to experience. The potentially hostile transport environments for the three modes are characterized by five descriptive parameters: impact, crush, puncture, fire, and immersion.

There is a brief review of knowledge about those conditions which the contents of a radioactive material package may encounter during a transportation accident. The final section contains results of package response tests for various environmental conditions.

\section{PLUTONIUM TRANSPORT PACKAGING}

Over the past years, plutonium has been transported in a variety of packagings. In general, the type of packaging selected has been a function of the form of plutonium being shipped.

The L-10 container shown in Figure A-1 was used to transport plutonium as plutonium nitrate liquid (Kelly et al. 1974). The physical dimensions of the $\mathrm{L}-10$ are presented following the figure. 


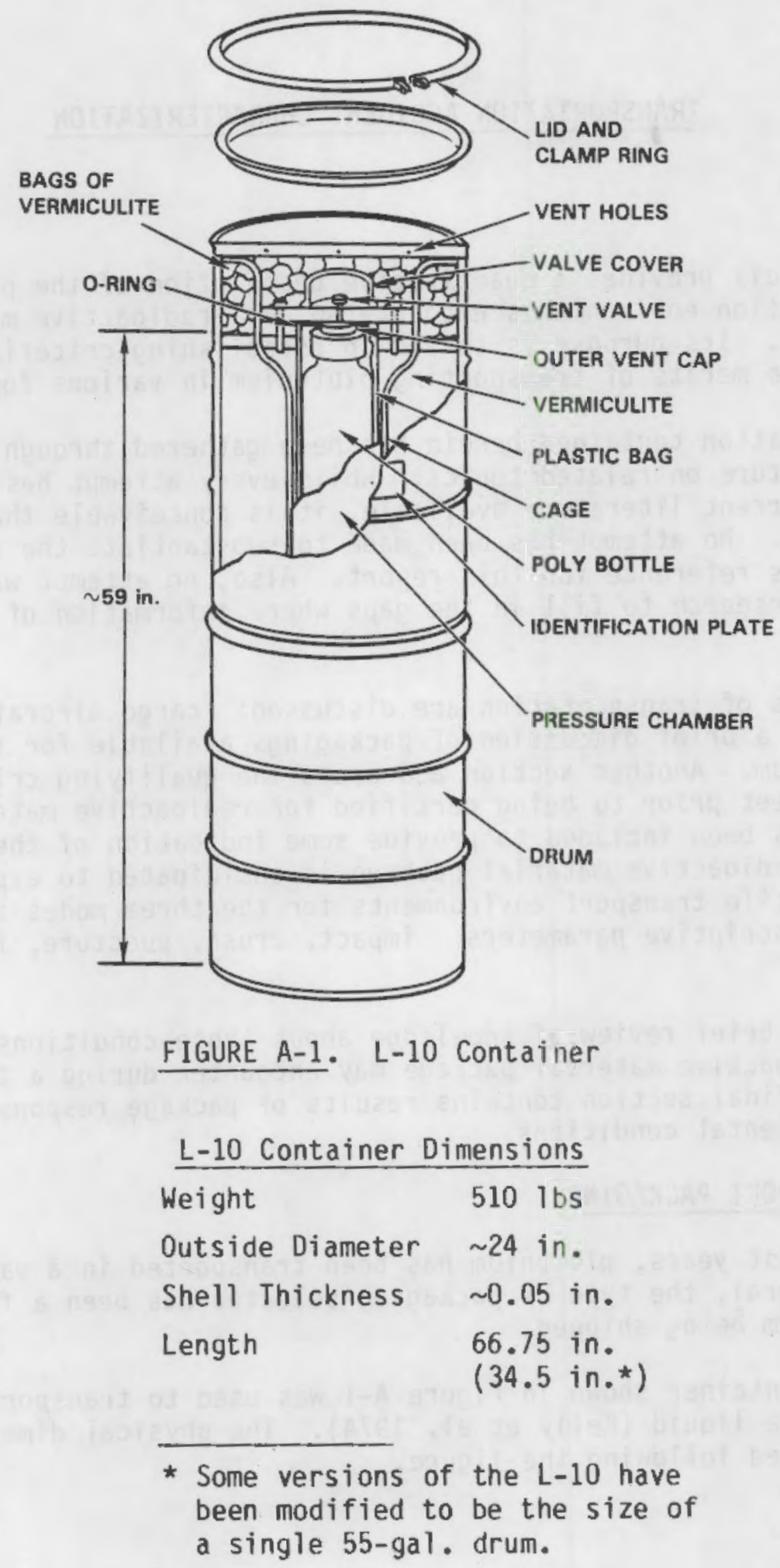

A. 2 
The container consists of two 55-gallon drums welded end to end (Stravasnik 1972). An L-10 design variation uses a single 55-gallon drum. The body is constructed of 18-gauge steel; the lid is 16-gauge. The lid is held in place by a 12-gauge steel locking ring which is secured with a $5 / 8$-inch diameter bolt. The inner container, or pressure vessel, made of schedule 80304 SS stainless steel pipe, is supported by a tubular steel frame. Vermiculite is used for insulation in the space between the drum and the pressure vessel.

Beginning on June 17,1978 , all shipments of plutonium in excess of 20 curies have been restricted to plutonium in solid form (Federal Register 1974). Two packagings that have been used in the past to make these shipments are the LLD-1 and the 6-M, shown in Figures $A-2$ and $A-3$ respectively (Kelly et a). 1974; McWhiter et al. 1975). The physical dimensions of these two containers are given below.

\begin{tabular}{ll} 
Weight & \multicolumn{2}{l}{ LLD-1 Dimensions } \\
Width (square) & $130 \mathrm{lbs}$ \\
Length & $26 \mathrm{in.}$ \\
& \\
Weight & $160 \mathrm{ins}$ \\
Outside Diameter & $\sim 15 \mathrm{in}$. \\
Shell Thickness & $\sim 0.05 \mathrm{in}$. \\
Length & $\sim 20 \mathrm{in}$.
\end{tabular}

The LLD-1 packaging consists of a cage framework of 0.75 -inch steel tubing (outside diameter) (McWhiter et al. 1975). The cage dimensions are 16 inches square by 25 inches high. A perforated aluminum sheet basket covers the tube framework. The whole assembly weighs 130 pounds and is referred to as the "birdcage." The "bird," a carbon steel cylinder about 17 inches long, is supported by the four curved tubes of the birdcage. The bird has an inside minimum diameter of 6.4 inches. Inside the bird is a second carbon steel cylinder (DOT-2R) with a length of 9 inches and an inside diameter of 4.5 inches. The two cylinders are insulated from each other by a felt liner. Plutonium is sealed inside a plastic bag and an aluminum or steel can before being placed in the inner cylinder. The inner cylinder has a screwed plug closure and is sealed with an elastomer 0-ring. The outer cylinder, or bird, is secured with closure lugs and sealed with a gas-filled 0-ring. 


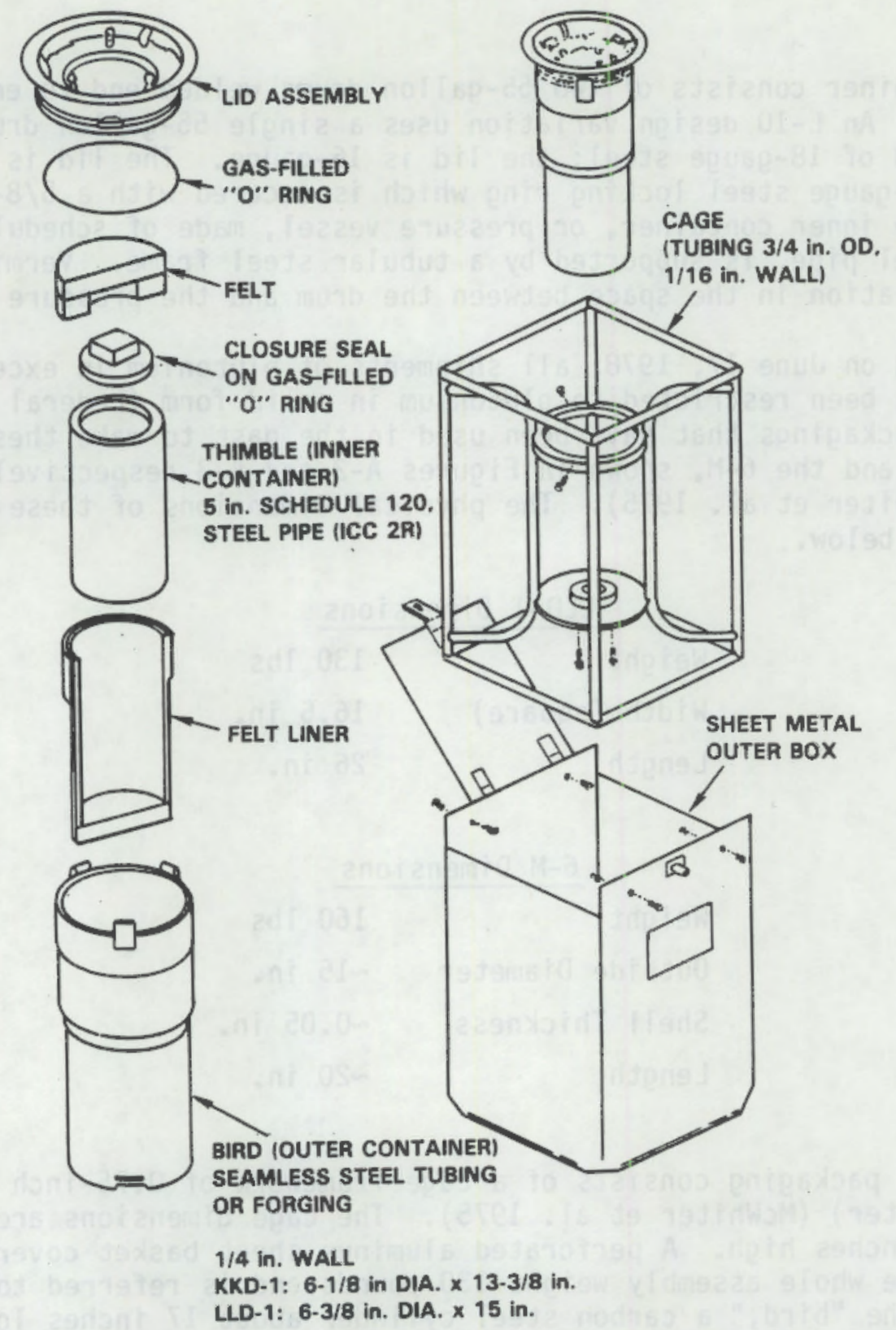

FIGURE A-2. LLD-1 Package

The 6-M container is made from a 10-gallon steel drum (Stravasnik 1972). The body is made of 20-gauge steel, the lid is 19-gauge, and the locking ring is 12-gauge. The locking ring is secured by a $5 / 16$-inch diameter bolt. Industrial fiberboard disks, 2 inches thick, are used inside the drum for thermal insulation, shock protection, and as a means for centering the inner pressure vessel. The inner pressure vessel is made from 4.75-inch diameter steel pipe with usable inside diameter of 4.18 inches and length of 10 inches. The normal closure technique for the inner pressure vessel of the 6-M is a threaded plug. One variation of the 6-M, the DOT Spec 5791 container, uses a bolted, flangetype closure on the inner pressure vessel. 


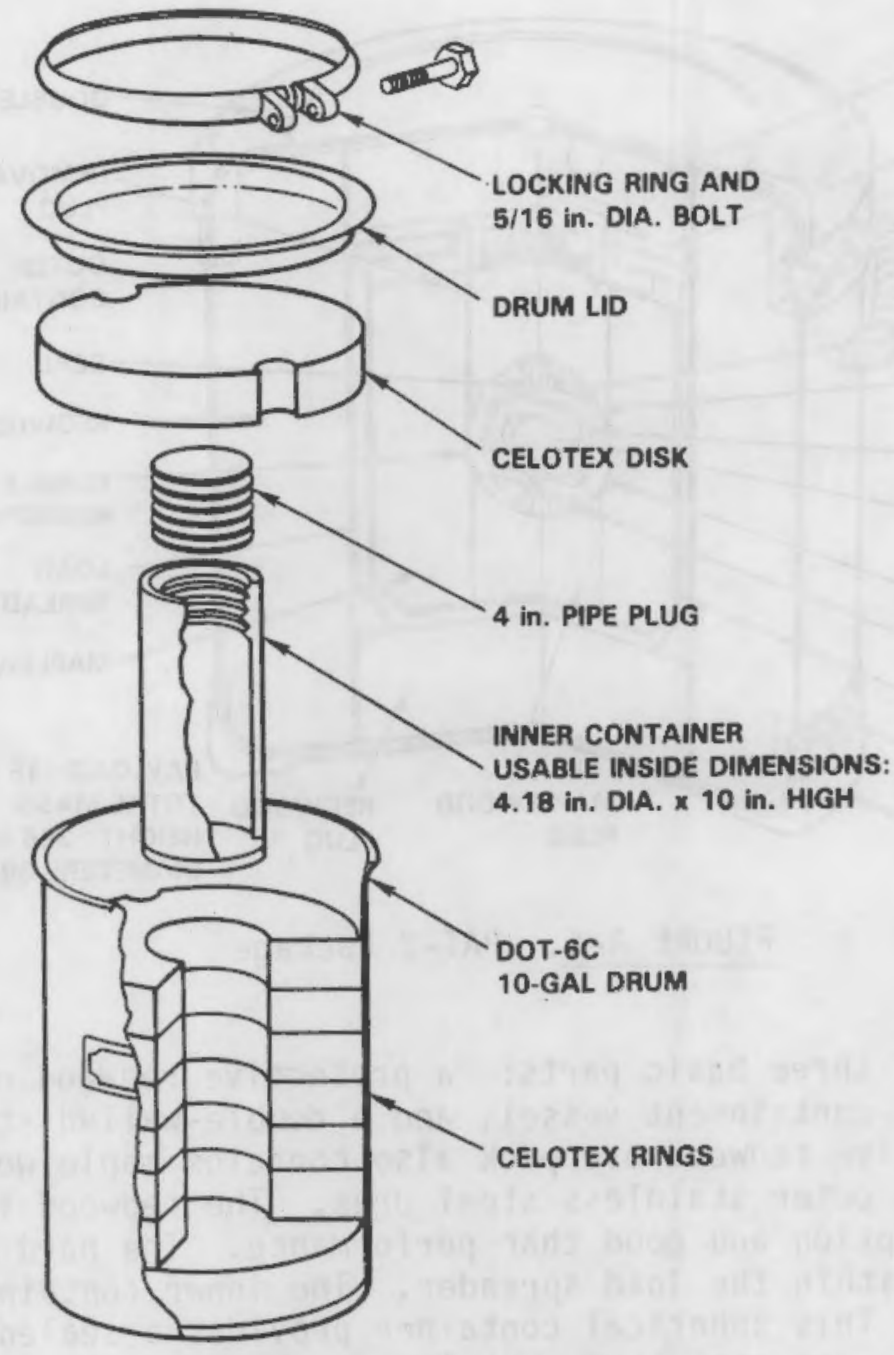

FIGURE A-3. 6-M Container

Need for an air-transport package like the PAT-2 was created in the late 1970 's, when all air transport of plutonium was suspended until a package could be designed and fabricated that met a more restrictive set of certificate criteria. Development of such a packaging has been progressing at the Sandia National Laboratories (Andersen et al. 1981). The PAT-2 is shown in Figure A-4. Its physical dimensions are summarized below.

\begin{tabular}{ll} 
Physical Dimensions of the PAT-2 \\
\hline Weight & $72 \mathrm{lbs}$ \\
Diameter & $15 \mathrm{in}$. \\
Height & $14 \mathrm{in.}$ \\
Drum Thickness & $0.056 \mathrm{in}$.
\end{tabular}




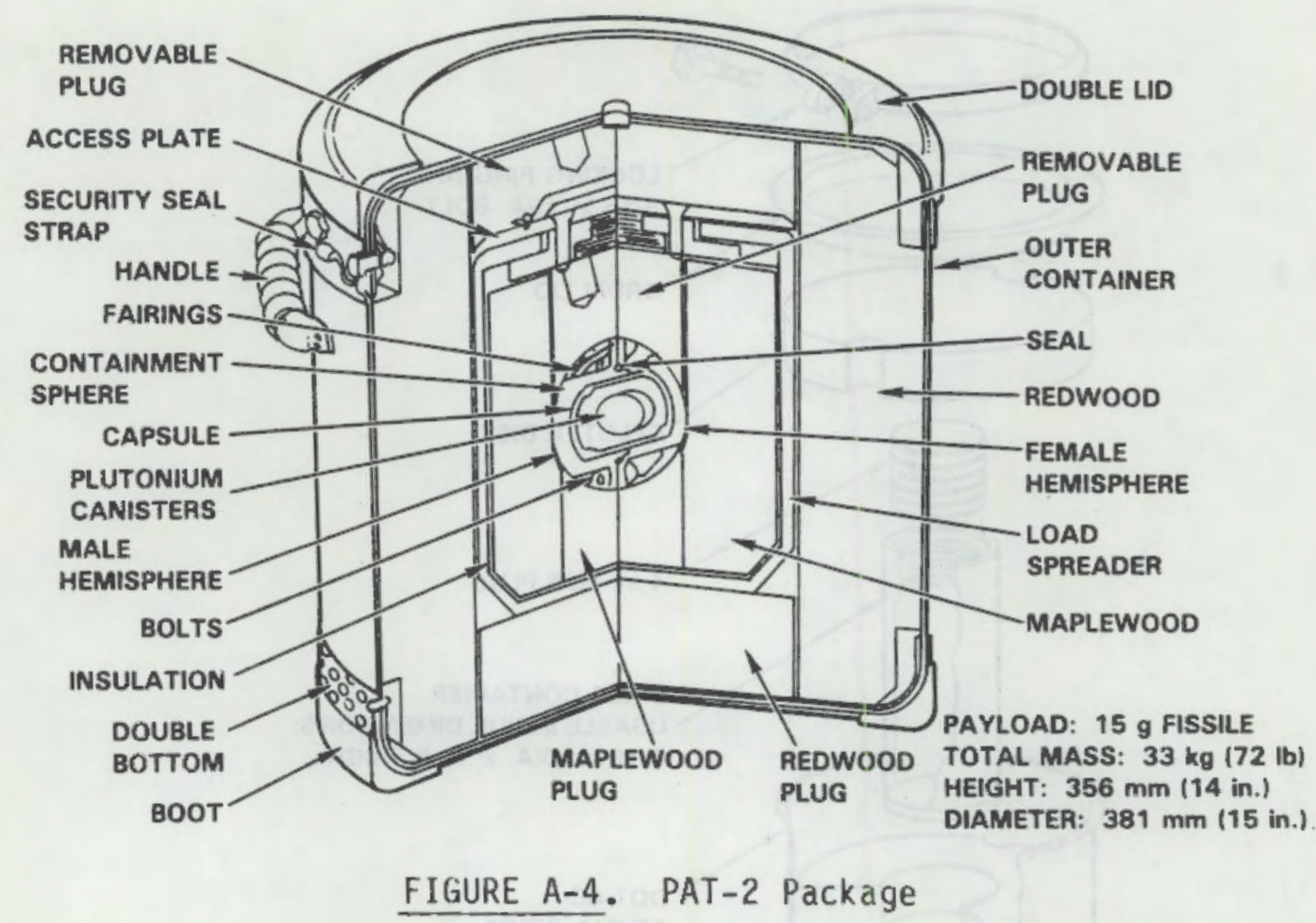

The PAT-2 consists of three basic parts: a protective redwood overpack, an iron-base alloy inner containment vessel, and a double-walled stainless steel capsule. The protective redwood overpack also contains maple wood, a titanium load spreader, and an outer stainless steel drum. The redwood is used for high specific energy absorption and good char performance. The hard maple provides high crush strength within the load spreader. The inner containment vessel is shown in Figure A-5. This spherical container provides a sealed, hightemperature, high-pressure-resistant containment which does not become vented in a transportation accident. The innermost stainless steel capsule is shown in Figure A-6. This capsule provides the required double containment for plutonium contents greater than 20 curies.

\section{PACKAGE TEST REQUIREMENTS}

When considering the environments that may be experienced by a radioactive material package during transport, two sets of well-defined conditions can always be included. These are the normal and accident conditions of transport as defined in 10 CFR 71 Appendices $A$ and B, respectively. These normal and accident conditions are used to certify packagings for use in transporting all radioactive materials.

With a couple of exceptions, essentially all radioactive material packagings must satisfactorily withstand the normal transport test conditions specified in 10 CFR 71 Appendix A. Exemptions to this requirement can occur for materials with low specific radioactivity, small quantities, or other material 

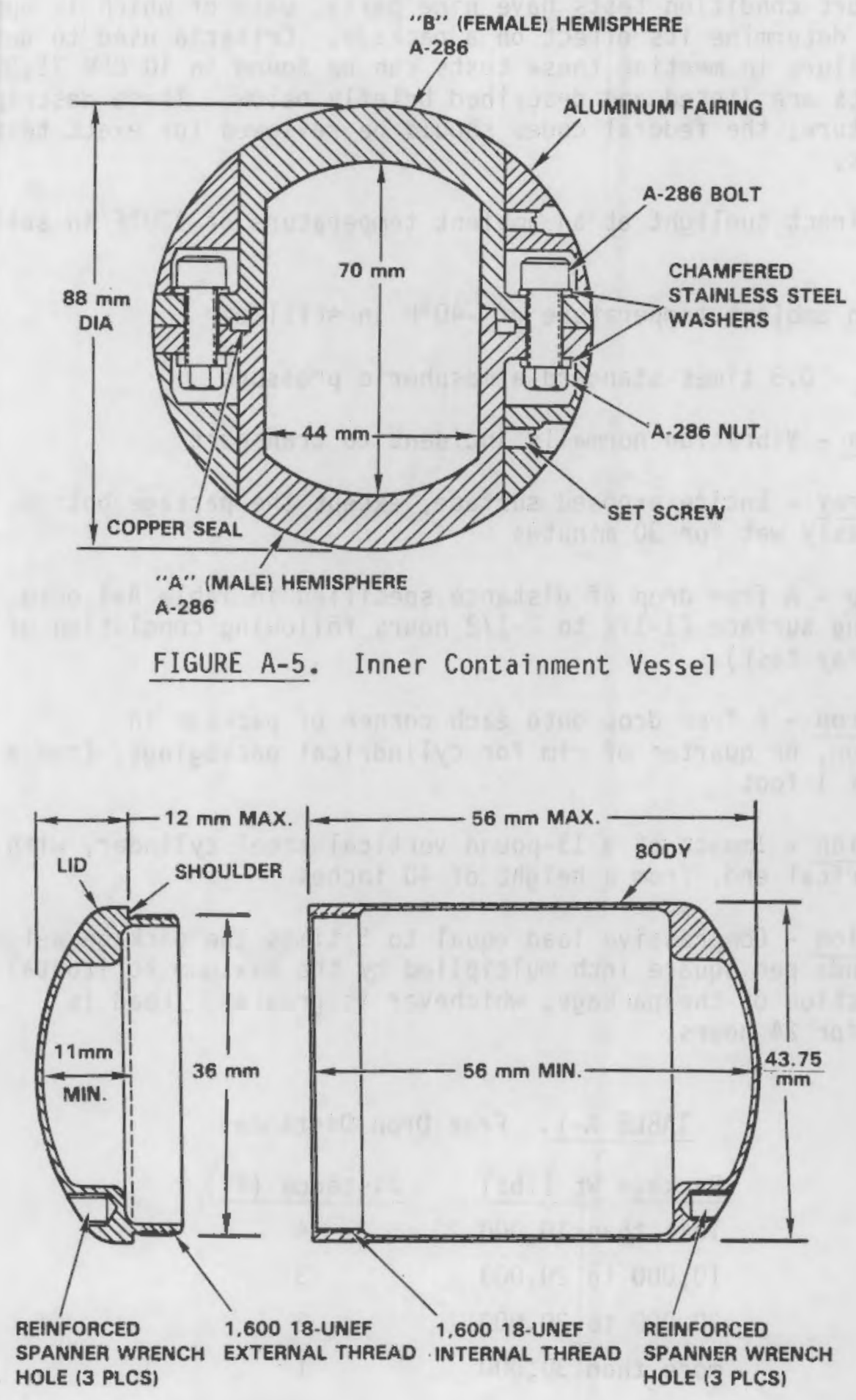

FIGURE A-6. Capsule Cross Section 
specially configured to reduce the mobility of the radioactive material. The normal transport condition tests have nine parts, each of which is applied separately to determine its effect on a package. Criteria used to determine success or failure in meeting these tests can be found in 10 CFR 71.35. The nine test parts are listed and described briefly below. These descriptions are summary in nature; the federal codes should be reviewed for exact test specifications.

Heat - Direct sunlight at an ambient temperature of $130^{\circ} \mathrm{F}$ in still air

Cold - An ambient temperature of $-40^{\circ} \mathrm{F}$ in still air

Pressure - 0.5 times standard atmospheric pressure

Vibration - Vibration normally incident to transport

Water Spray - Entire exposed surface, except the package bottom, continuousty wet for 30 minutes

Free Drop - A free drop of distance specified in Table A-1 onto unyielding surface ( $1-1 / 2$ to $2-1 / 2$ hours following conclusion of water spray test)

Corner Drop - A free drop onto each corner of package in succession, or quarter of rim for cylindrical packagings, from a height of 1 foot

Penetration - Impact of a 13-pound vertical steel cylinder, with a hemispherical end, from a height of 40 inches

Compression - Compressive load equal to 5 times the package weight or 2 pounds per square inch multiplied by the maximum horizontal cross section of the package, whichever is greater. Load is applied for 24 hours.

TABLE A-1. Free Drop 0istances

\begin{tabular}{lc} 
Package Wt (10s) & Distance $(\mathrm{ft})$ \\
\hline less than 10,000 & 4 \\
10,000 to 20,000 & 3 \\
20,000 to 30,000 & 2 \\
more than 30,000 & 1
\end{tabular}


Shipments of plutonium in excess of 0.01 curies must be packaged in containers that meet the accident conditions described in 10 CFR 71 Appendix B. This requirement is in addition to successful survival of the normal transport conditions described in 10 CFR Appendix A. There are four parts to the accident test conditions. The four parts are applied sequentially to a single package to determine their cumulative effect on the package. These four parts are listed below with a brief description of each. Again, the descriptions are summary, and the federal codes should be reviewed for exact test specifications.

Free Drop - A drop of 30 feet onto an unyielding surface

Puncture - A free drop of 40 inches onto a mild steel cylinder

8 inches long with a diameter of 6 inches

Thermal - Exposure to a $1475^{\circ} \mathrm{F}$ fire for 30 minutes

Water Immersion - Immersion in at least 3 feet of water for not Tess than 8 hours.

All air transport of plutonium in the U.S. has been suspended until a package can be developed to satisfy test criteria that have been established specifically for air transportation considerations. The test conditions are summarized below. If exact test specifications are needed, they can be found in NUREG-0360 (NRC 1978).

Impact - Impact at a velocity of not less than 422 feet per second onto an unyielding surface

Crush - A static compressive load of 70,000 pounds

Puncture - Drop of a 500-pound probe from a height of 10 feet

Tprobe dimensions specified in NUREG-0360)

Slash - The package struck by a steel angle section falling from a height of at least 150 feet (angle section description found in NUREG-0360)

Fire - Exposure to luminous flames of a JP-4 or JP-5 aviation fuel fire for at least 60 minutes

Immersion - Inmersion under 3 feet of water for at least 8 hours. HOSTILE ENVIRONMENTS ANTICIPATED FOR PACKAGES

The environments anticipated to be experienced by a radioactive material package have typically been described using five parameters. These include impact, crush, puncture, fire temperature and duration, and immersion (Hartman et al. 1974). 
- Impact. An impact is a collision between a container and some other body where the force of the collision is applied over a "wide" area of the container. Impact forces generally have a duration of less than 10 milliseconds. Common units for measuring impact are feet, arrived at by dividing the energy transferred to the container (ft-lbs) by the weight of the container (1bs).

- Crush. The crush parameter deals with the mechanical loading that cannot be characterized by impact, puncture, or immersion. Crush forces have durations much greater than 10 milliseconds. Usually they are due to loading from the displacement of other cargo or heavy sections of the transporting vehicle.

- Puncture. Puncture is the collision of a container with a body or bodies capable of penetrating the protective structures of the container. Puncture is typically characterized by dividing the collision velocity by the radius of puncture probe. In these cases, the units are "per second."

- Fire. The fire parameter refers to subjecting a container to an elevated temperature environment produced by combustion. Two aspects of the parameter, temperature and duration, are used to characterize the fire environment. In some literature, a single unit, temperature times duration, is used as the characterizing parameter.

- Imnersion. Immersion refers to the submersion of the container in a liquid medium (most commonly water). While the hostile factor in this case is usually a crushing type of overpressure, immersion is typically quantified in terms of depth in feet or meters.

Table A-2 presents the ranges of values expected of each parameter during a transportation accident (Hartman 1975; Clarke et al. 1976). The values represent reasonable assumed maximums (a) for each of the parameters listed. An important parameter not included in this table, however, is the probability of encountering any of these conditions. Also, inferences should not be made from this information concerning possible response of a radioactive material packaging to these conditions.

The importance of each of the parameters discussed above varies according to the transport mode involved (Hartman 1975). For aircraft, impact and fire appear to be most important. For truck and train, fire, puncture, and crush appear most significant. Importance in these cases is determined by the likelihood that each parameter will contribute significantly to the hostile environment.

(a) There will always be accident conditions in which parameters may exceed the table values, but the number of these will be small. 


\section{TABLE A-2. Accident Envelope Descriptions(a)}

Accident

Environment

Parameters

Impact $(b, c)$

Crush

Puncture ${ }^{(d)}$

Fire (Temp.)

$1400-2400^{\circ} \mathrm{F}$

$\left(5100^{\circ} \mathrm{F}\right)(\mathrm{e})$

Transport Modes

\begin{tabular}{clc}
$\begin{array}{c}\text { Cargo } \\
\text { Aircraft }\end{array}$ & \multicolumn{1}{c}{ Truck } & Train \\
$0-1 \overline{0} \mathrm{ft}$ & $0-1600 \mathrm{ft}-1 \mathrm{bs}$ & $0-\overline{\mathrm{ft}}$
\end{tabular}

Fire (Duration)

$0-200 \mathrm{~min}$

$0-90$ min

$0-330,000$ lbf

Immersion

$0-400 \mathrm{ft}$

$0-50 \mathrm{ft}$

$20-360 s^{-1}$

$20-360 s^{-1}$

$1400-2400^{\circ} \mathrm{F}$

$1400-2400^{\circ} \mathrm{F}$

$1400-2400^{\circ} \mathrm{F}$

0-160 min

$0-80 \mathrm{ft}$

(a) These values describe anticipated limits of accident environment. An important parameter not included in this table is the probability of encountering these conditions. Also, no inferences can be made from this information concerning the response of a radioactive material packaging to these conditions.

(b) Units are ft-lbs. Impact is a measure of absorbed energy.

(c) An alternative measure for impact magnitude is equivalent drop height onto an unyielding surface. Equivalent drop height ( $\mathrm{ft}$ ) is determined by dividing absorbed energy by package weight $(E / w)$.

(d) Projectile velocity divided by projectile radius. Units are "per second."

(e) Potential for local hot spots reaching $5100^{\circ} \mathrm{F}$.

\section{PACKAGE CONTENT ENVIRONMENT: TEST RESULTS}

The response of a package to a hostile environment essentially controls the degree of hostility or severity of the environment encountered by the package contents. This section utilizes the results of package failure threshold tests to gain insight into the response of various radioactive material packagings to severely damaging forces. While this information does not provide direct conclusions regarding the environment experienced by the package contents, it can provide a better understanding of forces needed to directly involve the contents of the package in an accident. 
In the failure-threshold tests performed to date, the test conditions can easily be quantified, but the package response is traditionally described in a qualitative manner. Table A-3 presents, in sumary form, the results of a series of special tests performed on plutonium shipping containers (Stravasnik 1972). In these tests, "survival" was defined as lạck of leakage from the inner containment vessel.

The tests described in Table A-3 were all applied individually to undamaged containers. Tests were also performed sequentially on the containers. When exposed to a puncture-fire combination, the L-10 container exposed the inner containment or pressure chamber to the fire environment (see Figure A.1). It is anticipated that this situation would result in failure of inner containment integrity. The 6-M container did not expose the inner containment vessel in the puncture-fire test; however, under fire test conditions alone, the 6-M did not survive. Therefore, it is also assumed (although this was not specifically stated in the reference document, Stravasnik 1972) that the 6-M probably would not survive the puncture-fire combination.

An impact-fire combination was also applied to these packagings. In this test, both the $L-10$ and $6-M$ exposed the inner containment to the fire environment. Therefore, it is assumed that neither container passed this combination test.

Several plutonium containers have also been subjected to the flight recorder survivability standards required by the Federal Aviation Administration (FAA) (Mcihiter et al. 1975). The results of these tests are presented in Table A-4. It is important to remember that the flight recorder tests were

TABLE A-3. Plutonium Container Test Results

\begin{tabular}{|c|c|c|c|}
\hline Test & Test Conditions & $L-10$ & $6 \mathrm{M}$ \\
\hline Impact & $\begin{array}{l}270 \mathrm{ft} \text { free drop } \\
(130 \mathrm{ft} / \mathrm{sec})\end{array}$ & $\begin{array}{l}\text { Survived } \\
\text { (Appeared near } \\
\text { threshold) }\end{array}$ & $\begin{array}{l}\text { Survived } \\
\text { (Threshold appeared } \\
\text { to be } \sim 150 \mathrm{ft} / \mathrm{s} \text { or } \\
\sim 350 \mathrm{ft} \text { ) }\end{array}$ \\
\hline Puncture & $\begin{array}{l}100 s^{-1} \\
\frac{V}{R}=\frac{25 f p s}{0.25 f t}=100 s^{-1}\end{array}$ & $\begin{array}{l}\text { Survived } \\
\text { (No threshold } \\
\text { projected) } \\
\text { Pressure vessel } \\
\text { exposed }\end{array}$ & $\begin{array}{l}\text { Survived } \\
\text { (No threshold } \\
\text { projected) }\end{array}$ \\
\hline Fire & $1800^{\circ} \mathrm{F}$ for $1 \mathrm{~h}$ & $\begin{array}{l}\text { Survived } \\
\text { Internal tempera- } \\
\text { tures } \sim \text { equal } \\
\text { to } 275^{\circ} \mathrm{F}\end{array}$ & $\begin{array}{l}\text { Failed } \\
\text { Internal tempera- } \\
\text { tures in excess of } \\
275^{\circ} \mathrm{F}\end{array}$ \\
\hline
\end{tabular}


applied sequentially to a single container for each container type. In the case of the LLD-1 container, all tests following the impact tests were applied to the inner container only. This was because the outer container of the LLD-1 was essentially destroyed in the impact test. Many of the test conditions noted are estimates of those test conditions when reported in units consistent with other portions of this report.

\section{TABLE A-4. Flight Recorder Test Results}

\begin{tabular}{|c|c|c|c|c|}
\hline Test & $\begin{array}{c}\text { Test } \\
\text { Condition } \\
\end{array}$ & $\mathrm{L}-10$ & $6 \mathrm{M}$ & LLD-1 \\
\hline Impact & $120 \mathrm{ft}(\mathrm{c})$ & $\begin{array}{l}\text { Lid lost, foam } \\
\text { plug lost, some } \\
\text { bolts loosened }\end{array}$ & Some damage & $\begin{array}{l}\text { Inner container } \\
\text { escaped, only } \\
\text { tested for } \\
\text { remainder of } \\
\text { standards }\end{array}$ \\
\hline Puncture & $2400 \mathrm{~s}^{-1(a)}$ & Survived (b) & Survived (b) & Survived (b) \\
\hline $\begin{array}{l}\text { Static } \\
\text { Crush }\end{array}$ & 5000 lbs & Survived & Survived & Survived \\
\hline Fire & $\begin{array}{l}2000^{\circ} \mathrm{F} \\
\text { for } 30 \mathrm{~min} .\end{array}$ & 0 -rings charred & $\begin{array}{l}\text { Thread sealant } \\
\text { charred, inner } \\
\text { container } \\
\text { paint removed }\end{array}$ & $\begin{array}{l}\text { Paint removed, } \\
0-\text { rings }^{\prime} \\
\text { destroyed }\end{array}$ \\
\hline Immersion & $\begin{array}{l}2 \mathrm{ft} \text { for } \\
48 \mathrm{hrs}\end{array}$ & $\begin{array}{l}\text { Small loss of } \\
\text { contents }\end{array}$ & $\begin{array}{l}\text { Water entered } \\
\text { inner container, } \\
\text { no loss of } \\
\text { contents }\end{array}$ & $\begin{array}{l}\text { Water entered } \\
\text { inner con- } \\
\text { tainer, no } \\
\text { loss of } \\
\text { contents }\end{array}$ \\
\hline
\end{tabular}

(a) Estimated assuming $0.0104-\mathrm{ft}$ radius probe and $25 \mathrm{ft} / \mathrm{s}$ velocity. $25 \mathrm{ft} / \mathrm{s}$ velocity is estimated from $10 \mathrm{ft}$ drop height.

(b) Survival may be due to probe dimensions. Outer containers were penetrated for L-10 and 6-M containers.

(c) This is the minimum distance calculated from the terminal velocity of $88 \mathrm{ft} / \mathrm{s}$ described in the procedure. 


\section{REFERENCES}

Andersen, J. A., E. J. Davis, T. A. Duffey, S. A. Dupree, 0. L. George, Jr., and A. Ortiz. 1981. PAT-2 (Plutonium Air-Transportable Model 2) Safety

Analysis Report. SAND-81-0001, Sandia National Laboratories, A1buquerque, New Mexico.

Clarke, R. K., J. T. Foley, W. F. Hartman, and D. W. Larson. 1976. Severities of Transportation Accidents, Volume II. SLA-74-0001, Sandia National Laboratories, Albuquerque, New Mexico.

Federal Register. 1974. Vol. 39, No. 117, Washington, D.C. June 17.

Hartman, W. F., R. K. Clarke, 0. W. Larson, and J. T. Foley. 1974. "The Analysis of Transportation Accident Environments--The Purpose, Method, and Introduction." In Proceedings of the Fourth Symposium on Packaging and Transportation of Radioactive Material. DOC-CONF-74901-P1-3, National Technical Information Service, Springfield, Virginia.

Hartman, W. F. 1975. A Study of the Physical Parameters of Transportation Accidents. Sandia National Laboratories, Albuquerque, New Mexico.

Kelly, W. S., J. M. Creer, S. N. Liu, and J. G. DeSteese. 1974. "Results of Structural Analysis of Plutonium Packaging." In Proceedings of the Fourth Symposium on Packaging and Transportation of Radioactive Materials, DOC-CONF-74901-PT-3, National Technical Information Service, Springfield, Virginia.

McWhiter, M., R. 0. Brooks, J. M. Stomp, and L. A. Dillingham. 1975. Final Report on Special Tests of Plutonium Oxide Shipping Containers to FFA FTight Recorder Survivability Standards. SAND-75-0446, (NUREG-SAND-75-0446), Sandia National Laboratories, Albuquerque, New Mexico.

NRC. 1978. Qualification Criteria to Certify a Package for Air Transport of Plutonium. U.S. Nuclear Regulatory Commission, Washington, D.C.

Stravasnik, L. F. 1972. Special Tests for Plutonium Shipping Containers 6M, SP5795, and L-10. SC-DR-72 0597, Sandia National Laboratories, A7buquerque, New Mexico. 
APPENDIX B

CRITERIA FOR SELECTION OF ALTERNATIVE PLUTONIUM SHIPPING FORMS

J. Mishima

C. G. Lindsey 
APPENDIX B

CRITERIA FOR SELECTION OF ALTERNATIVE PLUTONIUM SHIPPING FORMS

INTRODUCTION

Plutonium is one of the many radiotoxic materials produced by the irradiation of uranium. It is fissile and can be used to initiate a nuclear chain reaction. Thus, plutonium can be a source material or a product in the nuclear fuel cycle. For an uranium cycle with recovery or for a plutonium recycle, the plutonium would be separated from irradiated fuel elements. In the uranium cycle, it is assumed that the plutonium would be segregated from other radionuclides because of the long half-lives of some of the isotopes, their radiotoxicity, and criticality potential. In the plutonium cycle, it is a reusable material.

Current U.S. regulations (10 CFR 71.42) only allow shipment of significant quantities of plutonium in solid form in containers designed to withstand most of the anticipated accident stresses. The characteristics and performance of approved shipping containers are given in Appendix A. Transport of significant quantities of strategic special nuclear material also requires additional physical safeguards (10 CFR 73.25 and 73.67).

The primary hazard to humans from plutonium is inhalation and deposition in the deep lungs (alveolar sacs). Under accident conditions, airborne transport of released materials is an acute hazard and is less amenable to mitigative and remedial action than other pathways. The low absorption of plutonium by the GI tract, compared to its uptake in the deep lung (NRC 1977 Appendix C), is reflected in the Maximum Permission Concentration for air and water (10 CFR 20 Appendix B). Thus, some important considerations in evaluating the hazards associated with situations involving plutonium are its dispersibility and the aerodynamic characteristics of the airborne particles. The dispersibility of a material is an index of the fraction of the initial quantity present that is relocated as a consequence of the event, and it is a function of stresses imposed and the physiochemical properties of the material. The aerodynamic characteristics are those that describe its behavior in air (or gaseous media) and determine whether or how far the airborne particulate material can be transported downwind, whether it can be inhaled, and (once inhaled) in which region of the breathing apparatus the particles will be deposited. Figure B-1 presents the "respirable fraction" (the fraction of inhaled particles of a given size that will be deposited in the alveolar regions of the lungs) of airborne particles assumed for various lung deposition models used in the nuclear industry. To assume that all the fraction which is $10 \mu \mathrm{m} \mathrm{A.E.D.} \mathrm{or}$ less does reach the deep lung is conservative; since mass is a cubic function of diameter, the assumption is probably conservative by greater than an order of magnitude. 


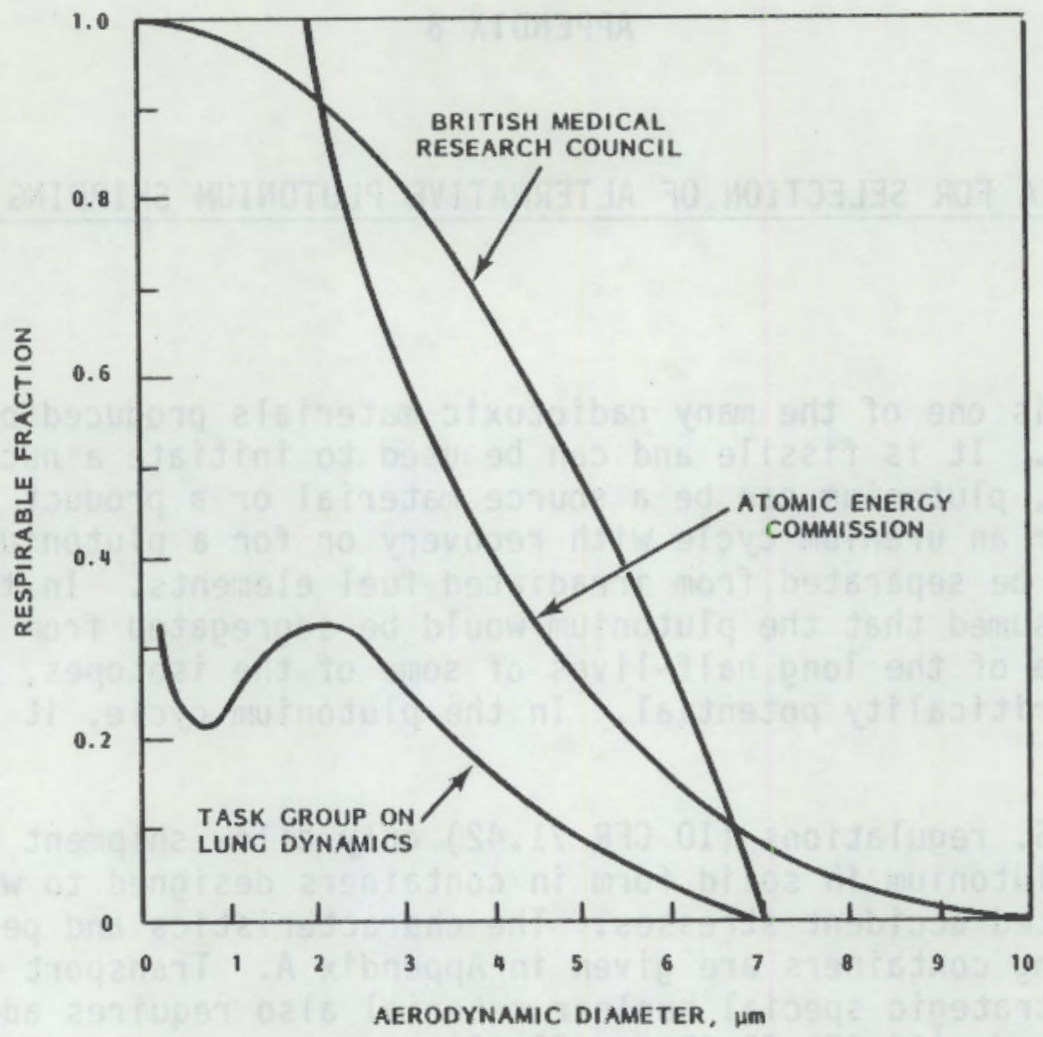

FIGURE B-1. "Respirable Fraction" of Airborne Particles (Based on Figure 5 in Mercer 1977)

Of the various forms of plutonium currently being shipped (unirradiated mixed oxide fuel elements, irradiated $\mathrm{UO}_{2}$ fuel elements, transuranic waste, and plutonium dioxide powder), the potential hazard from plutonium is greatest during the shipment of plutonium dioxide. In this form, the plutonium is undiluted, in relative abundance, and easily carried by air.

The U.S. Nuclear Regulatory Commission is sponsoring a study at the Pacific Northwest Laboratory, operated by Battelle Memorial Institute, to ascertain the feasibility of reducing, through physical or chemical changes in the forms shipped, the already small radiological hazard from shipping plutonium. Any changes considered should have slight impact upon subsequent operations.

\section{CHARACTERISTICS OF PLUTONIUM DIOXIDE SHIPPED}

\section{Material Use}

In the foreseeable future, significant quantities of plutonium are most likely to be shipped as fissile materials for fuel and as waste. A chemically stable form is desirable for both purposes. Plutonium dioxide is among the most chemically stable of plutonium compounds, and other forms considered should be equally stable. 


\section{Fuel Fabrication}

For mixed oxide $\left(\mathrm{UO}_{2}-\mathrm{PuO}_{2}\right)$ fuel, finely divided uranium dioxide and plutonium dioxide powder are intimately blended to assure a uniform mixture of material. A finely divided powder or coprecipitate is required to assure this uniformity. Figures B-2, B-3 and B-4 are some examples of particle size distributions of plutonium dioxide powder used for this purpose. The figures are expressed in linear diameter; the sizes should be multiplied by the square root of the mass density $(\sim \sqrt{11.5})$ to obtain the aerodynamic equivalent diameter.

\section{Waste}

If the spent fuel is processed to recover the uranium, the Purex process normally separates plutonium, along with the uranium, from the mixed fission products. The uranium would subsequently be separated from the plutonium. The

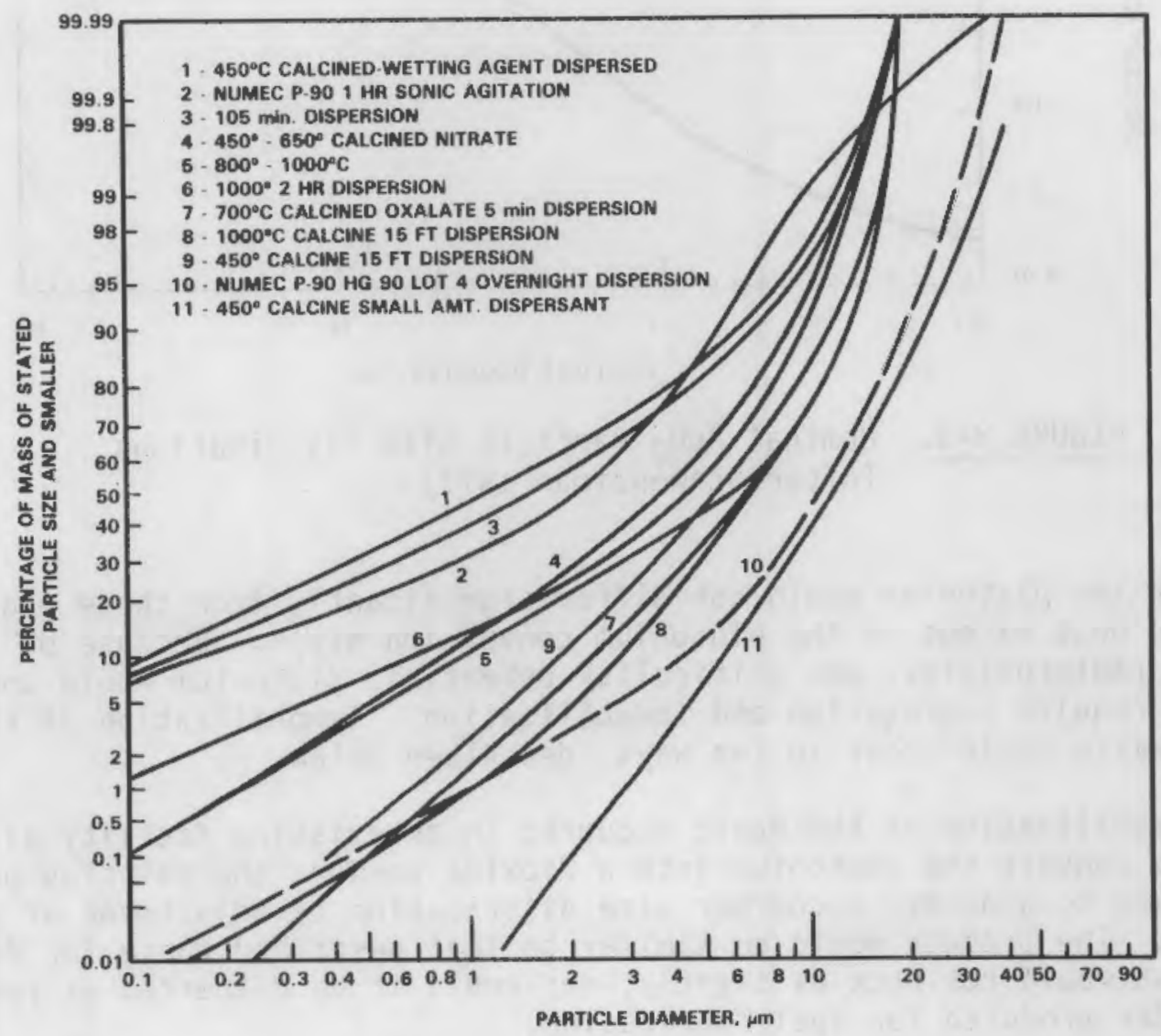

FIGURE B-2. Plutonium 0xide Particle Size Distributions (After Barr et al. 1970 and NUMEC 1962) 


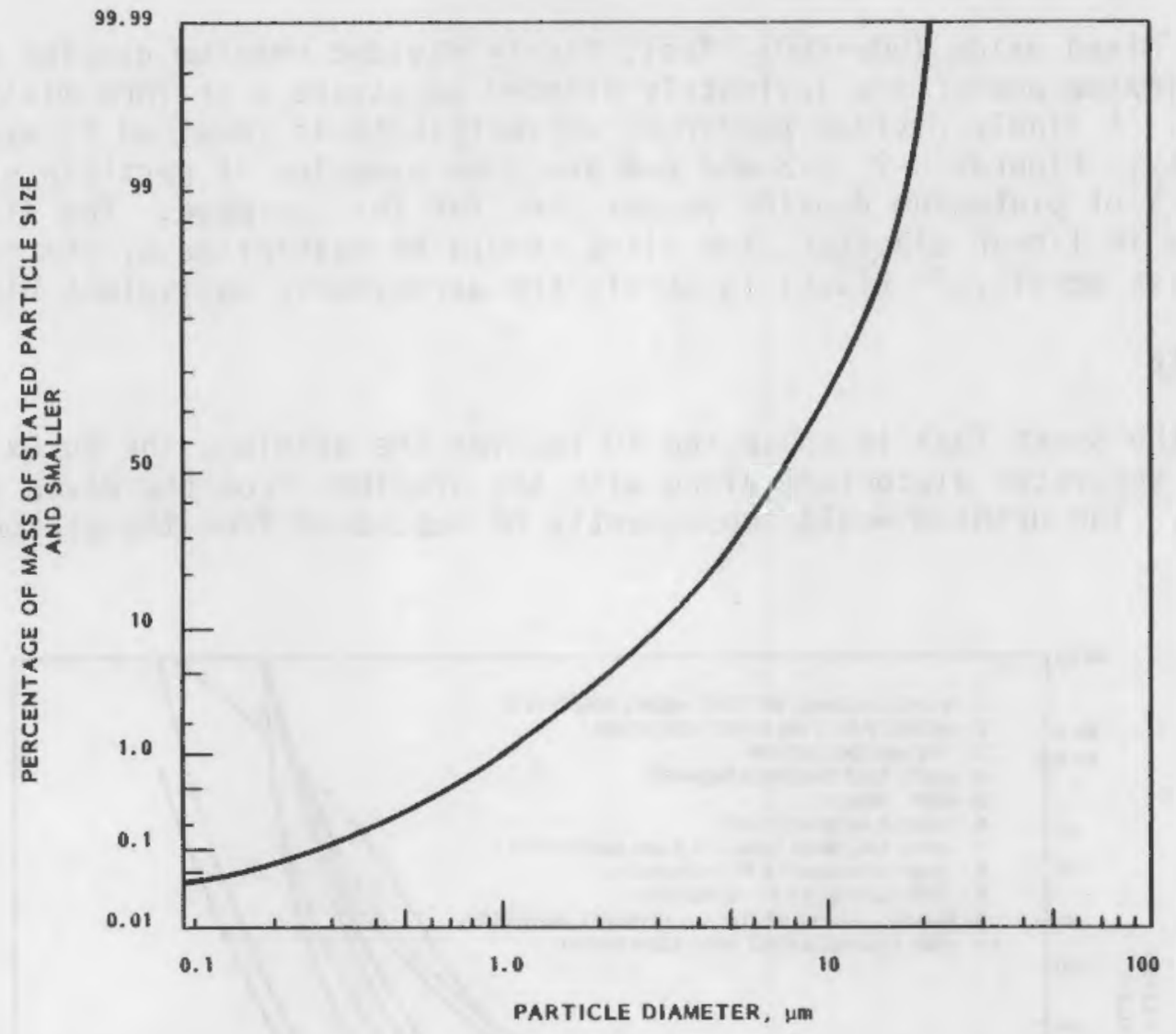

FIGURE_B-3. Nomina1 $\mathrm{PuO}_{2}$ Particle Size Distributions (After Schwendiman 1977)

handling of the plutonium would not differ significantly from those practices used in the past except in the plutonium conversion steps. Because of its long half-life, radiotoxicity, and criticality potential, plutonium would undoubtedly still require segregation and immobilization. Immobilization of the plutonium as waste could occur in two ways, described below.

If immobilization of the waste occurred in an existing facility already equipped to convert the plutonium into a dioxide powder, the existing process could be used to generate a coarser size distribution by adjustment of process parameters. The product would be similar to that described above for fuel fabrication but would not pack as tightly, nor could it be dispersed as readily, as the powder produced for fuel fabrication.

If immobilization occurred in a facility designed to handle the plutonium as a waste or if additional waste treatment capability was added to existing facilities, the product would be a highly stable, nondispersible material (e.g., massive, sintered, $\mathrm{Pu}_{2}$ pieces or plutonium mixed in a very stable material such as glass). In such a case, the objectives of this study have 


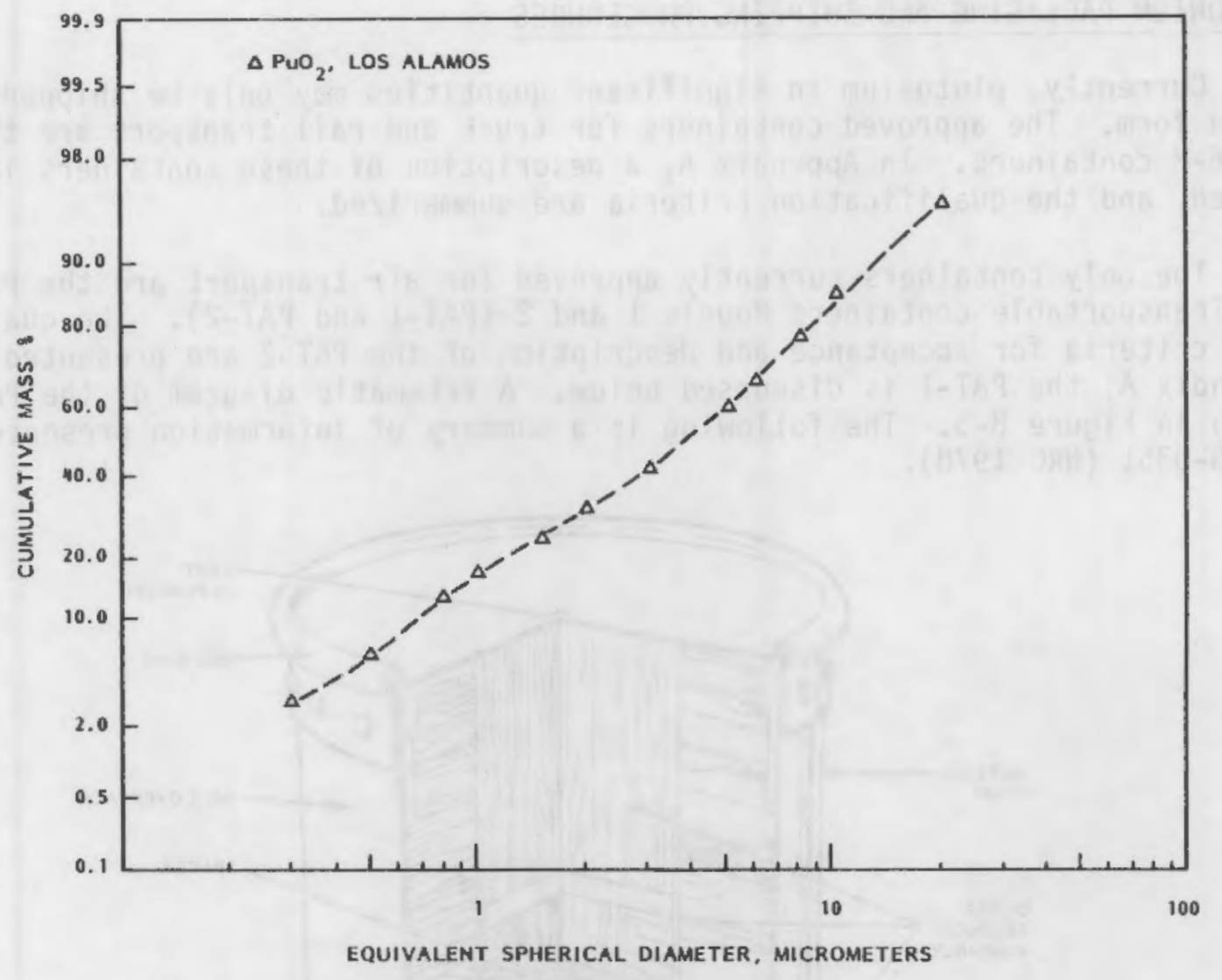

\section{FIGURE B-4. Particle Size Distribution (After Sutter et al. 1980)}

already been achieved by providing plutonium in a less vulnerable form for shipment. In the former case, the plutonium available for shipment would be similar to that considered for fuel fabrication; in the latter case, the plutonium is in less jeopardy and not of concern.

\section{Baseline Characteristics for Study}

The primary material of concern for both plutonium shipped for fuel fabrication and waste is a dioxide powder with the range of size distributions shown in Figures B-2, B-3 and B-4. The Mass Median Diameters range from 1.3 to $13 \mu \mathrm{m}$ (4.4 to $44 \mu \mathrm{m}$ Aerodynamic Equivalent Diameter), with 1.2 to $72 \%$ of the material $10 \mu \mathrm{m}$ A.E.D. or less. These characteristics form our baseline, and any alternative form considered should significantly reduce the potential airborne hazard without increasing other environmental hazards (such as water and food chain pathways) under accident conditions. 


\section{PLUTONIUM PACKAGING AND SHIPPING PROCEDURES}

Currently, plutonium in significant quantities may only be shipped in solid form. The approved containers for truck and rail transport are the LLD-1 and 6-M containers. In Appendix A, a description of these containers is presented, and the qualification criteria are summarized.

The only containers currently approved for air transport are the Plutonium Air Transportable containers Models 1 and 2 (PAT-1 and PAT-2). The qualification criteria for acceptance and description of the PAT-2 are presented in Appendix A; the PAT-1 is discussed below. A schematic diagram of the PAT-1 is shown in Figure B-5. The following is a summary of information presented in NUREG-0361 (NRC 1978).

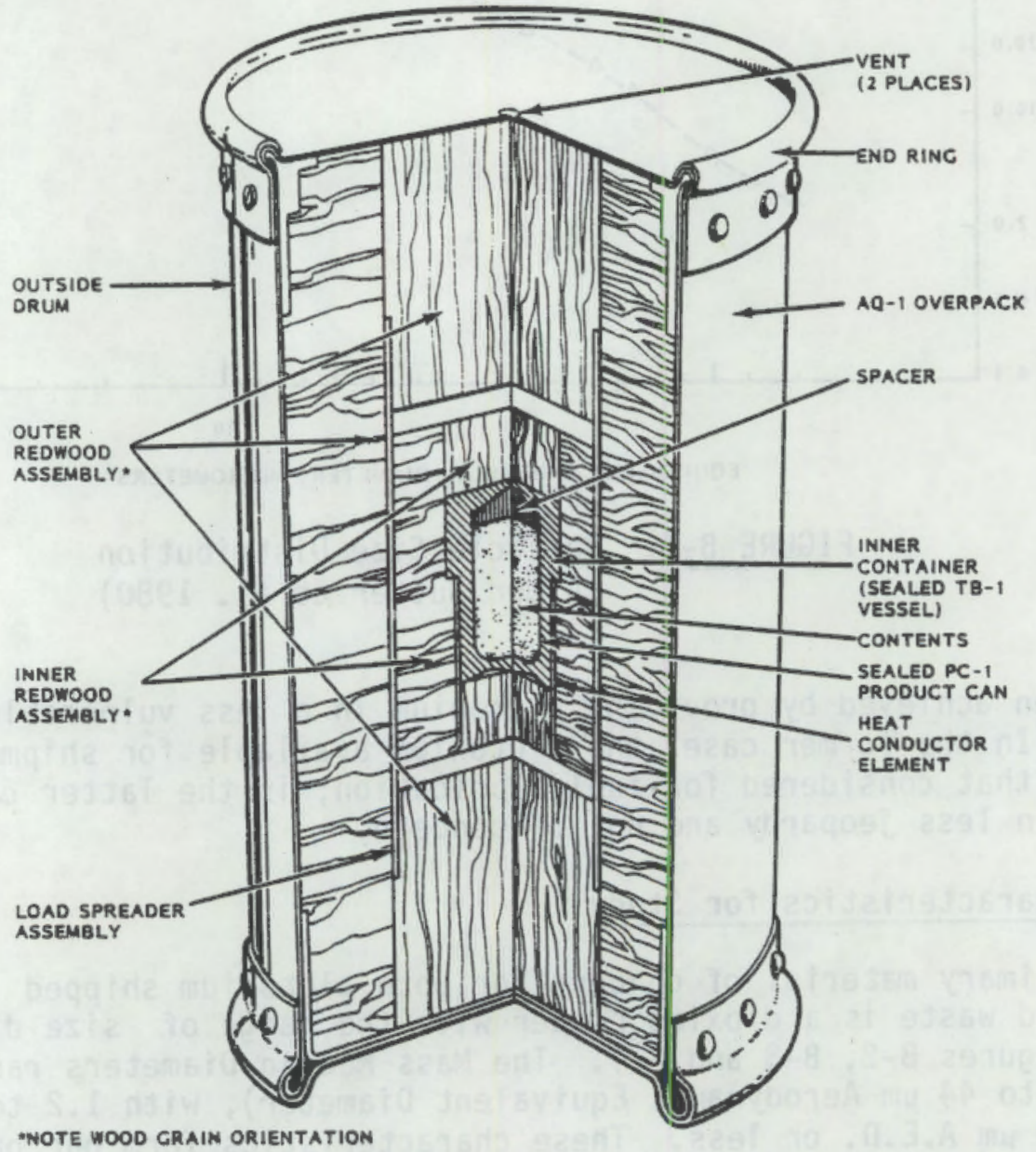

FIGURE B-5. Plutonium Air Transportable Package (PAT-1) 
The PAT-1 is a right circular cylinder, $241 / 2$ inches in diameter and $421 / 2$ inches long. The package has a gross weight of approximately $5001 \mathrm{lb}$. It has been designed for transport of up to $2.0 \mathrm{~kg}$ of plutonium dioxide having a maximum decay heat of 25 watts. The package qualifies as a Fissile Class I. The PAT-1 consists of 3 parts:

- The AQ-1 overpack includes the outer container, a 65-gallon drum that is fully lined with an inner drum. Both drums are 304 stainless steel. The remaining components are a redwood assembly (for energy absorption and fire protection), a load spreader, and an inner heat conductor tube.

- The TB-1 containment vessel (Figure B-6) is composed of a body, a lid, a copper gasket, and an 0 ring. The body and lid are made of precipitation-hardened stainless steel ( $\mathrm{PH13} 8 \mathrm{MO}$ ) with $\mathrm{H} 1075$ temper. The lid is hermetically sealed to the body by a copper gasket with knife-edge sealing beads on both body and lid. The closure is by twelve $1 / 2$-inch diameter bolts spaced uniformly around the circumference of the body. The 0 ring provides a secondary seal.

- The PC-1 product can is fabricated of 308 stainless steel and crimped shut. The can is sealed by welding or silver soldering and meets 10 CFR 71.42 requirements for a separate inner container.

Most commercial shipments of plutonium have been by trucks, where precautions like exclusive use of vehicles, special routes, escorts, and reduced speeds can be applied. Shipment by all other modes of transportation is much less frequent; and, because of the more stringent requirements, shipments by air have been suspended.

\section{Inner Packaging Considerations}

Due to the need to isolate plutonium from the biosphere, the oxide placed into the inner container is provided with multiple barriers. These barriers are only utilized to allow handling of the plutonium under nonrigorous operations to transmit the material from an enclosure such as a glove box to the shipping container and are assumed to have no integrity under accident conditions. The barriers consist of a sealed PVC or polyethylene bag to hold the plutonium, a press-fit sheet metal can taped shut to hold the bagged plutonium, and one or more sealed PVC or polyethylene bags around the can. Presence of plastic in the high-strength vessel during a fire aggravates the problem by generation of vapor and gases, some of which are corrosive. Vapors could also immobilize the powder by wetting it.

\section{Accident Stresses}

Appendix A, "Transportation Accident Characterization," includes a descriptive analysis of anticipated hostile environments and their parameters, as 

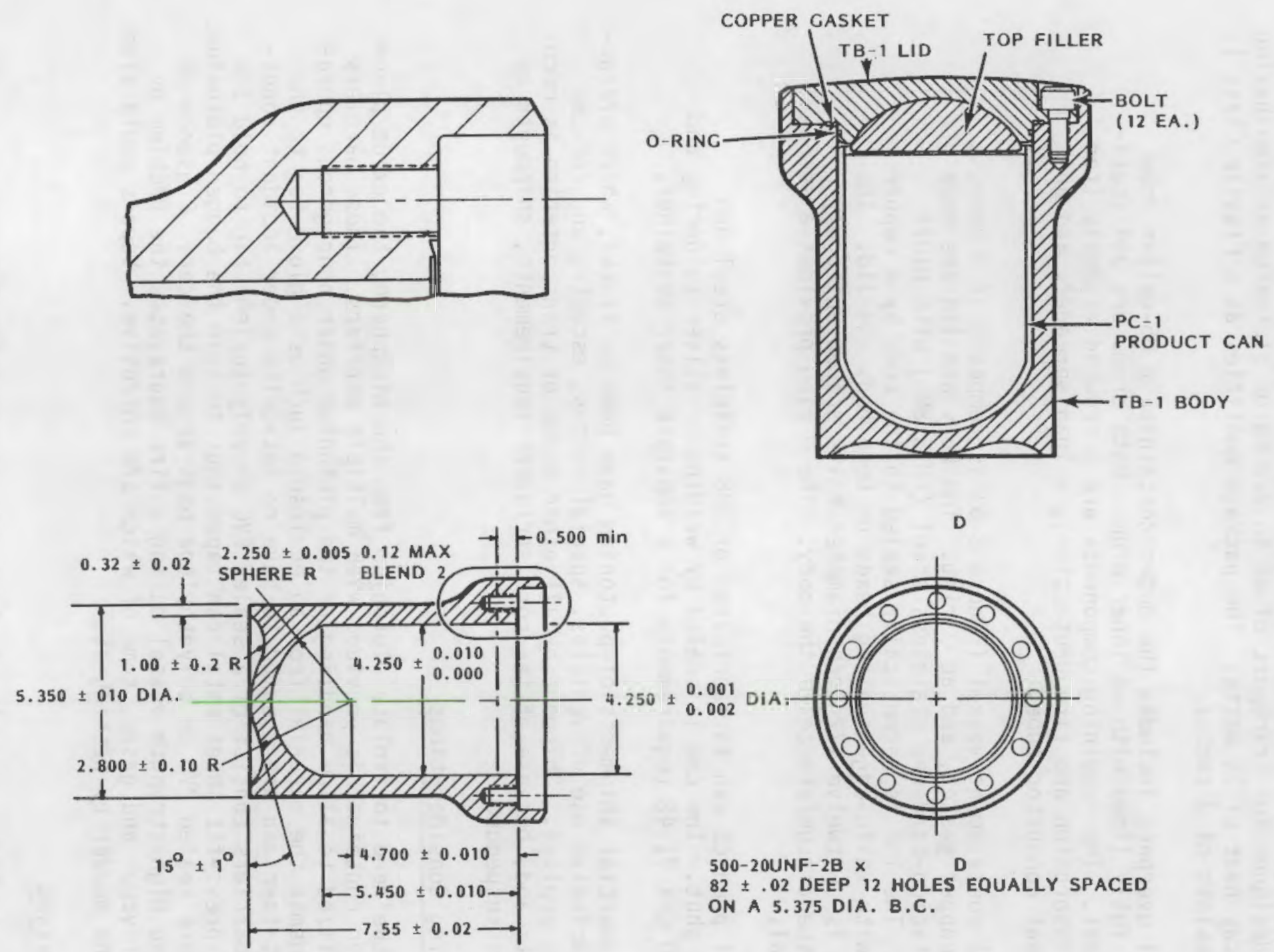

500-20UNF-2B $\times$

D

$82 \pm .02$ DEEP 12 HOLES EQUALLY SPACED

ON A 5.375 DIA. B.C.

FIGURE B.6. TB-1 Containment Vessel (all dimensions in inches) 
well as the anticipated responses of package contents to those environments. Results of several related tests involving various containers are discussed there.

\section{SELECTION CRITERIA}

The purpose of this study is to identify plutonium forms and release or dispersibility mitigation techniques that may reduce the perceived hazards from potential accidents during plutonium transport. Of primary concern is the potential downwind inhalation hazard, which can be acute and not readily amenable to remedial action. The near-field problems of contamination and potential intrusion into the food and water chains are also considerations. The initial objective, however, is to minimize the quantity of material which would leave the high-strength inner container in the event of an accident. The second consideration is to minimize the fraction of respirable, transportable particulate material in that which would be released from the container. As noted in Appendix A, the most likely condition leading to a failure of the high-strength container is fire. Both the 6-M and LLD-1 were shown to lose their integrities (are no longer leaktight) under that condition.

Loss of integrity is not synonymous with release. For a powder, some force must be present to deagglomerate and disperse particles. If the opening is properly aligned and of sufficient size, gravity may cause the powder to flow from the container. Powders of the fine-size distribution of the plutonium dioxide currently in use pack tightly and resist flow. The most severe dispersion force appears to be pressure buildup within the high-strength vessel, prior to failure, due to the heating of gases and the generating of decomposition products from organic materials present. Vibration or impact prior to, or during, the loss of integrity could contribute to deagglomeration and/or subdivision.

Various means could be used to achieve these objectives:

- Adjust process parameters to generate a coarser, less friable plutonium dioxide or a plutonium dioxide which sticks together with the application of heat.

- Use another plutonium compound with more desirable characteristics.

- Involve a second material, which combines with the plutonium dioxide in the event of an accident to produce a less dispersible mixture.

- Eliminate pressure-generating materials from the packages.

- Alter the inner package configuration so that it functions, in the event of an accident, to mitigate dispersion or generates conditions which are less favorable to dispersion. 
Based on the accident stresses given, the characteristics desired in the candidate materials and techniques are discussed below.

\section{Chemical Characteristics}

All materials should be chemically stable under accident conditions and remedial actions anticipated for such events. Since the only apparent cause of integrity loss of the high-strength containers is fire, the principal concerns are temperature and duration of the fire, the atmospheric gaseous products of a fire, and fire extinguishing agents:

- temperature: up to $1300^{\circ} \mathrm{C}\left(2400^{\circ} \mathrm{F}\right.$ ) for 200 min (a) (from Table $\mathrm{A}-2$, "Accident Envelope Descriptions")

- atmosphere: may contain carbon monoxide, carbon dioxide, water vapors, soot and pyrolyzates

- fire extinguishers: water, foam, carbon dioxide, nitrogen, dry agents, Halon, etc.

If a candidate does react, the reaction should

- not be strongly exothermic (generate excess heat)

- not generate a plutonium compound, under existing conditions, which is a gas, vapor, or of a finer size distribution than its precursor

- not be soluble in, or react with, commonly used extinguishing agents (water, carbon dioxide, dry chemicals, Halon, etc.) in a deleterious fashion.

\section{Physical Characteristics}

The materials considered should be solid under the normal range of process and handling conditions. Liguids, even of high viscosity, are undesirable except as additive material(B) to mitigate the effects of an accident. If a viscous liquid is used as an additive, it should not add significantly to the internal pressure of the high-strength container in the event of an accident. If the plutonium compound under consideration is a solid, the most desirable state would be a single, massive piece; if subdivided, a coarser size distribution is better. The size distribution should not approach that of the plutonium dioxide currently in use. The materials used should not produces gases or vapors under the accident conditions quantified or under the normal

(a) Flame temperature.

(b) Separated from the plutonium and only available in the event of an accident.

- Registered trademark of Davies Nitrate Company, Inc., Metuchen, New Jersey. 
remedial procedures anticipated. If a combination of materials is used, the combination or resultant mixture must meet all the criteria.

Process Considerations

Use and production of alternative plutonium shipping forms should not result in significant process changes that increase direct costs and personnel exposure. For example, they should be formed, handled, and used in current separations and fuel fabrication facilities without radical process redesign; and they should not require inordinate personnel attention and handing.

Transport Considerations

Transport of alternative plutonium shipping forms should not require radical new shipping containers or substantial changes in shipping and handling procedures which would increase direct costs and personnel exposure. Neither should there be any substantial increase in the number of shipments, resulting in high costs, greater risk of personnel exposure, and increased potential for traffic injuries or fatalities.

\section{Other Considerations}

An attempt should be made to recognize the direct costs (dollars for new equipment, man-hours, transportation) and indirect costs (potential personnel exposure, injuries/man-hour during operations, injuries and fatalities/shipment mile) and to select those alternatives which reduce risk and minimize cost impacts. It would be desirable if the selected alternative form aids in recovering plutonium from accident situations by localizing the spread of the material.

\section{SUMMARY}

The criteria for selection of candidate materials/techniques are not absolute, but are a comparison of relative merit in several areas. The prime concern is reduction of inhalation hazard, followed by the reduction of dispersibility/localization, and control of plutonium released from the inner container. Other considerations, such as direct and indirect costs, are not addressed under the current scope of this study, but warrant investigation at a later date.

The alternative form should not result in a particulate size distribution which is greater than $2 \mathrm{wt} \% 10 \mu \mathrm{m}$ A.E.D. When subjected to temperatures up to $1300^{\circ} \mathrm{C}$ or greater for 200 minutes. The form should be chemically stable or retain its function up to the temperature and fire conditions previously given: If the form is altered under such conditions, the products must not produce gases or vapors, and they must meet the above criteria. Forms undergoing minor deterioration at temperatures greater than $1000^{\circ} \mathrm{C}$ may be considered. When passed through small openings at pressures up to $1000 \mathrm{psig}$, the alternative form should not be subdivided to generate a size distribution less than that stated above. Once released, the alternative form should not subdivide to 
generate a size distribution less than stated above, i.e., (fraction released) $x$ (fraction of particles $10 \mu \mathrm{m} \mathrm{A.E.D.} \mathrm{or} \mathrm{less)}<2$ wt\% of plutonium in container, when subjected to crush forces of $30 \overline{0}, 000 \mathrm{lbf}$.

The alternative forms selected should attempt to minimize impacts upon subsequent operation. Although such impacts cannot be quantified without analysis, they can be minimized by minimizing departures from current practices. Thus, alternative forms which necessitate complex or lengthy procedures to produce or utilize, whose volume is significantly greater than plutonium dioxide powder (necessitating more shipments or larger transport containers), or those which require excessive manual manipulation, are not desirable.

\section{REFERENCES}

Barr, M. J.; M. W. Urie; J. L. Daniel; and S. J. Mayhan. 1970. Characterization of Some $\mathrm{UO}_{2}$ and $\mathrm{PuO}_{2}$ Powders. BNWL-1441. Pacific Northwest Laboratory, Richland, Washington.

10 C.F.R. 20. Code of Federal Regulations. Title 10, Atomic Energy, Part 20 "Standards for Protection Against Radiation," Appendix B, "Concentrations in Air and Water Above Natural Background."

10 C.F.R. 71.42. Code of Federal Regulations. Title 10, Atomic Energy, Part 71, "Packaging of Radioactive Material for Transport and Transportation of Radioactive Material Under Certain Conditions," Paragraph 71.42, "Special Requirements for Plutonium Shipments After June 17, 1978."

10 C.F.R. 73.25. 1982. Code of Federal Regulations. Title 10, Atomic Energy, "Performance Capabilities for Physical Protection of Strategic Special Nuclear Material in Transit."

10 C.F.R. 73.67. 1982. Code of Federal Regulations. Title 10, Atomic Energy, "Licensing Fixed Site and In-Transit Requirements for the Physical Protection of Special Nuclear Material of Moderate and Low Strategic Significance."

Hartman, W. F. 1975. A Study of the Physical Parameters of Transportation Accidents, Sandia National Laboratories, Albuquerque, New Mexico.

Hartman, W. F., R. K. Clarke, D. W. Larson, and J. T. Foley. 1974. "The Analysis of Transportation Accident Environments--The Purpose, Method, and Introduction." In Proceedings of the Fourth Symposium on Packaging and Transportation of Radioactive Material, DOC-CONF-74901-P1-3, Miami, Florida.

McWhiter, M.; R. 0. Brooks; J. M. Stomp; and L. A. Dillingham. 1975. Final Report on Special Tests of Plutonium 0xide Shipping Containers to Flight Recorder Survivability Standards, SAND 75-0446, Sandia National Laboratories, Albuquerque, New Mexico. 
Mercer, T. T. 1977. "Matching Sampler Penetration Curves to Definition of Respirable Fraction." Health Physics, 33:259-264.

NRC. 1977. Final Environmental Impact Statement on the Transportation of Radioactive Material by Air and Other Modes, Vol. 1. NUREG-0170, Office of Standards Development, U.S. Nuctear Regulatory Commission, Washington, D.C.

NRC. 1978. Plutonium Air Transportable Package Mode PAT-1, Safety Analysis Report. NUREG-0361, Office of Nuclear Material Safety and Safeguards, U.S. Nuclear Regulatory Commission, Washington, D.C.

Nuclear Materials and Equipment Corporation (NUMEC). 1968. Progress Report-Development of Plutonium-Bearing Fuel Material, NUMEC P-90, Apollo, Pennsylvania.

Schwendiman, L. C. 1977. Supporting Information for the Estimation of Plutonium Dioxide Leak Rates Through Very Small Openings. BNWL-2198, Pacific Northwest Laboratory, Richland, Washington.

Stravasnik, L. F. 1978. Special Tests for Plutonium Shipping Containers 6M.SP5795, and L10. SC-DR-72 0597, Sandia National Laboratories, Albuquerque, New Mexico.

Sutter, S. L.; J. W. Johnson; J. Mishima; P. C. Owzarski; L. C. Schwendiman; and G. B. Long, Editor. 1980. Depleted Uranium Dioxide Powder Flow Through Very Small Openings, NUREG/CR-1099 (PNL-31770). Pacific Northwest Laboratory, Richland, Washington. 



\section{APPENDIX C \\ RESULTS OF PRELIMINARY CONSIDERATION OF CANDIDATE TECHNIQUES}

J. Mishima 
APPENDIX C

\section{RESULTS OF PRELIMINARY CONSIDERATION OF CANDIDATE TECHNIQUES}

\section{INTRODUCTION}

Within the scope of the present study, changes to reduce the potential airborne release of plutonium in the event of an accident are limited to alterations of, and additions to, the materials in the high-strength container and (if not substantial) to the container itself. The proposed changes fall into three working areas:

- high-strength container

- inner packing (plastic bags, metal can)

- plutonium form

Within each area, various techniques could be applied to mitigate the deleterious effects of the accident or conditions generated by the accident. Some (but not necessarily all) of the techniques possible in each area are the following:

- high-strength container

- means of pressure relief

- low-melting material to tie up or bind released plutonium

- inner packaging

- substitute for plastic wrapping, to reduce pressure

- alteration of metal can: to provide pressure relief, incorporate materials which can tie up or bind plutonium in the event of an accident, or design a can with greater integrity

- plutonium

- coarser, harder fragments which will stick together upon heating

- coarser, harder matrix for the plutonium

- additive material as mix to tie up or bind plutonium under accident conditions. 
The participants in this investigation were requested to make a preliminary assessment as to the viability of these and other techniques that they would like to suggest. The team findings in the three areas are summarized in the following sections.

\section{HIGH-STRENGTH CONTAINER AND INNER PACKAGING MATERIAL}

Under present packaging methods, the innermost can contains substantial void space and plastics, which can act to generate dispersal forces for the fine particles. One line of defense would seem to be keeping the contents of the innermost sealed container from becoming hot enough to generate decomposition gases. Assuming that polyethylene or polypropylene is the packaging material, the temperature would be about $250^{\circ} \mathrm{C}$ to $300^{\circ} \mathrm{C}$. Two suggestions for achieving this are noted below:

- Use ablative materials to absorb heat. The redwood and other woods in a PAT-2 container do this, but there are better ablative materials than wood. Modern ablative materials are generally plastics of high char yield, reinforced so that the char stays attached and acts as an insulator. The ablator would be placed outside the inner sealed can, so that its pyrolysis gases would pass off without contributing to internal gas volumes.

- Use insulators to decrease the heat flux. Several good fibrous ceramic materials are available, and some of these have effective impact absorption properties. For example, the present materials used in the 6-M, such as celotex, also perform as insulation, but celotex will burn. It would appear that low cost was a primary design parameter in the design of the surface-transport containers; however, a PAT-2 container costs about $\$ 12 \mathrm{~K}$. One wonders whether it is justifiable to be using low-budget materials in the older containers such as 6-M or LLD-1.

If high temperatures inside the inner can must be accepted, there are some alternate ways of dealing with the problem, as detailed below:

- Eliminate the pressure-generating potential of packaging inside the inner can. Polyethylene and polypropylene are both very lowtemperature thermoplastics, melting at about $150^{\circ} \mathrm{C}$ and decomposing below $300^{\circ} \mathrm{C}$. Perhaps they should be replaced as inner wrappings. Aluminum foil might be a reasonable substitute.

- Place a porous, sintered stainless steel plug in the can lid to provide venting while retarding leakage of the $\mathrm{PuO}_{2}$. The vent would have to be guarded against blockage by plastic, unless plastic was eliminated.

- Place a braze preform on the package sealing surface, depending on normal fit-up until the braze melts. After melting, the braze would still vent; but upon cooling, it would seal the package. 
This concept would work best with screw-threads, which would not release the lid under modest pressures.

\section{PLUTONIUM}

Several suggestions were addressed for altering the plutonium form itself to produce a less dispersible material in the event of an accident. These suggestions and relative merits of each technique are discussed below.

$\mathrm{PuO}_{2}$ Agglomeration at $1300^{\circ} \mathrm{C}$

The particles of plutonium oxide are known to sinter at high temperatures. The size of the particles is expected to exceed 10 microns if heated at $1300^{\circ} \mathrm{C}$. Dispersion of respirable oxide may not be as severe a problem as believed.

\section{Potential Benefits}

A study of this candidate technique would provide evidence that might ameliorate the consequences of an accident. During a $1300^{\circ} \mathrm{C}$ fire, oxide may not be as dispersable as thought.

\section{Possible Disadvantages}

Some container-crushing accidents may occur with no fire, or oxide may be dispersed before reaching $1300^{\circ} \mathrm{C}$. A more stable form may be required.

\section{Modification of Oxide Preparation}

The parameters of plutonium oxalate precipitation and calcination can be modified to change oxide particle size. Variable parameters include temperature, acidity, residence time in the precipitation vessel and plutonium/oxalate ratio.

\section{Potential Benefits}

This approach is the easiest of all suggestions to implement because it does not require a new process. No new equipment is required, and the cost of implementation is the lowest of the suggested ideas.

\section{Possible Disadvantages}

The change in particle size may be insignificant for appreciably altering the dispersion effects during a violent accident. Whereas it may be possible to raise the particle size to more than 20 microns, and to reduce sharply the respirable fraction of plutonium oxide below 10 microns, new concerns (such as plutonium dispersion from the accident site) may continue to provoke the search for a shipping form that is not dispersible at all. 
A pellet configuration will reduce and possibly eliminate dispersion of fines during an accident. The equipment for pressing pellets is available for laboratory testing. The questions to be answered by a literature survey relate to pressing characteristics of plutonium dioxide and the nature and need for binders. Another question concerns removal, by the receiver, of the binder.

\section{Potential Benefits}

Green pressing uses low-fired oxide and does not jeopardize subsequent processing, if required. The chemical form of the material shipped is not changed. The equipment for manufacturing pellets is not overly complex, and no development of new process hardware is necessary.

\section{Possible Disadvantages}

Use of green pressing means additional hardware for both the shipper and receiver. The receiver may need to grind the pellets and process the oxide to remove the binder, but neither of these steps is anticipated to be a major obstacle.

\section{Sintered Pellets}

Pellets of plutonium oxide sintered at high temperatures are expected to provide a shipping form free of dispersible oxide fines. The technology is well established for Pu-U oxides, and data probably exists for pellets of plutonium alone.

\section{Potential Benefits}

Pellet pressing and sintering are established processes. The hardware requires no development. The resultant pellet is thought to be hard, with few or no fragments under 10 microns.

\section{Possible Disadvantages}

Additional hardware must be purchased for shippers' processing. Receivers will need to purchase equipment to grind the pellets and dissolve the oxide. Sintered plutonium oxide will require $\mathrm{HNO}_{3}-\mathrm{HF}$ to dissolve. The use of fluoride requires specially designed facilities to minimize corrosion.

\section{Sol-Gel Production of Plutonium Oxide Microspheres}

The technology of forming hard microspheres of $\mathrm{PuO}_{2}$ with $100 \mu \mathrm{m}$ diameters is established and documented. The microspheres are expected to resist dispersion during a violent accident and are not respirable. 


\section{Potential Benefits}

Microspheres of $\mathrm{PuO}_{2}$ appear to offer a dispersion-resistant form of plutonium oxide. The processing technology is developed and has been demonstrated on a pilot-plant scale.

\section{Possible Disadvantages}

The shipper would have to add an additional process to the oxide facility. The Sol-Gel flowsheet is complex, though not prohibitively so. Questions regarding receiver processing of the microspheres remain to be answered.

\section{Freeze-Dry Processing}

This technique was mentioned as a possibility. A brief followup revealed that processing steps were elaborate, and that the product was as fine or finer than present oxide-process powders. No other investigation is recommended at this time.

\section{Immobilization of $\mathrm{PuO}_{2}$ in Metal Lattice}

A metal lattice surrounding the oxide as a honeycomb surrounds honey would provide restraint to dispersion of oxide fines. A metal could be selected that would soften (but not flow) at $1300^{\circ} \mathrm{C}$. This soft metal would entrap the oxide and prevent major dispersion. This idea is conceptual only and has not been tested. The most immediate drawback is the reduction of shipping volume available in the high-strength vessel.

Immobilization of $\mathrm{PuO}_{2}$ in Ceramic/Salt Lattice

This idea, also conceptual, involves interspersing a suitable material in the oxide that would melt and entrap the $\mathrm{PuO}_{2}$ if heated. The disadvantage is that the oxide would remain dispersable in a nonfire accident that pierced the inner shipping container.

Change in the Chemical Form of Plutonium

Alternate forms of plutonium were considered, but each is less stable than $\mathrm{PuO}_{2}$ or turns into $\mathrm{PuO}_{2}$ at $1300^{\circ} \mathrm{C}$ in an air atmosphere. Consideration of alternate chemical forms is not recommended at this time.

Use of Inorganic Ion Exchangers

Inorganic ion exchangers have been identified as potential alternative shipping forms for plutonium. The method visualized for using inorganic ion exchangers for this purpose would consist of pumping a dilute plutonium salt solution through a suitably packaged ion exchange column until the ion exchange medium is loaded to capacity. The ion exchange column would then be rinsed free of soluble plutonium salts, drained, and dried for transport. Small influent and effluent lines to the column could be easily capped to seal the 
column. An eluting solution would be pumped through the column at the receiving station to recover the plutonium. The column could then be rinsed free of soluble plutonium salts and reused.

\section{Potential Benefits}

Anticipated advantages of using suitable inorganic ion exchangers as plutonium shipping media include the following:

- The media are highly resistant to decomposition by heating. If melting occurred, a glass might be formed which would contain the plutonium.

- The media are relatively coarse $(0.3$ to $1.0 \mathrm{~mm})$ and would not be dispersed as fine particulates upon impact of the shipping containers.

- The process of preparing the plutonium feed solution should be relatively simple and entail only minimal costs.

- Leaching by natural waters in case of an immersion accident would be very slow.

\section{Possible Disadvantages}

Possible disadvantages include the following:

- The plutonium-holding capacities of inorganic ion exchangers may be limited (probably less than $25 \%$ by weight).

- The volume of inorganic ion exchanger per gram of plutonium may be 10 times that of plutonium dioxide.

- Some potentially useful inorganic zeolites with high ion exchange capacities are not resistant to acids, which may limit their use for plutonium ion exchange.

No data are available on the ion exchange characteristics of zeolites for plutonium. The exchange of Pu (III) may be similar to that of the trivalent lanthanides, in which case a loading capacity may be estimated. Ames (1964) reported a high selectivity of $13-x$ zeolites for $\mathrm{Ce}^{+3}$ over $\mathrm{Na}^{+}$. The exchange capacity for $\mathrm{Ce}^{+3}$ was about $3 \mathrm{meq} / \mathrm{g}$ at $70^{\circ} \mathrm{C}$. The $13 \mathrm{X}$ is not resistant to strong acids; however, Pu (III) can be maintained in dilute solutions to about $\mathrm{pH}$ 7. The first hydrolysis constant for $\mathrm{Pu}$ (III) is about $7.0 \times 10^{-8}$ according to the following reaction (Cleveland 1979):

$$
\mathrm{Pu}^{+3}+\mathrm{H}_{2} \mathrm{O}=\mathrm{Pu}(\mathrm{OH})^{+2}+\mathrm{H}^{+}
$$

Pu (IV) requires a strongly acidic solution to prevent precipitation. 
Other inorganic ion exchangers which may be used as shipping media include zirconium phosphate, zirconium pyrophosphate and zirconium phosphatesilicate (Cleveland 1979). These exchangers are acid resistant and have been used for separation of trace quantities of plutonium from other ions. A distribution coefficient (Kd) of 3000 was reported for trace Pu (III) in $0.02 \mathrm{M}$ nitric acid with zirconium phosphate. The $\mathrm{Kd}$ for trace Pu (IV) in $0.5 \mathrm{M}$ nitric acid was 2000. In the case of zirconium pyrophosphate, a Pu (IV) Kd was reported for $0.2 \mathrm{M}$ nitric acid, but the $\mathrm{Kd}$ fell to 1300 in $0.5 \mathrm{M}$ nitric acid. The total ion exchange capacity for the zirconium pyrophosphate was given at $6.6 \mathrm{meq} / \mathrm{g}$, which is very high. The portion of this capacity that could be used for plutonium is unknown.

The physical stability of zirconium phosphate appears to compare favorably with zeolites in a simple crush test (rubbing it between two coins), but little is known about its drying characteristics (if completely dehydrated, it may crumble to powder).

\section{CONCLUSIONS}

Based upon our perceptions as to the availability of suitable candidate materials and viability of the techniques covered, several alternatives were selected for further study:

- pelletization of $\mathrm{PuO}_{2}$ (green pellets)

- conversion to Sol-Gel microspheres

- absorption of plutonium on inorganic ion exchangers

- mitigation of temperature effects by use of ablative materials in the high-strength container

- mitigation of pressure effects within the high-strength container during fires, through use of noncarbonaceous wrapping materials.

\section{REFERENCES}

Ames, L. L., Jr. 1964. Zeolite Type X Equilibria with Trivalent Cerium and Yttrium Cations. HW-SA-3433. U.S. Department of Energy, Hanford Works, Richtand, Washington.

Cleveland, J. M. 1979. The Chemistry of Plutonium. American Nuclear Society, La Grange Park, Illinois. 



\section{APPENDIX D \\ GREEN PELLETS AS AN ALTERNATIVE PLUTONIUM SHIPPING FORM \\ J. Vincent Panesko}

Rockwell Hanford Operations 
APPENDIX D

GREEN PELLETS AS AN ALTERNATIVE PLUTONIUM SHIPPING FORM

\section{INTRODUCTION}

The United States Nuclear Regulatory Commission (NRC) sponsored a study at the Pacific Northwest Laboratory (PNL), operated by the Battelle Memorial Institute, to ascertain the feasibility of reducing the radiological hazard in shipping plutonium oxide powder. The objective was to modify the shipping form to reduce the dispersibility of plutonium oxide in a catastrophic shipping accident.

A literature review was conducted by Rockwell Hanford Operations to determine how an alternative shipping form, specifically a pellet of compressed, unfired, plutonium oxide powder, would 1) be produced, 2) react in accident scenarios, and 3 ) be returned to the oxide form. The criteria for alternative shipping forms are described in Appendix B and are summarized as follows:

- Easy production (simple technology, low cost)

- Low dispersion during violent accident

- Easy return to oxide powder.

The question is, "Can green (unfired) pellets of plutonium oxide meet the criteria for an alternative shipping form?"

SUMMARY

Compaction of plutonium oxide powder into dense pellets should reduce the fine powder available for airborne dispersion in accident scenarios. The use of green pellets meets essentially all the criteria for alternative shipping forms.

\section{Advantages of Green Pellet Shipping Form}

- Green pellets have a density 3 to 4 times that of bulk powder, so more plutonium could be shipped with existing containers.

- Pellet size can be varied to suit shipping containers or customer needs.

- Production of green pellets is a simple and familiar process.

- Green pellets can be easily ground up into powder. 
- Pressing and grinding equipment can fit in glove boxes without major redesign.

- Many shippers and receivers already have equipment for pressing or grinding.

- In certain cases where the receiver now prepresses oxide into green pellets for subsequent processing, transferring the responsibility for green pressing to the shipper would not increase overall operating costs.

- The impact behavior of sintered pellets is well documented.

- The environmental Dehavior of sintered pellet fragments is well documented.

- Organic binders or trace moisture can be added to increase pellet strength.

- Unfired (green) pellets increase in strength at $1300^{\circ} \mathrm{C}$ for 4 hours because the granules adopt a closer molecular structure, yielding a harder, denser pellet.

\section{Oisadvantages of Green Pellet Shipping Form}

- Formation of green pellets requires pressing equipment.

- Shipping pellets rather than oxide powder increases operating costs. (There may be some savings from making fewer shipments due to increased densities).

- Green pellets are not particularly strong. This is commonly known but not quantitatively documented.

- There is no data on impact behavior of green pellets.

- There is no data on crush resistance of green pellets.

- Some organic binders may react with plutonium oxide and not be completely removed at low temperatures.

- Data on removal of organic binders by heat treatment is incomplete. Need for Future Work

- Oefine the impact behavior of green pellets.

- Oefine the effect of binders on impact behavior. 
- Define a production process for the "stickiest" pellet, i.e., a pellet that breaks into large agglomerates above 200 microns with essentially no fines under 200 microns.

- Define the behavior of binders in a closed shipping container heated to $1300^{\circ} \mathrm{C}$ for 4 hours.

- Define a process to debind the pellet without affecting the quality of plutonium oxide.

\section{PROGRAMS THAT USED GREEN PELLETS}

The formation of green pellets has been studied as part of three government programs summarized below. In each program, the formation of green pellets was an intermediate step in the process of making sintered pellets. Sintered plutonium oxide pellets were thoroughly characterized with respect to product optimization and accident scenarios. Unsintered, green pellets received attention only with regard to their influence on sinterability. Thus, green pellets received minimum characterization work (and no accident scenario studies). Nevertheless, substantial information about the green pellets is available from the three programs described below.

\section{Plutonium-Metal Fuel Forms}

In the early 1960's, Los Alamos National Laboratory investigated the nuclear fuel properties of mixtures of plutonium and metal oxides. These reports included data on green pellets of $\mathrm{PuO}_{2}$, as well as pellets consisting of $\mathrm{Pu} /$ metal mixtures (Pritchard et a1. 1961; Pritchard, Johnson and Leary $1963 \mathrm{a}, \mathrm{b})$.

Information was reported on density of pellets, effect of binders, and effects of the added metals on pellet properties. The value of these reports is as a source of information on green pellets of $\mathrm{PuO}_{2}$, plus information on pellets made of mixtures that may be similar to future scrap or waste that must be shipped.

Quality Test For FFTF $\mathrm{PuO}_{2}$ (HANFORD)

Plutonium for the first four loadings of the Fast Flux Test Facility (FFTF) at Hanford was purified by the Atlantic Richfield Hanford Company (ARHCO) prior to sending the oxide to the Nuclear Materials and Equipment Corporation (NUMEC, Apollo, Pennsyivania) for blending with $\mathrm{UO}_{2}$. The quality of $\mathrm{PuO}_{2}$ shipped to NUMEC was determined by performing a sinterability test on sample pellets of the $\mathrm{PuO}_{2}$ shipment.

In the process of developing test procedures, both NUMEC and ARHCO gained experience with green pellets of $\mathrm{PuO}_{2}$ and green pellets of $\mathrm{PuO}_{2} / \mathrm{UO}_{2}$. The value of these documents lies in the description of equipment, pressing techniques and green pellet densities for various types of $\mathrm{PuO}_{2}$ and $\mathrm{PuO}_{2} / \mathrm{UO}_{2}$ feed (ARHCO 1969a,b; Houston 1964, 1965; Marley 1966; NUMEC 1959, 1960a-c, 1961a,b, 1962, 1963a,b, 1965, 1968a-c, 1970; Rasmussen 1969). 
Plutonium Fuel For Nuclear Power Systems

An extensive development program for making plutonium-238 oxide pellets has been carried on at Los Alamos since the early 1970's. Equipment and procedures for ball milling, slugging (pressing of green pellets) and screening (breaking up of green pellets) have been described (Petrovic 1977; Baker 1977; LANL 1979a,b; Kent 1979; Maraman 1979, 1980a-e; Bronisz 1980; Folger 1981a-c; Tennery 1974).

The Los Alamos program is unique for several reasons listed below:

- Pellet size was as large as 27 millimeters in diameter by $27 \mathrm{milli}$ meters high.

- Sintered pellets underwent extensive mechanical property testing.

- Sintered pellets underwent extensive impact testing.

- Sintered pellet fragments, after impacts, were studied under a variety of environmental conditions (rain water immersion, sea water immersion, acid immersion, soil sorption).

- The facilities, equipment and trained personnel are in place to conduct impact tests on green pellets.

One goal of the Los Alamos program was to make pellets as hard as possible, so pellets were pressed at high temperatures. All impact and environmental studies were performed with plutonium oxide that was high fired (consolidated).

There is speculation that a low-density, unfired pellet would be disintegrated by sufficient physical shock, but there are no firm indications as to how large the fragments would be. There is also speculation that an organic binder might provide enough plastic flow through the pellet to prevent shattering. This speculation could be resolved with a future testing program.

\section{PREPARATION OF GREEN PELLETS}

\section{Source Materials}

Initially, this document was directed at shipping pure plutonium oxide pellets. As the literature search progressed, green pellet information was found on other forms, such as $\mathrm{PuO}_{2} / \mathrm{UO}_{2}$ and Pu-metal mixtures. This latter data was added for completeness.

\section{Plutonium 0xide}

The character of a $\mathrm{PuO}_{2}$ pellet varies with the history of the precursor oxide. 0ifferent pellets will be obtained, depending on whether the oxide source is calcined plutonium oxalate, calcined plutonium hydroxide, denitrated plutonium nitrate, burned plutonium metal or calcined plutonium peroxide (Houston 1965). 
The character of the oxide pellet is affected by the calcination temperature of the precursor oxide The higher the calcination temperature, the lower the surface area of oxide; the lower the surface area of oxide, the greater the final pellet density and strength.

The optimum conditions are a powder calcined above $500^{\circ} \mathrm{C}$ with a surface area less than $10 \mathrm{~m}^{2} / \mathrm{gram}$. This oxide will yield a green pellet with a density which is usually in the range of 6 to $7 \mathrm{~g} / \mathrm{cm}^{3}$.

Typical plutonium oxide characteristics are summarized in Table D-1. Most oxides shipped will have properties in the following ranges:

$\begin{array}{ll}\text { Bulk density } & 1.5 \text { to } 2.0 \mathrm{~g} / \mathrm{cm}^{3} \\ \text { Tap density } & 1.8 \text { to } 4.0 \mathrm{~g} / \mathrm{cm}^{3} \\ \text { Average particle size } & 1 \text { to } 3 \mathrm{microns} \\ \text { Surface area } & 1 \text { to } 70 \mathrm{~m}^{2} / \mathrm{g} \\ \text { Green density } & 5.3 \text { to } 8.9 \mathrm{~g} / \mathrm{cm}^{3} \text { (potential values). }\end{array}$

In sumary, every source of oxide has been documented to yield satisfactory green pellets with a density above $5 \mathrm{~g} / \mathrm{cm}^{3}$. Density increase is threefold (green pellet density compared to tap density) or fourfold (green pellet density compared to bulk density).

\section{$\mathrm{PuO}_{2} / \mathrm{UO}_{2}$}

$\mathrm{PuO}_{2}$ materials are used in breeder studies. The addition of $\mathrm{UO}_{2}$ to $\mathrm{PuO}_{2}$ lowers green densities of subsequent pellets near $5 \mathrm{~g} / \mathrm{cm}^{3}$. (See Table D-1, Houston 1965).

Lowered densities of $\mathrm{UO}_{2} / \mathrm{PuO}_{2}$ green pellets suggest a weaker pellet than a $\mathrm{PuO}_{2}$ green pellet. Comparative green pellet strengths were not found in the literature.

\section{$\underline{P u O}_{2}$ - Metal Oxides}

Plutonium oxide may exist as a mixture with metal oxides. Table D-I (Pritchard, Johnson and Leary 1963a) shows that 50/50 mixtures yield impressive green densities in the range of 6.8 to $7.6 \mathrm{~g} / \mathrm{cm}^{3}$. Only the $50 / 50 \mathrm{mix}$ with silicon lowered the green pellet density to $5 \mathrm{~g} / \mathrm{cm}^{3}$.

These data suggest that suitable green pellets might be obtained from a wide variety of plutonium oxide mixtures. 
TABLE D-1. Characteristics of $\mathrm{PuO}_{2}$

\begin{tabular}{|c|c|c|c|c|c|c|c|}
\hline Source & $\begin{array}{l}\text { Temp. of } \\
\text { Caic. (min) " } \mathrm{C} \\
\end{array}$ & $\begin{array}{c}\text { Surface } \\
\text { Area } \\
m^{2} / g \\
\end{array}$ & $\begin{array}{l}\text { Bulk } \\
\text { Densijty } \\
\mathrm{g} / \mathrm{cm}^{-} \\
\end{array}$ & $\begin{array}{l}\text { Tap } \\
\text { Density } \\
\mathrm{g} / \mathrm{cm}\end{array}$ & $\begin{array}{l}\text { Average } \\
\text { Part. Size } \\
\text { Microns }\end{array}$ & $\begin{array}{c}\text { Pellet F } \\
\text { Pressure } \\
\text { tsi }\end{array}$ & $\begin{array}{c}\text { Green } \\
\text { Density }\end{array}$ \\
\hline Oxalate(a) & $\begin{array}{l}420(5) \\
560(5) \\
760(30) \\
760(30) \\
760(30)\end{array}$ & $\begin{array}{l}69 \\
39 \\
4.4 \\
4.9 \\
5.8\end{array}$ & $\begin{array}{l}1.6 \\
1.4 \\
1.8 \\
1.5 \\
1.8\end{array}$ & $\begin{array}{l}2.0 \\
2.0 \\
3.6 \\
2.7 \\
3.1\end{array}$ & $\begin{array}{l}2.2 \\
1.9 \\
1.2 \\
1.4 \\
2.2\end{array}$ & $\begin{array}{l}38 \\
38 \\
38 \\
10 \\
20\end{array}$ & $\begin{array}{l}5.8 \\
6.4 \\
7.2 \\
6.5 \\
7.0\end{array}$ \\
\hline Hydroxide & $\begin{array}{l}850(120) \\
850(120) \\
850(120) \\
850(120) \\
850(120)\end{array}$ & $\begin{array}{l}5.0 \\
22 \\
5.7 \\
11 \\
28\end{array}$ & $\overline{--}$ & $\overline{-}$ & $\overline{-}$ & $\begin{array}{l}32 \\
32 \\
32 \\
32 \\
32\end{array}$ & $\begin{array}{l}8.1 \\
6.0 \\
7.8 \\
6.9 \\
5.8\end{array}$ \\
\hline Peroxide & $\begin{array}{l}490(30) \\
490(30) \\
490(30)\end{array}$ & $\begin{array}{l}26 \\
20 \\
24\end{array}$ & $\begin{array}{l}2: 8 \\
1.8 \\
2.1\end{array}$ & $\begin{array}{l}5.0 \\
3.8 \\
4.1\end{array}$ & $\begin{array}{l}2.3 \\
1.1 \\
1.2\end{array}$ & $\begin{array}{l}20 \\
40 \\
20 \\
40 \\
20\end{array}$ & $\begin{array}{l}6.6 \\
7.0 \\
6.2 \\
6.7 \\
7.1\end{array}$ \\
\hline Denitration & & & & & & 12 & 6.8 \\
\hline $\begin{array}{l}\text { Metal Oxida- } \\
\text { tion Air }\end{array}$ & & & & & & 40 & $8: 9$ \\
\hline $\begin{array}{l}\text { Metal 0xida- } \\
\text { tion Steam }\end{array}$ & $6 x^{2}=x^{2}=7$ & 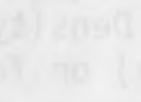 & 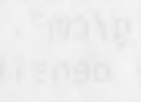 & a $=$ & $\sqrt{1}$ & 40 & 7.9 \\
\hline Oxalate (b) & $\begin{array}{l}760(28) \\
760(28) \\
760(28)\end{array}$ & $\begin{array}{l}8.7 \\
4.0 \\
3.7\end{array}$ & $\begin{array}{l}1.4 \\
1.7 \\
1.7\end{array}$ & $\begin{array}{l}2.6 \\
2.9 \\
3.0\end{array}$ & $\begin{array}{l}2.5 \\
1.9 \\
2.5\end{array}$ & & \\
\hline Oxalate (c) & $\begin{array}{l}350(35) \\
490(5) \\
560(5) \\
760(5) \\
760(30) \\
760(30) \\
760(30)\end{array}$ & $\begin{array}{l}57 \\
53 \\
39 \\
10 \\
4.4 \\
4.9 \\
4.9\end{array}$ & $\begin{array}{l}1.4 \\
1.4 \\
1.4 \\
1.7\end{array}$ & $\begin{array}{l}1.8 \\
1.8 \\
2.0 \\
2.4\end{array}$ & $\begin{array}{l}1.7 \\
1.8 \\
1.9 \\
2.0\end{array}$ & $\begin{array}{l}38 \\
38 \\
40 \\
10 \\
20\end{array}$ & $\begin{array}{l}5.8 \\
5.3-6.4 \\
7.2 \\
7.0 \\
7.0\end{array}$ \\
\hline $\begin{array}{l}\text { Oxalate } \\
\text { (III) }\end{array}$ & $750(60)$ & - & $1.5-2$ & $2.4-2.6$ & $2.1-2.5$ & & \\
\hline Oxalate ${ }^{(e)}$ & 450 & 39.4 & 1.6 & 2.0 & $11.8-12$ & & \\
\hline Oxalate $^{(f)}$ & $350(60)$ & 28.7 & 1.8 & 2.2 & 3.1 & & \\
\hline Oxalate ${ }^{(9)}$ & $625^{\circ} \mathrm{C}$ & 17.4 & & & & 15 & 6.4 \\
\hline
\end{tabular}


TABLE D-1. (contd)

\begin{tabular}{|c|c|c|c|c|c|c|c|}
\hline & & Surface & Bulk & Tap & Average & Pellet F & ormation \\
\hline Source & $\begin{array}{l}\text { Temp. of } \\
\text { Calc. (min) }{ }^{\circ} \mathrm{C}\end{array}$ & $\begin{array}{c}\text { Area } \\
m^{2} / g\end{array}$ & $\begin{array}{l}\text { Densijty } \\
\mathrm{g} / \mathrm{Cm}^{2}\end{array}$ & $\begin{array}{l}\text { Densijty } \\
\mathrm{g} / \mathrm{cm}\end{array}$ & $\begin{array}{l}\text { Part. Size } \\
\text { Microns } \\
\end{array}$ & $\begin{array}{c}\text { Pressure } \\
\text { tsi } \\
\end{array}$ & $\begin{array}{l}\text { Green } \\
\text { Density }\end{array}$ \\
\hline $\begin{array}{l}\text { Burned Pu } \\
\text { metal }\end{array}$ & - & 10.7 & & & & 15 & 7.6 \\
\hline Pu Mitrate & 450 & 6.3 & & & & & 6.4 \\
\hline Pu Nitrate & 650 & 5.7 & & & & & 6.8 \\
\hline Pu Nitrate & 800 & 3.5 & & & & & 7.1 \\
\hline Pu Nitrate & 1000 & $<1.0$ & & & & & 7.2 \\
\hline Oxalate $(h)$ & 900 & & & & & & \\
\hline $\begin{array}{l}50: 5 \mathrm{PO}_{2-} \\
5025 S\end{array}$ & Metal Powders & & & & & 50 & 7.6 \\
\hline $\begin{array}{l}50 \% \mathrm{PuO}_{2} \\
50 \mathrm{xNi}\end{array}$ & Metal Powders & & & t. & & 50 & $7.3-7.4$ \\
\hline $\begin{array}{l}50 \% \mathrm{PuO}_{2} \\
50 \% \mathrm{Cr}\end{array}$ & Metal Powders & & & & & 50 & $6.8-7.0$ \\
\hline $\begin{array}{l}50 \% \mathrm{PuO}_{2}- \\
50 \% \mathrm{Fe}\end{array}$ & Met al Powders & & 1 & 8. & & 50 & 7.1 \\
\hline $\begin{array}{l}50 \% \mathrm{PuO}_{2}- \\
50 \% \mathrm{Sr}\end{array}$ & Metal Powiders & & (9-2) & & & 50 & 5.0 \\
\hline Oxalate(b) & & & & & & 40 & 7.2 \\
\hline $\begin{array}{l}95 \mathrm{~m} / \mathrm{OPvO}_{2} \\
5 \mathrm{~m} / \mathrm{OSrO}\end{array}$ & & & & & & 40 & 7.0 \\
\hline Hydroxide (a) & $850(120)$ & & & & & 20 & 6.6 \\
\hline $\begin{array}{l}1.3 \mathrm{~m} / 0- \\
\text { Sro }\end{array}$ & & & & & & 20 & 6.6 \\
\hline $\begin{array}{l}2.4 m / 0- \\
C_{a O}\end{array}$ & 25091 & $625=$ & $\sqrt{6-2}=$ & & & 20 & 6.6 \\
\hline $\begin{array}{l}3.3 \mathrm{~m} / \mathrm{o}- \\
\mathrm{MgO}\end{array}$ & & & & & & 20 & 6.5 \\
\hline $\begin{array}{l}1.7 \mathrm{~m} / \mathrm{O}- \\
\mathrm{CaF}_{2}\end{array}$ & & & & & & 20 & 6.6 \\
\hline Oxalate & & & & & & 40 & 7.2 \\
\hline $5 \mathrm{~m} / \mathrm{oSrO}$ & & & & & & 40 & 7.0 \\
\hline
\end{tabular}


TABLE D-1. (contd)

\begin{tabular}{|c|c|c|c|c|c|c|c|}
\hline Source & $\begin{array}{l}\text { Temp. of } \\
\text { Calc. (min) }{ }^{\circ} \mathrm{C} \\
\end{array}$ & $\begin{array}{c}\text { Surface } \\
\text { grea } \\
\mathrm{m}^{2} / \mathrm{g} \\
\end{array}$ & $\begin{array}{l}\text { Bulk } \\
\text { Densijty } \\
\mathrm{g} / \mathrm{cm}^{3}\end{array}$ & $\begin{array}{l}\text { Tap } \\
\text { Densizty } \\
\text { g/em }\end{array}$ & $\begin{array}{l}\text { Average } \\
\text { Part. Size } \\
\text { Microns } \\
\end{array}$ & $\begin{array}{l}\text { Pellet F } \\
\text { Pressure } \\
\text { tsi } \\
\end{array}$ & $\begin{array}{c}\frac{\text { ormation }}{\text { Green }} \\
\text { Density }\end{array}$ \\
\hline $100 \% \mathrm{PuO}_{2}(\mathrm{i})$ & & & & & & 10 & 6.1 \\
\hline $\begin{array}{l}80 \mathrm{PuO}_{2}- \\
20 \mathrm{KuO}_{2}\end{array}$ & & & & & & 10 & 5.8 \\
\hline $\begin{array}{l}60 \mathrm{KPuO}_{2} \\
40 \mathrm{WUO}_{2}\end{array}$ & & & & & & 10 & 5.5 \\
\hline $\begin{array}{l}40 \mathrm{KPuO}_{2}- \\
60 \mathrm{KuO}_{2}\end{array}$ & & & & & & 10 & 5.2 \\
\hline $\begin{array}{l}20 \% \mathrm{PuO}_{2} \\
80 \% \mathrm{HO}_{2}\end{array}$ & & & & & & 10 & 5.0 \\
\hline $\begin{array}{l}0 \mathrm{PuO}_{2-} \\
100 \mathrm{HUO}_{2}\end{array}$ & & & & & & 10 & 4.7 \\
\hline $\mathrm{UO}_{2}(\mathrm{ADU})^{(g)}$ & & 9.5 & & & & 15 & 5.2 \\
\hline $\mathrm{UO}_{2}(\mathrm{~b})$ & $720(80)$ & & & & & 15 & 5.2 \\
\hline $\begin{array}{l}\mathrm{UO}_{2}-0.5 \\
\mathrm{wt} \neq \mathrm{PuO}_{2}\end{array}$ & $900(105)$ & 0.7 & 1.6 & 3.1 & 1.5 & 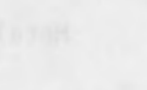 & and \\
\hline $\begin{array}{l}\mathrm{UO}_{2}-5 \text { wt } \% \\
\mathrm{PuO}_{2}\end{array}$ & $840(80)$ & 5.2 & 0.9 & 1.9 & 0.4 & & 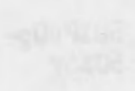 \\
\hline $\begin{array}{l}\mathrm{UO}_{2}-2 \mathrm{Wt} \% \\
\mathrm{PuO}_{2}\end{array}$ & $840(702)$ & 5.3 & 0.8 & 1.7 & & & \\
\hline $\begin{array}{l}\mathrm{UO}_{2}-50 \mathrm{wt} \% \\
\mathrm{PuO}_{2}\end{array}$ & $840(80)$ & 0.51 & 3.6 & 5.6 & & & 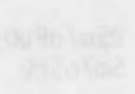 \\
\hline $\begin{array}{l}\mathrm{UO}_{2}-50 \text { wt\% } \\
\mathrm{PuO}_{2}\end{array}$ & $740(80)$ & 1.7 & 3.8 & 5.4 & & & \\
\hline
\end{tabular}

$\begin{array}{ll}\text { (a) Houston 1964 } & \text { (f) NUMEC 1961a } \\ \text { (b) NUMEC 1963b } & \text { (g) Barr et al. 1970 } \\ \text { (c) ARCHD 1969a } & \text { (h) Pritchard, Johnson and Leary 1963a } \\ \text { (d) Doty and Chong 1970 } & \text { (i) Houston 1965 } \\ \text { (e) Blair 1970 } & \end{array}$


Pretreatment of Oxide Before Pressing

There are several steps, before final pressing, that are designed to make the powder more flowable and that usually result in a stronger green pellet. These steps are ball milling (to reduce particles to a uniform size), dry slugging and granulation (to build up the size of particles), addition of binder (to improve strength of green pellets), and use of humidity (to act as a binder).

\section{Ball Milling}

Milling of plutonium oxide is often necessary to obtain a homogenous blend of $\mathrm{PuO}_{2}$ powder for accountability purposes and uniform particle size distribution (Rasmussen 1969).

Wet ball milling yields excellent uniformity, but the process is not easily scaled up to production levels. Dry ball milling may result in agglomeration of particles and coating of jar walls if moisture content is too high (Pritchard and Nance 1966).

Los Alamos found that ball milling converted a mixture of lath-shaped and rosette-shaped particles into a uniform powder consisting of less reactive rosette-shaped particles (Keenan, Kent and Zocher 1974). A presentation of equipment and procedures used at LoS Alamos is given in Attachment D-2.

While Los Alamos ball milled for 40 hours to get small homogeneous particles, NUMEC reported uniform blending of $\mathrm{UO}_{2}$ and $\mathrm{PuO}_{2}$ within 2 to 16 hours (NUMEC 1968b). It is noteworthy that ease of homogenization applies to oxalate-calcined $\mathrm{RuO}_{2}$, not to oxidized-metal $\mathrm{PuO}_{2}$. When NUMEC produced 10,000 pellets from oxidized metal $\mathrm{Pu}_{2}$, a ball-mill cycle of 40 hours was used (NUMEC 1968C).

The decision to ball mill depends on the source, size and uniformity of the oxide. For uniform, oxalate-calcined oxide less than 10 microns, ball milling may not be necessary. For nonuniform oxide, or oxide with particles larger than 10 microns, ball milling can be expected to improve green pellet formation.

\section{Prepressing, Dry Slugging and Granulation}

Studies at Hanford showed that prepressing oxide at lower pressure, followed by granulation through a 20 mesh screen before final pressing at a higher pressure, improved the density and strength of green pellets (ARHCO 1970b,C) Attempts to press fine $\mathrm{PuO}_{2}$ powder in one step yielded a weaker pellet than pressing in two steps.

NUMEC reported, "Die binding difficulties due to fines wedging between the punches and die-body were overcome by preliminary dry-slugging at 6500 psi in a 0.467 inch diameter die followed by hand granulation through a 20 -mesh screen. 
The green strength of these pellets $(0.19$-inch diameter. L/D ratio 1 to 2.4$)$ pressed in the range 10 to $90 \mathrm{tsi}$ was excellent (NUMEC 196la).

Westinghouse studied prepressing of mixed oxides at 10, 20, and $30 \mathrm{tsi}$, followed by granulation and repressing at 10 or 20 tsi. Although green densities were improved by prepressing, edges of green pellets were susceptible to chipping (Barr 1970).

\begin{tabular}{|c|c|c|}
\hline \multirow[b]{2}{*}{ Prepress } & \multicolumn{2}{|c|}{$\begin{array}{l}\text { Green Density of } \\
\text { Pellets After } \\
\text { Final Pressing }\end{array}$} \\
\hline & $10 \mathrm{tsi}$ & $20 \mathrm{tsi}$ \\
\hline None & 7 & 7.2 \\
\hline 10 tsi & 7.1 & 7.4 \\
\hline $20 \mathrm{tsi}$ & 7.1 & 7.4 \\
\hline $30 \mathrm{tsi}$ & 7.2 & 7.4 \\
\hline
\end{tabular}

The value of prepressing at 10 to 30 tsi was questionable.

Houston prepressed at $10 \mathrm{tsi}$, granulated through a 35 mesh screen, and final-pressed at 10 tsi to get a $0.3 \mathrm{~g} / \mathrm{cm}^{3}$ increase in green density of pure $\mathrm{PuO}_{2}$ pellets (see Figure D-1, from Houston 1965).

EURATOM studies in the early 1960 's showed that prepressing and granulation were necessary to obtain good green densities where oxides had surface areas of $50 \mathrm{~m}^{2} / \mathrm{g}$ (EURAEC 1963).

Westinghouse reported that prepressing and granulating were done so that a relatively nonflowable powder (fine $\mathrm{PuO}_{2} / \mathrm{UO}_{2}$ ) could be converted into sized granules which would reliably flow and fill a 5.8-nm diameter pellet pressing die (Goldman and Holten 1981). More details about procedures and equipment for prepressing are presented in Attachment D-3.

\section{Addition of Binder}

Organic binders above $0.5 \mathrm{wt} \%$ are usually not recommended for pellets fired at high temperatures because binders lower the sintered density and may interact with $\mathrm{PuO}_{2}$ (Pritchard and Nance 1966). For green, unfired pellets, however, the addition of binder is recommended to increase pellet strength and possibly avoid the need of a prepressing step (Rasmussen 1969).

The receiver of green pellets can debind organic material by lowtemperature heating (Ross, Atkins and Caldwell 1971). Debinding by heating will require quantification and documentation for each binder used.

A more complete discussion of binders is presented in Attachment D-4. 


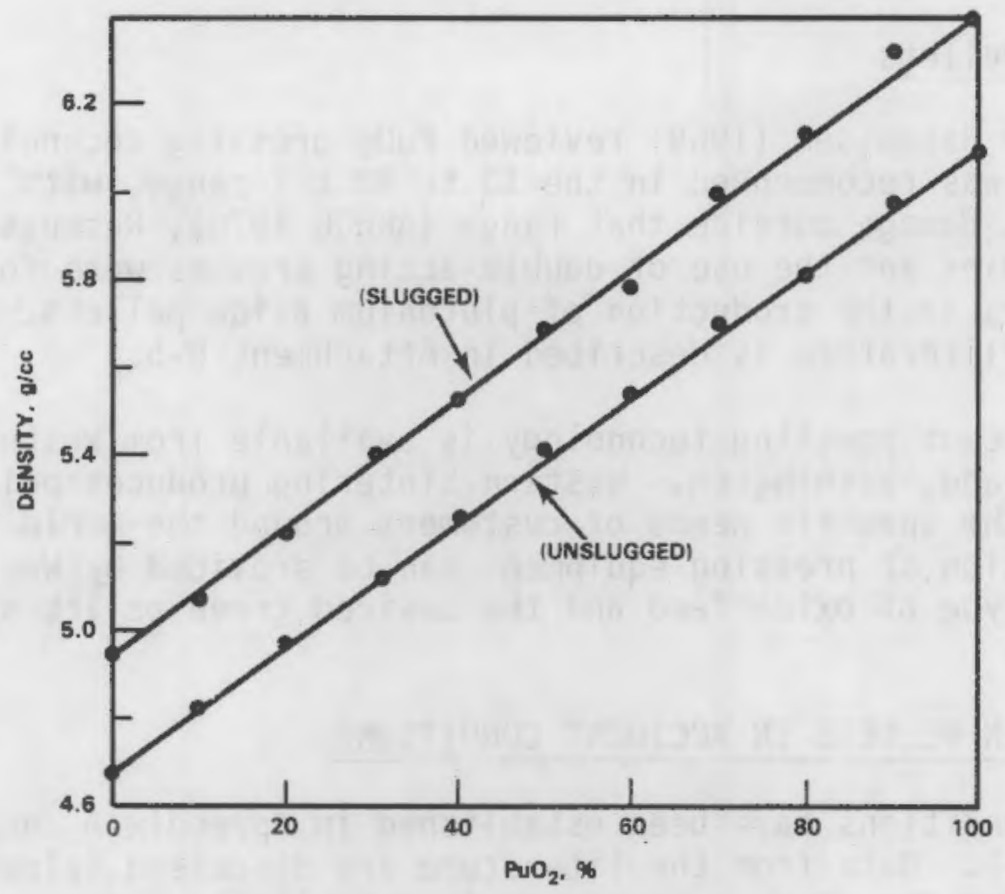

FIGURE D-1. Green Pellet Density Versus Composition $\mathrm{UO}_{2}-\mathrm{PuO}_{2}$ Compacted at 10 tsi (Houston 1965)

\section{Effect of Moisture}

Gibby (1971) reported forming green pellets of mixed $\mathrm{PuO}_{2} / \mathrm{UO}_{2}$ oxide by pressing at 20 tsi using only a small amount of moisture as lubricant and binder. The small amount of moisture was not quantified.

Rasmussen (1969) documented the water absorption in $\mathrm{PuO}_{2}$ as a function of humidity. Undocumented work showed that oxide exposed to glove box atmospheres yielded improved green pellet strength where no binder was used.

Blair (1970) reported some pellet laminating and powder build-up on the punch when moisture level of the feed powder was too high.

NUMEC (1961b) reported that lower temperature feeds ( 350 to $560^{\circ} \mathrm{C}$ ) picked up enough moisture from glove-box air to serve as the best binder studied. Powders calcined at $760^{\circ} \mathrm{C}$ were less absorbent, and additional water had to be added.

The effect of moisture on green pellet strength needs to be quantified and documented. 
Pressing Green Pellets

A report by Rasmussen (1969) reviewed $\mathrm{PuO}_{2}$ pressing technology through 1969. Pressing was recommended in the 10 to 40 tsi range, with increased frequency of pellet damage outside that range (ARHCO 1970a; Rasmussen 1969). Lubrication of dies and the use of double-acting presses were found to be important factors in the production of plutonium oxide pellets. The pellet pressing in the literature is described in Attachment D-5.

The most recent pressing technology is available from Western Sintering Company in Richland, Washington. Western Sintering produces pellet presses tailor-made to the specific needs of customers around the world. A more detailed definition of pressing equipment can be provided by Western Sintering Company if the type of oxide feed and the desired green pellet specifications are known.

\section{BEHAVIOR OF GREEN PELLETS IN ACCIDENT CONDITIONS}

Accident conditions have been established in Appendix $A$ and are described in Attachment D-1. Data from the literature are discussed below for each accident condition for which a criterion is established.

Stability in Fire

Attachment D-1 (derived from Appendix B) notes a requirement that less than 2 wt\% of the particles should be below 10 microns A.E.D. at temperatures of $1300^{\circ} \mathrm{C}$ for 200 minutes. The present shipping form of plutonium is typically $100 \%$ below 10 microns A.E.D.

Exposure of a green pellet to elevated temperatures increases the overall strength of the pellet. This is caused by consolidation of particles into a more dense configuration. Engel reported a heat capacity for $\mathrm{Pu}_{2}$ increasing from $0.06 \mathrm{cal} / \mathrm{g}^{\circ} \mathrm{K}$ at $300^{\circ} \mathrm{K}$ to $0.07 \mathrm{cal} / \mathrm{g}^{\circ} \mathrm{K}$ to $1100^{\circ} \mathrm{K}$, (Engel 1969). The oxide is physically stable up to a melting point of $2240^{\circ} \mathrm{C}$ (Chikalla et al. 1964). Heating pellets in the range of $920^{\circ} \mathrm{C}$ to $1395^{\circ} \mathrm{C}$ in oxygen produced no change in the form of $\mathrm{PuO}_{2}$ (Cina 1963). Pellets underwent shrinkage of up to $3 \%$ when sintered (Keenan, Kent and Zocher 1974). A more detailed review of the literature is provided by Rasmussen (1969).

In conclusion, the stability of a green pellet when heated should be excellent. There are no mechanisms inherent to the material structure that cause particles below 10 microns A.E.D. to be formed in excess of 2 wt $\%$ when the pellet is heated to $1300^{\circ} \mathrm{C}$ for 200 minutes.

\section{Chemical Stability}

Another criterion is that the alternate form should be chemically stable (or retain its function) at $1300^{\circ} \mathrm{C}$ for 200 minutes (Attachment $\mathrm{D}-1$ ). Whereas plutonium oxide has a reputation for adsorbing water vapor, $\mathrm{CO}, \mathrm{CO}_{2}, \mathrm{NO}$ and 
$\mathrm{NO}_{2}$, these gases were driven out of the oxide upon heating to $1300^{\circ} \mathrm{C}$ (Chikalla 1961b; Hodkin, Pitman and Mardon 1965; Stakebake and Dringman 1968). As ignition temperature was increased to $1200^{\circ} \mathrm{C}$, the oxide completely lost its affinity for water (Stakebake 1971). Carbon reacted irreversibly with $\mathrm{PuO}_{2}$ at $1100^{\circ} \mathrm{C}$ to $1300^{\circ} \mathrm{C}$, reducing the $\mathrm{PuO}_{2}$ to $\mathrm{PuO}_{1.8}$ (Cina 1963).

The presence of organic binders within a pellet might result in plutonium carbide species being formed during a fire (Chikalla 1960a; Cina 1963). The question to be resolved is whether the binder degradation products are in a chemical form that can react with $\mathrm{Pu}_{2}$ at $1300^{\circ} \mathrm{C}$. Green pellets heated to $1300^{\circ} \mathrm{C}$ for 200 minutes appear to have excellent chemical stability.

Reaction with Extinguishing Agents

The alternative form should not be soluble or react in a deleterious fashion with commonly used extinguishing agents, e.g., water, carbon dioxide or dry chemicals (Attachment D-1). Studies showed that mixed oxide pellets with up to $15 \mathrm{wt} \% \mathrm{PuO}_{2}$ were not affected by water or steam at various pressures and temperatures (Marley 1966).

A series of reports documents the low solubility of plutonium oxide pellets in water (Baker 1977; LANL 1979a,b; Maraman 1979, 1980a-e; Bronisz 1980; Folger 1981a-c).

Plutonium dioxide was found to exhibit a strong gettering action toward carbon dioxide (Stakebake and Dringman 1968). Approximately 95\% of the carbon dioxide can be removed by outgassing the oxide at $700^{\circ} \mathrm{C}$. Therefore, at lower temperatures a $\mathrm{PuO}_{2}$ pellet would absorb $\mathrm{CO}_{2}$ from a fire extinguisher which could be desorbed by reheating.

The scant available literature suggests that no deleterious reaction can be expected between heated $\mathrm{PuO}_{2}$ pellets and commonly used extinguishing agents. Further tests will be required, however, to gain more specific details.

Impact During Accident

Los Alamos has been conducting impact tests with pellets of sintered plutonium-238 oxide for more than 10 years. No documents were found that discussed impacts of green pellets.

Since sintered pellet particles are considered to be more tightly bound than in green pellets, the fragments of a sintered pellet should be larger than the fragments of a green pellet. The fragment data listed in Tables $D-2$ and D-3 are for sintered pellets impacted at $820^{\circ} \mathrm{C}$ or $850^{\circ} \mathrm{C}$ at $58 \mathrm{~m} / \mathrm{s}$ (Bronisz 1980).

Pellets 1,3 and 4 yielded $2.8 \%, 2.2 \%$ and $0.8 \%$ fragments, respectively, under 177 microns. The same pellets yielded $0.3 \%, 0.4 \%$ and $0.1 \%$ fragments under 10 microns. Table $0-4$ presents data from an impact test series conducted at Los Alamos (Baker 1977). 
TABLE D-2. Impact Data for Four Pellets (Bronisz 1980)

\begin{tabular}{|c|c|c|c|c|}
\hline Measurements & 1 & 2 & 3 & 4 \\
\hline Diameter (in.) & 1.087 & 1.088 & 1.089 & 1.089 \\
\hline Length (in.) & 1.085 & 1.086 & 1.087 & 1.085 \\
\hline Weight (g) & 149.29 & 149.48 & 149.43 & 148.39 \\
\hline Density $(\% T D)^{(a)}$ & 83.9 & 83.7 & 82.7 & 83.7 \\
\hline
\end{tabular}

(a) Percent theoretical density.

TABLE D-3. Fractional Distribution for Four Pellets (Bronisz 1980)

\begin{tabular}{|c|c|c|c|c|}
\hline \multirow[b]{2}{*}{ Size Range ${ }^{(\mathrm{a})}(\mathrm{mm})$} & \multicolumn{4}{|c|}{ Pellet Number } \\
\hline & 1 & 2 & 3 & 4 \\
\hline+6 & 0.728 & 0.490 & 0.240 & 0.529 \\
\hline$-6,+2$ & 0.173 & 0.281 & 0.478 & 0.334 \\
\hline$-2,+0.841$ & 0.045 & 0.134 & 0.183 & 0.097 \\
\hline$-0.841,+0.420$ & 0.017 & 0.050 & 0.051 & 0.023 \\
\hline$-0.420,+0.177$ & 0.009 & 0.045 & 0.025 & 0.009 \\
\hline$-0.177,+0.125$ & 0.002 & N.D. (b) & 0.004 & 0.001 \\
\hline$-0.125,+0.074$ & 0.004 & N.D. & 0.005 & 0.002 \\
\hline$-0.074,+0.044$ & 0.005 & N.D. & 0.003 & 0.001 \\
\hline$-0.044,+0.030$ & 0.006 & N.D. & 0.002 & 0.0009 \\
\hline$-0.030,+0.020$ & 0.003 & N.D. & 0.001 & 0.0005 \\
\hline$-0.020,+0.010$ & 0.005 & N.D. & 0.003 & 0.0012 \\
\hline-0.010 & 0.003 & N.D. & 0.004 & 0.0013 \\
\hline
\end{tabular}

(a) sic; + defines "greater than," and - defines "less than." (b) N.D. = not determined. 
TABLE D-4. Impact Test Series (Baker 1977)

\begin{tabular}{|c|c|c|c|c|c|}
\hline Fuel & Temp $\left({ }^{\circ} \mathrm{C}\right)$ & $\begin{array}{c}\text { Impact } \\
\text { Velocity } \\
\text { (m/s) } \\
\end{array}$ & $\begin{array}{r}\text { Maximum } \\
\text { Diametral } \\
\text { Strain (\%) } \\
\end{array}$ & Strain (\%) & $\begin{array}{c}\text { Fuel Breakup } \\
\text { (Weight Fraction) } \\
\text { Under } 10 \mu \mathrm{m}\end{array}$ \\
\hline $\begin{array}{l}\text { High-density } \\
\text { pellet }\end{array}$ & $\begin{array}{r}1300 \\
760 \\
1300 \\
760 \\
760\end{array}$ & $\begin{array}{l}43.0 \\
43.0 \\
65.4 \\
62.8 \\
86.7\end{array}$ & $\begin{array}{l}5.3 \\
3.4 \\
8.4 \\
6.1 \\
9.1\end{array}$ & $\begin{array}{l}0 \\
0 \\
-3.9 \\
-1.5 \\
-4.6\end{array}$ & $\begin{array}{l}0.0008 \\
0.0025 \\
0.0025 \\
0.0042 \\
0.0073\end{array}$ \\
\hline $\begin{array}{l}\text { Low-density } \\
\text { pellet }\end{array}$ & $\begin{array}{r}1300 \\
760 \\
1300 \\
760\end{array}$ & $\begin{array}{l}45.8 \\
45.4 \\
73.4 \\
71.4\end{array}$ & $\begin{array}{l}12.5 \\
11.2 \\
14.5 \\
15.1\end{array}$ & $\begin{array}{r}-7.5 \\
-7.6 \\
-12.6 \\
-12.2\end{array}$ & $\begin{array}{l}0.0029 \\
0.0042 \\
0.0060 \\
0.0285\end{array}$ \\
\hline $\begin{array}{l}\text { Large pellet } \\
\text { fragments }\end{array}$ & $\begin{array}{r}1300 \\
760 \\
1300 \\
760\end{array}$ & $\begin{array}{l}49.9 \\
50 \\
75.9 \\
75.5\end{array}$ & $\begin{array}{l}13.2 \\
11.6 \\
14.6 \\
15.2\end{array}$ & $\begin{array}{l}-12.6 \\
-14.7 \\
-21.0 \\
-15.6\end{array}$ & $\begin{array}{l}0.0230 \\
0.0251 \\
0.0718 \\
0.0649\end{array}$ \\
\hline
\end{tabular}

Impacted green pellets would be expected to yield a higher percentage of fines, depending on the amount of moisture or binder. Impact studies are needed to quantify the results of impacts with green pellets.

\section{External Crushing Forces}

In Attachment D-1 of this report, a criterion is established that no more than 2 wt\% of the alternative form that is released be less than 10 microns A.E.D. if the outer container is crushed at $300,000 \mathrm{lbf}$. The criteria do not indicate what forces would actually be transferred to the inner container of pellets.

Petrovic at Los Alamos studied compression of sintered $\mathrm{Pu}\left(238 \mathrm{O}_{2}\right.$ pellets (Petrovic 1977). At temperatures up to $1400^{\circ} \mathrm{C}$, the sintered pellets were brittle in the sense that stress-strain curves were linear until near the ultimate stress. The stress-strain curves became nonlinear just before the pellets fractured catastrophically into small pieces. At $1500^{\circ} \mathrm{C}$, the sintered pellets displayed generalized plastic deformation. A pellet would crack, but would not fracture catastrophically.

Since green pellets have less internal bridging, they would be expected to crack into pieces at low pressures and low strain rates (rather than to fracture catastrophically). The size of green pellet fragments needs to be characterized.

Figures $\mathrm{D}-2$ to $\mathrm{D}-5$ show how ultimate stress in sintered pellets varies with conditions. In Figure $\mathrm{D}-2$, the solid $\mathrm{UO}_{2}$ line is displayed for 


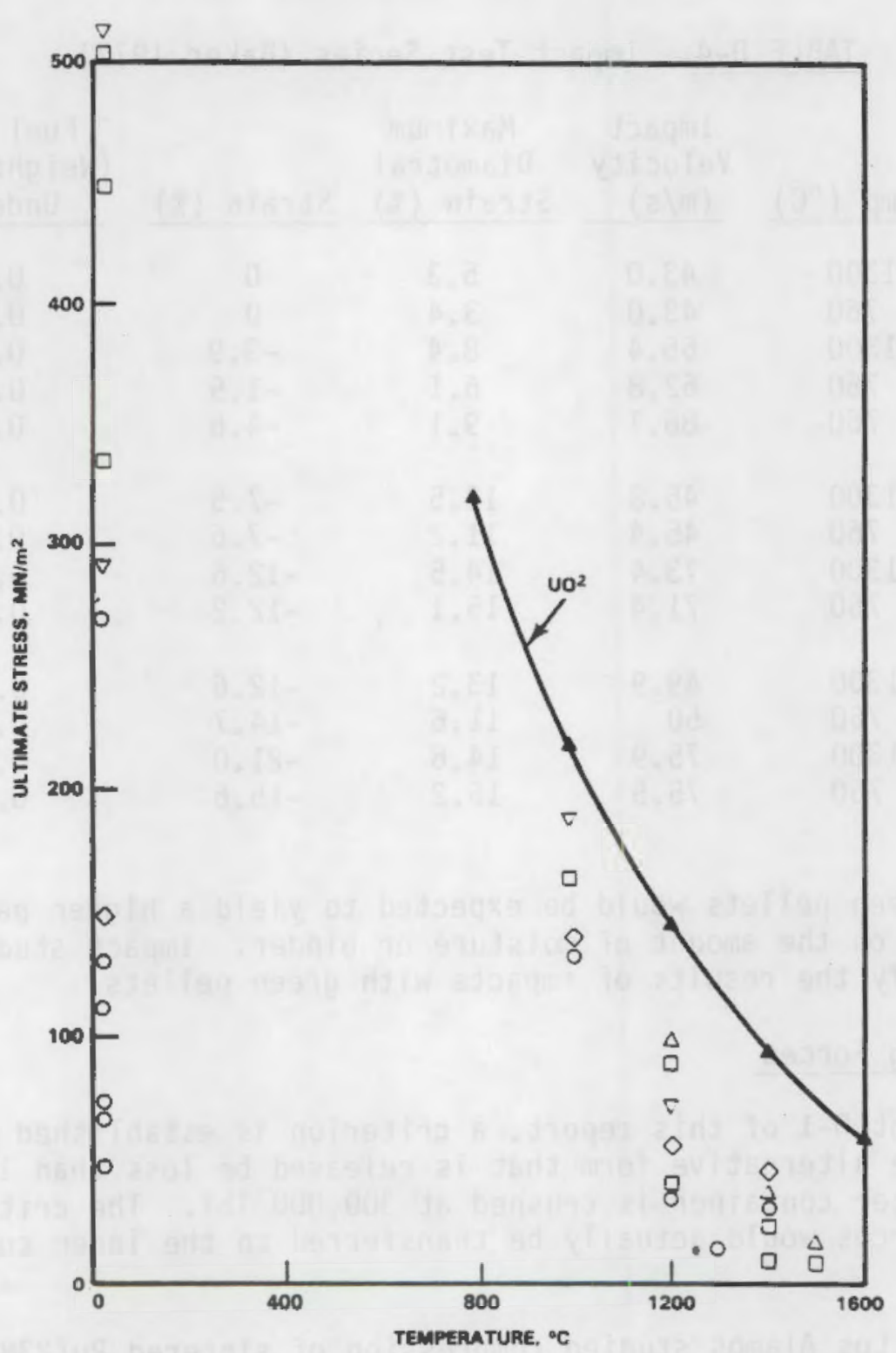

FIGURE D-2. Pu(238) $\mathrm{O}_{2}$ Compressive Ultimate Stress Versus Test Temperatures (Petrovic 1977)

comparative purposes. The ultimate stress is quite temperature sensitive. Figure D-4 demonstrates that the ultimate stress is not a marked function of grain size. At higher temperatures, as grain size increases, it decreases only slightly. As shown in Figure D-5, Ultimate stress levels are highly sensitive to strain rate and increase as the strain rate increases. It is not possible to extrapolate all of these curves to green pellets, with the possible exception of the theoretical density curve (Figure D-3). 


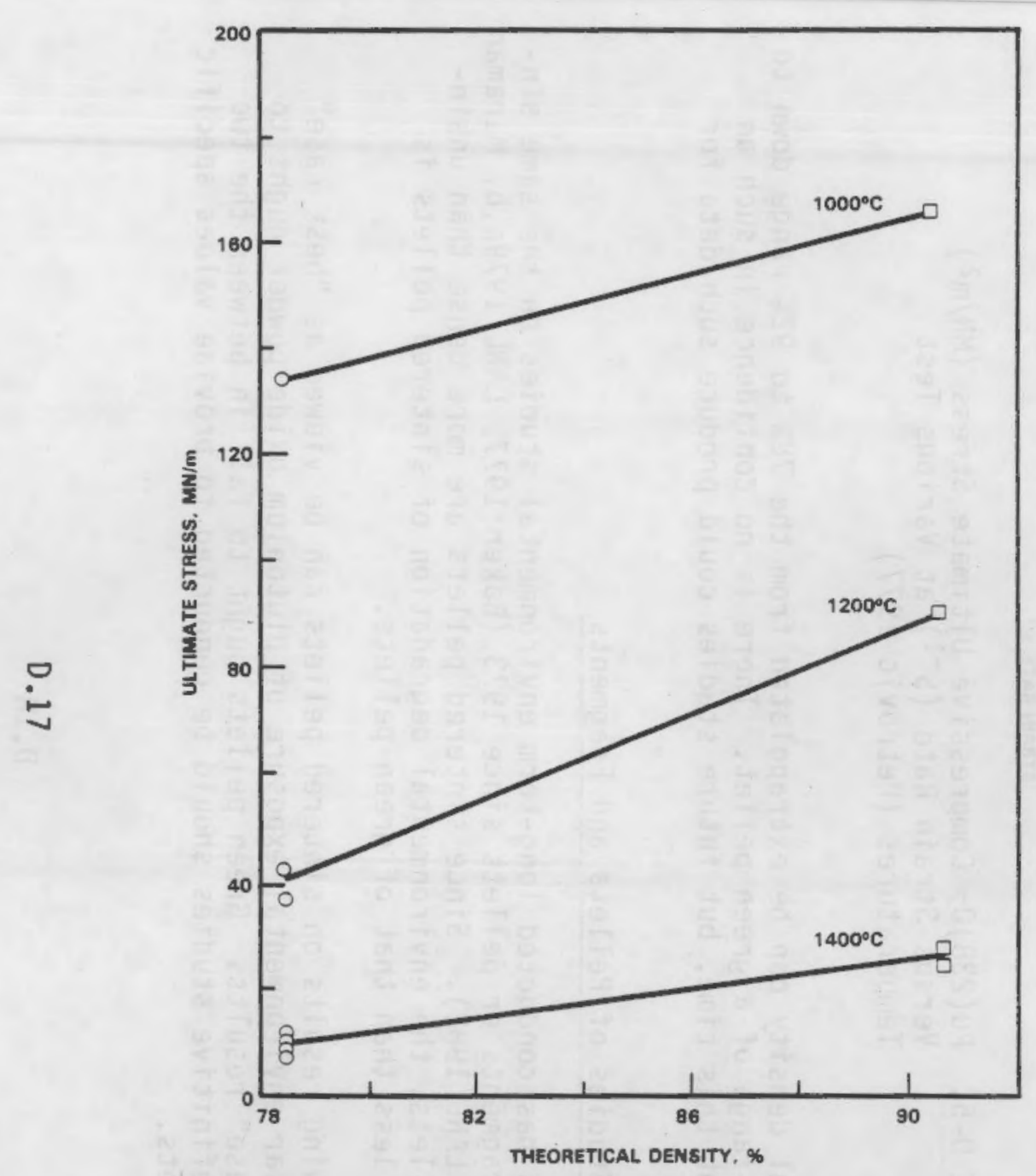

FIGURE D-3. $\quad \mathrm{Pu}(238) \mathrm{O}_{2}$ Compressive U1timate Stress Versus Percent Theoretical Pellet Density at Various Test Temperatures (Petrovic 1977)

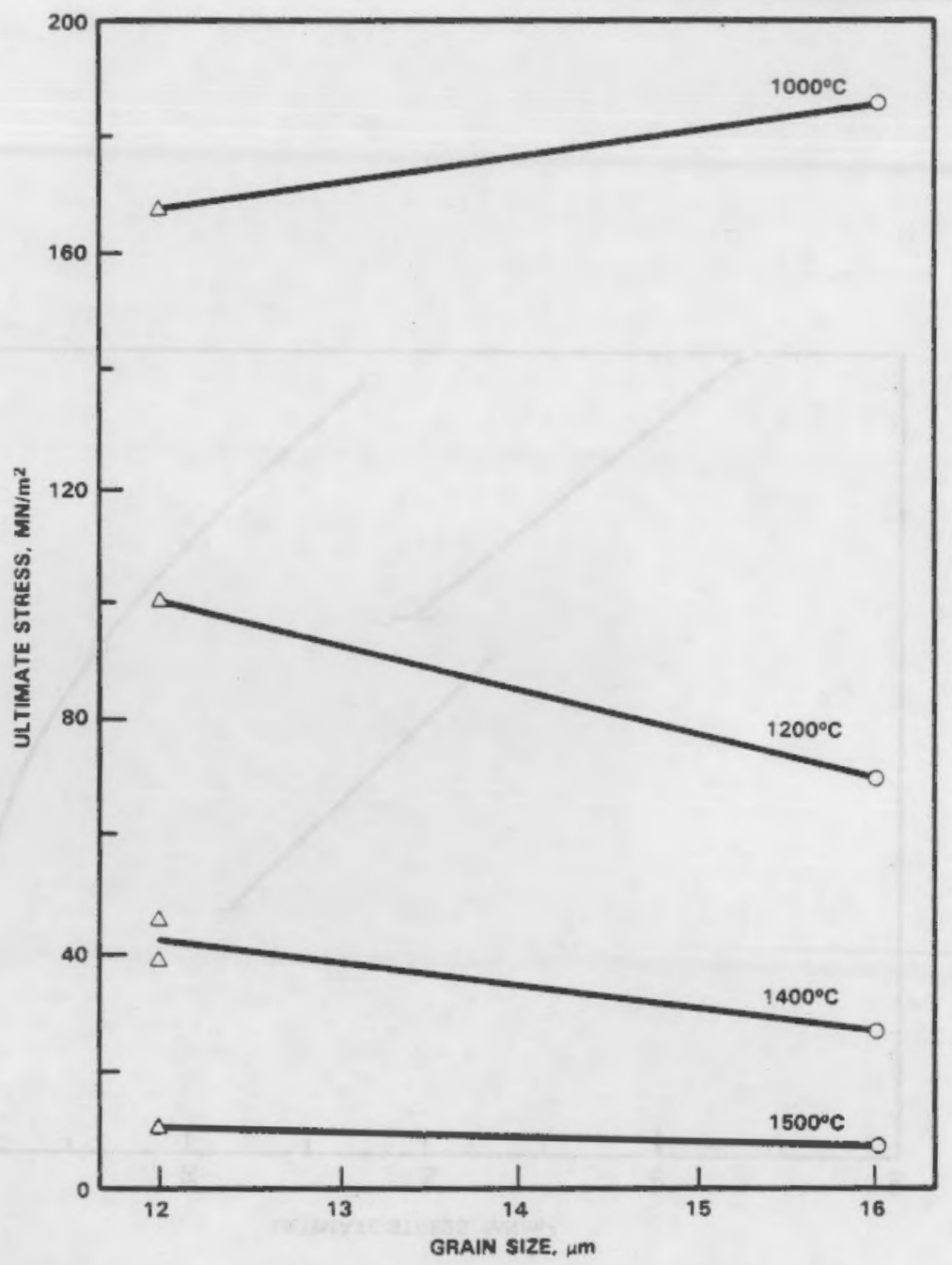

FIGURE D-4. $\quad \mathrm{Pu}(238) \mathrm{O}_{2}$ Compressive U1timate Stress ( $\mathrm{MN} / \mathrm{m}^{2}$ ) Versus Grain Size (microns) at Various Test Temperatures (Petrovic 1977) 


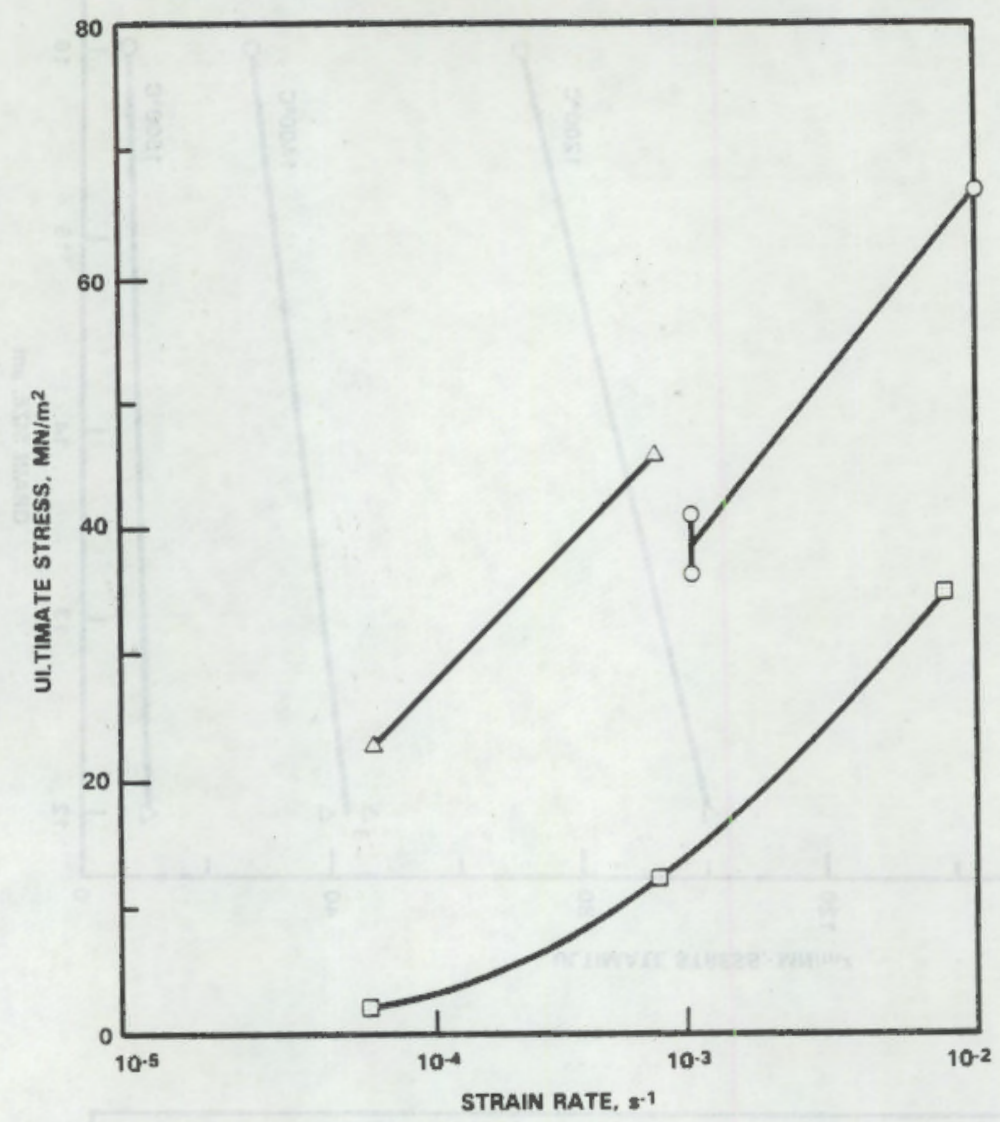

FIGURE D-5. Pu(238) $0_{2}$ Compressive Ultimate Stress $\left(\mathrm{MN} / \mathrm{m}^{2}\right)$

Versus Strain Rate $\left(\mathrm{S}^{-1}\right)$ at Various Test

Temperatures (Petrovic 1977)

Theoretical density can be extrapolated from the $78 \%$ to $92 \%$ range down to the $50 \%$ to $60 \%$ range of a green pellet. There is no confidence in such an extrapolation at this time, but future studies could produce such data for green pellets.

\section{Environmental Studies of Pellets and Fragments}

Los Alamos has conducted long-term environmental studies on the same sintered pellet fragments or pellets since 1973 (Baker 1977, LANL 1979a,b, Maraman $1979,1980 a, b ;$ LANL 1982). Since sintered pellets are more dense than unsintered green pellets, the environmental degradation of sintered pellets is expected to be less than that of green pellets.

The following results on sintered pellets can be viewed as "best case" results. Similar environmental exposure of plutonium oxide powder ought to yield "worst case" results. Green pellets ought to fall in between the two cases. More definitive studies should be conducted to provide values specific for green pellets. 
Certain data reported below apply as well to green pellet fragments. For example, the physical transport (or lack of transport) of fines through a soil column should be the same for green or sintered particles of equal size.

\section{Plutonium Removed by Rain Water}

Large pieces and fines of one impacted pellet were set on loam soil in separate environmental chambers beginning in 1973 and 1975 . Each chamber was programmed to alternate between winter and summer conditions.

Pellet fragments larger than $6 \mathrm{~mm}$ diameter (224 grams total weight) were subjected to several rains (1-1.5 inches each) during winter seasons. Typical collections of percolated rain water were 4.2 to $9.1 \ell$ average (of 4 rains) with average plutonium content of 54 to 94 nanograms (ng) per collection.

Fines from the same pellet ( $28 \mathrm{~g}$ total with diameters between 0.01 and $6 \mathrm{~mm}$ ) under similar treatment (started 22 months after leaching of big fragments) yielded 20 to $180 \mathrm{ng}$ in 2.7 to 13.2-1iter collections. On a per-gram basis, the leach rate of the fines was ten times higher than that of the larger fragments (Table D-5).

The data in Table D-5 represent only a limited random sampling. The final overall values for the experiment will be different from values given.

\section{Soil Sorption of Soluble Plutonium}

Soil columns containing $55 \mathrm{~cm}^{3}$ of silt loam retained $99.73 \%$ and $99.98 \%$ of the $1 \mu \mathrm{g} / \ell$ plutonium-238 solution fed continuously for 1099 days. Sodium bicarbonate caused a slow removal of the plutonium from the soil.

Transport of Insoluble Plutonium Through Soil Column

Three soil columns of silt loam $14 \mathrm{~cm}$ high and $2.4 \mathrm{~cm}$ diameter were loaded, respectively, with $3.5 \mathrm{mg}$ of $\mathrm{PuO}_{2}$ (40-60 microns), $2.2 \mathrm{mg}$ of $\mathrm{PuO}_{2}$ (12 microns average), and $2.6 \mathrm{mg}$ of $\mathrm{PuO}_{2}$ (7 microns average) and were eluted continuously with water (Table D-6). Ninety-nine percent of the plutonium remained at the top of each column. Almost $90 \%$ of the plutonium found in the eluates after 347 days was obtained in the first five days of operation. This was thought to be from water suspensions of particles used to place the particles on the columns. The leach rates increased slightly as the particle size of the axide decreased.

\section{Immersion in Sea Water}

Sintered pellets immersed in sea water at $10^{\circ} \mathrm{C}$ had plutonium release rates of 3.7 to $13 \mathrm{nCi} / \mathrm{m}^{2}-\mathrm{s}$ after 1904 days of immersion. A pellet raised out of the sea water every 12 hours to simulate tidal action had a release rate of $660 \mathrm{nCi} / \mathrm{m}^{2}$-s after 20 days, decreasing to $60 \mathrm{nCi} / \mathrm{m}^{2}-5$ after 856 days. It cracked after day 103, and broke into two pieces on day 393 , seven pieces on day 404, and over thirty pieces by day 471 . The breakup was attributed to thermal shock. 
TABLE D-5. Plutonium-238 Removed by Rain Water from Pellet Fragments

Elapsed Time Ave. Vol. Pu Removed

Date $\quad$ (Days) $-($ (l) $-(\mathrm{ng}) \quad \mathrm{g} / \mathrm{\ell} \mathrm{Pu-238}$

Large Fragments

(224 grams

over $6 \mathrm{~mm}$ )

$\begin{array}{lcccc}\operatorname{Dec} .77(\mathrm{a}) & 1616 & 7 & 82 & 11.7 \times 10^{-9} \\ \text { Feb. } 79 \text { (b) } & 2073 & 9.2 & 60 & 6.5 \times 10^{-9} \\ \text { Apr. } 79 \text { (c) } & 2134 & 8.5 & 54 & 5.8 \times 10^{-9} \\ \text { Sept. } 79 \text { (d) } & 2287 & 4.2 & 54 & 13 \times 10^{-9} \\ \text { Jan. } 80 \text { (e) } & 2409 & 8.9 & 94 & 10 \times 10^{-9} \\ \text { Feb. } 80 \text { (f) } & 2440 & 9.1 & 71 & \frac{7.8 \times 10^{-9}}{9 \times 10^{-9} \mathrm{~g} / \mathrm{l}}= \\ & & & \text { AVG }= & \begin{array}{l}4 \times 10^{-7} \mathrm{~g} \\ \end{array} \\ & & & & \begin{array}{l}\text { eached } / 1-\mathrm{g} \\ \text { Pu0 }\end{array}\end{array}$

Fines (28 grams between $0.01 \mathrm{~mm}$ and $6 \mathrm{~mm}$ )

\begin{tabular}{|c|c|c|c|c|}
\hline $\operatorname{Dec} .77(a)$ & 944 & 8.2 & 20 & $2.4 \times 10^{-9}$ \\
\hline Feb. 79 (b) & 1401 & 6.6 & 180 & $27.3 \times 10^{-9}$ \\
\hline Apr. $.79(\mathrm{C})$ & 1462 & 5.3 & 88 & $16.6 \times 10^{-9}$ \\
\hline Sept. 79 (d) & 1615 & 2.7 & 40 & $14.8 \times 10^{-9}$ \\
\hline $\operatorname{Jan} .80(\mathrm{e})$ & 1737 & 3.8 & 31 & $8.2 \times 10^{-9}$ \\
\hline \multirow[t]{2}{*}{ Feb. $80^{(f)}$} & 1768 & 13.2 & 123 & $9.3 \times 10^{-9}$ \\
\hline & & & $A V G=$ & $\begin{array}{l}13 \times 10^{-9} \mathrm{~g} / \mathrm{e}= \\
46 \times 10^{-7} \mathrm{~g} \\
\text { leached } / 1-\mathrm{g} \\
\mathrm{PuO}_{2}\end{array}$ \\
\hline
\end{tabular}
(a) Baker 1977
(b) LANL 1979a
(c) LANL $1979 c$
(d) Maraman 1979
(e) Maraman 1980a
(f) Maraman 1980b 
TABLE 0-6. Transport of Plutonium Through Soil

\begin{tabular}{|c|c|c|c|c|c|c|}
\hline \multirow[b]{2}{*}{$\mathrm{PuO}_{2} \quad(\mathrm{mg})$} & \multirow[b]{2}{*}{ Size $(\mu \mathrm{m})$} & \multicolumn{2}{|c|}{347 Days (a) } & \multicolumn{2}{|c|}{1216 Days $(b)$} & \multirow{2}{*}{$\begin{array}{l}\text { Leach Rate } \\
\text { (gm leach/ } \\
1 \text {-gm Pu02) }\end{array}$} \\
\hline & & Vol (l) & $\begin{array}{l}\text { Pu Moved } \\
\text { (ng) }\end{array}$ & Vol (l) & $\begin{array}{l}\text { Pu Moved } \\
\text { (ng) }\end{array}$ & \\
\hline 3.5 & $40-60$ & 23.4 & 17.9 & 88.5 & 32.3 & $1 \times 10^{-7}$ \\
\hline 2.2 & Avg 12 & 19.9 & 16.5 & 76.2 & 28.9 & $1.7 \times 10^{-7}$ \\
\hline 2.6 & Avg 7 & 8.7 & 34.8 & 39.7 & 41.7 & $4 \times 10^{-7}$ \\
\hline
\end{tabular}

(a) Baker 1977

(b) Maraman 1980b

Immersion in Fresh Water

Pellets immersed in fresh water had a relatively constant plutonium release rate in the range of 100 to $400 \mathrm{nCi} / \mathrm{m}^{2}-\mathrm{s}$ over a period of 2165 days ( $\sim 6$ yrs). Fresh water released about 30 times more plutonium than sea water.

Conversion of Green Pellets to Oxide

\section{Grinding Pellets}

Green pellets can be returned to oxide by a simple grinding action. Most of the studies referred to hand grinding through screens. On a larger production scale, high-capacity size reduction equipment is readily available.

\section{Debinding}

Blair (1970) debound green pellets at $675^{\circ} \mathrm{C}$ for three hours in a Harper muffle furnace. The binder removal firing cycle is shown in Figure D-6.

Ross debound green pellets in a flowing $\mathrm{CO}_{2}$ stream at $800^{\circ} \mathrm{C}$ for 4 hours (Ross, Atkins and Caldwell 1971). Considering that 1.12 wt\% of carbowax was added before the pressing step, the debinding step was quite successful, yielding a carbon level less than $150 \mathrm{ppm}$.

Barr (1970) reported that all carbon due to binders, plus the $250 \mathrm{ppm}$ carbon originally present in the raw powder, was removed to below the detection limit of $50 \mathrm{ppm}$. The pellets (mixed oxide) were heated in argon-8\% $\mathrm{H}_{2}$ at $1650^{\circ} \mathrm{C}$ for 2 to 4 hours. There was apparently no detectable carbon with plutonium oxide.

\section{Conclusions}

1. The equipment for manufacturing green pellets is readily available and can be custom designed for specific applications. 


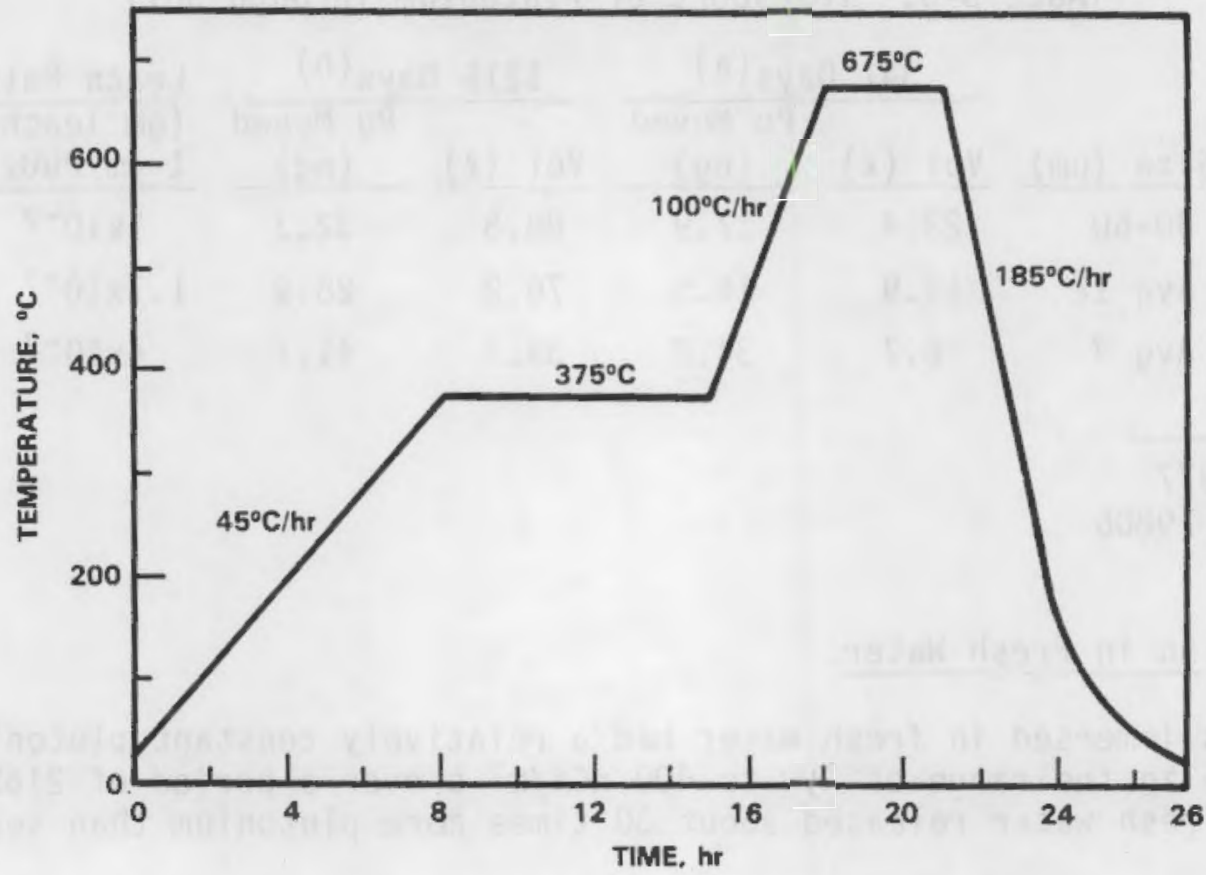

FIGURE D-6. Binder Removal Firing Cycle (Blair 1970)

2. The strength of green pellets can be increased with moisture or organic binders. This effect has not been quantitatively determined.

3. Green pellets are stable in fire.

4. Green pellets are chemically stable.

5. There is no deleterious reaction predicted between green pellets and fire extinguishing agents. This prediction should be verified.

6. The effects of impacts and crushing actions on green pellets need to be determined.

7. A green pellet holds oxide fines together and thus reduces the dispersion potential compared to present shipping forms.

8. Receivers of green pellets may be able to eliminate a preslugging (prepressing) step if they receive green pellets instead of oxide powder. 


\section{REFERENCES}

Atlantic Richfield Hanford Company (ARHCO). 1969a. 200 Areas Operations Monthly Report--November. ARH-1110, Richland, Washington (Secret). (Pages G1-7 and G1-8 have been declassified.)

Atlantic Richfield Hanford Company (ARHCO). 1969b. 200 Areas 0perations Monthly Report--December. ARH-1111, Richland, Washington (Secret). (Pages G1-6 and G1-7 have been declassified.)

Atlantic Richfield Hanford Company (ARHCO). 1970a. 200 Areas Operations Monthly Report--September. ARH-1509, Richland, Washington (Secret). (Pages GI-4 to GI-8 have been declassified.)

Atlantic Richfield Hanford Company (ARHCO). 1970b. 200 Areas Operations Monthly Report--0ctober. ARH-1510, Richland, Washington (Secret). (Pages G1-11 and G1-12 have been declassified.)

Atlantic Richfield Hanford Company (ARHCO). 1970c. 200 Areas Operations Monthly Report--November. ARH-1511, Richland, Washington (Secret). (Pages GI-6 and G1-7 have been declassified.)

Baker, R. D. 1977. General-Purpose Heat Source Project, Space Nuclear Safety Program, and Radioisotopic Terrestrial Safety Program. LA-7091-PR, Los ATamos National Laboratory, Los ATamos, New Mexico.

Barr, M. J., M. W. Urie, J. L. Daniel, and S. J. Mayhan, 1970. Characterization of Some $\mathrm{UO}_{2}$ and $\mathrm{PuO}_{2}$ Powders. BNWL-1441, Pacific Northwest Laboratory, Richland, Washington.

Barr, M. J., J. L. Jaech and A. G. Anderson. 1970. Investigation of Mixed Oxide (75\% U, 25\% Pu) $\mathrm{O}_{2}$ Processing Using a Nine Variable Fractional Factoria? Experiment. BNWL-1445, Pacific Northwest Laboratory, Richland, Washington.

Barr, M. J. 1970. Aspects of Density Manipulation in Fabrication of Mixed (U, Pu) Oxide Fuel Pellets. WHAN-FR-7, WADCO Corporation, Richland, Washington.

Blair, H. T. 1970. Fabrication Report--FFTF Prototypic Fuel Pellets for Analytical Chemistry Program. BNWL-1214, Pacific Northwest Laboratory, RichTand, Washington.

Brett, N. H., and L. E. Russe11. 1960. "The Thermal Expansion of $\mathrm{PuO}_{2}$ and Some Other Actinide 0xides Between Room Temperature and 1000C." In Proceedings of the Second International Conference on Plutonium, p. 397 . GrenobTe, France.

Bronisz, Stan E. 1980. Progress Report, Space Nuclear Safety and Fuels Program, November 1980. LA-8735-PR, Los Alamos National Laboratory, Los Alamos, New Mexico. 
Chikalla, T. D. 1960a. "Studies on the Oxides of Plutonium." In Proceedings of the Second International Conference on Plutonium Metallurgy, p. 455.

Grenobie, France.

Chikalla, T. D. 1960b. "Stability of Plutonium Dioxide." In Quarterly Progress Report--Plutonium Metallurgy Operation, October-December $1960,0 . \mathrm{J}$. Wick, ed., p. 3.28-3.34. HW-67765, U.S. Department of Energy, Hanford Works, Richland, Washington.

Chikalla, T. D., et al. 1964. "The Plutonium-Oxygen System." J. Nucl. Matl. 12:131-141.

Cina, B. 1963. "Some Decomposition Effects in $\mathrm{PuO}_{2}$ on Sintering." J. Nucl. Mat1. 9:85-100.

Doty, J. W., and C. H. H. Chong. 1970. "Preparation of Micron-Sized Pu-238 0xide." J. Nucl. Mat1. 35:247-249.

Engel, T. K. 1969. "The Heat Capacities of $\mathrm{Al}_{2} \mathrm{O}_{3}, \mathrm{UO}_{2}$ and $\mathrm{PuO}_{2}$ from 300 to 1100 K." J. Nucl. Mat1. 31:211-214.

European Atomic Energy Community (EURAEC). 1963. Correlation Between the Methods of Precipitating Plutonium Sales and Sintering Their Oxides. Presented at the 8th Nuclear Congress, June 17-23, 1963, Rome.

Folger, R. L. 1981a. Pu(238) Fuel Form Processes Quarterly Report, JanuaryMarch 1980. DPST-80-128-1, Savannah River Laboratory, Aiken, South Carolina.

Folger, R. L. 1981b. Pu(238) Fuel Form Processes Quarterly Report, JulySeptember 1980. DPST-80-128-3, Savannah River Laboratory, Aiken, South Carolina.

Folger, R. L. 1981c. Pu(238) Fuel Form Processes Quarterly Report, OctoberDecember 1980. DPST-80-128-4, Savannah River Laboratory, Aiken, South Carolina.

Gibby, R. L. 1971. "The Effect of Plutonium Content on the Thermal Conductivity of (U, Pu) $0_{2}$ Solid Solutions." J. Nucl. Mat1. 38:163-177.

Goldman, L. H., Jr., and C. C. Holley. 1981. Roll Compaction and Granulation System for Nuclear Fuel Material. DOE CONF-810897-1 (HEDL-SA-2498-FP), National Technical Information Service, Springfield, Virginia.

Hodkin, D. J., R. S. Pitman and P. G. Mardon. 1965. Gas Evolution from Solid Plutonium-Bearing Residues During Storage. AERE-M-1644, United Kingdom Atomic Energy Research Establishment, Harwell, England.

Houston, M. D. 1964. Sintering Behavior of Plutonium Dioxide. NUMEC-2389-6, Nuclear Materials and Equipment Corporation, Apollo, Pennsylvania. (Available from National Technical Information Service, Springfield, Virginia.) 
Houston, M. D. 1965. Effect of $\mathrm{PuO}_{2}$ Content on Sintering Behavior of Mechanically Mixed U02-Pu0)2. NUMEC-2389-8, Nuclear Materials and Equipment Corporation, Apollo, Pennsyivania. (Available from National Technical Information Service, Springfield, Virginia.)

Keenan, T. K., R. A. Kent, and R. W. Zocher. 1974. The Relationship of Fabrication Parameters to Selected Properties of Pu(238) $\mathrm{O}_{2}$ Radioisotopic Fuels; Dimensional Changes, Stoichiometrics, and Microstructural Features. LA-5622-MS, Los ATamos NationaT Laboratory, Los ATamos, New Mexico.

Kent, R. A. 1979. LASL Fabrication Flowsheets for GPHS Fuel Pellets. LA-7972-MS, Los Alamos National Laboratory, Los Alamos, New Mexico.

Los Alamos National Laboratory (LANL). 1979a. Genera1-Purpose Heat Source Project, Space Nuclear Safety Program, and Radioisotopic Terrestrial Safety Program, February 1979. LA-7805-PR, Los ATamos, New Mexico.

Los Alamos National Laboratory (LANL). 1979b. General-Purpose Heat Source Project, Space Nuclear Safety Program and Radioisotopic Terrestrial Safety Program, April 1979. LA-7868-PR, Los A7amos, New Mexico.

Los Alamos National Laboratory (LANL). 1982. Quarterly Report, Environmental and Radiological Safety Studies, January-March 1982. LA-9391-PR, Los ATamos National Laboratory, Los Alamos, New Mexico.

Maraman, W. J. 1979. General-Purpose Heat Source Project, Space Nuclear Safety Program, and Radioisotopic Terrestrial Safety Program. LA-8150-PR, LoS ATamos National Laboratory, Los ATamos, New Mexico.

Maraman, W. J. 1980a. General-Purpose Heat Source Project and Space Nuclear Safety and Fuels Program, January 1980. LA-8311-PR, Los Alamos National Laboratory, Los Alamos, New Mexico.

Maraman, W. J. 1980b. General-Purpose Heat Source Project and Space Nuclear Safety and Fuels Program, February 1980. LA-8386-PR, Los Alamos National Laboratory, Los Alamos, New Mexico.

Maraman, W. J. 1980C. General-Purpose Heat Source Project and Space Nuclear Safety and Fuels Program, July 1980. LA-8582-PR, Los ATamos National Laboratory, Los ATamos, New Mexico.

Maraman, W. J. 1980d. General-Purpose Heat Source Project and Space Nuclear Safety and Fuels Program, August 1980. LA-8713-PR, Los Alamos National Laboratory, Los Alamos, New Mexico.

Maraman, W. J. 1980e. General-Purpose Heat Source Project and Space Nuclear Safety and Fuels Program, September 1980. LA-8714-PR, Los ATamos Nationa7 Laboratory, Los Alamos, New Mexico. 
Marley, J. L. 1966. Water and Steam Corrosion Characteristics of Mixed Plutonium-Uranium 0xide Pellets. NUMEC-3463-13, Nuclear Materials and Equipment Corporation, Apollo, Pennsylvania. (Available from National Technical Information Service, Springfield, Virginia.)

Nuclear Materials and Equipment Corporation (NUMEC). 1959. Progress Report-Development of Plutonium-Bearing Materials, July 1-December 31, 1959. NUMEC P-10, Apollo, Pennsylvania. (Available from National Technical Information Service, Springfield, Virginia.)

Nuclear Materials and Equipment Corporation (NUMEC). 1960a. Progress Report-Development of Plutonium-Bearing Materials, January-March 1960. NUMEC P-20, Apol1o, Pennsylvania. (Available from National Technical Information Service, Springfield, Virginia.)

Nuclear Materials and Equipment Corporation (NUMEC). 1960b. Progress Report-Development of Plutonium-Bearing Fuel Material, April-June 1960. NUMEC P-30, Apollo, Pennsylvania. (Available from National Technical Information Service, Springfield, Virginia.)

Nuclear Materials and Equipment Corporation (NUMEC). 1960C. Monthiy Progress Letter--Development of Plutonium-Bearing Fuel Materials, July 1960. NUMEC P-8, Apollo, Pennsylvania. (Available from National Technical Information Service, Springfield, Virginia.)

Nuclear Materials and Equipment Corporation (NUMEC). 1961a. Progress Report-Development of Plutonium Bearing Fuel Materials, January 1-March 31, 1961.

NUMEC P-60, Apollo, Pennsylvania. (Available from National Technical Information Service, Springfield, Virginia.)

Nuclear Materials and Equipment Corporation (NUMEC). 1961b. Progress Report-Development of Plutonium-Bearing Fuel Materials, July-September 1961. NUMEC P-80, Apollo, Pennsylvania. (Available from National Technical Information Service, Springfield, Virginia.)

Nuclear Materials and Equipment Corporation (NUMEC). 1962. Progress Report-Development of Plutonium-Bearing Fuel Materials, April-June 1962. NUMEC P-100, Apollo, Pennsylvania. (Available from National Technical Information Service, Springfield, Virginia.)

Nuclear Materials and Equipment Corporation (NUMEC). 1963a. Progress Report-Development of Plutonium-Bearing Fuel Materials, January-March 1963. NUMEC P-104, Apollo, Pennsylvania. (Available from National Technical Information Service, Springfield, Virginia.)

Nuclear Materials and Equipment Corporation (NUMEC). 1963b. Progress Report-Development of Plutonium-Bearing Fuel Materials, July-September 1963.

NUMEC P-106, Apollo, Pennsylvania. (Available from National Technical Information Service, Springfield, Virginia.) 
Nuclear Materials and Equipment Corporation (NUMEC). 1965. Progress Report-$\mathrm{PuO}_{2}-\mathrm{ZrO}_{2}-\mathrm{UO}_{2}$ Fuel Development Program, March-June 1965. NUMEC 3505-5, ApolTo, Pennsylvania. (Available from National Technical Information Service, Springfield, Virginia.)

Nuclear Materials and Equipment Corporation (NUMEC). 1968a. Quarterly Report--Development and Testing of $\mathrm{PuO}_{2}-\mathrm{UO}_{2}$ Fast Reactor Fuels, January-March 1968. C. S. Caldwell and M. J. Zambernard. NUMEC 3524-50, Apollo, Pennsylvania. (Available from National Technical Information Service, Springfield, Virginia.)

Nuclear Materials and Equipment Corporation (NUMEC). 1968b. Quarterly Report--Development and Testing of $\mathrm{PUO}_{2}-\mathrm{UO}_{2}$ Fast Reactor Fuels, ApriT-June 1968. NUMEC 3524-55, Apollo, Pennsylvania. (Available from National Technical Information Service, Springfield, Virginia.)

Nuclear Materials and Equipment Corporation (NUMEC). 1968c. Quarterly Report--Development and Testing of $\mathrm{PUO}_{2}-\mathrm{UO}_{2}$ Fast Reactor Fuels, July-September 1968. NUMEC 3524-58, Apollo, Pennsylvania. (Available from National Technical Information Service, Springfield, Virginia.)

Nuclear Materials and Equipment Corporation (NUMEC). 1970. Fabrication of Low Density $\mathrm{PuO}_{2}-\mathrm{UO}_{2}$ LMFBR Fuel Pellets, NUMEC 3524-75, Apollo, Pennsylvania. (Available from National Technical Information Service, Springfield, Virginia.)

Nyman, D. H., et al. 1980. "Automated Fabrication of Reactor Fuel." Trans. Am. Nucl. Soc. $34: 253$.

Petrovic, J. J. 1977. Mechanical Properties of Pu(238)02 . LA-6529, Los Alamos National Laboratory, Los Alamos, New Mexico.

Pritchard, W. C., K. A. Johnson, I. A. Leary, and W. J. Maraman. 1961. Compaction and Sintering of $\mathrm{PuO}_{2}$-Mo Powder Mixtures. LA-2621, Los Alamos National Laboratory, Los Alamos, New Mexico.

Pritchard, W. C., K. A. Johnson, and J. A. Leary. 1963a. Compatibility of the Major Elemental Components of Type 302-B Stainless Steel with $\mathrm{PuO}_{2}$ and $\mathrm{UO}_{2}$. LA-2828, Los Alamos National Laboratory, Los Alamos, New Mexico.

Pritchard, W. C., K. A. Johnson, and J. A. Leary. 1963b. Compaction and Sintering of $\mathrm{PuO}_{2}$-Type 302B Stainless Steel Powder Mixtures. LAMS-2898, Los Alamos National Laboratory, Los Alamos, New Mexico.

Pritchard, W. C., and R. L. Nance. 1966. Studies on the Formation of $\mathrm{Pu}_{2} \mathrm{O}_{3}$ in the Sintering of $\mathrm{PUO}_{2}$. LA-3493, Los Alamos NationaT Laboratory, Los ATamos, New Mexico.

Rasmussen, 0. R. H. 1969. Ceramic Properties of $\mathrm{PuO}_{2}$. ARH-1153, Atlantic Richfield Hanford Company, Richland, Washington. 
Ross, W. J., R. J. Atkins, and C. S. Caldwell. 1971. Development of Continuous Sintering of Low 0xygen-to-Metal Ratio, Mixed Oxide Pellets for Improved Fast Breeder Fuels. NUMEC-4281-1, Nuclear Materials and Equipment Corporation, Leechburg, Pennsylvania. (Available from National Technical Information Service, Springfield, Virginia.)

Stakebake, J. L., and M. R. Dringman. 1968. Desorption from Plutonium Dioxide. RFP-1248, Dow Chemical Company, Rocky Flats Division, Golden, Colorado.

Stakebake, J. L. 1971. "The Storage Behavior of Plutonium Metal, Alloys, and 0xide; A Review." J. Nuc1. Mat1. 38:241-259.

Tennery, V. J. 1974. "Heat Transfer and Thermal Conductivity of Multi-Hundred. Watt Pu(238) $0_{2}$ Fuel Sphere." J. Nucl. Mat1. 54:73-78. 


\section{ATTACHMENT D-1}

\section{CRITERIA FOR ALTERNATIVE SHIPPING FORMS}

Criteria for alternative shipping forms have been defined in Appendix $B$. For the study on green pellets, the criteria were organized into three major sections discussed below:

1. Production of Alternative Shipping Form

- The form should be prepared and handled in existing facilities without radical process redesign.

- The new form should fit in existing shipping containers.

- The new process should not interfere with receivers' ability to convert the new shipping form back to oxide.

2. Behavior in Accident Scenario

- At temperatures of $1300^{\circ} \mathrm{C}$ for 200 minutes, less than 2 wt $\%$ of the particles should be below 10 microns A.E.D.

- The alternative form should be chemically stable (or retain its function) at $1300^{\circ} \mathrm{C}$ for 200 minutes.

- The alternative form should not be soluble or react in a deleterious fashion with commonly used extinguishing agents, e.g., water, carbon dioxide, dry chemicals.

- If subjected to pressures of $1000 \mathrm{psig}$ and allowed to escape through a small opening, no more than 2 wt\% of the alternative form should be less than 10 microns A.E.D.

- If the shipping container is crushed at 300,000 lbf and plutonium is released, no more than 2 wt\% of the plutonium should be less than 10 microns A.E.D.

3. Conversion of Alternative Shipping Form

- The conversion of the alternative shipping form back to oxide powder should be done in existing facilities without radical process redesign.

- The resultant oxide should not contain deleterious elements or compounds as a result of the alternative form. 
BALL MILLING: PURPOSE, EQUIPMENT AND PROCEDURE (a)

PURPOSE

Ball milling is performed to produce the desired particle size and powder morphology. The as-received powder (in Kent's study) consists of two types of particles and has a mass median diameter of about $2.7 \mu \mathrm{m}$.

One type of particle is rosette-shaped; the other is lath-shaped. The lath-shaped particles have an extremely high surface activity and cause the material to shrink excessively when sintered. Milling the powder converts most of the lath-shaped particles to the less reactive rosette-shaped ones. The results of developmental studies performed at LANL indicate that the reactivity of the feed will be adequately adjusted if the powder is milled to produce a mass median diameter of about $0.6 \mu \mathrm{m}$. This requires $40 \mathrm{~h}$ in the LANL ball mill.

The LANL mills operate at $27 \mathrm{rpm}$, and approximately $2 \mathrm{ppm}$ of iron are introduced to the feed powder per hour of milling. Slight changes in precipitation conditions at SRP can effect a change in the ratio of lath-shaped to rosette-shaped particles. If the material is, or is suspected of being, too reactive, it is simply milled longer. Feed powder has been milled for more than $100 \mathrm{~h}$ with no noticeable deleterious effects; i.e., it cannot be overmilled. Milling times which are too short, however, definitely result in pellets that shrink excessively when sintered. It is conceivable that the milling time could be shortened if the rolling rates were increased; however, this has not been proven conclusively. Furthermore, faster rolling rates could result in a significant increase in the iron content.

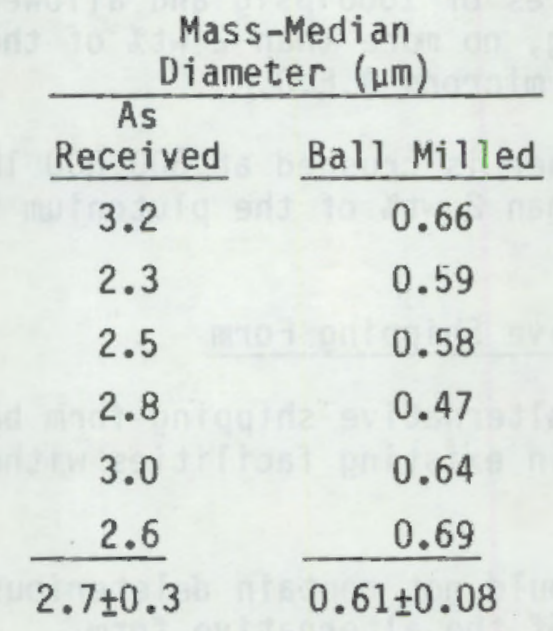

(a) Information presented in this attachment was gleaned from Kent (1979). 


\section{EQUIPMENT}

Each Los Alamos ball-milling assembly consists of a set of rollers and stainless steel jars. Each jar contains fifty-five, $15.9 \mathrm{~mm}$ diameter, hardened steel $(440 \mathrm{C})$ balls. Details for the roller assembly and jar may be examined in Kent (1979).

NUMEC (Ross, Atkins and Caldwell 1971) used a U.S. Stoneware ball mill with 1.3 gallon neoprene, rubber-lined, mill jars and tungsten carbide milling media. One-half-inch diameter balls were used in the milling operation. Stainless steel screens and pans were used for separation of the powder from the milling media after ball milling.

PROCEDURE (Kent 1979)

1. Check that stainless steel jars and balls are clean and that each jar contains the proper number of balls.

2. Weigh the charge for a single jar, 50 to $70 \mathrm{~g}$ of plutonium oxide.

3. Load the jar, using stainless steel funnel. Close and seal the jar, tightening bolts evenly.

4. Repeat Steps 2 and 3 for other jars until all material is loaded. The number of jars and the charge per jar should be selected so as to have approximately the same weight of powder per jar.

5. Check that jar lids are tight, place jars on rollers, set timer and begin milling. Record time and rpm.

6. After milling is completed, empty contents of one jar onto a clean No. 8 or 10 stainless steel screen positioned above a clean, tared stainless steel pan. Use a stainless steel brush to clean the balls, passing the feed through the screen to the pan below. Replace balls in jar and seal lid.

7. Weigh milled powder and record weight.

8. Weigh and record a $1 \mathrm{~g}$ analytical sample if particle size is to be measured. If insufficient milling has occurred, reload the emptied jar and mill all jars longer.

9. If particle size data is satisfactory, repeat Steps 6 and 7 for the other jars.

10. Load the milled powder into clean stainless steel containers for transfer to the slugging and screening area.

11. From the initial and milled weights, determine the processing losses, if any. Record these. 
ATTACHMENT D-3

\section{PREPRESSING AND GRANULATION: EQUIPMENT AND PROCEDURE}

EQUIPMENT: NUMEC

Prepressing at NUMEC was performed with a Stokes Model R-4 automatic press (Ross, Atkins and Caldwell 1971). The Stokes Model R-4, with a 20-ton capacity, was a single-punch, eccentric-cam-type press with pressure applied simultaneously from above and below.

Tool steel punches and dies were used. The glove box was attached to a die table area in a mounting plate.

An agitated feed shoe provided uniform die fills, thus minimizing pelletto-pellet differences. The hydraulic release and pressure equalizer provided for improved uniformity in pressing to a specified green density.

Granulation at NUMEC was performed with an Erweka-type KU1 granulator. A replaceable, granulating screen (usually 16 mesh) allowed for control of granule size.

\section{EQUIPMENT: WESTINGHOUSE HANFORD}

Westinghouse Hanford designed and documented a roll compactor and granulation machine. Goldman and Holley (1981) provide a detailed description of production-scale, automated equipment.

\section{EQUIPMENT: LOS ALAMOS}

Prepressing is performed with a Carver Model $C$ laboratory press that can be operated manually or can be hydraulically plumbed for remote operation (Kent 1979). The die is made of ferrotic C, although hardened tool steel works as well. Both dies have been approved by the LANL Die Safety Committee for use to $1.1 \mathrm{GPa}$.

The die punches are lubricated with molybdenum disulfide, and no binder is added to the plutonium powder. All screens, pans, rollers, funnels, forceps, and brushes used in these operations are stainless steel.

PROCEDURE: LOS ALAMOS (Kent 1979)

1. Record Lot ID and bulk weight as transferred after ball milling.

2. Clean and polish die assembly with clean cheesecloth.

3. Lubricate punches sparingly with molybdenum disulfide, taking care that no lubricant gets on punch faces. 
4. Position bottom punch in die. Load appropriate amount of feed powder using funnel, then position top punch.

5. Place die assembly on bottom press platen and slowly raise assembly until top punch touches and is square with top platen.

6. Apply force of $33.8 \mathrm{kN}$, hold for 1 minute, and release.

7. Apply force of $67.6 \mathrm{kN}$, hold for 1 minute, and release.

8. Apply force of $101.4 \mathrm{kN}$, hold for 1 minute, and release.

9. When pressing cycle is completed, remove and invert die assembly. Remove top punch and position spacer. Reposition die assembly and eject pellet, using minimum force.

10. Remove pellet with forceps and place on 600- $\mu \mathrm{m}$ screen positioned above a $125-\mu \mathrm{m}$ screen that, in turn, is positioned above a tared pan.

11. Use roller to gentiy break up pellet. Use roller and brush to pass all material through the $600-\mu \mathrm{m}$ screen, and collect granules on $125 \mu \mathrm{m}$ screen.

12. Use roller to pass material through $125-\mu \mathrm{m}$ screen to pan below. Use brush for residual tailings only.

13. If there are any granules $>125 \mu \mathrm{m}$, weigh and transfer them to a residue container.

14. Weigh tared pan to determine weight of $<125-\mu \mathrm{m}$ granules. Record weight.

15. Repeat Steps 2 through 14 until all material is slugged and screened.

16. From initial weight and weight of slugged and screened granules, determine and record any processing losses. 


\section{ADDITION OF BINDER TO STRENGTHEN GREEN PELLETS}

\section{BATTELLE STUDIES}

Barr, Jaech and Anderson (1970) reported that pressing with binders helps to distribute pressures throughout the pellet, thereby increasing green strength and minimizing laminations, cracks and diameter taper. Methylcellulose and Carbowax were selected on the basis of their wide industrial use, availability and a few preliminary experiments.

Barr stated that methyl-cellulose is considered a pore former and also improves the green strength of pellets. Carbowax is generally not considered a pore former and therefore has little effect on density when used in percentages below about 4 wt\%.

Carbowax, being highly water soluble, can easily be uniformly dispersed throughout a powder, permitting a more equitable distribution of pressure. Barr showed that Carbowax yielded denser green pellets than methyl-cellulose.

\section{ATLANTIC RICHFIELD HANFORD STUDIES}

Rasmussen (1969) reported that the addition of a binder to plutonium oxide served the following purposes:

- Lubrication of particles during pressing gives the green pellet a uniform density throughout.

- The addition of binder increases the green pellet density and permits higher compaction pressure without causing serious pellet structure problems.

- A binder gives the green pellet sufficient strength to withstand normal handling without damage.

- The binder can serve as a die lubricant, or a separate die lubricant can be added.

LOS ALAMOS STUDIES

Pritchard, Johnson and Leary (1963) showed that the addition of binder increased green pellet density (Table $\mathrm{D}-7$ ). The higher density of PuO2 from peroxide is also shown in comparison with $\mathrm{PuO}_{2}$ from oxalate.

Trademark of Union Carbide Corporation, Danbury, Connecticut. 
TABLE D-7. Effect of Binder on Green Pellet Density

\begin{tabular}{|c|c|c|c|}
\hline \multirow[b]{2}{*}{ Type $\mathrm{PuO}_{2}$} & \multicolumn{3}{|c|}{ Green Pellet Density $\left(\mathrm{g} / \mathrm{cm}^{3}\right)$} \\
\hline & Pressure (tsi) & Without Binder & $\begin{array}{l}\text { With } 0.5 \text { wt\% } \\
\text { Parawax Binder }\end{array}$ \\
\hline Peroxide & 20 & 7.8 & 8.1 \\
\hline Peroxide & 40 & 8.2 & 8.5 \\
\hline Oxalate & 50 & 7.8 & 8.1 \\
\hline Peroxide & 60 & 8.5 (Laminated) & 8.8 \\
\hline Peroxide & 80 & 8.6 (Fractured) & 8.9 \\
\hline Peroxide & 100 & Fractured & Fractured \\
\hline
\end{tabular}

\section{NUMEC STUDIES}

Ross, Atkins and Caldwell (1971) blended Carbowax granules (less than 125 microns but greater than 74 microns) with powder prior to prepressing. Carbowax granules were prepared by ball milling and screening.

Carbowax 6000 consisted of polyethylene glycols with molecular weight of 6000 to $7000 ; \mathrm{HOCH}_{2}\left(\mathrm{CH}_{2}-\mathrm{OCH}_{2}\right) \mathrm{CH}_{2} \mathrm{OH}$.

Table D-8 summarizes components of the various binder studies.

\section{POTENTIAL DISADVANTAGES OF BINDERS}

Pritchard and Nance (1966) at Los Alamos reported observations concerning adverse binder behavior at elevated temperatures. They reported that volatile degradation products of paraffin binder were present, as indicated by deposits on the cool sightglass of the furnace.

They presumed that these volatile compounds may have reacted with $\mathrm{PuO}_{2}$. This presumption could have been supported if elevated carbon levels were found in the oxide. No carbon analyses were reported to have been made on the oxide.

Houston (1964, 1965) did not use a binder, reportedly to avoid possible side effects. These side effects have not-been conclusively documented. 
TABLE D-8. Types of Binders

\begin{tabular}{|c|c|c|}
\hline Reference & Binder & Comment \\
\hline Rasmussen 1969 & Carbowax 6000 & Added as granules to oxide \\
\hline $\begin{array}{l}\text { Barr, Jaech and Anderson } \\
1970\end{array}$ & $\begin{array}{l}\text { Carbowax } \\
\text { Methyl-cellulose }\end{array}$ & $\begin{array}{l}2 \text { to } 4 w t \% \\
2 \text { to } 4 \mathrm{wt} \%\end{array}$ \\
\hline $\begin{array}{l}\text { Pritchard, Johnson and Leary } \\
1963\end{array}$ & Parawax & 0.5 wt\% \\
\hline Brett and Russell 1960 & Naphthalene & $5 \mathrm{wt} \%$ \\
\hline Pritchard and Nance 1966 & Paraffin & $0.5 \mathrm{wt} \%$ \\
\hline NUMEC 1965 & $\begin{array}{l}\text { Sterotex die } \\
\text { lubricant }\end{array}$ & 0.3 wt\% \\
\hline Chikalla 1960 & $\begin{array}{l}\text { Carbowax 20M; } \\
\text { Sterotex }\end{array}$ & $0.2 w t \%$ \\
\hline
\end{tabular}




\section{ATTACHMENT D-5}

\section{GREEN PELLET PRESSING}

NUMEC

Early pellet pressing at NUMEC (1960c) involved a Carver (a) hard press, equipped with a micrometer-controlled, gunpowder dispenser that gave reproducible loadings of $\pm 6 \%$ on a 2.5 -gram sample. Miscellaneous hand tools and die sets were used.

Fine test powder was found to plug the gunpowder dispenser (NUMEC 1960b). However, 20-mesh powders flowed satisfactorily and did not bind.

Attempts to press as-received plutonium oxide powder were unsuccessful because the punches could not be pressed readily from the die. This was presumably due to the binding of fine powder between the punches and the die body (NUMEC 1961a).

The problem was solved by pre-pressing the powder at 6500 psi in a 0.467-inch diameter die followed by granulation through a 20-mesh screen. This resultant granules were hand pressed, with no binder, in an 0.187-inch diameter die at pressures ranging from 5 to $95 \mathrm{tsi}$.

A die-and-punch lubricant was applied as a saturated solution in trichlorethylene. The green strength of all pellets pressed at 10 tsi and over was excellent, with no difficulties encountered during pellet press-out or punch removal. The effect of varying the pellet length (changing the $L / D$ ratio) was shown to have no major effect within the range studied (Table D-9). Increasing pressing pressure from 10 to $90 \mathrm{tsi}$ increased green densities (see Figure D-7).

Pressing pressures of 35 to 46 tsi were used for most of the NUMEC work (NUMEC 1961b).

Whenever the feed $\mathrm{PuO}_{2}$ had been calcined at 350 to $560^{\circ} \mathrm{C}$, green densities were in the range of 4.64 to $5.9 \mathrm{~g} / \mathrm{cm}^{3}$ (NUMEC 1961b). Feed powders calcined at $760^{\circ} \mathrm{C}$ yielded green densities of 6.8 to $7.11 \mathrm{~g} / \mathrm{cm}^{3}$. Pressing success, then, depended on prepress parameters as well as pressing parameters.

Later studies at MUMEC used a production-scale, Stokes, (b) automatic double-acting press (NUMEC-3505-14). Sterotex $(0.3$ wt $\%$ ) was added to the powder for Tubrication (NUMEC 1968c).

(a) Murray-Carver Inc., Bridgewater, Massachusetts.

(b) Div. of Pennwalt Corp., Philadelphia, Pennsylvania.

- Trademark of Capital City Products Co., Columbus, Ohio. 
TABLE D-9. Effect of Pellet Length on Density (0.188 in. dia Pellet at 70 tsi Pressing Pressure)

\begin{tabular}{|c|c|}
\hline $\begin{array}{l}\text { Length } \\
\text { (in.) }\end{array}$ & $\begin{array}{l}\text { Pellet Density } \\
\quad\left(\mathrm{g} / \mathrm{cm}^{3}\right) \\
\end{array}$ \\
\hline 0.106 & 6.89 \\
\hline 0.187 & 6.74 \\
\hline 0.201 & 6.44 \\
\hline 0.201 & 6.69 \\
\hline 0.212 & 6.75 \\
\hline 0.238 & 6.46 \\
\hline 0.262 & 6.80 \\
\hline 0.333 & 6.83 \\
\hline 0.392 & 6.76 \\
\hline 0.431 & 6.46 \\
\hline 0.450 & 6.64 \\
\hline Range & 6.44 to 6.89 \\
\hline
\end{tabular}

By 1971, the Stokes Model R-4 automatic press was used for prepressing (described in Attachment D-3), and a Hydramat Model HC-12 press was used for final pressing. The Hydramat Model HC-12 is an opposed-ram, die-type, hydraulic powered, powder compaction press (Ross, Atkins and Caldwell 1971).

The basic press consists of pne upper pressing ram, two lower filling, pressing, and ejection rams, a hydraulically actuated feed shoe with a fixed die table and remote control panel. The sequencing of the various motions is programmed by a combination of the upper ram position or movement, automatic pressure-sensing devices, and adjustable timers.

The upper ram motion, in addition to actuating the feed mechanism, indicates its position by a limit switch cam rack which, in turn, programs the lower rams. The pre-set tonnage is sensed automatically and starts a pressure dwell timer. Upon timing out, the upper ram withdraws, and the compact is ejected by the lower ram.

The $\mathrm{PuO}_{2}-\mathrm{UO}_{2}$ powder was blended with a minus-200-mesh sterotex powdered die lubricant in a Patterson-Kelley twin-shell blender prior to pressing.

\section{Early Studies at Hanford}

Chikalla (1960a) prepared green pellets of $\mathrm{UO}_{2} / \mathrm{PuO}_{2}$ by mixing $\mathrm{UO}_{2}$ powder with an aqueous solution of Carbowax $20 \mathrm{M}$. The powder was dried at $70^{\circ} \mathrm{C}$ and passed through a 20-mesh screen. 


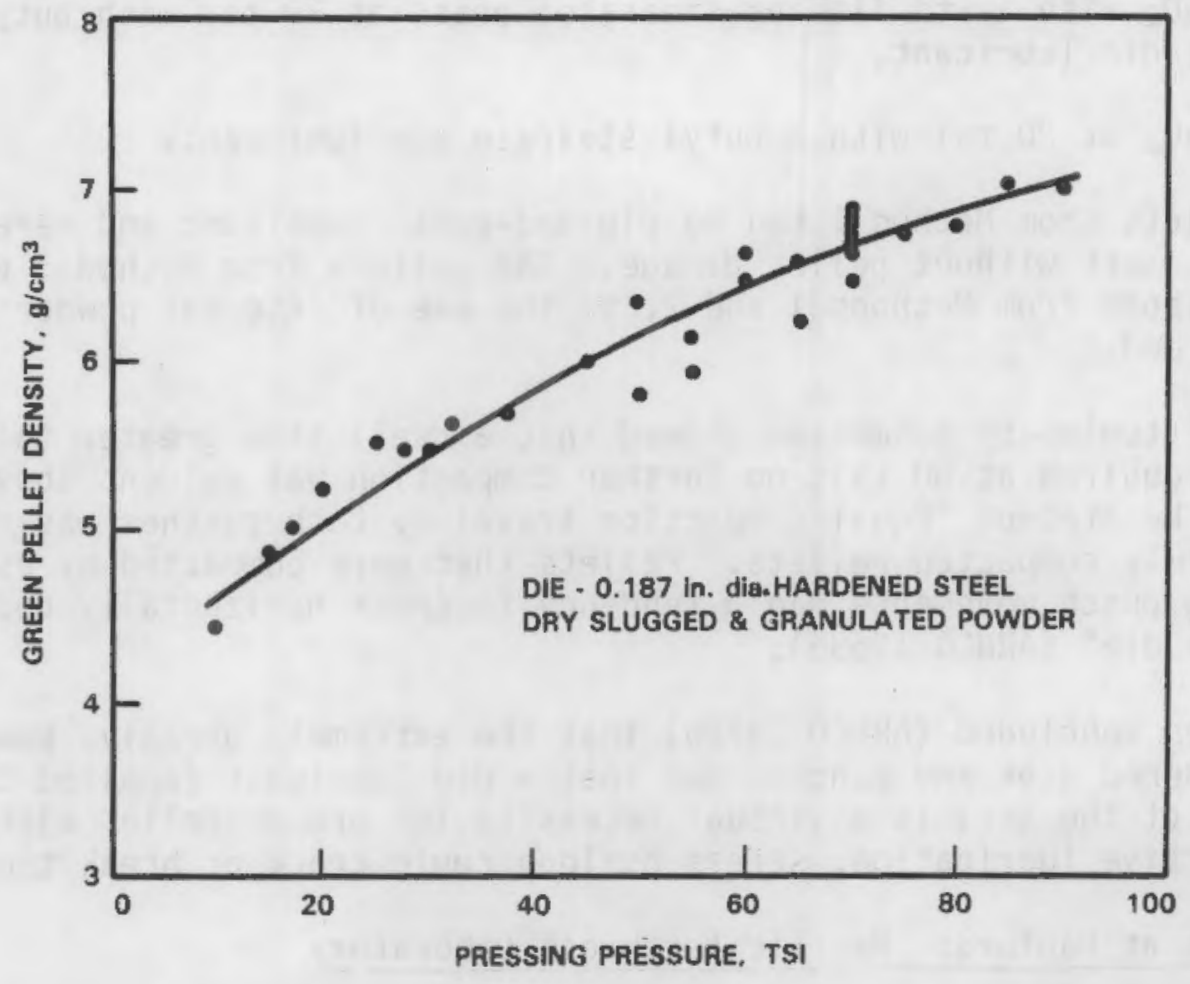

FIGURE D-7. Effect of Pressing Pressure on Green Pellet Density (NUMEC 1961a)

Plutonium oxide and $0.2 \mathrm{wt} \%$ sterotex were added, blended and pressed in a double-acting die at pressures up to 65 tsi. Green densities varied by as much as $0.35 \mathrm{~g} / \mathrm{cm}^{3}$, regardless of attempts to improve uniformity.

\section{Early Studies at Los Alamos}

Pritchard, Johnson and Leary (1963a) pressed 50-50 mixes of Pu02-metal oxides at 50 tsi in a floating tungsten carbide die 0.407 inch ID by 1.25 inches in depth without use of a lubricant. The pressure was applied slowly and the final pressure maintained for 15 seconds. Green densities near $7 \mathrm{~g} / \mathrm{cm}^{3}$ were obtained in most cases.

\section{Early Studies at Hanford: ARHCO}

Rasmussen studied three methods of green pellet fabrication using a Western Sintering pellet press (ARHCO 1969a):

1. Blend $\mathrm{PuO}_{2}$ with 2 wt\% lithium stearate lubricant; prepress at

4 tsi; granulate (20 mesh); press at 20 tsi with no die lubricant. 
2. Blend $\mathrm{PuO}_{2}$ with 1 wt\% lithium stearate; press at 20 tsi with butyl stearate die lubricant.

3. Press $\mathrm{PuO}_{2}$ at 20 tsi with a butyl stearate die lubricant.

The pellets from Method 1 had no die-and-punch lubricant and were difficult to eject without pellet damage. The pellets from Method 3 were superior to those from Methods 1 and 2, so the use of internal powder lubricant was discontinued.

Further studies by Rasmussen showed that a dwell time greater than five seconds was required at $30 \mathrm{tsi}$; no further compaction was evident above 60 seconds. He stated, "Equal compaction travel by both punches was necessary to get uniformly compacted pellets. Pellets that were compacted by essentially single-acting punch movements had a tendency to crack horizontally upon ejection from the die" (ARHCO 1969b).

Rasmussen concluded (ARHCO 1970b) that the extremely abrasive powder requires hardened dies and punches and that a die lubricant (applied to the inside walls of the die) is a virtual necessity for proper pellet ejection. Without effective Tubrication, stress buildup could crack or break the pellets.

Later Studies at Hanford: Pacific Northwest Laboratory

Blair (1970) used a Western Sintering pellet press, Model H-10-2, to press granulated mixed oxide (with binder) into pellets at 10 tsi using a one-second dwell time. The pressing rate was 320 pellets per hour.

The die and punches were made of D-2-type tool steel hardened to approximately 58 Rockwell C. The die cavity diameter was 0.246 inch. Average diameter was $0.2478 \mathrm{inch}$, and average length was $0.3118 \mathrm{inch}$.

Some pellet laminating occurred when the moisture level of the feed powder was too high.

\section{Westinghouse Hanford Studies}

D. H. Nyman et al. (1980), reported the design of equipment to remotely produce pellets containing plutonium.

Summary of Presses Used in Green Pellet Studies

The types of presses that were used to make the green pellets described above are summarized in Table 0-10. 
TABLE D-10. Summary of Presses

\begin{tabular}{|c|c|c|c|}
\hline Reference & Location & Press & Comment \\
\hline NUMEC $1960 \mathrm{c}$ & NUMEC & Carver hand press & Sterotex Tubricant \\
\hline NUMEC $1968 \mathrm{c}$ & NUMEC & $\begin{array}{l}\text { Stokes automatic } \\
\text { press }\end{array}$ & $\begin{array}{l}\text { Production scale, } \\
\text { double acting; } \\
\text { sterotex lubricant. }\end{array}$ \\
\hline $\begin{array}{l}\text { Ross, Atkins } \\
\text { and Caldwell } \\
1971\end{array}$ & NUMEC & Stokes Model R-4 & $\begin{array}{l}\text { 20-ton, double } \\
\text { acting, used for } \\
\text { prepressing. }\end{array}$ \\
\hline $\begin{array}{l}\text { Ross, Atkins } \\
\text { and Caldwell } \\
1971\end{array}$ & NUMEC & $\begin{array}{l}\text { Hydramet Model } \\
\mathrm{HC}-12\end{array}$ & Used for pressing. \\
\hline $\begin{array}{l}\text { Rasmussen } \\
1969\end{array}$ & $\begin{array}{l}\text { ARHCO } \\
\text { (Hanford) }\end{array}$ & Western Sintering & \\
\hline Blair 1970 & $\begin{array}{l}\text { PNL } \\
\text { (Hanford) }\end{array}$ & Western Sintering & Model $\mathrm{H}-10-2$ \\
\hline
\end{tabular}





\author{
APPENDIX E \\ SHIPPING CHARACTERISTICS OF SOL-GEL MICROSPHERES \\ T. D. Cooper \\ Rockwell Hanford Operations
}


APPENDIX E

\section{SHIPPING CHARACTERISTICS OF SOL-GEL MICROSPHERES}

\section{INTRODUCTION}

Plutonium is obtained from nuclear reactions involving uranium. It is fissile and is both a source material and a product of the nuclear fuel cycle. Plutonium is separated from the other fission products during chemical reprocessing and either reused as fissile material or stored as a long-lived radiotoxic waste product.

During the handling, shipping, or storage of plutonium, the primary hazard to humans is from inhalation and deposition in the deep lungs. Many pathways exist for internal deposition; however, airborne transport of plutonium is the most hazardous and the hardest to prevent or mitigate.

The problem persists because all industrial processes currently favored for plutonium oxide production uniformly produce particles less than 100 microns in diameter, which are easily suspended in air. The fraction of particles within the respirable range (<10 microns) varies from $30 \%$ to $99 \%$ (Barr et al. 1970). A process which uniformly produces nondispersable particles above the 100-micron diameter limit would greatly reduce the hazards associated with handling or transporting plutonium. Particles of such size would not normally become airborne and consequently would not be breathed by humans.

Plutonium dioxide (plutonia) is normally contained and not allowed to contaminate breathing air; however, under accident conditions, the containment could be breached. It would be wise to specify a form of plutonia, for shipping, which would not become airborne if the containment were breached.

Containers are designed to withstand severe accident conditions. Typical. maximum credible accident conditions are given in Table E-1 (Hartman 1975).

The Table E-1 values were chosen to represent reasonable maximum values for each listed parameter. These parameters are defined as follows:

Impact is a collision between a container and some other body where the force of the collision is applied over a "wide" area of the container. Impact forces generally have a duration of less than 10 milliseconds. Common units for measuring impact are feet. These are arrived at by dividing the energy transferred to the container (ft-lbs) by the weight of the container (lbs). 
TABLE E-1. Assumed Maximum Credible Accident Conditions(a)

Accident

Environment

Parameters

Impact (b)

(c)

Cargo Aircraft $\frac{\text { Transport Modes }}{0-1600 \mathrm{ft}-1 \mathrm{bs}}-\frac{\text { Train }}{\ldots}$

Crush

$0-170 \mathrm{ft}$

$0-15 \mathrm{ft}$

$0-4 \mathrm{ft}$

Puncture ${ }^{(d)}$

$0-80,0001 \mathrm{bf}$

$0-180,000$ lbf

$0-330,000 \quad 1 b f$

Fire (Temp)

$---$

$20-360 s^{-1}$

$20-360 s^{-1}$

Fire (Temp)

$1400-2400^{\circ} \mathrm{F}$

$1400-2400^{\circ} \mathrm{F}$

$1400-2400^{\circ} \mathrm{F}$

Fire (Duration)

$0-200$ min

0-90 min

$0-160 \mathrm{~min}$

Immersion

$0-400 \mathrm{ft}$

$0-50 \mathrm{ft}$

$0-80 \mathrm{ft}$

(a) There will always be accident conditions in which the parameters may exceed the table values, but the number of these is believed to be small.

(b) Units are ft-lbs. Impact is a measure of absorbed energy.

(c) Equivalent drop height $=\frac{\text { impact energy }}{\text { package weight }}(\mathrm{ft})$.

(d) Projective velocity divided by projectile radius.

(e) Potential for local hot spots reaching $5100^{\circ} \mathrm{F}$.

Crush deals with the mechanical loading that cannot be characterized by impact, punctures, or immersion. Crush forces have durations of much greater than 10 milliseconds. Usually they are due to inertial loading from other cargo or heavy sections of the transporting vehicle.

Puncture is the collision of a container with a body or bodies capable of penetrating the protective structures of the container. Puncture is typically characterized by dividing the collision velocity by the radius of the puncture probe. In these cases, the units are "per second."

Fire refers to the subjection of a container to elevated temperature produced by combustion. Two aspects, temperature and duration, are used to characterize the fire environment.

Immersion involves the submersion of the container in a liquid medium (most commonly water). Immersion is typically quantified in terms of depth in feet or meters. 
Shipping containers are designed to withstand severe accident conditions. However, if the maximum accident conditions are applied sequentially, containers have been known to fail and become breached. Breaching of containment can lead to severe airborne contamination with all forms of plutonia powder presently being shipped.

The remainder of this report is devoted to discussing a relatively new plutonia process (Sol-Gel), which produces a plutonia powder that does not become airborne easily and is relatively noncontaminating under accident conditions.

\section{DISCUSSION}

\section{Sol-Gel Applications}

Sol-Gel processes can be used to create pure PuU2 microspheres which could prove useful as a shipping form, or can produce mixed-oxide (Pu-U) microspheres. Indeed, Sol-Gel processes originated from the need to create spherical particles containing nuclear fuel for high-temperature gas-cooled reactors (HTGR).

Since their creation, the Sol-Gel particles have proved to be an ideal fuel form for all existing reactors. These particles are hard, smooth spheres. They can be handled with minimum contamination and can be stacked by vibratory compaction into fuel pins without the customary pelletizing operations necessary for all other plutonia powders.

The Sol-Gel process is also extremely useful for producing mixed oxide fuels, since it is a coprecipitation process producing homogeneity with respect to element distribution within the particle cross section. The size of the primary particles in the material and the texture of the material are such that a high chemical-thermal reactivity is characteristic of the green material. A homogeneous distribution of plutonium in uranium is of vital importance for mixed oxide fuels and especially for "fast reactor" fuel. Some fast reactor fuel assemblies have preferentially used Sol-Gel particles to obtain the desired homogeneity, even though the Sol-Gel particles were incorporated into pellets as the final fuel form (Hermans 1973).

Sol-Gel processes are characterized by a high degree of product reproducibility. Wide compositional ranges are easily obtained, and the porosity of the final product is easily adjusted. The processes are ideally suited for automatic controls and remote operation.

The Sol-Gel process is the only proven process for manufacturing nuclear fuel particles with controlled dimensions such that each particle is fairly uniform in size. Sol-Gel microspheres can range in size from five microns to 1000 microns, depending upon the manufacturing process, and can be uniformly produced with a size range greater than that normally transportable through air. 
Sol-Gel Process Chemistry

Sol-Gel process chemistry is described below as an aid in understanding both the chemistry required for producing the particles and their resulting properties.

The first step in any precipitation process is the formation of primary nonfilterable nuclei, which grow into colloidal particles ranging from 0.001 to 0.1 microns in diameter. The colloidal particle is bathed in an electrolyte solution. The electrostatic force fields of the surface ions extend into the solution, attracting oppositely charged solute ions into the adsorbed-ion layer. A colloid may be viewed, therefore, as a large molecule with large mass and charge characteristics. If the adsorbed-ion layer contains primarily hydroxide ions, or hydrated ions, then a hydrophilic colloid, sometimes called a gel, is formed with substantial inter-molecular attractive force between the colloid phase and water. The colloidal particles form in flocs or jellies containing much water in and around the particles.

If the adsorbed-ion layer contains primarily nonaqueous ions and nonhydrated ions, a hydrophobic colloid, commonly called a sol, is formed which does not incorporate water into its structure. These colloids eventually agglomerate into dense, curdy precipitates. Silver chloride is an example of such a precipitate.

Both hydrophobic and hydrophilic colloids are stabilized by the adsorbedion charge layer, which prevents agglomeration by coulombic repulsion.

A sol may be converted to a gel by a number of techniques. The transition is slow compared to normal precipitation procedures, but this is necessary to insure a homogeneous texture in the product. The effect of gelation can be described as a controlled, and thereby oriented, flocculation of the crystallites into an open, three-dimensional network, enclosing all of the water. Such a network upon drying, may exhibit an initial porosity as high as $90 \%$.

In a colloid, the interaction between the particles is determined by two types of forces: Coulombic repulsion tends to separate the particles, and London-Van der Wals attractive forces draw the particles together at close range. Accordingly, flocculation may be accomplished by two techniques:

- The surface charge is gradually diminished, so that particles form strings and networks but retain an open structure through reduced residual surface charges on the networks.

- The particles are forced together through water extraction until the attractive forces predominate. The presence of the surface charge again insures the creation of an open, three-dimensional network. 
For plutonium Sol-Gel processes, the initial sols formed consist of "Pu (IV) polymer," (Forthman and Blass 1973; Lloyd and Haire 1978; Sperry 1979). The equations are:

$$
\begin{gathered}
\mathrm{Pu}\left(\mathrm{NO}_{3}\right)_{4}+4 \mathrm{H}_{2} \mathrm{O} \ldots \mathrm{Pu}(\mathrm{OH})_{4} \cdot \mathrm{HNO}_{3}+3 \mathrm{HNO}_{3} \\
\mathrm{Pu}(\mathrm{OH})_{4} \cdot \mathrm{HNO}_{3} \rightarrow-\mathrm{PuO}_{2} \cdot \mathrm{HNO}_{3} \cdot 2 \mathrm{H}_{2} \mathrm{O} \\
(\text { Polymer) }
\end{gathered}
$$

Historically, polymeric plutonium refers to a hydrolytic form of $\mathrm{Pu}$ (IV) that is characterized by a bright green color and a distinctive absorption spectrum.

Electron micrographs of these sols indicate that $\mathrm{Pu}$ (IV) polymer consists of very small, discrete particles. The primary particles are less than 20 Angstroms in diameter; most are approximately 10 Angstroms in diameter.

Electron diffraction studies and electron microscopy (Lloyd and Haire 1978 ) indicate clearly that plutonium polymer is, in reality, a cubic $\mathrm{PuO}_{2}$ fluorite structure. Freshly precipitated material is amorphous; however, aging the material allows the amorphous material to convert to a crystalline structure. There is no indication of a definite hydroxide precipitate such as $\mathrm{Pu}(\mathrm{OH})_{4}$. This is true over a wide range of precipitation conditions, and it indicates that the initial hydroxide precipitated material from $\mathrm{Pu}$ (IV) nitrate is plutonium polymer particles that are not colloidally dispersed.

Colloidal solutions of plutonium polymer are ideally realized at a nitrate-to-plutonium mole ratio of 0.8 , regardless of the amorphous-crystalline characteristics of the primary particles. Precipitated plutonium polymer cannot be repeptized with nitric acid to form the characteristic dark green colloidal solution until the $\mathrm{NO}_{3} / \mathrm{Pu}$ mole ratio equals or exceeds 0.8 . Colloidal solutions with higher nitrate ratios may be evaporated to dryness at temperatures below $100^{\circ} \mathrm{C}$ to remove excess $\mathrm{HNO}_{3}$. The solids readily peptize with the addition of water, and the $\mathrm{NO}_{3} / \mathrm{Pu}$ mole ratio approaching 0.8 is manifest in all diverse methods employed for forming plutonium polymer.

If the primary polymer particle is composed of two unit cells on each edge, a centrosymmetric particle containing eight unit cells with a diameter of 11 Angstroms is obtained, which is consistent with electron microscopy results. The crystal structure is a face-centered cubic array. Of the plutonium atoms, $80 \%$ are surface oriented within this size crystal structure; and if each surface atom is assigned one nitrate ion, the characteristic $0.8 \mathrm{NO} / / \mathrm{Pu}$ mole ratio is readily explained.

An important conclusion which can be drawn from the above discussion is that the plutonium polymer sol can be converted to a gel by slowly removing nitric acid below the $0.8 \mathrm{NO}_{3} / \mathrm{Pu}$ mole ratio limit. This is accomplished by 
either acid extraction with a long chain alcohol, by chemical reaction (as with formic acid), or by neutralization reactions with hydroxide ions.

Sol-Gel Processes Development

Several procedures have been developed and evaluated to produce Sol-Gel microspheres. The following sections briefly review these procedures.

\section{ORNL: Dehydration}

In 1968, Oak Ridge National Laboratory (ORNL), reported (Lloyd and Haire 1968) on a Sol-Gel process for preparing plutonium oxide microspheres. The objective of this work was to make a sol of plutonia which could be mixed with other actinide sols, gelled, and calcined to form strong dense microspheres of the oxides. In this method, precipitation, digestion, and peptization techniques were used to prepare the plutonia solution. A flow sheet for this process is shown in Figure E-1. The process involved the use of dilute ammonium hydroxide $\left(\mathrm{NH}_{4} \mathrm{OH}\right)$ to precipitate hydrous plutonia. The precipitate was washed and aged in water for two hours, then dissolved in dilute nitric acid to obtain a polymer solution with a $\mathrm{NO}_{3} / \mathrm{Pu}$ mole ratio which ranged from 1 to 2.5. This high-nitrate sol was evaporated to dryness and denitrated at $240^{\circ} \mathrm{C}$ for 2 to 5 hours. The denitrated solids were resuspended in water to form a 1 to 3 molar plutonium sol solution. During the baking process, the primary particle grew to approximately 100 Angstroms in diameter, which required a $\mathrm{NO}_{3} / \mathrm{Pu}$ mole ratio of 0.1 to 0.15 .

This plutonia sol solution was dispersed as droplets into a fluidized gelation column of 2-ethyl hexanol (2EH), which converted the sol to gelled microspheres by extracting water from the droplets. The droplets flowed from the column, with their residence time in the column controlled by the countercurrent upward flow of $2 \mathrm{EH}$, which suspended or fluidized the droplets. As water was extracted from the droplets, their densities and settling velocities were increased, and the gelled microspheres settled to the column bottom.

Although the ORNL precipitation-digestion-peptization method of preparing the plutonia sol was considered a viable process, it was also considered difficult to perform. The denitration step required careful attention to prevent formation of solids which could not be repeptized in water. Deviations from stated precipitation conditions resulted in the formation of a polymer that did not behave properly during subsequent steps and often did not form stable plutonia sols. These problems, along with low-process throughputs, led Babcock and Wilcox (B\&W) to conclude that this particular Sol-Gel process could not be scaled up to commercially acceptable process levels (Carlson 1970).

\section{ORNL: Nitrate Extraction}

In 1970, ORNL reported that a method was being developed of preparing plutonia sols by procedures readily amenable to scale-up. By 1973, ORNL had completed lab development work on an alcohol-plutonium nitrate extraction pro-

cess (APEX). The flow sheet for this process is presented in Figure E-2. ORNL 


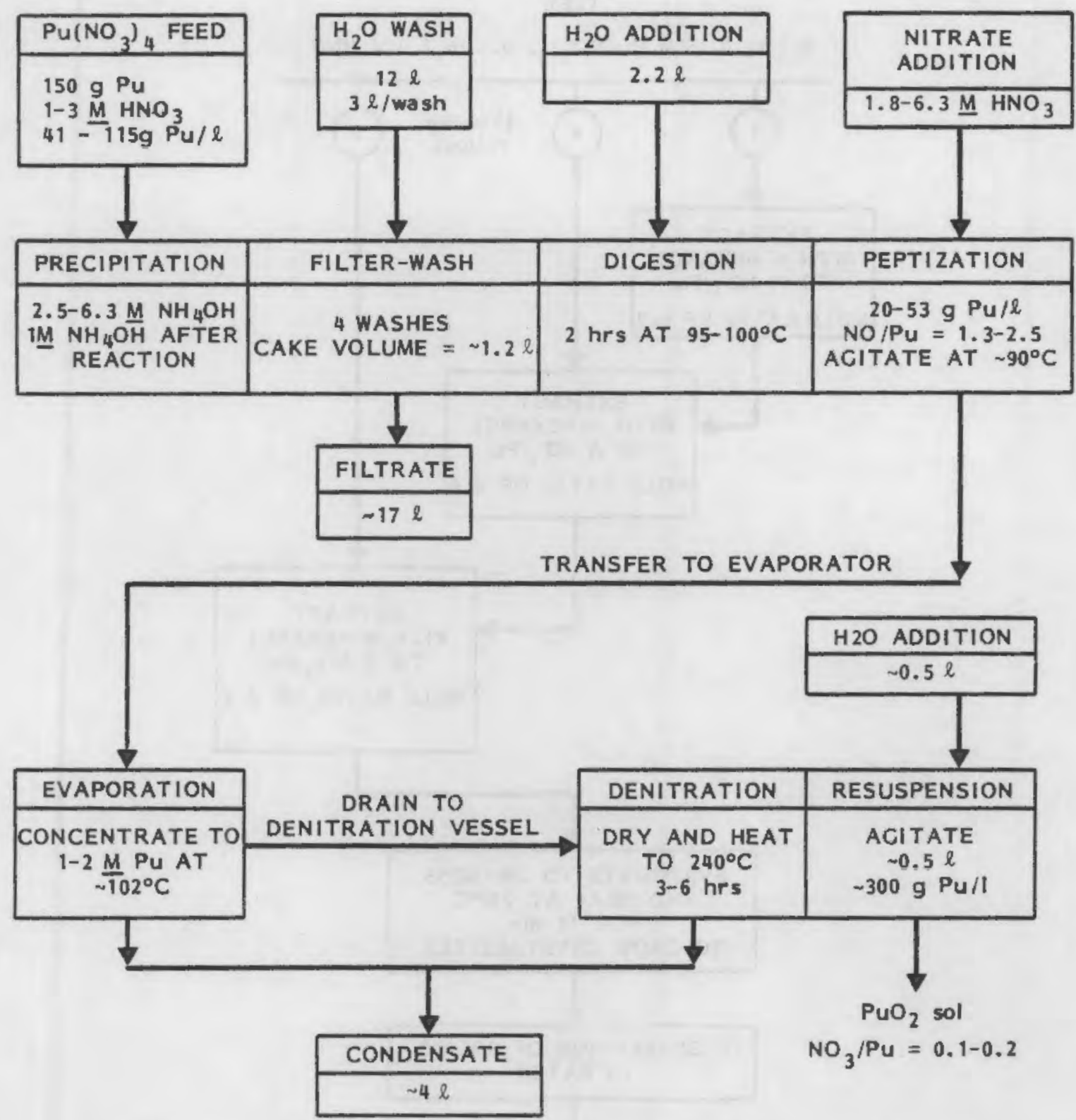

FIGURE E-1. ORNL Flow Sheet for the Preparation of $\mathrm{PuO}_{2}$ Sol

reported that the APEX process combined the versatility of products prepared by the precipitation-digestion-peptization method, along with potential advantages of continuous processing afforded by solvent extraction. The APEX method appears amenable to scale-up and adaptable to remote operations behind shielding.

With the APEX process, nitrate was continuously extracted from an aqueous $\mathrm{Pu}\left(\mathrm{NO}_{3}\right)_{4}-\mathrm{HNO}_{3}$ feed solution with $\mathrm{N}$-hexanol. The initial feed solution was repeatedly circulated through a contactor-separator extraction column, until a 
FEED

0.1 to $0.15 \mathrm{M} \mathrm{Pu}\left(\mathrm{NO}_{3}\right)_{4}, 0.5$ to $1.0 \mathrm{M} \mathrm{HNO}_{3}$

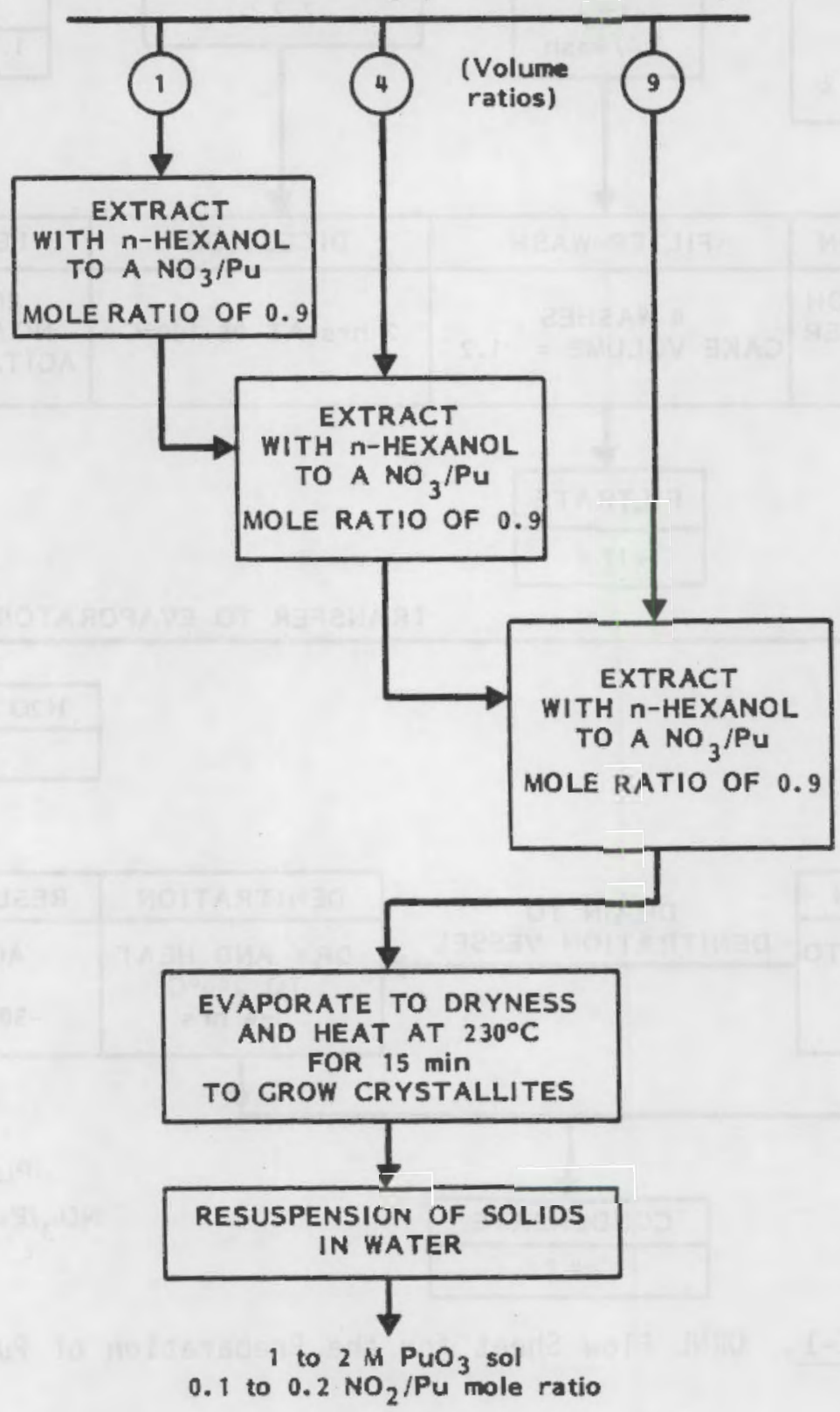

FIGURE E-2. ORNL-Modified APEX Process for the Preparation of Low-Nitrate Plutonia Sol 
plutonia solution with a $\mathrm{NO}_{3} / \mathrm{Pu}$ mole ratio of 1 was achieved. During these extraction steps and before the $\mathrm{NO}_{3} / \mathrm{Pu}$ mole ratio was reduced to 4.6 , a sol seed solution, with a $\mathrm{NO}_{3}-\mathrm{to}_{\mathrm{-Pu}} \mathrm{mole}$ ratio of 1 , was added to the feed. This seed produced a sol in which the primary crystallites were arranged in an aggregated micelle structure. After seeding, and upon completion of nitrate extraction, the sol solution was evaporated to dryness and denitrated. It was found that the micelle structure of the sol solution affected the subsequent denitration step and that the micelle size, in effect, determined the size of the $\mathrm{PuO}_{2}$ crystallite. The $\mathrm{PuO}_{2}$ crystallite solids were resuspended in water to form a highly crystalline sol solution with a $\mathrm{NO}_{3} / \mathrm{Pu}$ mole ratio between 0.1 and 0.2 . These APEX sols were very stable both as plutonia and as mixed plutoniaurania sol solutions. The ORNL fluidized gelation column and procedure described earlier were used to form $\mathrm{PuO}_{2}$ microspheres from these APEX sol solutions.

\section{CNEN: Acid Extraction}

A nuclear agency of the Italian government, Cometato Nazional per 7 'Energia Nucleare (CNEN), developed a process for the preparation of plutonia sols by amine solvent extraction of nitric acid from the plutonium nitrate feed solution. The $\mathrm{NO}_{3}-\mathrm{t}_{0}-\mathrm{Pu}$ mole ratio of $0.2 \mathrm{molar} \mathrm{Pu}\left(\mathrm{NO}_{3}\right)_{4}$ feed solution was reduced to 1 , and this dilute sol was concentrated by evaporation to a 2 molar plutonia sol solution.

CNEN sol-to-gel processes were based upon the removal of the stabilizing anion. Controlled hydrolysis resulted in the formation of a network of particles which reduced the degree of freedom of the particles. The CNEN gelation process utilized a sol droplet dispersion technique in which the dispersing medium was water-saturated Alphanol $79^{\circ}$, a product of Shell Chemical Company, with 1 to $2 \%$ primene JMT , a product of Rohm \& Haas Company, and a $0.5 \%$ Span-85 surfactant, a product of Geigy Company. The Span-85 was added to prevent agglomeration and coalescence of the droplets upon reactor walls during the gelling process. For microspheres 100 microns in diameter or smaller, a baffled cylindrical vessel with a blade-type stirrer was used to form an emulsion of gelled microspheres. For larger microspheres, a gelation column was used. Gelation was considered complete when the $\mathrm{NO}_{3} / \mathrm{Pu}$ molar ratio ranged from 0.1 to 0.2 . Drying and denitrating of the microspheres was performed in an argon-5\% hydrogen atmosphere. The temperature reached $1200^{\circ} \mathrm{C}$ in 4 hours, and the samples were maintained at this temperature for two hours. The CNEN process block diagram is given in Figure $E-3$.

SNAM: Gel-Supported Precipitation

In the early 1960 's, the Research Branch of the Italian SNAM-Progetti Company started work on Sol-Gel processes; however, until 1970, detailed descriptions of the SNAM process were available only in the patent literature. In 1970, the SNAM Sol-Gel process was described in the open literature (Brambilla et al. 1970). A block diagram for process is given in Figure E-4. 


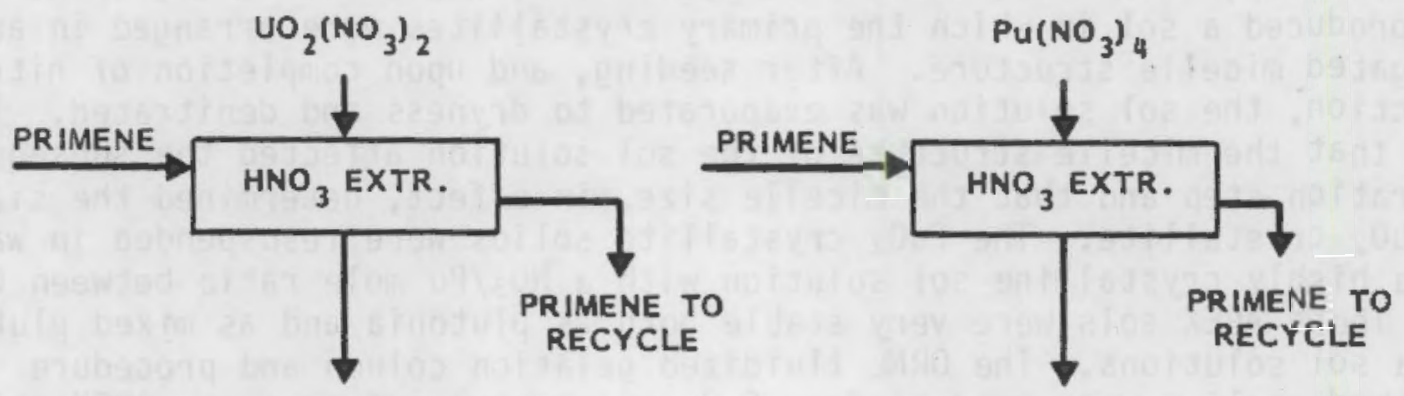

ACID-DEFICIENT SOLN. $\mathrm{NO}_{3} / \mathrm{U}(\mathrm{VI})=1-1.5$

ACID-DEFICIENT SOLN.

$\{U(V I)]=1 \mathrm{M}$ $\mathrm{NO}_{3} / \mathrm{Pu}=1-1.5$ $[\mathrm{Pu}]=0.2 \mathrm{M}$
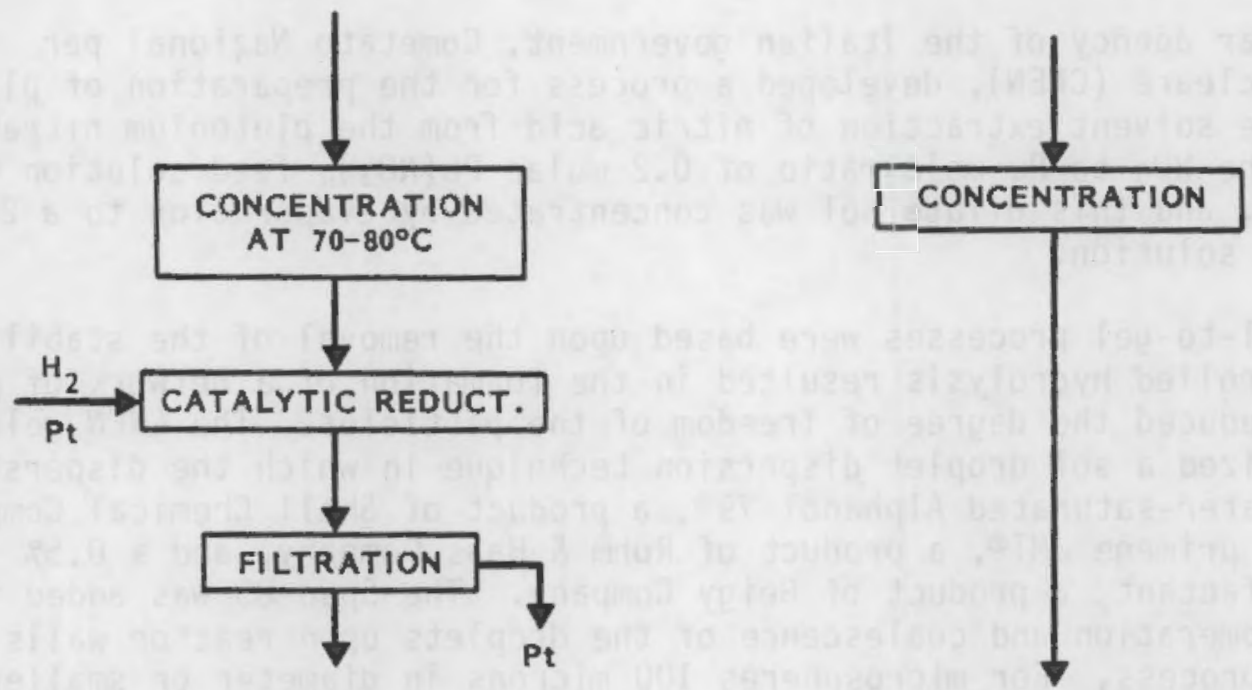

U(VI) SOL

$\mathrm{NO}_{3} / \mathrm{U}=1$

[U(IV)] $=2-3.5 \mathrm{M}$

Pu(IV) SOL

$\mathrm{NO}_{3} / \mathrm{Pu}=1$

$[\mathrm{Pu}]=1.2 \mathrm{M}$
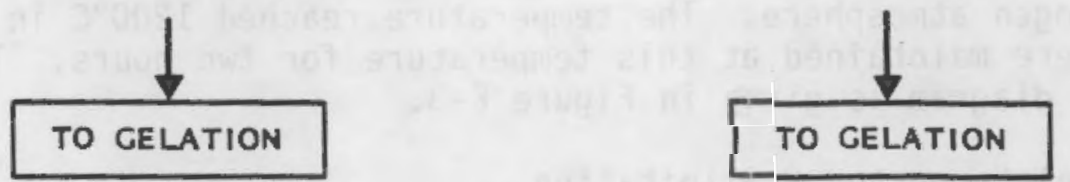

FIGURE E-3. Preparation Schemes for Urania and Plutonia Sols, CNEN Process 


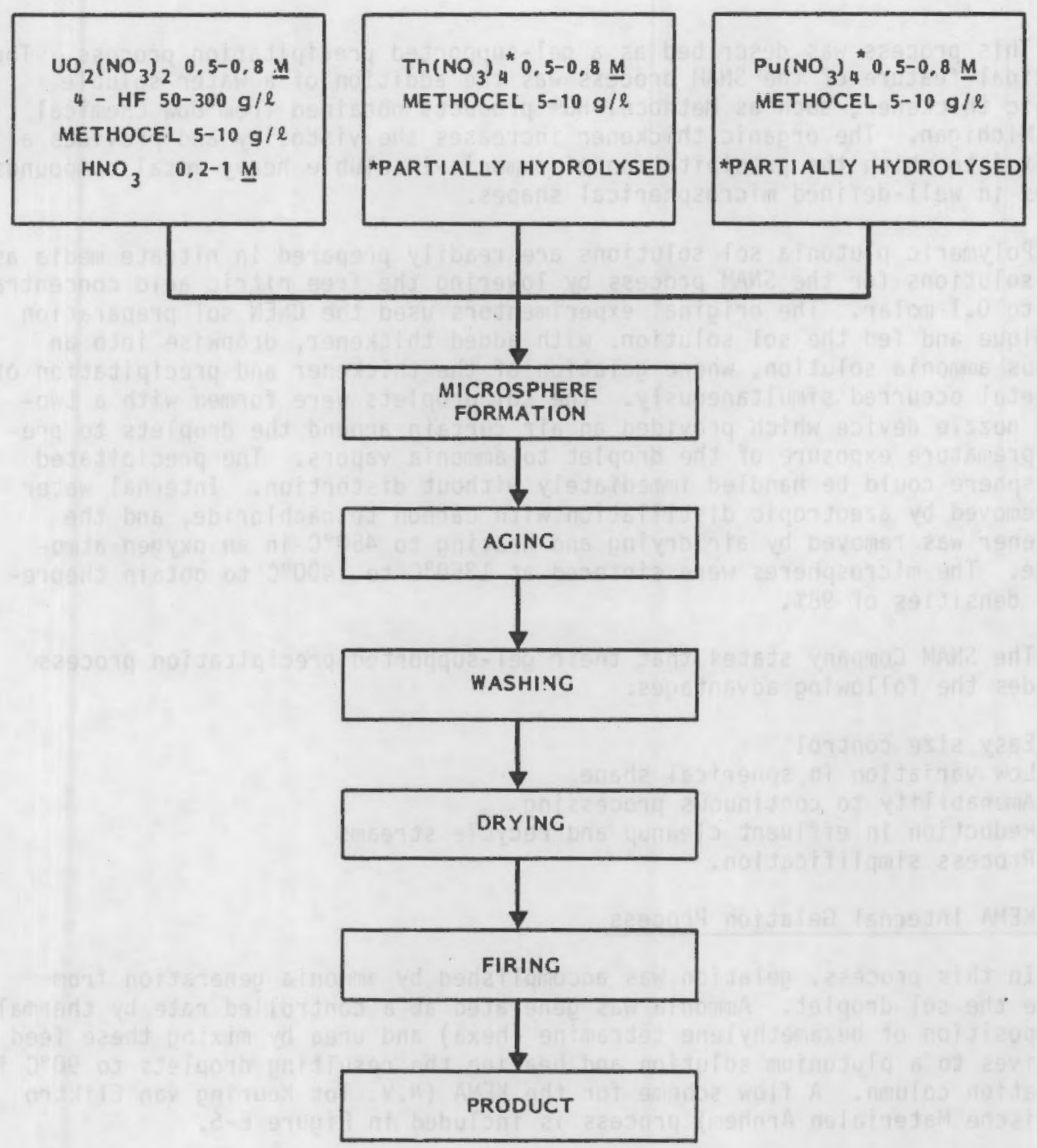

FIGURE E-4. Block Diagram of the SNAM Process for Preparation of $\mathrm{UO}_{2}$, $\mathrm{ThO}_{2}$ and $\mathrm{PuO}_{2}$ Microspheres 
This process was described as a gel-supported precipitation process. The principal feature of the SNAM process was the addition of a water-soluble organic thickener, such as Methocel-HG products obtained from Dow Chemical Co., Michigan. The organic thickener increases the viscosity and provides a matrix into which the precipitation of ammonia-insoluble heavy metal compounds occurs in well-defined microspherical shapes.

Polymeric plutonia sol solutions are readily prepared in nitrate media as feed solutions for the SNAM process by lowering the free nitric acid concentration to 0.1 molar. The original experimentors used the CNEN sol preparation technique and fed the sol solution, with added thickener, dropwise into an aqueous ammonia solution, where gelation of the thickener and precipitation of the metal occurred simultaneously. The sol droplets were formed with a twofluid nozzle device which provided an air curtain around the droplets to prevent premature exposure of the droplet to ammonia vapors. The precipitated microsphere could be handled immediately without distortion. Internal water was removed by azeotropic distillation with carbon tetrachloride, and the thickener was removed by air drying and heating to $450^{\circ} \mathrm{C}$ in an oxygen atmosphere. The microspheres were sintered at $1350^{\circ} \mathrm{C}$ to $1400^{\circ} \mathrm{C}$ to obtain theoretical densities of $98 \%$.

The SNAM Company states that their gel-supported precipitation process provides the following advantages:

- Easy size control

- Low variation in spherical shape

- Amenability to continuous processing

- Reduction in effluent cleanup and recycle streams

- Process simplification.

\section{KEMA Internal Gelation Process}

In this process, gelation was accomplished by ammonia generation from inside the sol droplet. Ammonia was generated at a controlled rate by thermal decomposition of hexamethylene tetramine (hexa) and urea by mixing these feed additives to a plutonium solution and heating the resulting droplets to $90^{\circ} \mathrm{C}$ in a gelation column. A flow scheme for the KEMA (N.V. Tot Keuring van Eliktro Technische Materialen Arnhem) process is included in Figure E-5.

An important modification of the KEMA process includes the preparation of an acid-free, concentrated, non-polymeric, plutonium nitrate feed solution. A flow sheet for its preparation is shown in Figure E-6. This ideal, acid-free feed solution was developed by the Swiss Federal Institute for Reactor Research (EIR). Nitrates were removed by anion exchange using resin in the hydroxide form. The resulting solution was concentrated by vacuum distillation at $38^{\circ} \mathrm{C}$ and 40 torr.

A concensus has developed among many Sol-Gel scientists that the KEMA internal gelation process is the simplest and most reliable of the reported 


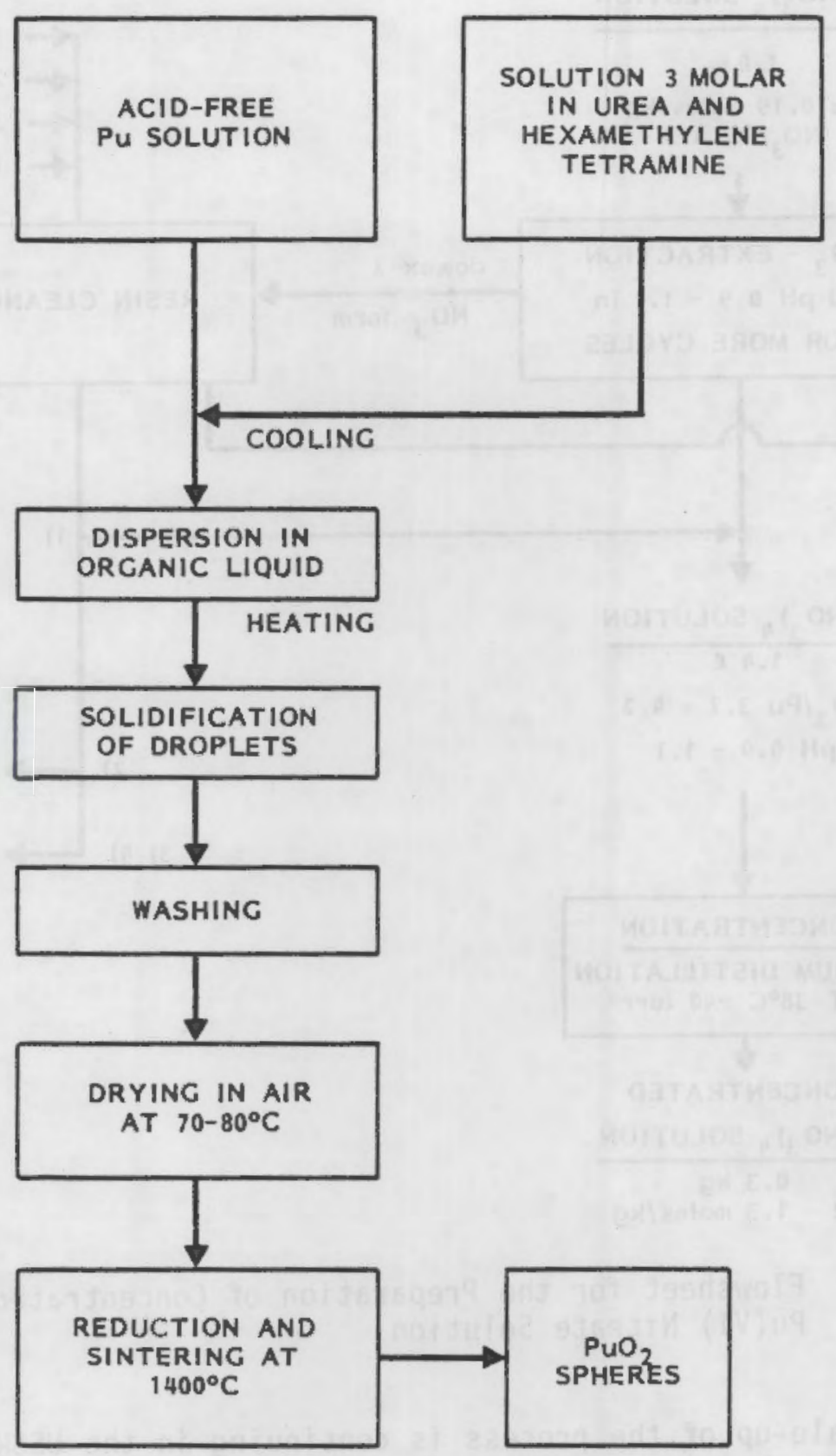

FIGURE E-5. Flow Scheme for the KEMA Internal Gelation Process 


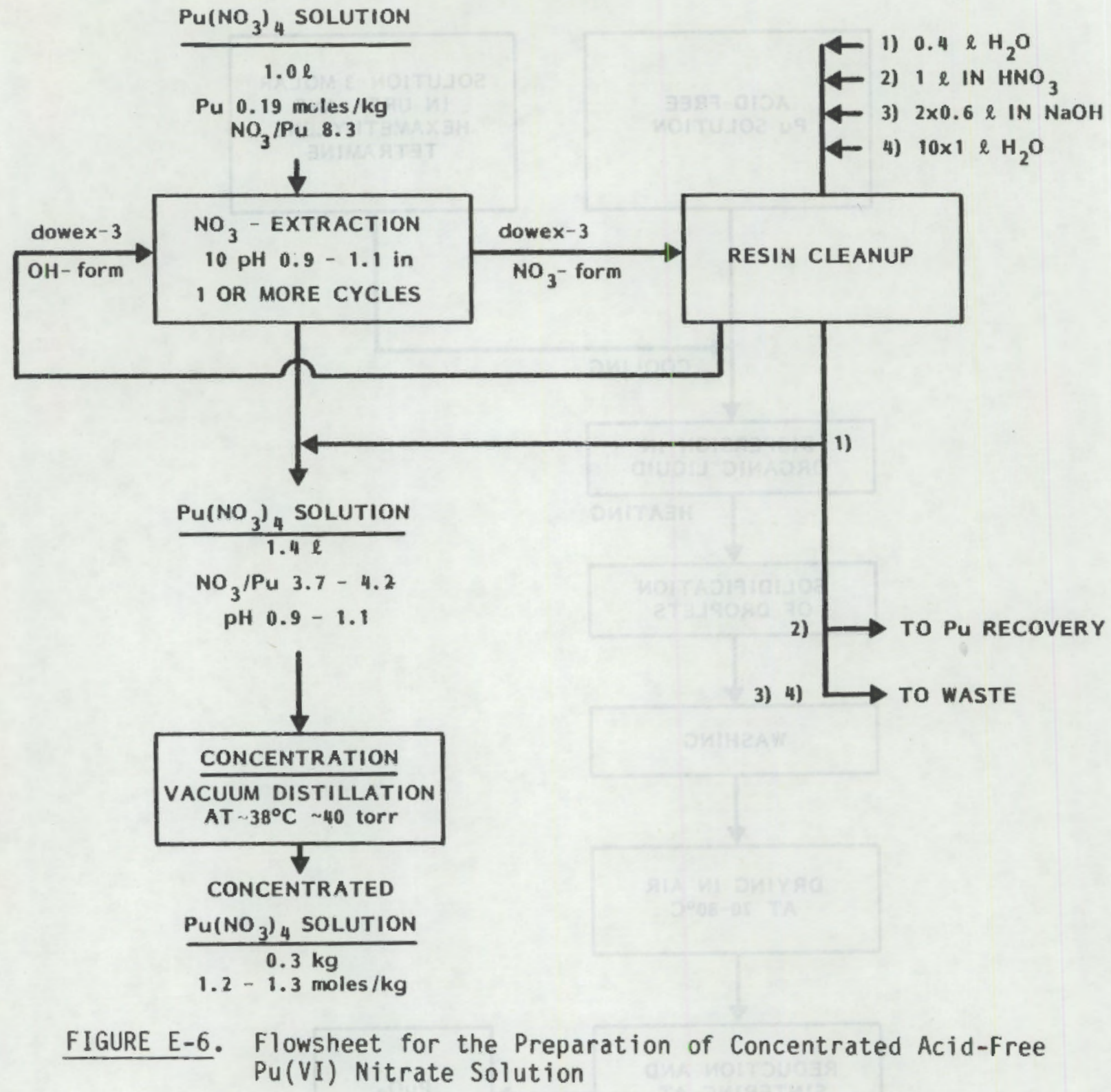

processes, and scale-up of the process is continuing in the USSR, The Federal Republic of Germany, and in Czechoslovakia.

Physical and Chemical Particle Characteristics

The sphere particles should be characterized for density, temperature stability, mechanical strength, porosity, surface area, solubility, homogeneity (for mixed oxides), and particle size. Qualitative descriptive phrases were found in the literature describing these spheres as large, dense, dust-free, insoluble, homogeneous, and uniformly-sized particles. Almost no quantitative data were discovered to allow one to compare these properties against $\mathrm{PuO}_{2}$ 
powder produced by conventional techniques. It is anticipated that microspheres formed by the Sol-Gel processes will excel as a relatively noncontaminating, nonrespirable $\mathrm{PuO}_{2}$ shipping form; however, it is the recommendation of this report that specific quantitative data be obtained experimentally to characterize the microspheres so that this concept can be confirmed.

Significant Process Variables

Significant process variables include the following:

- Plutonium feed concentration

- $\mathrm{NO}_{3} / \mathrm{Pu}$ molar ratio

- Precipitating reagent concentration

- Droplet size

- Gelation time

- Wash time and temperature

- Drying time and temperature

- Sintering time and temperature

- Sintering atmosphere.

Each of these variables will be discussed in turn.

The plutonium feed concentration is important since the stability of the feed solution, the primary particle size, and the microsphere size depend upon the plutonium feed concentration.

The nitrate-to-plutonium molar ratio is important in terms of stabilizing a colloid prior to forcing the sol into a three-dimensional network and subsequent gelation. It has been shown that each surface-oriented plutonium atom needs one nitrate ion to stabilize the colloid. The required ratio of nitrate to plutonium is equal to the percentage of surface-oriented plutonium atoms in the colloidal particle. Theoretically and experimentally, it has been verified that primary particles with dimensions approaching 11 Angstroms in diameter will surface orient $80 \%$ of their plutonium atoms, and the required $\mathrm{N}_{\overline{3}} / \mathrm{Pu} \mathrm{molar}$ ratio is also $80 \%$. Similarly, primary particles with dimensions approaching 100 Angstroms or 1 micron will surface orient approximately $10 \%$ of their plutonium atoms and will similarly require a $\mathrm{NO}_{\overline{3}} / \mathrm{Pu}$ molar ratio of $10 \%$ to achieve colloid stability. Control of the $\mathrm{NO} \overline{3} / \mathrm{Pu}$ parameter can thus be used to insure a stable colloid feed solution and also to influence the primary particle size.

The precipitating reagent concentration will affect the precipitation rate, which will in turn affect the crystalline size resulting from the precipitation. A fast crystallization rate will tend to create a greater number of primary particles, with a smaller mean diameter, than will a slow crystallization rate. Generally, the precipitating reagents are concentrated to produce small colloidal particles that can create a stable sol prior to gelling.

The droplet size ultimately determines the size of the resulting microsphere if all other factors are constant. Small droplets can be created by 
forcing the liquid through a tiny orifice and/or exposing the liquid to shear forces in a slip stream of gas. Large droplets can be created by forcing the liquid through a vibrating capillary tube which contains a relatively large orifice.

The gelation time is an important parameter. If agglomeration of the colloidal particles occurs too quickly, large crystallites are formed without the interstitial voids and three-dimensional stringering effect. If the gelation time is too long, the throughput of the process is adversely affected. Experimentally, gelation times of 10 to 15 minutes have proven satisfactory in the ORNL tapered gelation column.

After gelation, the microspheres must be washed free of excess nitrates and organic chemicals. Ammonium nitrate crystals will decompose upon subsequent drying steps, emitting relatively large quantities of gas, and will crack the microspheres if contained therein. The washing, therefore, must completely remove water-soluble compounds from the microspheres prior to drying. The washing time period and temperature required will vary according to the specific composition of the microspheres and the reagents used in the precipitation process. $\mathrm{PuO}_{2}$ microspheres are much more difficult to wash than are $\mathrm{UO}_{2}$ microspheres. The washing time period will have to be determined experimentally for each process and feed composition.

The drying time and temperature will be a function of the composition and size of the microspheres and will depend upon whether the microspheres are heated externally, with radiant heat, or internally, with microwave energy. The internal temperature rise must not lead to excessive steam pressures inside the microspheres, since this could lead to cracking of the spheres. The proper drying parameters must be determined experimentally for each precipitation and drying process.

The sintering time and temperature will determine such important properties of the microspheres as porosity, surface area, mechanical strength, chemical reactivity, and solubility, and will affect the final microsphere dimensions. Typical sintering conditions include heating to $1200^{\circ} \mathrm{C}$ within 4 hours and holding at $1200^{\circ} \mathrm{C}$ to $1400^{\circ} \mathrm{C}$ for an additional two hours. Such sintering conditions have yielded microspheres with actual densities equal to $98 \%$ of theoretical densities.

The sintering atmosphere will vary according to the microsphere composition. Mixed oxide fuel requires an argon-4\% hydrogen atmosphere to reduce $\mathrm{UO}_{3}$ to $\mathrm{UO}_{2}$, while $\mathrm{PuO}_{2}$ particles require an oxygen atmosphere to prevent reduction of $\mathrm{PuO}_{2}$ to $\mathrm{Pu}_{2} \mathrm{O}_{3}$.

Impact on Shipping Procedures and Equipment

If Sol-Gel microspheric particles of $\mathrm{PuO}_{2}$ are shipped in place of conventional powders, no adverse impact is foreseen on present shipping procedures and equipment. 
Sol-Gel Pu02 particles will not dissolve in normal aqueous solutions encountered in accident conditions; however, mixed oxide Sol-Gel fuels are very homogeneous and dissolve readily in nitric acid without requiring the addition of fluorides. This simplified dissolution during chemical processing will reduce corrosion of plant equipment and reduce or eliminate fluoride and aluminum from the radioactive waste streams coming from reprocessing plants.

Sol-Gel technology is still in the pilot-plant stage; and fuel fabrication costs are still expensive compared to other, conventional, powder technologies. The cost differential will undoubtedly be reduced as the technology matures and becomes a commercially important process. No specific cost-comparison data were available from the literature sources reviewed.

\section{Sol-Gel Particles in Accident Envelope Conditions}

An ideal conclusion to this report would be to consider each of the accident environment parameters listed in Table E-1, and to provide convincing data from the literature to prove whether Sol-Gel microspheres could survive each of these conditions, either inside or outside the inner shipping container. Regrettably, no specific data was found in the literature surveyed to allow such specific predictions. The general statements found as to the denseness and uniform particle sizes lead us to believe that the Sol-Gel particles would be a superior $\mathrm{PuO}_{2}$ shipping form. This statement is reasonable; the particles are noted for being dust free and non-air transportable or respirable because of the relatively large particle sizes available.

\section{Future Trends in Plutonium Technology}

Plutonium dioxide is used in two industries. The first use, historically, was as an intermediate material in the production of plutonium metal and the second as a fuel for power reactors. No discussion of $\mathrm{PuO}_{2}$ shipping forms would be complete without assessing the impact of such forms upon the two industries using $\mathrm{PuO}_{2}$.

No references were discovered which directly compare Sol-Gel $\mathrm{PuO}_{2}$ particles with conventionally produced $\mathrm{PuO}_{2}$ powders as an intermediate material in plutonium-metal production cycle. The main criteria for metal-grade $\mathrm{PuO}_{2}$ powder are that the plutonium be free from neutron-absorbing nuclei (cominonly called "poisons"); that the precipitation process be efficient, with relatively small plutonium losses; and that the resulting powder be chemically reactive toward fluorination, which is the next chemical step towards metal production. Assuming an adequately pure plutonium feed solution, there is no data in the literature reviewed for this study to indicate that the Sol-Gel process will not meet these criteria.

A detailed analysis of various mixed-oxide fuels production techniques was performed by LeBlanc and Vanden Bemden (1978), and it is referred to extensively in this report. 
The main $\mathrm{PuO}_{2}$ criteria to be considered during chemical reprocessing are described below.

\section{Fuel Solubility}

The industrial use of plutonium is dependent upon reprocessing spent reactor fuels to recover plutonium. Pure plutonium oxide is practically insoluble in nitric acid; this is an important disadvantage in reprocessing. Indeed, spent fuel dissolution is carried out in strong nitric acid. If pure plutonium oxide were present in the spent fuel, it could accumulate with other insoluble fission product residues in the dissolver vessel. Recovery of residual plutonium oxide would necessitate the addition of hydrofluoric acid. The acid increases the corrosion rate of the dissolver vessel and piping and requires the use of special alloys to combat the corrosion problem. The presence of fluoride ions further complicates the disposal of nuclear waste products in certain waste disposal materials like glass.

The solubility in strong nitric acid of plutonium oxide can be considerably improved when it is mixed with uranium oxide. The mixed oxides are readily soluble in strong nitric acid up to a plutonium oxide concentration of 30-35\% (assuming homogeneous solid solution fuel particles).

Sol-Gel precipitation of mixed plutonia-urania sols is one technique for producing an ideal homogeneous solid solution fuel particle.

\section{Automation and Remote Controllability}

The conversion of plutonium nitrate to plutonium oxide powder should be performed with as few process steps, and as automatically and remotely, as possible. Such simplification would promote overall safety and economy for the first plutonium cycle and becomes increasingly important if reprocessing perpetrates plutonium in the fuel cycle. The percentages of Plutonium 238, 240, 241, and 242 and Anericium-241 isotopes increase with fuel exposure to an integrated neutron flux. A fuel containing $2 \%$ Pu-238 will produce thermal energy by aray absorption equivalent to 20 watts per $g$ of powder. This thermal energy production causes many operating difficulties whenever pure $\mathrm{PuO}_{2}$ powder is handled in large quantities. A reduction in the number of "hands on" powder-handling steps is therefore important.

Neutrons are emitted from spontaneous fission as well as from $(\alpha, N)$ reactions by $\mathrm{Pu}-238,239$, and 240 . The only practical way to protect workers from neutron exposure from a given fuel mass is to provide thermal neutron shielding. Such a neutron absorber (shield) must have a thickness of several centimeters; this suggests that the largest simplification possible be incorporated into the process.

Gamma $(\gamma)$ activity from Americium-241 is dependent upon the Americium-241 concentration and the surface-to-volume ratio of the fuel particles. The result of the latter factor is that activity becomes very important when $\mathrm{PuO}_{2}$ powder is spread in small quantities in the working area. The primary dose to 
the hands and arms of nuclear workers involved in fuel production comes mainly from $\mathrm{PuO}_{2}$ dust deposits. Gamma exposure can be sharply reduced by using a dust-free fabrication process which is extensively automated and mechanized. The oxide particles involved must be larger than common dust dimensions; also, they must be sufficiently strong to resist breaking or attrition, which could produce oxide dust.

After considering these and other factors, Leblanc and Vanden Bemden (1978) compared the main processes envisioned today for mixed oxide production:

- Coprecipitation

- Codenitration

- Pressurized aqueous reduction

- Sol-Gel.

They concluded that Sol-Gel techniques are best suited for producing mixed oxide fuels.

\section{CONCLUSIONS}

For several reasons, the Sol-Gel process is recommended as a superior process for the nuclear chemical reprocessing industry:

- The process is mechanically simple, and remote control is easy.

- The number of handling steps is reduced.

- Dusting, contamination spreads, and airborne contamination are reduced.

- Worker exposure is reduced.

- A nuclear fuel particle with outstanding strength and homogeneity characteristics is created.

- Mixed oxide Sol-Gel particles are easily redissolved in strong nitric acid for continued reprocessing.

Sol-Gel particles are recommended as a nuclear fuel because they excel in every specification required for conventional powders. Furthermore, they can be compacted into fuel assemblies directly, without being pelletized as are other powders.

Sol-Gel particles are recommended as a suitable plutonium oxide shipping form. In the case of an accidental breaching of the inner shipping container, Sol-Gel particles would not easily or generaliy become airborne, and they could be expected to reduce surface contamination problems by several orders of magnitude. 
The only negative factor discovered in this survey for Sol-Gel technology is that the direct cost for producing Sol-Gel particles is higher than for conventional powder technologies. The higher direct cost can be attributed in part to the lack of maturity and scale of the present Sol-Gel processes. The impact of the direct costs is lessened considerably when one considers all of the indirect cost savings realized by Sol-Gel technology. With consideration of all factors associated with the two technologies, it is possible that the Sol-Gel technology is more cost effective than the conventional powder technologies.

\section{REFERENCES}

Barr, M. J., M. W., Urie, J. L., Daniel, and S. J., Mahan. 1970. Characterization of Some $\mathrm{UO}_{2}$ and $\mathrm{PuO}_{2}$ Powders, BNWL-1441. Pacific Northwest Laboratory, Richland, Washington.

Brambilla, G., P. Gerontopulos, A. G. Facchini, and D. Neri. 1970. "The SNAM Process for the Production of Ceramic Nuclear Fuel Microspheres." Symposium on Sol-Gel Processes and Reactor Fuel Cycles, Gatlinburg, Tennessee. Conf-700502, U.S. Department of Commerce, Springfield, Virginia.

Carlson, R. V. 1970. "Preparation of Plutonia-Urania Sol-Gel Microspheres for EBR-II Testing." Symposium on Sol-Gel Processes and Reactor Fuel Cycles, Gatlinburg, Tennessee. Conf-700502, U.S. Department of Commerce, Springfield, Virginia.

Forthmann, R., and G. Blass. 1977. "Fabrication of Uranium-Plutonium Oxide Microspheres by the Hydrolysis Process." Journal of Nuclear Materials, $64: 275-280$.

Hartman, W. F. 1975. A Study of the Physical Parameters of Transportation Accidents. Sandia National Laboratories, Albuquerque, New Mexico.

Hermans, M. E. A. 1973. "Sol-Ge1 Process - A Curiosity or a Technique." Powder Metallurgy International, 5(3).

Leblanc, J. M. and E. Vanden Bemden. 1978. "Chemical Aspects of Mixed 0xide Fuel Production." Radiochim. Acta (25) 149-152.

Lloyd, M. H., and R. G. Haire. 1968. "A Sol-Gel Process for Preparing Dense Forms of $\mathrm{PuO}_{2}$." Nuclear Applications 5.

Lloyd, M. H., and R. G. Haire. 1978. "Chemistry of Plutonium in Sol-Gel Processes." Radiochim. Acta (25) 139-148.

Sperry, W. E. 1979. Sol-Gel Process for Plutonium Nitrate to Oxide Conversion, RFP-2605, Rockwell International, Rocky Flats PTant, Golden, Colorado. 


\section{APPENDIX $F$ \\ EVALUATION OF INORGANIC ION EXCHANGERS AS AN \\ ALTERNATE SHIPPING FORM FOR PLUTONIUM}

B. W. Mercer 


\section{INTRODUCTION}

A review was conducted of available literature to evaluate the potential for using inorganic ion exchangers as a medium for shipping plutonium. Plutonium is presently shipped as fine plutonium oxide powder. This powder can be more easily dispersed than coarse granular material, such as inorganic ion exchangers, if the shipping container is breached in an accident. Breaching of the shipping container could occur in accidents involving a fire that destroyed the sealing gasket of the shipping container. The high temperatures encountered in these accident scenarios also require that the plutonium shipping medium be resistant to decomposition at elevated temperatures, a condition that cannot be met by organic ion exchangers. A further requirement of a shipping medium is resistance to physical attrition by harsh accidental impacts or by the ordinary vibration of transport. Physical attrition resulting in a fine powder would be a major concern under accident conditions, although in the case of an ion exchange medium, plugging of the ion exchange bed could be a severe process limitation. The plutonium contained in the shipping medium must also exhibit a very low leach rate with water to minimize dispersal in accidents involving water contact.

The shipping container visualized for transporting ion exchange media containing plutonium would consist of a vessel equipped with an inlet and outlet for admitting or removing plutonium-laden streams, eluant solutions, water rinses and gas streams for drying the media prior to shipping. There are four basic steps for loading the shipping container: 1) pumping the plutonium product solution through the ion exchange bed until loading is complete, 2) rinsing the bed with deionized water to remove residual plutonium salts, 3) draining the ion exchange bed and drying it with a hot, dry gas stream, and 4) sealing the inlet and outlet and placing the vessel in the protective container for shipping. Unloading the plutonium at the receiving site would involve five steps: 1) rehydrating the ion exchange media with moist air or steam, 2) backwashing the bed with water to remove trapped air or gas, 3) pumping a suitable eluant through the bed to unload the plutonium, 4) rinsing the bed with water to remove soluble plutonium salts, and 5 ) drying the bed with hot dry gas and sealing it for return shipment.

\section{DISCUSSION}

\section{Zeolite Ion Exchangers}

Description

Zeolites are crystalline aluminosilicate materials which contain exchangeable cations. They are identified by their chemical compositions and 
crystalline structures as manifested in X-ray diffraction patterns. Forty known zeolite minerals are recognized, and the total reported synthetic types now number over 150 (Breck 1979). Only a small number of mineral and synthetic zeolites have reached the commercialization stage, however. The principal zeolite types now used in commercial application are listed in Table F-1. Extensive use of zeolites as molecular sieve absorbents and catalysts has developed over the past three decades, but ion exchange applications have been very limited until recent years.

Large crystals of zeolites (e.g., greater than 20 mesh) are neither found in abundant quantities in nature nor are they produced synthetically for commercial use. The diffusion rate of ions or molecules is too slow inside the zeolite crystal for practical application of large discrete crystals of this material to industrial separations. Commercially useful forms of zeolites in nature are usually found in deposits of altered volcanic tuffs, where tiny zeolite crystals are imbedded in a porous silica matrix. The large surface area per unit volume of those minute crystals and the porosity of the matrix combine to give satisfactory diffusion rates for industrial applications. Commercial synthetic zeolites are also produced as tiny crystals, and these are generally cemented together in a porous clay matrix. The percentage of clay binder in the commercial synthetic zeolites is typically $20 \%$. Crushing and sieving are generally performed on both the mineral zeolites and the extruded synthetic products to obtain the desired particle size range for ion exchange grade zeolite (e.g., $20 \times 50$ mesh or 0.6 to $1.5 \mathrm{~mm}$ ).

TABLE F-1. Zeolite Types in Commercial Applications (Breck 1979)

Zeolite Minerals

Mordenite

Chabazite

Erionite

Clinoptilolite

Synthetic Zeolites

$\begin{array}{ll}\text { Type } & \\ \text { A } & \text { Zeolon (Mordenite) } \\ X & \text { ZSM-5 } \\ \text { L } & \text { F } \\ \text { Omega } & \text { W }\end{array}$




\section{Properties}

The ratio of silicon to aluminum (Si/Al) influences both the ion exchange capacity and the stability of zeolites. The general trend in the transition of properties with increasing Si/Al ratios is summarized in Table F-2.

TABLE F-2. Transition in Zeolite Properties (Flanigan 1980)

$$
\text { Si/Al Ratios from } 1 \text { to } \infty
$$

$\begin{array}{lll}\frac{\text { Property Trend }}{\text { 1. Decreasing ion exchange capacity }} & & \text { Range } \\ \text { 2. Increasing thermal stability } & & \sim 700^{\circ} \mathrm{C} \text { to } 1300^{\circ} \mathrm{C} \\ \text { 3. Increasing acid stability } & & \text { unstable to completely stable }\end{array}$

The high ion exchange capacity of the low Si/Al zeolites is desirable to maximize the plutonium loading of the shipping media. However, low-silica zeolites are at best fragile in acid; therefore, a feed preparation step to eliminate most of the acid in plutonium product solutions from chemical separation plants would be required before the plutonium is loaded on the zeolite. Possible methods of deacidifying plutonium product solutions are discussed in the section entitled "Plutonium Processing."

The thermal stability listed in Table F-2 concerns the crystalline structure of the zeolites. Destruction of the zeolite crystalline structure does not necessarily mean the release of exchangeable cations. Indeed, these cations may become fixed or less leachable by water in the new aluminosilicate materials. At temperatures above $1300^{\circ} \mathrm{C}$, zeolites will melt and form glassy substances. Vitrification of zeolites loaded with radioactive fission productions is currently under study at Pacific Northwest Laboratory as a means of fixing the radioactivity for ultimate storage or disposal.

Various properties of some of the commercial zeolites pertinent to the application of this material as plutonium shipping media are given in Table F-3. Ion exchange capacities of hydrated forms vary from a low of about $2.0 \mathrm{meq} / \mathrm{g}$ for $\mathrm{AW}-500$ and Zeolon 900 to $4.4 \mathrm{meq} / \mathrm{g}$ for Type $4 \mathrm{~A}$. Zeolites are available in a variety of particle sizes. The $20 \times 50$-mesh size is generally preferred for ion exchange applications, and larger sizes for molecular sieve applications. All of the zeolites in Table $F-3$ are available in the $20 x$ 50 -mesh size, consisting of irregularly shaped particles. These particles are, however, subject to greater physical attrition if allowed to grate against one another (e.g., in a fluidized bed) because the sharp edges of the particles are easily broken off. The pellets, extrudates, and large spheres are more resistant to physical degradation but have slower exchange rates compared to the $20 \times 50$-mesh sizes. 
TABLE F-3. Properties of Selected Commercial Zeolites (Breck 1974)

\begin{tabular}{|c|c|c|c|c|c|c|c|c|c|c|}
\hline Zeolite & Structure Type & Si/Al & $\begin{array}{l}\text { Total Ion } \\
\text { Capactty, } \\
\text { Anhydrous }\end{array}$ & $\begin{array}{l}\text { Exchange } \\
\text { meq/g } \\
\text { Hydrated }\end{array}$ & Cat1ons. & $\begin{array}{c}\text { Particle } \\
\text { S1ze }\end{array}$ & $\begin{array}{l}\text { Bulk } \\
\text { Density } \\
\text { lb/ft }{ }^{3}\end{array}$ & Strength & $\begin{array}{l}\text { Water } \\
\text { Content }\end{array}$ & $\begin{array}{l}\text { Hater } \\
\text { Capacity }\end{array}$ \\
\hline Type $4 A$ & $A$ & 1 & 5.6 & 4.4 & $\mathrm{Na}$ & $\begin{array}{l}\text { 8-12-mesh } \\
\text { spheres }\end{array}$ & 44 & 7 Ibs & 1.5 & 23 \\
\hline Type $13 x$ & $x$ & 1.25 & 5.1 & 3.8 & $\mathrm{Na}$ & $\begin{array}{l}\text { 8-12-mesh } \\
\text { spheres }\end{array}$ & 43 & 6 Ins & 1.5 & 29.5 \\
\hline $\begin{array}{l}\text { SK-40 } \\
\text { (Linde) }\end{array}$ & $Y$ & 2 & 4.0 & 3.0 & $\mathrm{Na}$ & $\begin{array}{l}1 / 8^{\prime \prime}-1 / 4^{\prime \prime} \\
\text { extrudate }\end{array}$ & 38 & 30 lbs & $\ldots$ & $\ldots$ \\
\hline $\begin{array}{l}\text { AW } 500 \\
\text { (Linde) }\end{array}$ & Chabazite & 2 & $2.0-2.5(a)$ & $1.8-2.2$ & $\mathrm{Na}, \mathrm{Ca}$ & $\begin{array}{l}1 / 8,1 / 16^{\prime \prime} \\
\text { pellet }\end{array}$ & 45 & $\cdots$ & & 11 \\
\hline $\begin{array}{l}\text { Zeolon } \\
900 \\
\text { (Norton) }\end{array}$ & Mordenite & 2.6 & $\cdots$ & $\sim 2$ & $\mathrm{Na}$ & $\begin{array}{l}1 / 8^{\prime \prime} \\
\text { extrudate }\end{array}$ & 40 & $-\infty$ & -- & 10 \\
\hline $\begin{array}{l}1010-A(b) \\
(A n a c o n d a)\end{array}$ & Clinoptilolite & 4.5 & $\cdots$ & $2 . ?$ & $\begin{array}{l}\mathrm{Na}, \mathrm{K}, \\
\mathrm{Ca}, \mathrm{Mg} \\
\mathrm{Ba}\end{array}$ & $\begin{array}{l}20 \times 50 \\
\text { mesh }\end{array}$ & $42-57$ & 2500 psi & $\cdots$ & $\sim 12$ \\
\hline
\end{tabular}

(a) Ion exchange capacity of $20 \times 50$ mesh form marketed as Linde Ionsivo IE-95 Ion Exchanger by Union Carbtde Corporation, Danhury, Connecticit.

(b) Anaconda Natural Zeolites. Technical Data, Bulletín No. 11. 
Crush strength is an important factor in controlling the formation of small zeolite particles upon severe impact of a container containing the zeolite. Equating the crush strength values given in Table F-3 to formation of fine particulate matter is not possible at this time. The zeolites will fracture under pressure, but this does not mean that complete conversion to a fine powder will occur. Crushing of the zeolites will produce a range of particle sizes, including some fine powder. Impact testing of the zeolites in a shipping container is believed necessary to determine accurately the amount of finely powdered zeolite formed under impact conditions.

\section{Moisture Removal}

Drying of the zeolites would be required after loading with plutonium, in order to prevent excessive pressure buildup in the sealed containers under accident conditions involving fire and high temperatures. Zeolites are generally excellent dessicants. They possess a great affinity for water, so drying them to a nearly anhydrous form is a difficult task. A combination of high temperature and very dry purge air is required. A process of drying isotopeloaded zeolites to a moisture content of $<0.5 \mathrm{wt} \%$ was evaluated at Hanford in conjunction with a proposed ultimate storage/disposal concept for high-level nuclear wastes (Mercer and Schmidt 1966; DeMier 1963). The zeolites were first purged with room air at a superficial velocity(a) of $1 \mathrm{ft} / \mathrm{sec}$ for 10-20 minutes to remove loose or interstitial water. The remaining water was removed by forcing hot air $\left(800^{\circ} \mathrm{F}\right.$ and a dew point of $\left.-100^{\circ} \mathrm{F}\right)$ through the zeolite bed. With this air flowing at a superficial velocity of $1 \mathrm{ft} / \mathrm{sec}$, the zeolite was dehydrated at a rate of 0.6 lineal $\mathrm{ft} / \mathrm{hr}$. The temperature and pressure drop history for a cubic foot hed of $1 / 16-i n .13 x$ pellets is illustrated in Figure F-1. Analysis of zeolite samples subjected to the above drying procedure indicated $<0.4 \mathrm{wt} \%$ moisture when the ratio of outlet-to-inlet air temperature reached a constant.

Removal of moisture from the zeolites is important to prevent excessive pressure buildup from steam formation if the sealed zeolite containers are subjected to high temperatures. It was estimated in the Hanford studies that drying of the zeolites to $<0.5 \%$ moisture would prevent pressures in excess of $500 \mathrm{psig}$ at a temperature of $1300^{\circ} \mathrm{F}\left(704^{\circ} \mathrm{C}\right)$. Pressure buildup can also result from radiolysis of water; however, other Hanford studies indicate that this would not be a severe problem with zeolite loaded with ${ }^{90} \mathrm{Sr}$. A container filled with Type A zeolite loaded with $90 \mathrm{Sr}$ was sealed and subjected to $101 \mathrm{l}_{\mathrm{R}}(\mathrm{b})$. The maximum pressure increase from radiolysis was $35 \mathrm{psig}$ at a centerline temperature of $500^{\circ} \mathrm{F}\left(260^{\circ} \mathrm{C}\right)$. At this pressure, the rate of the

(a) Superficial velocities are based on the cross section of the empty container and gas volumes measured at 1 atmosphere pressure at $32^{\circ} \mathrm{F}$.

(b) Roentgens. 


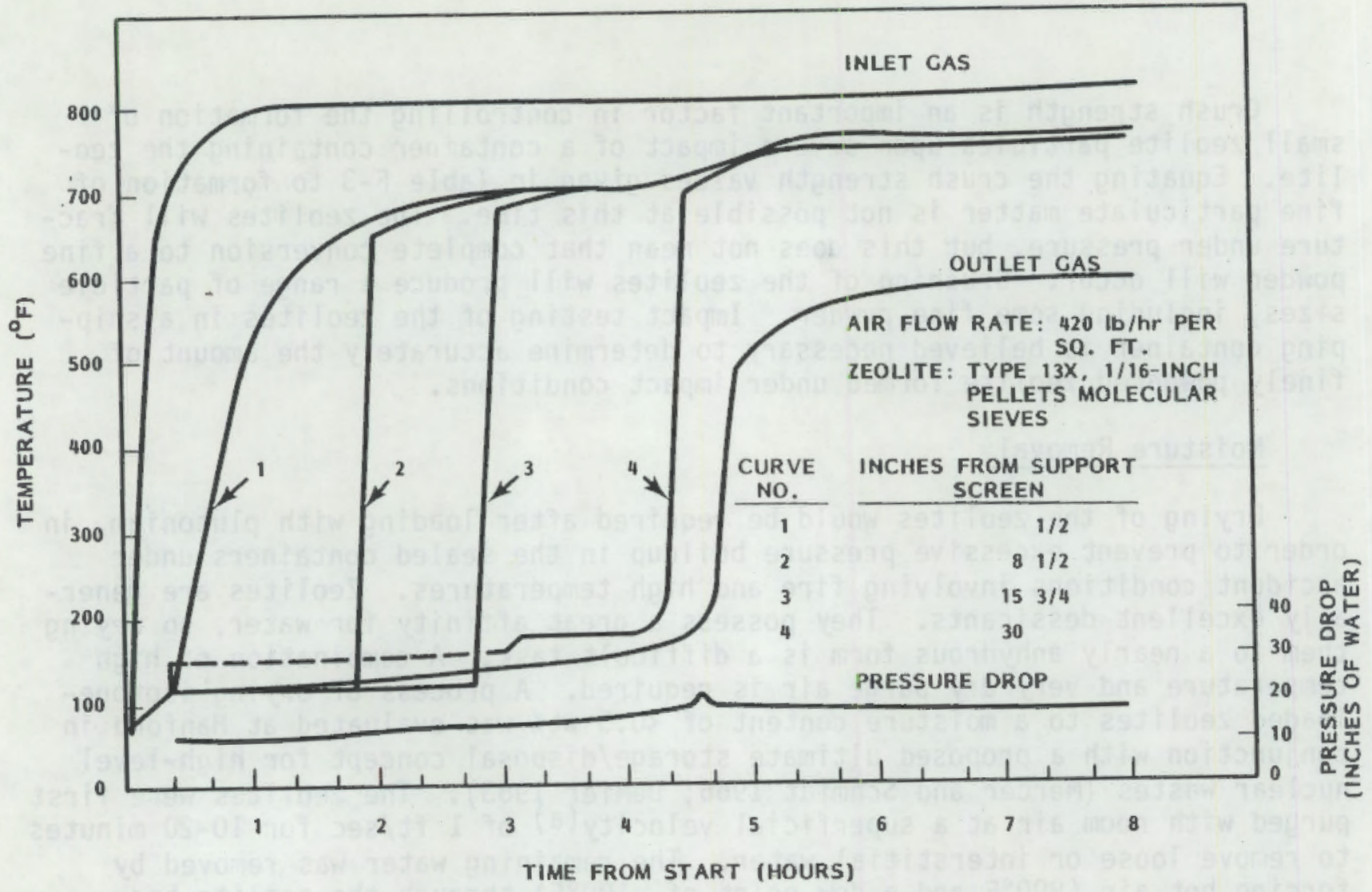

FIGURE F-1. Temperature and Pressure Drop History

recombination reaction appears to be in equilibrium with the rate of the formation reactions; therefore, no additional pressure increase is experienced:

$$
2 \mathrm{H}_{2} \mathrm{O} \rightleftharpoons 2 \mathrm{H}_{2}+\mathrm{O}_{2}
$$

or

$$
2 \mathrm{H}_{2} \mathrm{O} \rightleftharpoons \mathrm{H}_{2}+\mathrm{H}_{2} \mathrm{O}_{2}
$$

It is not known whether hydrogen and oxygen would recombine at lower temperatures and pressures in the presence of alpha radiation. A possible explosion hazard could exist if recombination did not occur.

Dust loadings were determined in the Hanford study (DeMeir 1963) to evaluate off-gas cleanup system requirements. Synthetic zeolites Type $4 A$ and $13 x$, also the natural zeolite clinoptilolite, were used in the dust loading study, the results of which are shown in Table F-4. It was concluded that no extensive gas cleanup facilities would be required for the materials listed in the table. Another run made with zeolite AW 400 is not summarized in Table F-4 because dust loadings were so great that the results were meaningless. It appeared that the AW-400 required more extensive washing than the other zeolites. 
TABLE F-4. Dust Loading and Particle Size Distribution

$\frac{\begin{array}{c}4 A \\ 14-30 \text { Mesh }\end{array} \times 10^{-5}}{1 \times 14-30 \text { Mesh }} \begin{gathered}\begin{array}{c}\text { C1 inoptilolite } \\ 13 \times\end{array} \\ 6 \times 10^{-4}\end{gathered}$

Dust Loading (grains $/ \mathrm{ft}^{3}$ ) at 20 SCFM

Particle Size Distribution

(percent below stated size)

Microns

\section{2}

6

8

10

25

50

80

100
Percent Below Stated Size

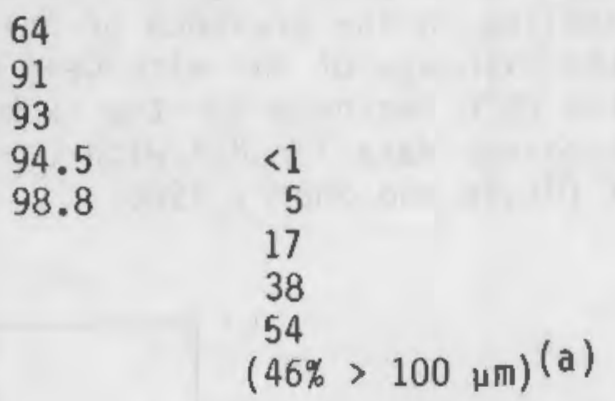

(a) The larger particles appeared to be agglomerates of about 25- $\mu$ m material.

\section{Ion Exchange Behavior}

Unique Characteristics of Zeolite. The predominant uses of zeolite for ion exchange have been concerned with the removal of cesium and strontium from radioactive wastewaters, ammonium from municipal wastewaters and hardness ions (principally calcium added with detergent in powder form) from laundry waters. No information concerning the ion exchange behavior of plutonium with zeolites is available; however, comparisons can be made with similar ions such as the lanthanides and other actinides.

There are two major differences between zeolites and commercial organic ion exchangers that are reflected in their ion exchange behavior: 1) because of structural differences, cation selectivities in zeolites do not follow rules typical for the organic exchangers, and 2) because of their relatively rigid structural frameworks, most zeolites do not undergo shrinking and swelling with changes in cation composition (Breck 1979). Unique features associated with zeolite structures result in unusual types of cation selectivity and sieving. Zeolites can be visualized as being constructed of cages where ion exchange sites are located and channels through which the ions must move to or from the cages. Size restrictions in both the cages and channels may limit the sizes of ions that can be exchanged. Furthermore, several different sizes of cages may exist, some of which will permit entry of only small ions, and others which will permit entry of both large and small ions. The charge distribution inside 
the cages is also important in selectivity relationships among ions. Trivalent and tetravalent ions are frequently not acceptable because they cannot fulfill charge distribution requirements inside the zeolite cages.

\section{Pu(III) Exchange}

Ion exchange processes have been developed and successfully employed for separation and purification of plutonium as the +3 ion using organic cation exchange resins (Bruce 1958, Prevot and Regnaut 1958). No data are available on $\mathrm{Pu}$ (III) exchange on zeolites; however, analogies can be made with other trivalent ions--especially trivalent lanthanides, which closely resemble trivalent actinides. High $\mathrm{Ce}^{3}{ }^{3}$ and $\mathrm{Y}+{ }^{3}$ selectivities were reported for Type $13 \mathrm{X}$ zeolite in the presence of $\mathrm{Na}+$ (Ames 1964). The $25^{\circ} \mathrm{C}$ and $70^{\circ} \mathrm{C}$ isotherms for the exchange of $\mathrm{Na}+$ with $\mathrm{Ce}^{3}$ on Type $13 \mathrm{X}$ are shown in Figures $\mathrm{F}-2$ and $\mathrm{F}-3$. The $25^{\circ} \mathrm{C}$ isotherm for the exchange of $\mathrm{Na}+$ with $\mathrm{Y}+3$ is given in Figure $\mathrm{F}-4$. Exchange data for Nat with $\mathrm{La}^{3}{ }^{3}$ are presented in Figure F-5 for zeolites $X$ and $Y$ (01son and Sherry 1968).

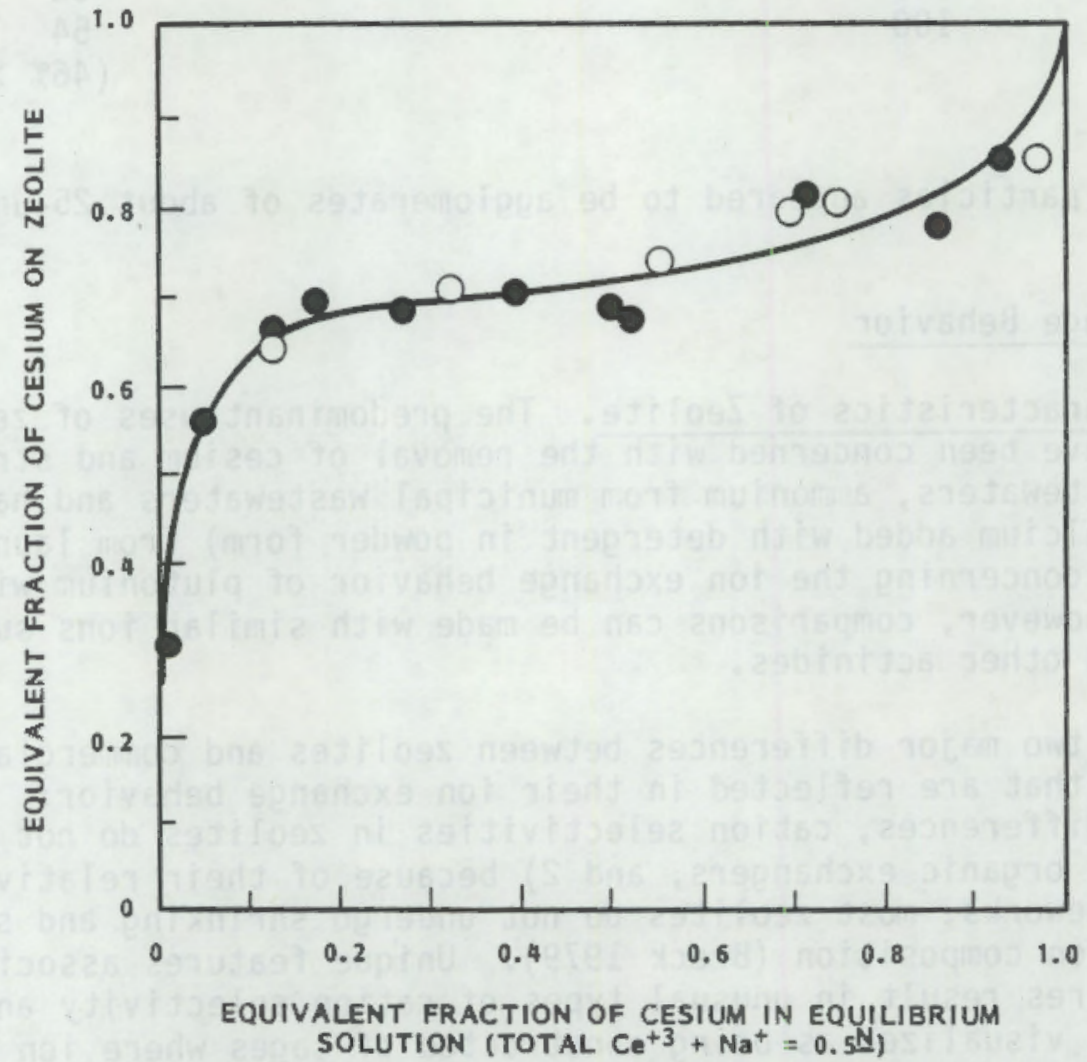

FIGURE F-2. The $23^{\circ} \mathrm{C}$ Isotherm for the Reaction $3 \mathrm{Na}_{z}+\mathrm{Ce}_{\mathrm{s}} \rightleftharpoons \mathrm{Ce}_{2}+$ $3 \mathrm{Na}_{\mathrm{s}}$ with Type $\times$ Zeolite 


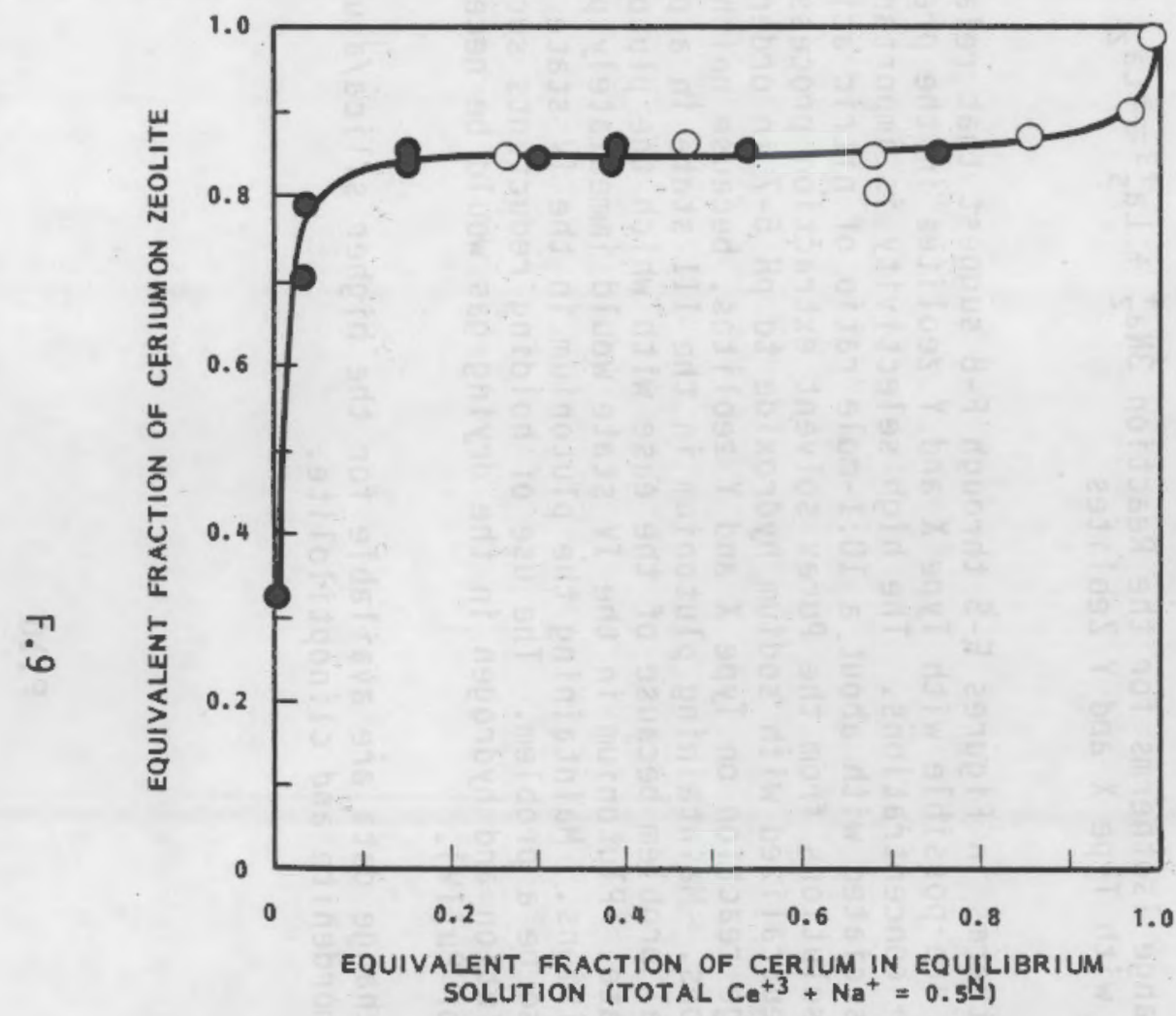

FIGURE F-3. The $70^{\circ} \mathrm{C}$ Isotherm for the Reaction $3 \mathrm{Na}_{z}+\mathrm{Ce}_{s} \rightleftharpoons \mathrm{Ce}_{z}+3 \mathrm{Na}$ with Type $x$ Zeolite

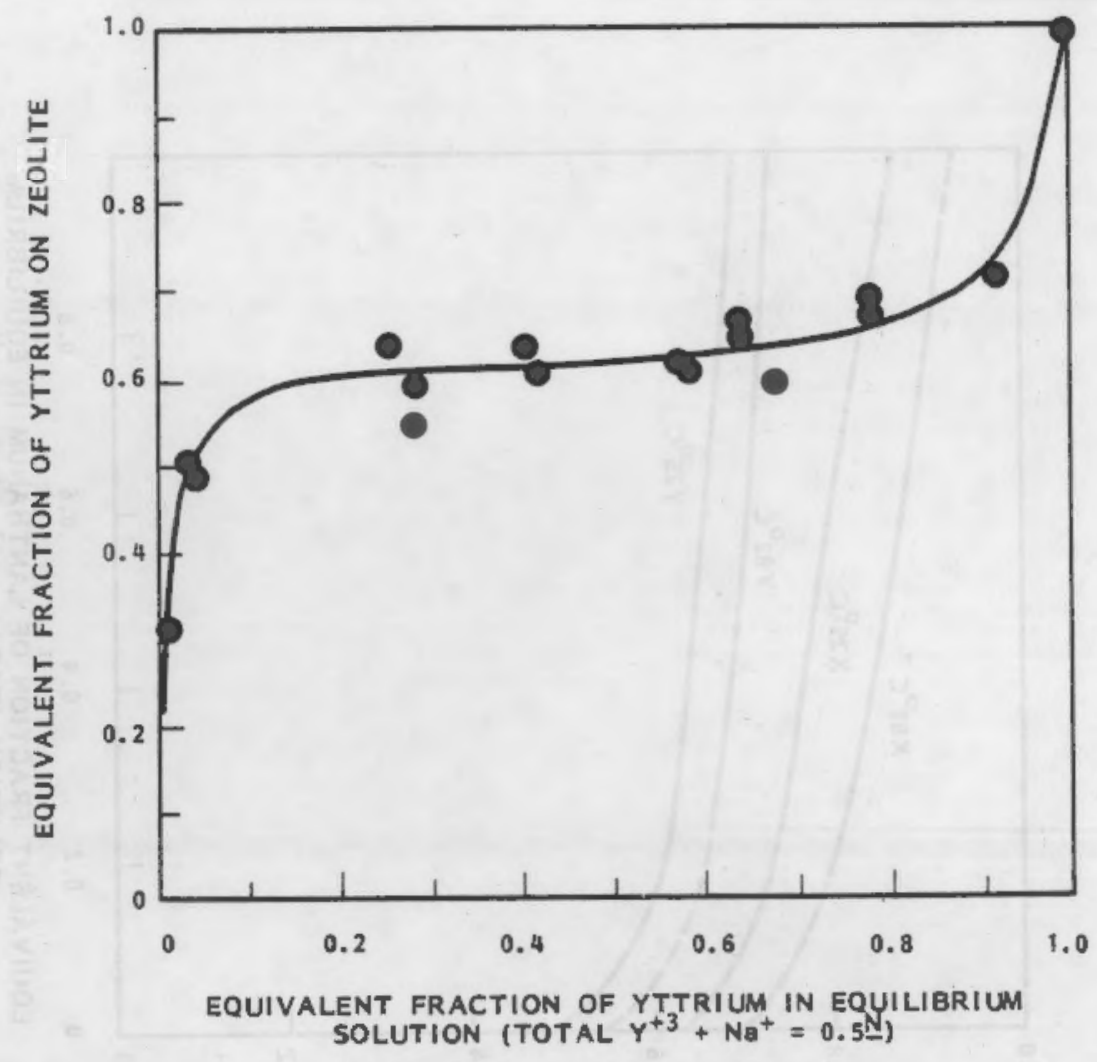

FIGURE F-4. The $25^{\circ} \mathrm{C}$ Isotherm for the Reaction $3 \mathrm{Na}_{2}+\mathrm{Y}_{\mathrm{s}} \underset{\mathrm{F}}{\rightleftharpoons} \mathrm{Y}_{2}+3 \mathrm{Na}_{\mathrm{s}}$ with Type $X$ Zeolite 


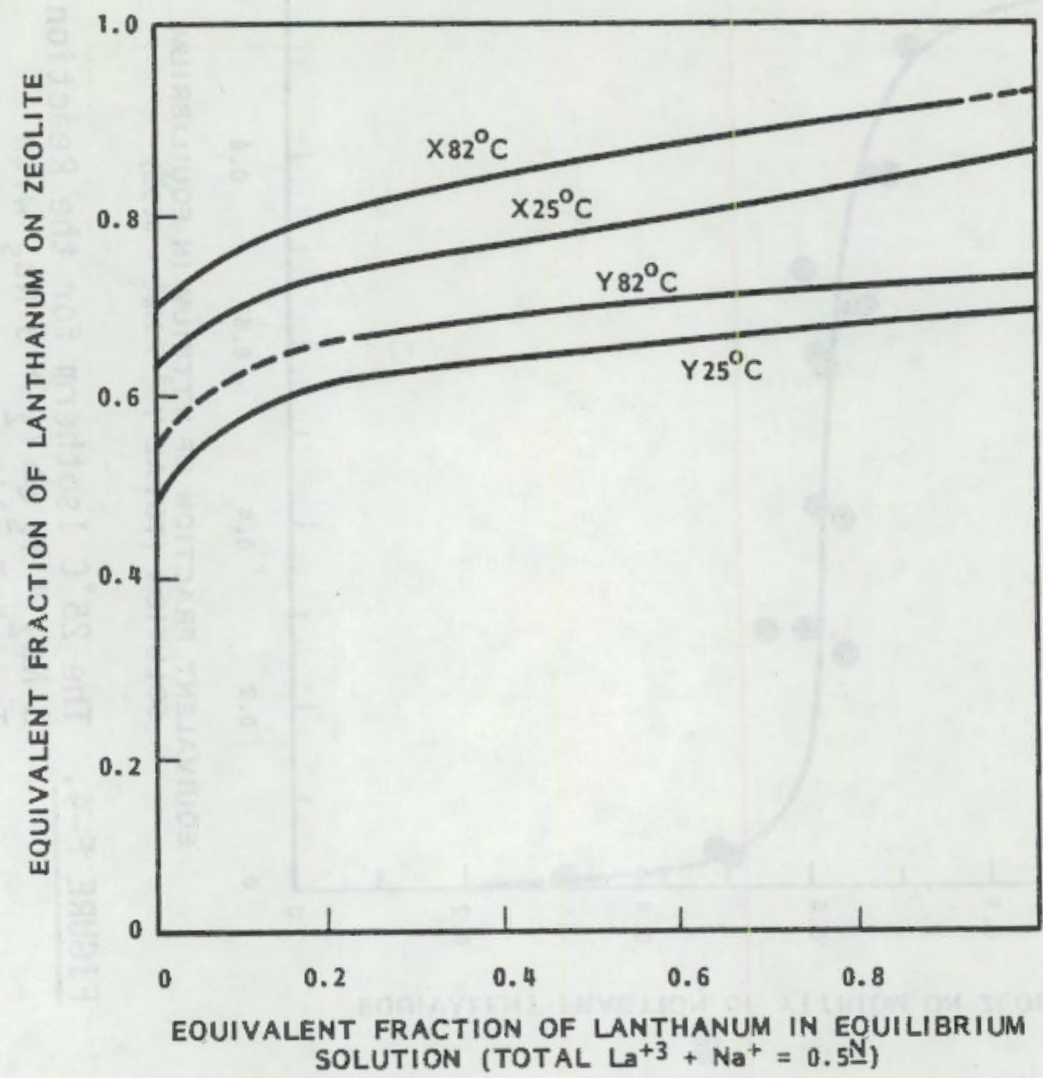

FIGURE F-5. Exchange Isotherms for the Reaction $3 \mathrm{Na}_{z}^{+}+\mathrm{La}_{\mathrm{s}}^{+3} \rightleftharpoons \mathrm{La}_{\mathrm{Z}}+$ $3 \mathrm{Na}_{\mathrm{S}}$ with Type $X$ and $Y$ Zeolites

The exchange isotherms in Figures F-5 through F-8 suggest that relatively high Pu(III) loadings are possible with Type $X$ and $Y$ zeolites in the presence of large competing Na+ concentrations. The high selectivity is important, since plutonium is associated with about a 10:1-mole ratio of nitric acid to plutonium in product solutions from the Purex solvent extraction process. The nitric acid must be neutralized with sodium hydroxide to $\mathrm{pH} \mathrm{5-7}$ in order to accomplish the exchange reaction on Type $X$ and $Y$ zeolites, because neither is stable in acid solutions. Maintaining plutonium in the III state in a pH 5-7 solution is a potential problem because of the ease with which the plutonium is oxidized to the IV state. Plutonium in the IV state would immediately precipitate under these conditions. Maintaining the plutonium in the IV state during a drying stage may also be a problem. The use of holding reductants such as hydroxylame in the solution and hydrogen in the drying gas would be necessary to prevent formation of $\mathrm{Pu}$ (IV).

No lanthanide exchange data are available for the higher silica/alumina zeolites, chabazite, mordenite and clinoptilolite. 


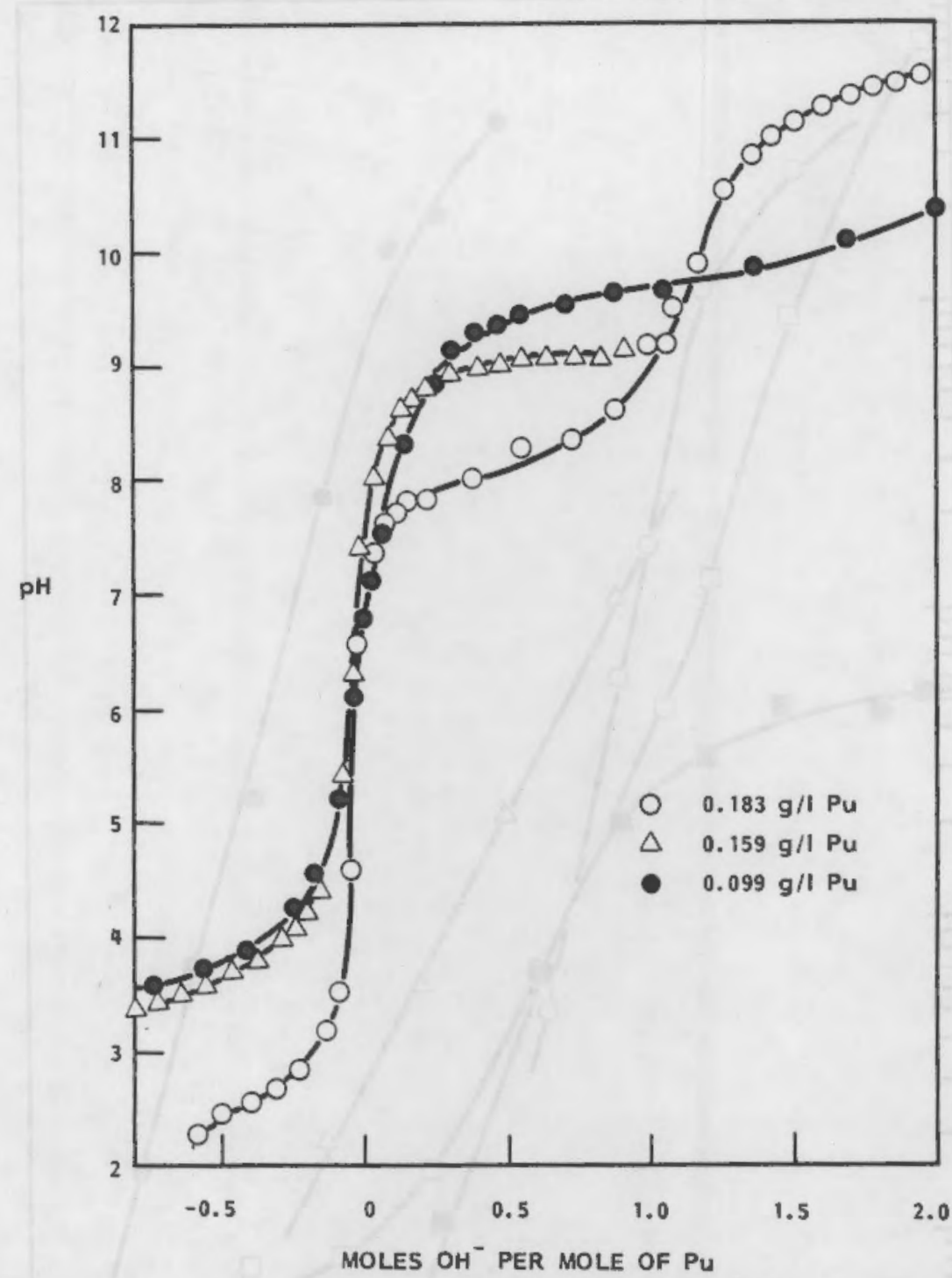

FIGURE F-6. Acid-Base Titration Curves of Pu(V)

\section{Pu(IV) Exchange}

A low $\mathrm{pH}$ is required to maintain soluble $\mathrm{Pu}$ (IV) because of hydrolysis and polymer formation. Low $\mathrm{pH}$ rules out the use of low silica/alumina zeolites like Types $X$ and $Y$. High silica/alumina zeolites like clinoptilolite are unlikely to show a favorable selectivity coefficient for Pu(IV) in the presence of relatively high acid concentrations.

\section{Pu(V) Exchange}

No ion exchange data are available for $P u(V)$ exchange on zeolites. Because $\mathrm{Pu}(V)$ exists as a relatively large univalent ion, $\mathrm{PuO}_{2}{ }^{+}$; in solution, 


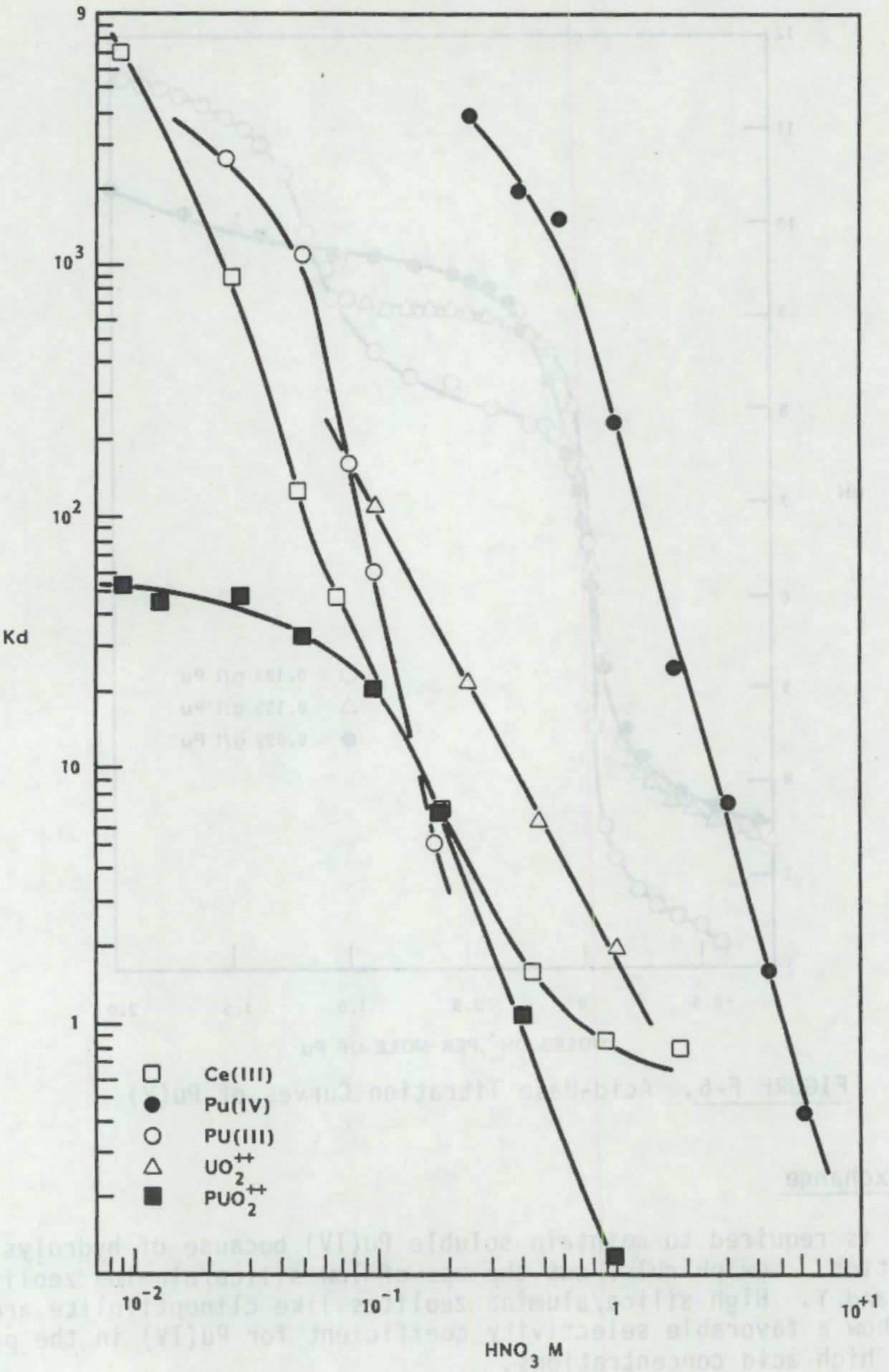

FIGURE F-7. The Dependence of the Distribution Coefficients on the Equilibrium $\mathrm{HNO}_{3}$ Concentration (Gal and Ruvarac 1964) 


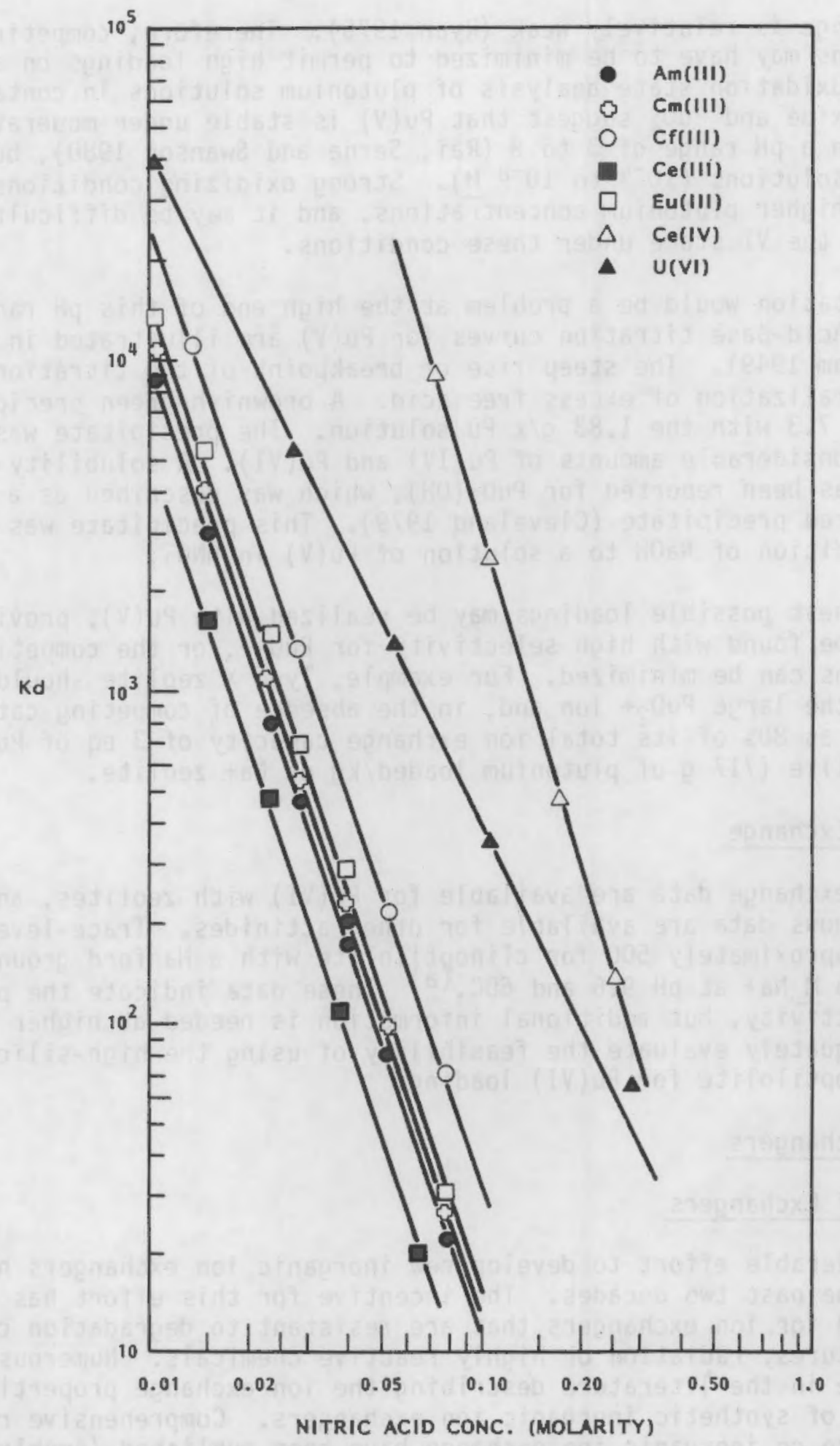

FIGURE F-8. Change in the Distribution Coefficient of Zirconium Phosphate $\left(\mathrm{PO}_{4} / \mathrm{Zr}=1.34\right)$ with Nitric Acid Concentrate at $75^{\circ} \mathrm{C}$ and Equilibrium Time of 4-5 Hours (Horwitz 1966) 
cation exchange is relatively weak (Ryan 1975). Therefore, competing cation concentrations may have to be minimized to permit high loadings on an ion exchanger. Oxidation state analysis of plutonium solutions in contact with $\mathrm{Pu}$ (IV) hydroxide and $\mathrm{PuO}_{2}$ suggest that $\mathrm{Pu}(\mathrm{V})$ is stable under moderate oxidizing conditions in a pH range of 3 to 8 (Rai, Serne and Swanson 1980), but only in very dilute solutions $\left(10^{-4}\right.$ to $\left.10^{-8} \mathrm{M}\right)$. Strong oxidizing conditions would be required at higher plutonium concentrations, and it may be difficult to avoid oxidation to the VI state under these conditions.

Precipitation would be a problem at the high end of this $\mathrm{pH}$ range above $0.01 \mathrm{M}$ Pu. Acid-base titration curves for $\mathrm{Pu}(\mathrm{V})$ are $i l l u s t r a t e d$ in Figure F-6 (Kraus and Dam 1949). The steep rise or breakpoint of the titration curves denotes neutralization of excess free acid. A brownish-green precipitate formed at $\mathrm{pH} 7.3$ with the $1.83 \mathrm{~g} / \ell \mathrm{Pu}$ solution. The precipitate was believed to contain considerable amounts of $\mathrm{Pu}$ (IV) and $\mathrm{Pu}(\mathrm{VI})$. A solubility product of $\sim 5 \times 10^{-10}$ has been reported for $\mathrm{PuO}_{2}(\mathrm{OH})$, which was described as a grey-white to rose-colored precipitate (Cleveland 1979). This precipitate was formed at $\mathrm{pH} 6.8$ by addition of $\mathrm{NaOH}$ to a solution of $\mathrm{Pu}(\mathrm{V})$ in $\mathrm{HNO}_{3}$.

The highest possible loadings may be realized with $\mathrm{Pu}(V)$, provided that a zeolite can be found with high selectivity for $\mathrm{PuO}_{2}{ }^{+}$, or the competing cation concentrations can be minimized. For example, Type $X$ zeolite should be able to accommodate the large $\mathrm{PuO}_{2}+$ ion and, in the absence of competing cations, may load as much as $80 \%$ of its total ion exchange capacity of 3 eq of $\mathrm{PuO}_{2}+/ \mathrm{kg}$ of hydrated zeolite (717 $\mathrm{g}$ of plutonium loaded $/ \mathrm{kg}$ of $\mathrm{Na}+$ zeolite.

\section{Pu(VI) Exchange}

No ion exchange data are available for $\mathrm{Pu}$ (VI) with zeolites, and very little analogous data are available for other actinides. Trace-level Kd's for U(VI) were approximately 500 for clinoptjlolite with a Hanford groundwater containing $0.015 \mathrm{M} \mathrm{Na}+$ at $\mathrm{pH} 9.6$ and $60 \mathrm{C}$. (a) These data indicate the possibility of some selectivity, but additional information is needed at higher concentrations to adequately evaluate the feasibility of using the high-silica zeolites such as clinoptilolite for Pu(VI) loading.

\section{Inorganic Exchangers}

\section{Types of Exchangers}

A considerable effort to develop new inorganic ion exchangers has taken place over the past two decades. The incentive for this effort has resulted from the need for ion exchangers that are resistant to degradation caused by high temperatures, radiation or highly reactive chemicals. Numerous articles are available in the literature describing the ion exchange properties of a wide variety of synthetic inorganic ion exchangers. Comprehensive reviews of the literature on inorganic ion exchange have been published (Amphlett 1964;

(a) Ames, L. L., 1982, Personal Communication. 
Churms 1965; Materova et al. 1965; Vesely and Pekarek 1972; Pekarek and Vesely 1972; Clearfield, Nancollas and Blessing 1973). The large number of synthetic inorganic ion exchange materiais (excluding zeolites) can be classified as follows:

\section{1. hydrous oxides}

2. acid salts of multivalent metals

3. salts of heteropoly acids

4. insoluble ferrocyanides

5. miscellaneous other substances.

In spite of the tremendous effort to develop the ion exchangers in the above classifications, very few commercial applications have taken place. Limited quantities of these materials have been available mostly through laboratory supply companies.

\section{Properties of Selected Inorganic Ion Exchangers}

Due to the limited commercial production of synthetic inorganic ion exchangers, little effort has been made to characterize physical properties pertinent to industrial use. Table F-5 lists several exchangers that have been promoted for industrial use, especially for radionuclide separations. Zirconium phosphate, an acid multivalent metal salt, has been the subject of numerous investigations. This exchanger was evaluated for plutonium sorption in the early period of transuranic chemistry research of the Manhattan Project (Ryan 1975). During the 1960 's, zirconium phosphate gels were investigated for removal of ${ }^{137} \mathrm{Cs}$ from acidic nuclear fuel reprocessing wastewaters (Amphlet $1964)$.

Zirconium phosphate can be prepared either as gel (amorphous) or as a crystalline substance. The formula given in Table F-5 is for the a crystalline form but can also represent a gel with a $\mathrm{P} / \mathrm{Zr}$ ratio of 2 (Clearfield, Nancollas and Blessing 1973). The crystalline zirconium phosphate is produced as fine particles only, whereas the gel can be produced in either fine or coarse particles. The ion exchange properties of the gel vary greatly, depending on the method of preparation and the $\mathrm{P} / \mathrm{Zr}$ ratio. Water forms an integral part of the structure, and complete dehydration causes a loss of ion exchange capacity. The ion exchange capacity drops to near zero if either the gel or crystalline form is heated above $500^{\circ} \mathrm{C}$.

Polyantimonic acid belongs to the hydrous oxide class of inorganic ion exchangers, but unlike the hydrous oxides of the tetravalent metals (e.g., hydrous zirconium oxide), it acts as a cation exchange in strong acids. This material is produced in powdered form and has been used in mixtures with asbestos to increase the porosity of the ion exchange beds used in experimental studies (Murphy et al. 1977). No information is available on pelletized forms of polyantimonic acid. This exchanger also depends on "structural water" for its ion exchange capacity. The structural water is lost when the exchanger is heated above $300^{\circ} \mathrm{C}$. 
TABLE F-5. Properties of Selected Inorganic Ion Exchangers

\begin{tabular}{|c|c|c|c|c|c|c|}
\hline Exchanger & Chemical Formula & $\begin{array}{c}\text { Total } \\
\text { Capacity, } \\
\text { Meq/g } \\
\end{array}$ & $\begin{array}{l}\text { Physical } \\
\text { Form } \\
\end{array}$ & $\begin{array}{l}\text { Decompo- } \\
\text { sition } \\
\text { Temp., }{ }^{\circ} \mathrm{C} \\
\end{array}$ & $\begin{array}{c}\text { Water } \\
\text { Content, } \\
\text { wt\% } \\
\end{array}$ & References \\
\hline $\begin{array}{l}\text { Zirconium } \\
\text { Phosphate }\end{array}$ & $\mathrm{Zr}\left(\mathrm{HPO}_{4}\right)_{2} \cdot \mathrm{H}_{2} \mathrm{O}$ & $4-5$ & $\begin{array}{l}\text { powder or } \\
\text { granular }\end{array}$ & 500 & 6 & $\begin{array}{l}\text { Clearfield } \\
\text { et al. 1973; } \\
\text { Ahrland et } \\
\text { al. } 1964\end{array}$ \\
\hline $\begin{array}{l}\text { Polyantimonic } \\
\text { Acid }\end{array}$ & $\left(\mathrm{H}_{2} \mathrm{O}\right)_{2} \mathrm{Sb}_{2} \mathrm{O}_{5}(\mathrm{OH})_{2}$ & 5 & powder & 300 & 18 & $\begin{array}{l}\text { Abe 1979; } \\
\text { Abe and Itoh } \\
1980\end{array}$ \\
\hline $\begin{array}{l}\text { Hydrous Titanium } \\
\text { Oxide }\end{array}$ & $\mathrm{H}_{2}\left(\mathrm{Ti}_{2} \mathrm{O}_{5} \mathrm{H}\right)$ & 4 & powder & 500 & 4 & $\begin{array}{l}\text { Tallant 1979; } \\
\text { Dosch 1981 }\end{array}$ \\
\hline $\begin{array}{l}\text { Ammonium } \\
\text { Molybdophosphate }\end{array}$ & $\left(\mathrm{NH}_{4}\right)_{3}\left[\mathrm{PMO}_{12} \mathrm{O}_{40}\right] \cdot \mathrm{H}_{2} \mathrm{O}$ & 1.6 & powder & 400 & 1 & $\begin{array}{l}\text { Smit et al. } \\
1959 \text {; } \\
\text { Wendlandt } \\
1970\end{array}$ \\
\hline $\begin{array}{l}\text { Ferrocyanide } \\
\text { Molybdate }\end{array}$ & {$\left[\mathrm{H}_{4} \mathrm{Fe}(\mathrm{CN})_{6}\right]_{4}\left[\mathrm{MoO}_{3}\left(\mathrm{H}_{2} \mathrm{O}\right)_{x}\right]_{16}$} & 4 & granular & NA & variable & $\begin{array}{l}\text { Baetsle } \\
\text { et al. 1965; } \\
\text { Baetlse } \\
\text { et al. } 1966\end{array}$ \\
\hline
\end{tabular}


Hydrous titanium dioxide, also known as sodium titanate when produced in its sodium form, has been evaluated by Sandia Laboratories for decontamination of defense wastes. The sodium titanate is produced in powdered form; however, pelletized forms have been prepared (Dosch 1981). The pelletized forms of sodium titanate had acceptable crush strength ( 5 lb for $1 / 16$ in. pellets), but the ion exchange capacity of the pellets could not be established due to the high variability of the results. Hydrous titanium dioxide would be expected to act as an anion exchanger in strong acid solutions. It loses its ion exchange capacity when "structural water" is removed by heating to about $500^{\circ} \mathrm{C}$.

Ammonium molybdophosphate belongs to the class "salts of heteropoly acids" and was originally developed as a highly specific exchanger for $\mathrm{Cs}^{+}$(Smit, Robb and Jacobs 1959). This material is stable in acid, but not in strong alkali. It has a relatively low ion exchange capacity and decomposes at about $400^{\circ} \mathrm{C}$. It is expected to lose $\mathrm{NH}_{3}$, as well as water, upon decomposition at high temperatures.

Ferrocyanide molybdate is an insoluble ferrocyanide cation exchanger that is also highly specific for $\mathrm{Cs}^{+}$. It can be prepared in granular form suitable for large ion exchange columns. No information is available on decomposition temperature.

\section{Ion Exchange Behavior}

Transuranics. Ion exchange reactions for the transuranic elements on inorganic ion exchangers have been reviewed through 1974 (Ryan 1975). Much of the literature on this subject concerns trace or low concentration of transuranics in solution in competition with relatively high concentrations of other ions, particularly $\mathrm{H}^{+}$. Distribution ratios for these systems are useful in developing separation processes, but the ratios can only indicate trends with respect to loadings at higher transuranic concentrations and low competing ion concentrations. Ion exchange isotherms with competing ions, I, in equivalent ratios, I/Pu, are needed to accurately compute maximum possible plutonium loadings for a given binary system.

\section{Pu(III) Exchange. Trace level distribution coefficients for Pu(III),} (IV), (VI), and Ce(III) and U(VI), in the presence of varying concentrations of nitric acid and $0.02 \mathrm{M}$ redox stabilizers [hydrazine for $\mathrm{Pu}(\mathrm{III}), \mathrm{NaNO}_{2}$ for $\mathrm{Pu}(\mathrm{IV})$, and $\mathrm{KBrO}_{3}$ for $\left.\mathrm{Pu}(\mathrm{VI})\right]$, are presented in Figure $\mathrm{F}-7$ for zirconium phosphate. Sorption of $\mathrm{Pu}$ (VI) or $\mathrm{PuO}_{2}{ }^{+2}$ appears to be weaker than $\mathrm{Pu}$ (III); however, this may be explained by the presence of $K+$ from the redox stabilizer $\mathrm{KBrO}_{3}$ used to hold the plutonium in the VI state (Gal and Ruravac 1964). The Kd curve for $U(V I)$ or $\mathrm{UO}_{2}+^{2}$ is probably a better indicator of $\mathrm{Pu}(\mathrm{VI})$ sorption. The $\mathrm{UO}_{2}+^{2}$ appears to be more strongly sorbed than $\mathrm{Pu}$ (III) above $0.1 \mathrm{M}$ nitric acid. The Pu(IV) is much more strongly sorbed than Pu(III).

Additional Kd data in nitric acid is given in Figure $F-8$ for trivalent lanthanides and actinides and $\mathrm{Ce}$ (IV) and U(VI) with zirconium phosphate. Sorption for the trivalent ions appears weaker than sorption for either Ce(IV) or $U(V I)$. The $K d$ values for $C e(I I I)$ are lower in Figure F-8 relative to 
Figure F-7, probably as a result of differences in temperature and possible differences in preparation of the zirconium phosphate exchangers. The, capacity of zirconium phosphate with $\mathrm{PO}_{4} / \mathrm{Zr}$ mole ratios of 1.34 and 1.13 for $\mathrm{Nd}$ (III) at $\mathrm{pH} 2.0$ and $75^{\circ} \mathrm{C}$ is $0.60 \mathrm{meq} / \mathrm{g}$ and $0.35 \mathrm{meq} / \mathrm{g}$, respectively (Horwitz 1966). These mole ratios of $\mathrm{PO}_{4} / \mathrm{Zr}$ were utilized to prepare the zirconium phosphate because higher ratios resulted in greater hydrolysis of the zirconium phosphate and release of phosphate which might interfere with the exchanger reaction.

Distribution coefficients for several actinides and lanthanides with titanate ion exchange material (hydrous titanium oxide) are given in Figure $\mathrm{F}-9$. Trivalent ions $\mathrm{Eu}^{3}$ and $\mathrm{Gd}+3$ (also assumed trivalent $\mathrm{Am}$ and $\mathrm{Cm}$ ) exhibit $\mathrm{Kd}^{\prime}$ 's that are about $1 / 10$ of the $\mathrm{Ce}^{+{ }_{3}}$ in Figure $\mathrm{F}-7$ for zirconium phosphate.

Pu(IV) Exchange. The distribution coefficients for Pu(IV) shown in Figure $\mathrm{F}-7$ show strong sorption of this ion by zirconium phosphate. High plutonium loadings in the presence of strong nitric acid would greatly simplify feed preparation from plutonium product streams from the Purex solvent extraction process. A potential problem exists with sorption of tetravalent ions such as Pu(IV) on zirconium phosphate, wherein sorption may be irreversible for these ions (Vesely and Pekarek 1972).

Plutonium (IV) sorption on polyantimonic acid (PA) appears very favorable relative to ammonium molybdophosphate (AMP) and ammonium phosphotungstale (APW) and is comparable to that for zirconium phosphate as illustrated in Figure F-10. The addition of phosphoric acid during the preparation of PA forms polyphosphoantimonic acid (PPA), which exhibited the highest $K d$ values of the exchangers studied over the range of $2 \mathrm{M}$ to $10 \mathrm{M}$ nitric acid. Column breakthrough capacities for $\mathrm{Pu}$ (IV) $(0.0007 \mathrm{M}$ to $0.00 \overline{\mathrm{O}} \mathrm{M})$ in $\mathrm{HNO}_{3}(0.3 \mathrm{M}$ to $3 \mathrm{M})$ are given in Table F-6. At $10.2 \%$ breakthrough plutonium, the capacity of PA with

TABLE F-6. Breakthrough Capacity of Exchanger PA(a)

Feed Composition

\begin{tabular}{|c|c|}
\hline $\mathrm{HNO}_{3}(\mathrm{M})$ & $\mathrm{Pu}(\mathrm{ug} / \mathrm{ml})$ \\
\hline 0.3 & 192 \\
\hline 0.5 & 164 \\
\hline 1.0 & 200 \\
\hline 2.0 & 200 \\
\hline 3.0 & 200 \\
\hline
\end{tabular}

Breakthrough Capacity

\begin{tabular}{cc}
$\left.\frac{\text { of } P A}{\text { At } 1 \% \text { BT }} / \mathrm{g}\right), 60^{\circ} \mathrm{C}$ \\
\hline 8.3 & $\frac{\text { At } 10 \% \mathrm{BT}}{10.2}$ \\
7.2 & 8.7 \\
7.0 & 8.0 \\
5.2 & 6.7 \\
1.0 & 1.5
\end{tabular}

(a) Weight of exchanger - $1 \mathrm{~g}$; Column dimension $-1 \mathrm{~cm}(\mathrm{i} . \mathrm{d}) \times 12 \mathrm{~cm}(\mathrm{ht})$; Flow rate $-0.1-0.2 \mathrm{me} / \mathrm{min}$ 


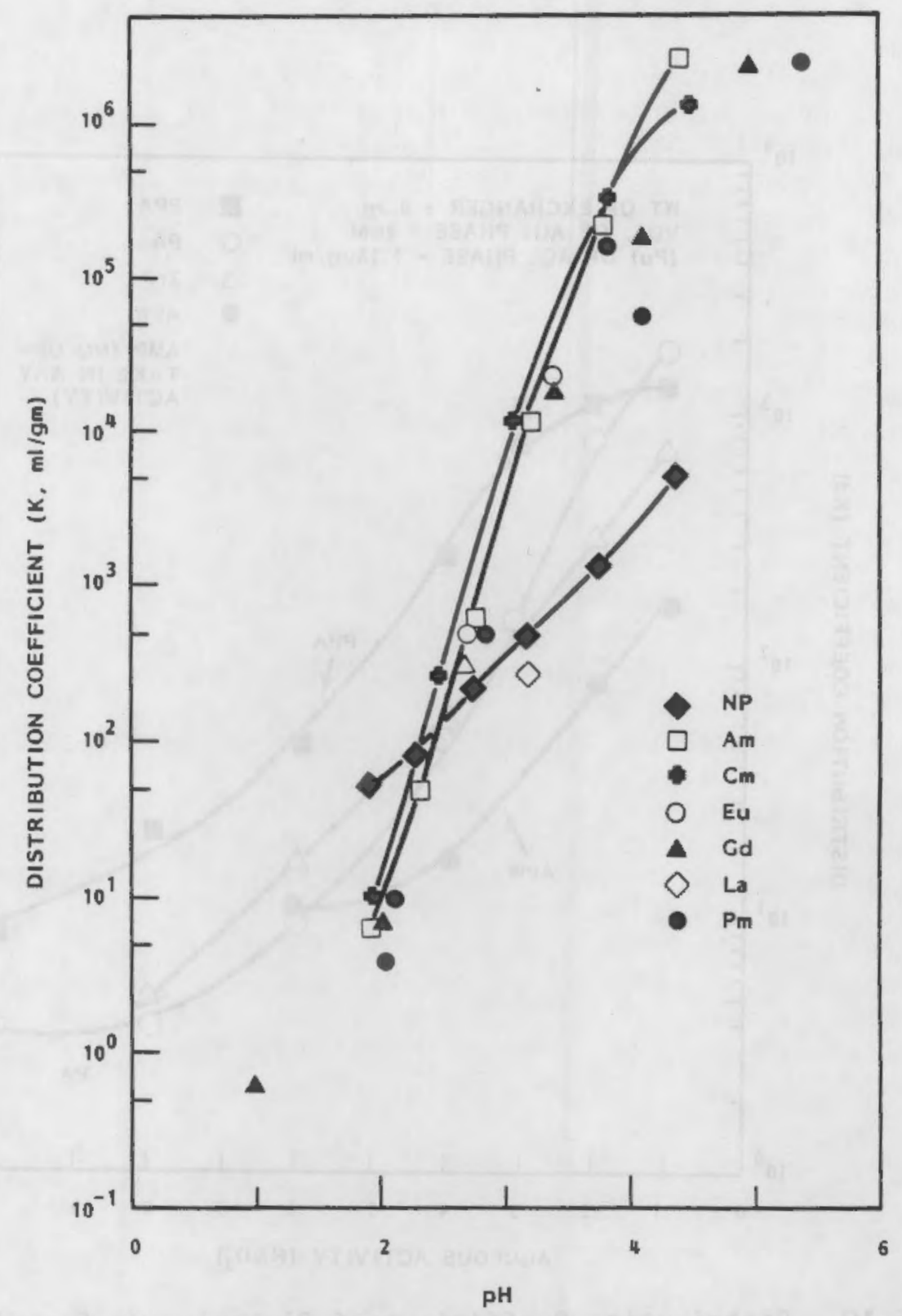

FIGURE F-9. Distribution Coefficients (Kd) of Certain Lanthanides and Actinides on Titanate Ion Exchange Material

Conditions:

1. $0.25 \mathrm{~g}$ exchanger in $15 \mathrm{ml}$ solutions

2. $\mathrm{pH}$ adjusted with dilute $\mathrm{HNO}_{3}$ or $\mathrm{NaOH}$

3. Temp. $20^{\circ}-28^{\circ} \mathrm{C}$

$0.0007 \mathrm{M} \mathrm{Pu}$ in $0.3 \mathrm{M} \mathrm{HNO}_{3}$ would be only $4 \times 10^{-5} \mathrm{meq} / \mathrm{g}$. Column data indicate that elution of the plutonium should take place immediately after loading is completed to avoid excessive "tailing" of the plutonium in the eluate. This suggests that plutonium may be very difficult to elute after long periods of time with a plutonium-loaded shipping canister with this exchanger. 


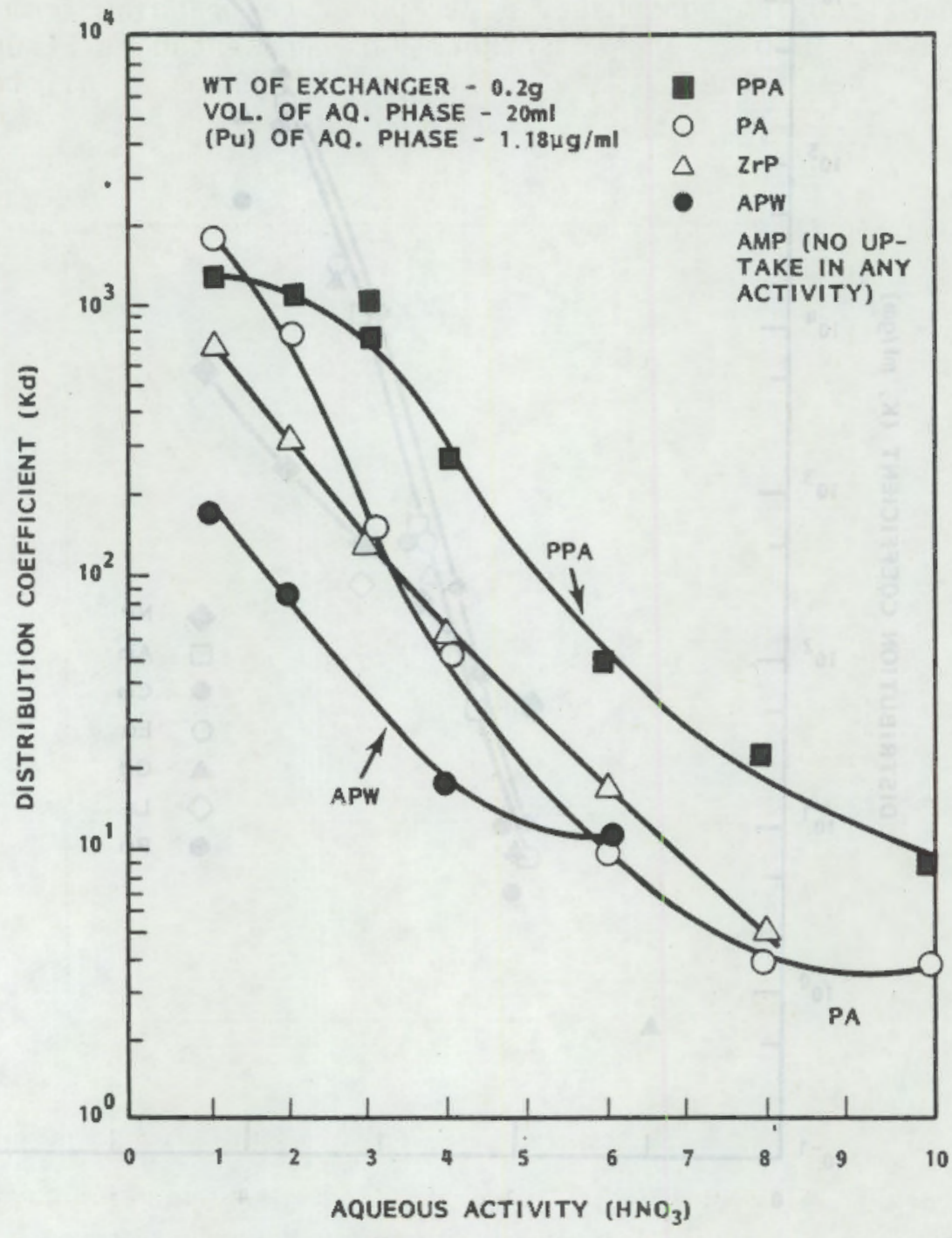

FIGURE F-10. Distribution Coefficient of Plutonium on Some Inorganic Ion Exchangers (Murphy et al. 1977)

\section{Pu(v) Exchange}

Sorption of pentavalent actinides by inorganic exchangers is reported to be very weak (Ryan 1975).

\section{Pu(VI) Exchange}

Distribution coefficients for $\mathrm{UO}_{2}+2$ indicate stronger sorption for $\mathrm{PU}$ (VI) than $\mathrm{Pu}(\mathrm{III})$ as illustrated in Figures $\mathrm{F}-7$ and $\mathrm{F}-8$ (as previously mentioned; the $\mathrm{Kd}$ 's for $\mathrm{Pu}(\mathrm{VI})$ in Figure $\mathrm{F}-7$ are probably biased low due to presence of $\mathrm{KBrO}_{3}$ in equilibrium solution). Exchange isotherms are reported for $\mathrm{UO}_{2}+^{2}$ at 
an ionic strength of $0.3 \mathrm{M}\left[\mathrm{HNO}_{3}+\mathrm{UO}_{2}\left(\mathrm{NO}_{3}\right)_{2}\right]$ for amorphous, semicrystalline and crystalline zirconium phosphate, at temperatures ranging from $25^{\circ} \mathrm{C}$ to $250^{\circ} \mathrm{C}$ (Ruvarac and Vesely 1970). These isotherms are presented in Figures F-11, $\mathrm{F}-12$, and $\mathrm{F}-13$. The isotherms show unfavorable exchange at all temperatures

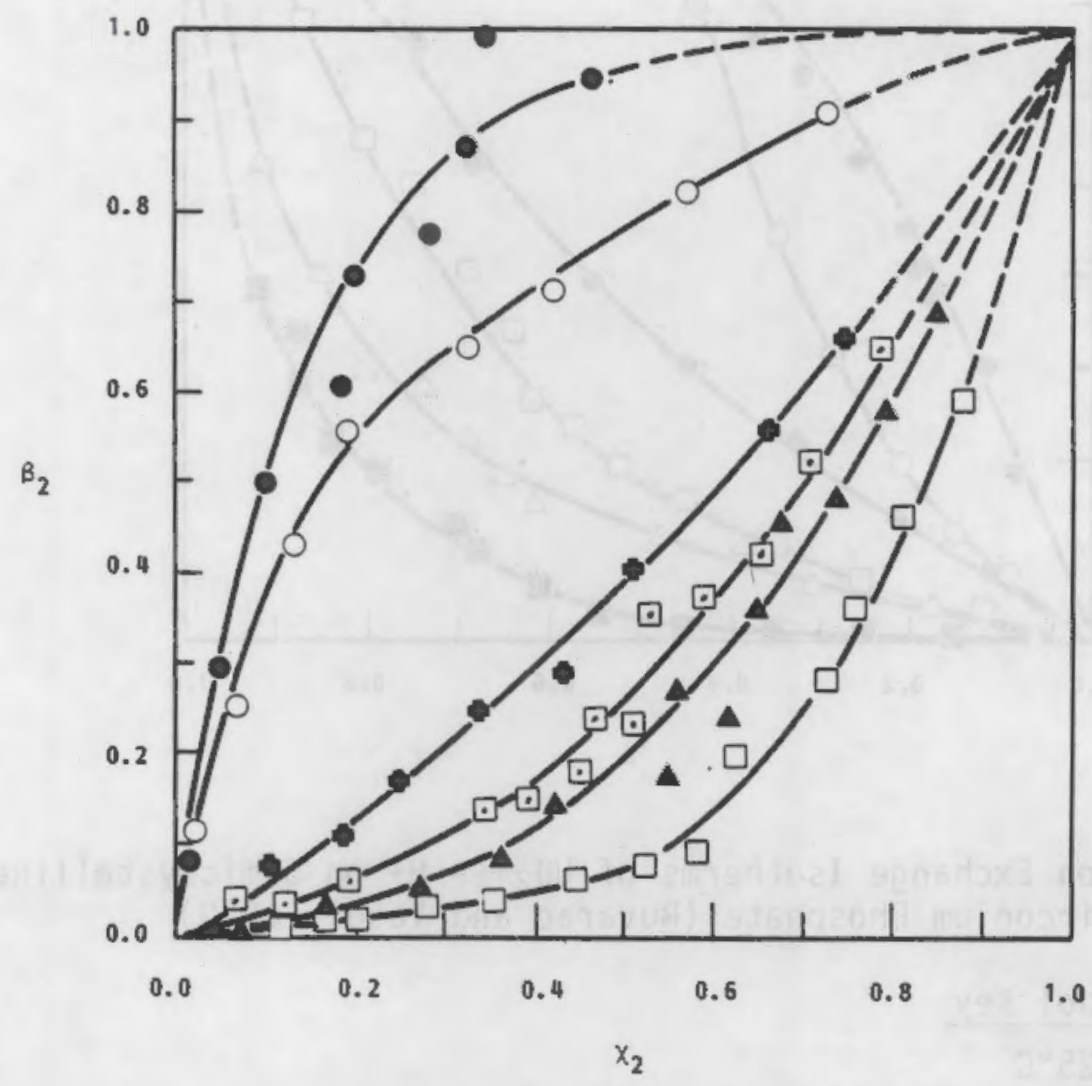

FIGURE F-11. Ion Exchange Isotherms of $\mathrm{UO}_{2}+{ }^{2}--\mathrm{H}+$ on Amorphous Zirconium Phosphate (Ruvarac and Vesely 1970).

Symbol Key

$x_{2}$-uranyl equivalent fraction in the solution

$B_{2}$-uranyl equivalent fraction in the solid

$\square-25^{\circ} \mathrm{C}$

$\triangle-50^{\circ} \mathrm{C}$

口- $80^{\circ} \mathrm{C}$

- $-100^{\circ} \mathrm{C}$

O $-175^{\circ} \mathrm{C}$

$-250^{\circ} \mathrm{C}$ 


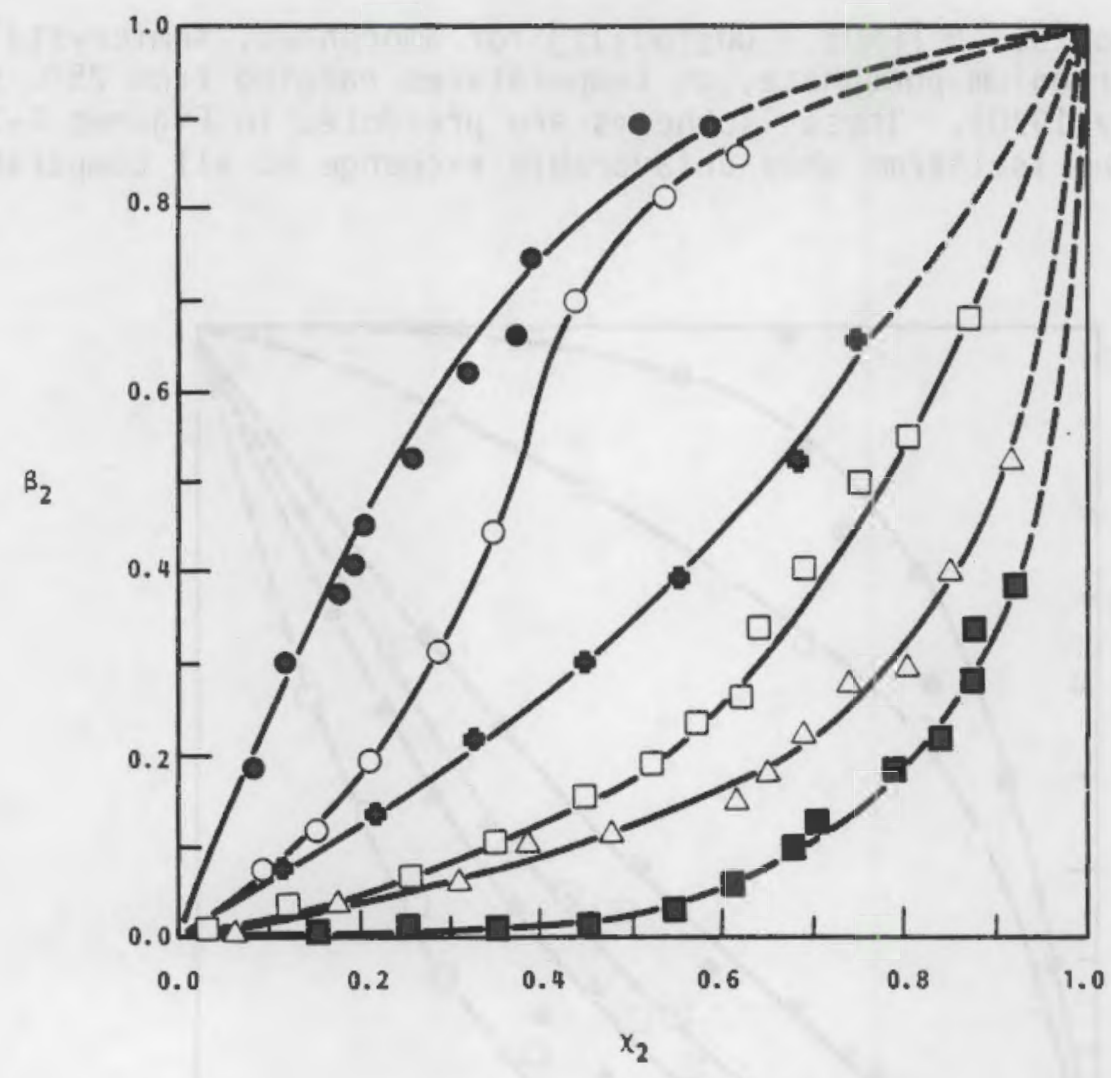

FIGURE F-12. Ion Exchange Isotherms of $\mathrm{UO}_{2}{ }^{2}--H+$ on Semicrystalline Zirconium Phosphate (Ruvarac and Vesely 1970)

$$
\begin{aligned}
& \text { Symbol Key } \\
& \hline-25^{\circ} \mathrm{C} \\
& \Delta-50^{\circ} \mathrm{C} \\
& \square-80^{\circ} \mathrm{C} \\
& -100^{\circ} \mathrm{C} \\
& 0-175^{\circ} \mathrm{C} \\
& -250^{\circ} \mathrm{C}
\end{aligned}
$$

below $100^{\circ} \mathrm{C}$. Therefore, in order to obtain high loadings, the nitric-acid-to$\mathrm{UO}_{2}+2$ ratios must be minimized. The exchange capacities of the zirconium phosphate materials used to determine the isotherms are given in Table F-7. As noted there, only one hydrogen ion is exchanged in the nitric acid solutions, which reduces the capacity listed in Table F-5 for zirconium phosphate. 


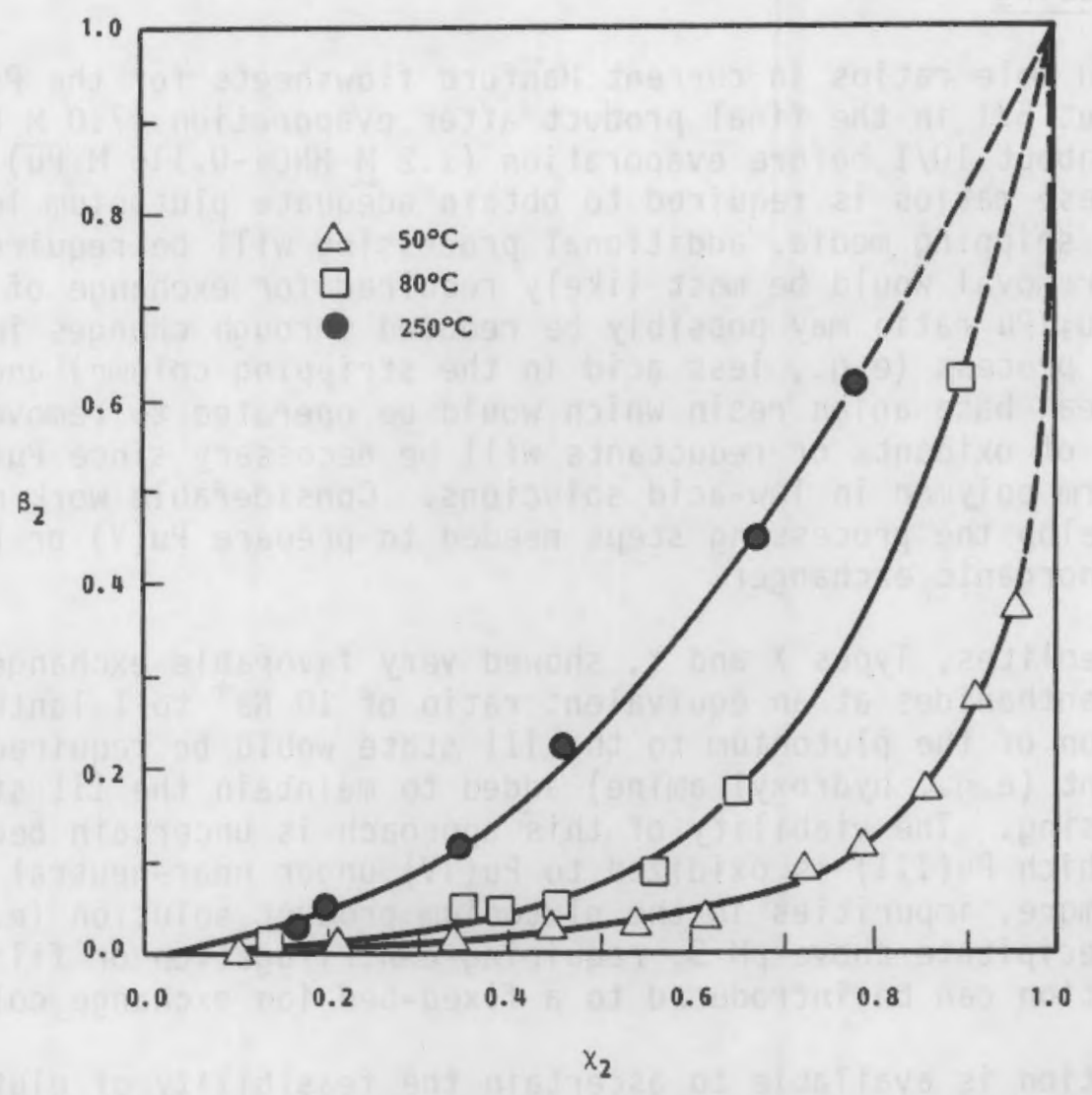

FIGURE F-13. Ion Exchange Isotherms of $\mathrm{UO}_{2}+2--\mathrm{H}+$ on Crystalline Zirconium Phosphate (Ruvarac and Vesely 1970)

TABLE F-7. Characteristics of Zirconium Phosphate Samples (Ruvarac and Vesely 1970)

\begin{tabular}{|c|c|c|c|}
\hline Crystalline Form & $\underline{P} / Z r$ & $\begin{array}{c}\text { Stoichiometric } \\
\text { Formula }\end{array}$ & $\begin{array}{c}\text { Stoichiometric Capacity for } \\
1 \text { Hydrogen Ion Exchanged } \\
\text { (m-equil. } / \mathrm{g})\end{array}$ \\
\hline \multirow[t]{2}{*}{ Amorphous } & $2-02$ & $\mathrm{ZrO}_{2} \cdot \mathrm{P}_{2} \mathrm{O}_{5} \cdot 3 \cdot 25 \mathrm{H}_{2} \mathrm{O}$ & 3.09 \\
\hline & & {$\left[\mathrm{Zr}\left(\mathrm{HPO}_{4}\right)_{2} \cdot 2 \cdot 25 \mathrm{H}_{2} \mathrm{O}\right]$} & \\
\hline Semicrystalline & $1-96$ & $\mathrm{Zr}\left(\mathrm{HPO}_{4}\right)_{2} \cdot 2 \cdot 14 \mathrm{H}_{2} \mathrm{O}$ & 3.21 \\
\hline Crystalline & $1-86$ & $\mathrm{Zr}\left(\mathrm{HPO}_{4}\right)_{2} \cdot \mathrm{H}_{2} \mathrm{O}$ & 3.32 \\
\hline
\end{tabular}


Plutonium Processing

The $\mathrm{HNO}_{3} / \mathrm{Pu}$ mole ratios in current Hanford flowsheets for the Purex process are about $5 / 1$ in the final product after evaporation $(7.0 \mathrm{M} \mathrm{HNO} 3-$ $1.46 \mathrm{MPu})$ and about $10 / 1$ before evaporation $\left(1.2 \mathrm{M} \mathrm{HNO}_{3}-0.116 \mathrm{MPu}\right.$ ). (a) If a reduction in these ratios is required to obtain adequate plutonium loading on an ion exchange shipping media, additional processing will be required for acid removal. Acid removal would be most likely required for exchange of $\mathrm{Pu}(\mathrm{V})$ and $\mathrm{Pu}(\mathrm{VI})$. The $\mathrm{HNO}_{3} / \mathrm{Pu}$ ratio may possibly be reduced through changes in the solvent extraction process (e.g., less acid in the stripping column) and/or by ion exchange on a weak base anion resin which would be operated to remove acid only. Addition of oxidants or reductants will be necessary since Pu(IV) will hydrolyze or form polymer in low-acid solutions. Considerable work may be required to develop the processing steps needed to prepare $\mathrm{Pu}(\mathrm{V})$ or $\mathrm{Pu}(\mathrm{VI})$ for loading an an inorganic exchanger.

The open zeolites, Types $X$ and $Y$, showed very favorable exchange isotherm for trivalent lanthanides at an equivalent ratio of $10 \mathrm{Na}^{+}$to 1 lanthanide (III). Reduction of the plutonium to the III state would be required, and a holding reductant (e.g., hydroxyl amine) added to maintain the III state during loading and rinsing. The viability of this approach is uncertain because of the ease with which $\mathrm{Pu}$ (III) is oxidized to Pu(IV) under near-neutral pH conditions. Furthermore, impurities in the plutonium product solution (e.g., $\mathrm{Fe}^{+{ }_{3}}$ and $\mathrm{C}_{2}^{+}$) may precipitate above $\mathrm{pH} 3$, requiring centrifugation or filtration before the solution can be introduced to a fixed-bed ion exchange column.

No information is available to ascertain the feasibility of eluting or removing plutonium from a dehydrated ion exchanger. Conversion of other plutonium oxidation states to the IV state during or after the loading step will almost certainly cause problems during the elution step. Plutonium oxide formed inside the exchanger would require severe chemical treatment (e.g., $\mathrm{HNO}_{3}-\mathrm{HF}$ ) for dissolution and removal.

\section{CONCLUSIONS}

- Feed preparation requirements appear to be minimal for loading Pu(III) on Type $X$ and $Y$ zeolites as long as the plutonium can be easily maintained in the III state. Neutralization of a dilute plutonium product solution from the Purex process to $\mathrm{pH} 5-7$ would be required to avoid degradation of the zeolite; this is expected to be difficult to accomplish. Plutonium-III is very easily oxidized to $\mathrm{Pu}$ (IV), which would precipitate in the zeolite and be very difficult to remove.

- Reduction in the $\mathrm{HNO}_{3} / \mathrm{Pu}$ ratio of plutonium product solutions would probably be required to attain adequate loadings of $\mathrm{Pu}(\mathrm{V})$ or $\mathrm{Pu}(\mathrm{VI})$ on inorganic ion exchangers. Considerable work may be required to

(a) Swanson, J. L. 1982. Personal Communication. 
develop a process to prepare $\mathrm{Pu}(\mathrm{V})$ or $\mathrm{Pu}(\mathrm{VI})$ in low-acid solution. The highest theoretical loading computed for a zeolite was $0.7 \mathrm{~kg}$ of $\mathrm{Pu}(\mathrm{V}) / \mathrm{kg}$ of Na-Type $X$ zeolite.

- The question of an allowable moisture content for the shipping media will have to be resolved to ascertain the feasibility of using inorganic exchangers. The inorganic exchangers require a certain amount of "structural water" to maintain their ion exchange capacity. Most zeolites can be dehydrated to essentially zero moisture without suffering loss of ion exchange capacity.

- Information is needed on the plutonium elution characteristics of dehydrated ion exchangers, and as to whether the desired oxidation state of the plutonium can be maintained throughout the loading, drying, transport, and elution phase.

- More information is needed on the Pu(V) and Pu(VI) ion exchange characteristics with both the zeolites and inorganic ion exchangers.

- Some question remains as to whether these exchangers are sufficiently selective for $\mathrm{Pu}(V)$ or $\mathrm{Pu}(V I)$ to minimize feed preparation requirements (e.g., acid removal).

- Impact testing of the inorganic exchangers would be required to determine the amount of fine particulates formed by crushing of the exchangers.

- A qualitative summary of properties pertinent to the use of these exchangers for plutonium shipping media is given in Table F-8. 
TABLE F-8. Qualitative Summary of Exchanger Properties

\begin{tabular}{|c|c|c|c|c|}
\hline Exchanger & $\begin{array}{c}\text { Acid } \\
\text { Resistance } \\
\end{array}$ & $\begin{array}{c}\text { Resistance to } \\
\text { Distribution by } \\
\text { Dehydration }\end{array}$ & $\begin{array}{l}\text { Ion } \\
\text { Exchange } \\
\text { Capacity }\end{array}$ & $\begin{array}{l}\text { Available } \\
\text { Physical } \\
\text { Form } \\
\end{array}$ \\
\hline Type 4A & $p(c)$ & $G(a)$ & G & G \\
\hline Type $13 \mathrm{X}$ & $P$ & G & G & G \\
\hline SK 40 & $F^{(b)}$ & G & G & G \\
\hline AW 500 & $\mathrm{~F}$ & G & $F$ & G \\
\hline Zeolon & G & G & $\mathrm{F}$ & G \\
\hline $1010-A$ & G & G & $F$ & G \\
\hline $\begin{array}{l}\text { Zirconium } \\
\text { Phosphate }\end{array}$ & G & $P$ & G & G \\
\hline $\begin{array}{l}\text { Polyantimonic } \\
\text { Acid }\end{array}$ & G & $P$ & G & $P$ \\
\hline $\begin{array}{l}\text { Hydrous Titanium } \\
\text { Oxide }\end{array}$ & G & $\mathrm{P}$ & G & P \\
\hline $\begin{array}{l}\text { Ammonium- } \\
\text { Molybdophosphate }\end{array}$ & G & $\mathrm{p}$ & $\mathrm{F}$ & P \\
\hline $\begin{array}{l}\text { Ferrocyanide } \\
\text { Molybdate }\end{array}$ & G & $P$ & G & G \\
\hline
\end{tabular}
(a) $G=$ Good
(b) $F=$ Fair
(c) $P=$ Poor 


\section{REFERENCES}

Abe, M. 1979. "Synthetic Inorganic Ion-Exchange Materials--XVIII." J. Inorg. Nucl. Chem. 41:85-89.

Abe, M., and T. Itoh. 1980. Synthetic Inorganic Ion-Exchange Materials--XXV." J. Inorg. Nucl. Chem. 42:1641-1644.

Ahrland, S., J. Albertsson, L. Johansson, B. Niklgard and L. Nilsson. 1964. "Inorganic I on Exchangers." Acta. Chem. Scand. 18:1357-1367.

Ames, L. L. 1964. "Zeolite Type X Equilibria with Trivalent Cerium and Yttrium Cations." HW-SA-3433, General Electric Company, Richland, Washington.

Amphlet, C. B. 1964. "Inorganic Ion Exchanges." Elsevier, Amsterdam.

Baetsle, L. H., D. Van Deyck and D. Huys. 1965. "Ferrocyanide Molybdate, A New Inorganic Ion Exchanger--I." J. Inorg. Nucl. Chem. 27:683-695.

Baetsle, L. H., D. Huys and D. Van Deyck. 1966. "Ferrocyanide Molybdate, A New Inorganic Ion Exchanger--II." J. Inorg. Nucl. Chem. 28:2385-2394.

Breck, D. W. 1974. Zeolite Molecular Sieves. John Wiley and Sons, New York.

Breck, D W. 1979. "Potential Uses of Natural and Synthetic Zeolites in Industry." Conference Proceeding on the Properties and Applications of Zeolites, The City University, London, April 18-20, 1979, R. P. Towsend, Ed., Special Publication No. 33, The Chemical Society, Burlington House, London, WIVOBN.

Bruce, F. R. 1958. "The Concentration and Purification of Uranium and Plutonium by Ion Exchange." In Progress in Nuclear Energy Series III Process Chemistry, F. R. Bruce, J. M. Fletcher and H. H. Hyman, eds., Pp. 362-376. Pergamon Press, New York.

Churms, S. C. 1965. "Inorganic Ion Exchangers" (I) (II) (III) (IV) (V) S. African Ind. Chemist. $19,26,45,68,87,148$.

Clearfield, A. G. H. Nancollas and R. H. Blessing. 1973. "New Inorganic Ion Exchangers." In Ion Exchange and Solvent Extraction, J. C. Marinsky and Y. Marcus, eds. Marcel Dekker, New York.

Cleveland, J. M. 1979. The Chemistry of Plutonium. American Nuclear Society, La Grange Park, Illinois.

DeMier, W. V. 1963. "Dehydration of Inorganic Ion Exchange Media." HW-78893, General Electric Company, Richland, Washington. 
Dosch, R. G. 1981. Final Report on the Application of Titanates, Niobates and Tantalates to Neutralized Defense Waste Decontamination--Materials, Properties, Physical Forms, and Regeneration Techniques. Sand 80-1212, Sandia National Laboratories, Albuquerque, New Mexico.

Flanigan, E. M. 1980. "Molecular Sieve Zeolite Technology--The First TwentyFive Years." Pure and Applied Chemistry, 52, 2191-2211.

Gal, I., and A. Ruvarac. 1964. "The Separation of Plutonium from Uranium and Fission Products on Zirconium Phosphate Columns." J. Chromatog 13:549-555.

Horwitz, E. P. 1966. "The Sorption of Certain Transplutonium Ions on Amorphous Zirconium Phosphates." J. Inorg. Nuclear Chem 28:1469-1478.

Kraus, K. A., and J. R. Dam. 1949. "Hydrolytic Behavior of Plutonium(V). Acid Constant of Plutonyl Ion." The Transuranic Elements Natural Nuclear Energy Series, IV, G. T Seaborg, J. J. Katz and W. M. Manning, eds. pp. 466-477. McGraw-Hill Book Co., New York.

Materova, E. A., F A. Belinskaya, E. A. Militsina and P. A. Skabichevskii. 1965. "Inorganic Ion Exchangers." Ionnyi Abmen. Leningr. Gos. Univ., 3.

Mercer, B. H., and W. C. Schmidt. 1966. Storage of Long-Lived Fission Products on Alumino-Silicate Zeolites. BNWL-SA-532, Pacific Northwest Laboratory, Richland, Washington.

Murphy, T. S., M. Ananthakrishnan, P. C. Mayou Kutty, V. V. S. Mani and M. N. Nadkarni. 1977. Studies on Inorganic Ion Exchangers Part I. "Application of Polyantimonic Acid for Polishing of Uranium Product of Reprocessing Stream." H.A.R.C. 915, Bhabha Atomic Research Center, Bombay, India.

01son, D. H., and H. S. Sherry. 1968. "An X-ray Study of Strontium--Sodium Ion Exchange. An Example of a Two-Phase Zeolite System." J. Phys. Chem. 72, 4095 .

Pekarek, V., and V. Vesely. 1972. "Synthetic Ion Exchangers-II." Talonta, 19:1245-1283.

Prevot, I., and P. Regnaut. 1958. "The Purification and Concentration of Solution of Plutonium by Ion Exchange." In Progress in Nuclear Energy Series III Process Chemistry, F. R. Bruce, J. M. Fletcher and H. H. Hyman, eds. pp. 377-385. Pergamon Press, New York.

Rai, D., R. J. Serne and J. L. Swanson. 1980. "Solution Species of Plutonium in the Environment." J. Environ. Quality 9.

Ruvarac, A., and V. Vesely. 1970. "Thermodynamics of Uranyl Ion Exchange on Zirconium Phosphates of Various Crystallinities." J. Inorg. Nucl. Chem.

32: $3939-3948$. 
Ryan, J. L. 1975. "Ion Exchange Reaction." In Gmelin Handbook ders

Amorganischen Chemie Band 21, Transurane, Teil D-2: Chemie in Losung, von Gunter Koch, ed., pp. 373-408. Springer-Verlag, New York.

Smit, J., Van R., W. Robb and J. J. Jacobs. 1959. "Cation Enchange on Ammonium. Molybdophosphate - I." J. Inorg. Nucl. Chem. 12,:104-112.

Tallant, D. R. 1979. Application of Inorganic Sorbent in Actinide Separation Processes. NITS, PC A02/MF A01, National Technical Information Service, Springfield, Virginia.

Vesely, V., and V. Pekarek. 1972. "Synthetic Inorganic Ion Exchangers - I." Talanta, 19:219-262.

Wendlandt, W. W. 1970. "The Thermolysis of Ammonium 12-Molybdophosphate." Anal. Chim. Acta 20:267-270. 

APPENDIX G

REDUCTION/ELIMINATION OF PUO $\mathrm{O}_{2}$ AEROSOLIZATION IN SHIPPING ACCIDENTS

L. R. BUNNELL 
APPENDIX G

REDUCTION/ELIMINATION OF PU02 AEROSOLIZATION IN SHIPPING ACCIDENTS

\section{INTRODUCTION}

The purpose of this work was to critically examine present practices in shipment of $\mathrm{PuO}_{2}$ as a fine powder and to suggest changes that would reduce or eliminate $\mathrm{PuO}_{2}$ aerosolization in shipping accidents. In these accidents, the major threats to containment are by fire or a combination of fire and impact.

A materials science background was used to examine present practices, beginning with the $\mathrm{PuO}_{2}$ form itself and concluding with outer packaging.

Ultimate cost was not considered in these suggested changes, except to eliminate ideas that would obviously be unacceptable from a cost standpoint. The result is a list of suggestions that could be adopted independently or in toto, as further analysis dictates. The suggested changes are as follows:

- pressing the $\mathrm{PuO}_{2}$ into pellets, without use of binder

- minimizing plastic bagout material, changing from PVC to polyethylene or polypropylene

- using a metallic gettering alloy to capture products of plastic decomposition

- upgrading all other packings to PAT-2 performance standards by use of similar materials and design.

PRESSED-PELLET FORM FOR PU0 2

Large quantities of $\mathrm{PuO}_{2}$ are shipped, principally for use in the manufacture of mixed-oxide fuel, in which case the $\mathrm{PuO}_{2}$ is blended with $\mathrm{UO}_{2}$, pressed into pellets and sintered at high temperatures to produce a solid solution. Blending and solid-solution formation are both aided by use of finely divided $\mathrm{PuO}_{2}$, which means that it will contain a fairly high fraction of respirable particles.

With a gel process, $\mathrm{PuD}_{2}$ spheres can be made which are much less dusty than the present powder. Such material may ultimately be used, but was not considered a sufficiently mature process for this analysis. $\mathrm{PuO}_{2}$ could even be shipped as a metal, with the user performing final conversion to powder. Concerns over nuclear proliferation and the pyrophoric nature of the metal effectively eliminate this option. 
Pressing the $\mathrm{PuO}_{2}$ into a pellet will decrease the amount of material that is dispersible in fire or impact-and-fire scenarios which are relevant to air or truck transport. These scenarios would not involve the multiple impacts necessary to reduce pellets to original particle size distribution. It is recommended that no binder be used in pressing the pellets, in order to eliminate a gas generation source during a fire, and to facilitate regaining the original size distribution. A binderless pellet could be reduced to powder by ball milling. Besides ball mills, other granulators exist which could yield a powder of the desired fineness.

A binderless pellet can be produced using a conventional punch and die set in a hydraulic press, at a pressure of 10,000 to 20,000 psi. If the press is hand operated, the pellets should be as large as possible to minimize the number of pressing operations. When pressing a powder without organic binder additions, atmospheric moisture present in the powder acts as a binder. The $\mathrm{PuO}_{2}$ powder of interest would be very dry if processed in a dry glove-box atmosphere, and it might be necessary to add $1 \%$ to $2 \%$ moisture. This could be done by storing the powder overnight in a sealed container with a water source.

Stronger and higher-quality pellets free of laminations (a common defect) can be produced by isostatic pressing in a device such as that illustrated in Figure G.1. Such pellets would be less regular in shape, but would probably require fewer hand operations. The device in Figure G.1 is an adaptation of

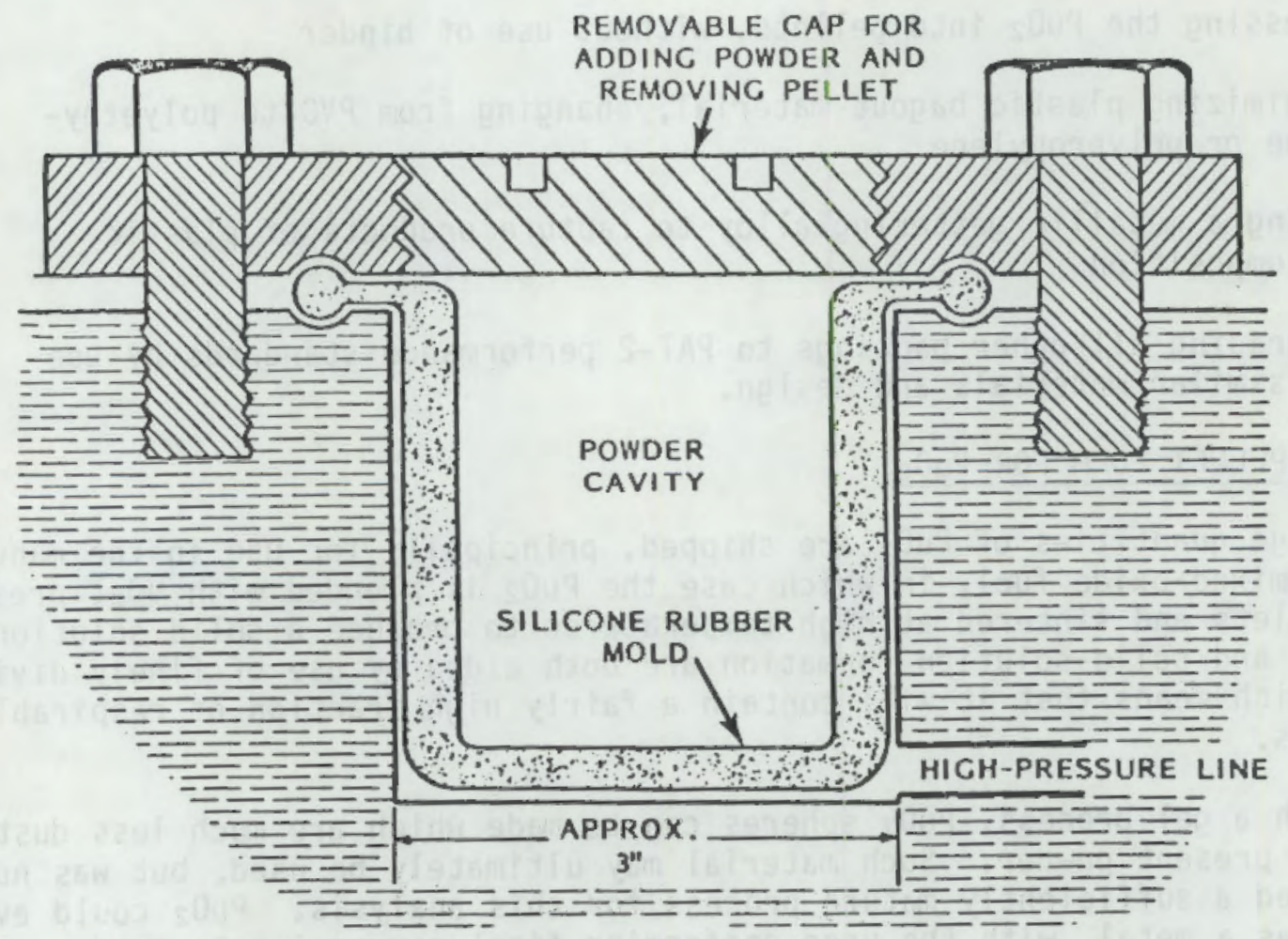

FIGURE G.1. Conceptual Drawing of an Isostatic Pressing Arrangement Which Could be Built Into the Floor of a Giove Box 
the method used commercially to produce spark plug insulators and appears to be a very convenient way to produce large pellets in a glove box. Even a major rupture is not of great consequence.

\section{PLASTIC MATERIAL MINIMIZATION}

In current practice, the $\mathrm{PuO}_{2}$ powder is placed in a metal can with a slipfit lid while in the glove box, and the lid is secured with plastic tape. This procedure is as compatible with pellets as with powder, and there is no reason to change it.

The next step is to take the can out of the glove box, using conventional "bag-out" procedures for contamination control. The can is passed into a polyvinyl chloride (PVC) bag, which protrudes from the glove box, and the plastic is then tightly bundled and cut off with a heated knife, which fuses the plastic and traps any loose $\mathrm{PuO}_{2}$ particles which may be present.

In an accident involving fire, this plastic (inside the innermost pressure barrier) is the major source of gas pressurization (Anderson et al. 1981) which provides stored energy for $\mathrm{PuO}_{2}$ dispersal if containment integrity is lost. The most practical method for reducing pressure is to reduce the amount of plastic, but the plastic used has several desirable characteristics which preclude eliminating it completely. A method of reducing the plastic used in the inner vessel is to redesign the plastic bag to fit the metal can as well as possible and by making flat bag-out seals. The plastic itself might also be changed fom PVC, which generates $\mathrm{HCl}$ on decomposition, to polyethylene or polypropylene, which generate somewhat larger volumes of noncorrosive gases such as $\mathrm{H}_{2} \mathrm{O}, \mathrm{CO}_{2}, \mathrm{CO}$, and $\mathrm{H}_{2}$. These latter gases are also more amenable to gettering, as explained below. Thermoplastics such as polyethylene are eminently suited to the "bag-out" procedure used in glove boxes. The plastic is fused at a modest temperature (ca. $125^{\circ} \mathrm{C}$ ) and effectively traps loose $\mathrm{PuO}_{2}$ particles, immobilizing them. Considering the different modifications of polyethylene or polypropylene that are available, there is probably at least one version with properties (1ike tear resistance) which are equivalent to PVC.

More extreme changes, such as aluminum foil bonded to thin plastic to provide a sealing surface, would certainly reduce plastic inventory. However, the contamination control probably would not be so effective.

\section{USING A METALLIC GETTERING ALLOY TO REDUCE CONTAINMENT PRESSURIZATION}

It would be desirable to have a simple and passive method for minimizing, or preventing, pressurization of the sealed containment by plastic decomposition gases. These are special alloys, mainly based on the Al-Zr system (Porta et al. 1962), which are used commercially to getter large quantities of gases like $\mathrm{CO}$ and $\mathrm{H}_{2}$. These alloys function best when heated to a few hundred degrees centigrade, as the sealed containment vessel would be during the latter stages of a fire. Table G.1 lists the gettering rates of a typical getter alloy, at $100^{\circ} \mathrm{C}$ and $400^{\circ} \mathrm{C}$, but under conditions of high vacuum. At atmospheric pressure, volumes of gas reacted per unit time are much less. The ability to 
reduce gas pressure is a function of exposed getter surface area, so it would be reasonable to coat the entire inner surface of the pressure container with the getter alloy. The efficacy of this approach is probably best determined by a simple experiment, in which a sealed pressure bomb containing plastic is controllably heated while its pressure is monitored. The gases in Table G.1 are, except for $\mathrm{N}_{2}$, among the decomposition products expected for a simple plastic such as polyethylene or polypropylene, but there is no indication as to how the getter alloy would perform with $\mathrm{HCl}$, the main decomposition product of PVC. In the event that PVC is retained, a slightly different approach might be required; a reactive metal could be used to scavenge the resultant hydrogen. The getter approach requires further investigation, some of it experimental, but would seem to have potential for reducing pressures borne by the inner pressure barrier.

TABLE G.1. Gettering Rates at $100^{\circ} \mathrm{C}$ and $400^{\circ} \mathrm{C}$ and at a Gas Pressure of $3 \times 10^{-6}$ torr for $1 \mathrm{~cm}^{2}$ of $5 \mathrm{t} 101$ Alloy Getters,
and After a Gas Exposure of $3 \times 10^{-5}$ torr-min

$\begin{array}{lrlr}\frac{\text { Gas }}{\mathrm{C} 0} & \frac{100^{\circ} \mathrm{C}}{200 \mathrm{~cm}^{3} \mathrm{~s}^{-1}} & \frac{400^{\circ} \mathrm{C}}{1600 \mathrm{~cm}^{3} \mathrm{~s}^{-1}} \\ \mathrm{H}_{2} & 620 \mathrm{~cm}^{3} \mathrm{~s}^{-1} & 2110 \mathrm{~cm}^{3} \mathrm{~s}^{-1} \\ \mathrm{~N}_{2} & 50 \mathrm{~cm}^{3} \mathrm{~s}^{-1} & 260 \mathrm{~cm}^{3} \mathrm{~s}^{-1}\end{array}$

(a) (Porta et a1. 1962)

\section{ABLATIVE PACKAGING MATERIALS}

An ablative material is one which absorbs significant quantities of energy by sacrificial chemical reactions. These reactions and other attendant energy absorption processes greatly restrict the heat flow to the underlying material. Modern ablative materials have been developed for such tasks as protecting aerospace vehicles from aerodynamic heating during hypersonic flight and resisting the extreme conditions encountered in rocket motor nozzles (Baer 1964).

Ablative materials which will perform in the extreme environments above are generally composed of plastics because of their high heat of decomposition per unit volume. In order to provide dependable, high-level mechanical properties and promote adherance of char, glass fibers are generally used as reinforcement. The char layer resulting from plastic decomposition is held in place by the glass, where it acts as a good insulator. The char also provides a bed in which decomposition gases from the underlying plastics are heated, absorbing more energy. Another mechanism for energy loss is provided by a char of high surface emittance, such that its outer surface can radiate heat to the environment. Melting of glass fibers is a final avenue for energy absorption. 
Present ablative materials are designed to be used in environments much more extreme than the fire exposure anticipated for shipping accidents, but the design exposure time is tens of seconds or a few minutes, rather than the onehour exposure which must be resisted by the $\mathrm{PuO}_{2}$ packaging materials. Performance of present ablatives in terms of energy absorption per unit mass actually increases with exposure severity, so it is possible that performance will not be as spectacular as imagined. Test conditions under which these highperformance materials were evaluated bear little relation to those in a jet fuel fire.

There are applications for ablators in which unreinforced plastics, even a thermoplastic like polyethylene, are used. The longer-term, lower-heat flux required for $\mathrm{PuO}_{2}$ packaging materials precludes this type of ablator, which would simply heat uniformly and melt. A nonmelting thermoset is thus indicated, such as a phenolic resin, reinforced with glass fibers. Because of its high strength and toughness, this sort of material is also more likely to survive impact force.

The design of the PAT-2 shipping container includes two types of wood-redwood and maple--between inner and outer containments. Although these woods were chosen primarily for high energy absorption during impact, wood can function as a natural ablative material under the right conditions. First, the outer containment must not be torn completely apart by any credible impact or impact plus slash; this was demonstrated for the PAT-2 container (Anderson et al. 1981). Secondly, any punctures should be small, so as to limit the supply of oxygen to the wood; this was also demonstrated by Anderson et al. (1981) for the PAT-2. If the outer containment had no holes, the redwood charred to a depth of $<2$ inches in a fire of duration and temperature described in NUREG-0360 (NRC 1978) of $1010^{\circ} \mathrm{C}, 60 \mathrm{~min}$. Even when the outer container was punctured by previous puncture or slash, the maple char remained as char after the redwood had burned to ash. In even this case, low thermal conductivity of wood and its natural moisture content limited the temperature of the inner container to $<582^{\circ} \mathrm{C}$ (a conservative estimate). This peak temperature was obtained after the outer container was holed; it represents a very severe accident scenario. Even after this test, the intermost container was still leak-tight to. helium.

In summary, the ablative protection provided by well-chosen woods is completely adequate for the accidents which are likely to happen. Modern ablatives would be more costly and might reduce inner containment temperatures still further, but they would not perform nearly as well as impact energy absorbers. Wood is an impressive material for absorbing mechanical energy on a unit mass basis (Hill and Joseph 1979), which will be important for air transport. Thus, there is little incentive to change to a different packaging material. 


\section{REFERENCES}

Anderson, J.A., et al. 1981. PAT-2 (Plutonium Air Transportable Model 2) Safety Analysis Report. SAND-81-001, Sandia National Laboratories,

Albuquerque, New Mexico.

Baer, E., ed. 1964. Engineering Design for Plastics, Reinhold Publishing Corp., New York.

Hill, T. K., and W. W. Joseph. 1979. Energy-Absorbing Characteristics of Materials, JLA-74-0159, Sandia Laboratories, Albuquerque, New Mexico.

NRC. 1978. Qualification Criteria to Certify a Package for Air Transport of Plutonium. U.S. Nuclear Regulatory Commission, Washington, D.C.

Porta, P. D., et al. 1962. Trans. 8th Vacuum Symposium and 2nd International Congress, p. 229 , London. 
No. of

Copies

\section{OFFSITE}

D. 0. Nell is

Office of Nuclear Regulatory Research

Division of Risk Analysis

Washington, D.C. 20555

U.S. Nuclear Regulatory Commission

Division of Technical

Information and Document Control

7920 Norfolk Avenue

Bethesda, MD 20014

2 DOE Technical Information Center

U.S. Department of Energy

P.0. Box 62

Oak Ridge, TN 37830

H. H. Aaroe

West Virginia Department of Health

151 Eleventh Avenue

S. Charleston, WV 25303

N. Armstrong

University of Texas at Austin

Austin, TX 78712

Atomic Industrial Forum

7101 Wisconsin Avenue

Bethesda, MD 20014

L. G. Blalock

Transportation Bureau

U.S. Department of Energy

Dak Ridge, TN 37830
No. of

Copies

W. Brobst

The Transport Environment

SR 285 0ld Squaw Drive

Kitty Hawk, NC 27949

H. Calley

Environmental Protection Agency

Office of Radiation Programs (ANR-461)

Washington, DC 20460

W. Carriker

U.S. Department of Transportation (MTB)

4007 th Street SW

Washington, DC 20590

M. H. Carter

Georgia Institute of

Technology,

Department of Engineering

Atlanta, GA 3032B

S. Cole

Southern Interstate Nuclear

Board

919-18th St. NW

Room 510

Washington, DC 20006

R. F. Cumerland

UKEA

Atomic Energy Research

Establi ishment

Berkshire, Harwell

UNITED KINGDOM

J. Deal

U.S. Department of Energy (EPD-PSB)

Mail Stop E 201

Hashington, DC 20545 
No. of

Copies

Embassy of France. Scientific Attache 2011 J. Street NW Washington, DC 20006

W. S. Fellows

Southern States Energy Board

Suite 1230, 1 Exchange Place

Atlanta, GA 30338

G. R. Fleming

Occupational Safety \&

Emergency Planning

North Carolina Department of Transportation

Raleigh, NC 27611

F. Gunderloy

Environmental and Energy

Systems Division

Rockwell International

2421 West Hill Crest Drive

Newbury Park, CA 91320

C. M. Hardin

Conference of Radiation Control

Program Directors

65 Fountain Place

Frankfort, KY 40601

Executive Director

Hazardous Materials Advisory

Council

110017 th St. NW

Suite 908

Washington, DC 20036

G. Hill

Southern States Energy Board

One Exchange Place, Suite 1230

Atlanta, GA 30338

R. D. Hume

School of Public and

Environmental Affairs

Indiana University

400 E. Seventh Street

Bloomington, IN 47401
No. of

Copies

B. Kahn

Environmental Resources Center Georgia Institute of Technology Atlanta, GA 30326

C. L. Page

Texas A\&M University

Div. of $0 i 1$ \& Hazardous

Materials Control

Engineering Extension

College Station, TX 77843

R. Rawl

U.S. Department of

Transportation (MTB)

4007 th Street SW

Washington, DC 20590

L. Suiter

Tennessee Emergency Management Agency

3042 Cidco Drive

Nashville, TN 37204

P. W. Trott

3 M Company

Building 549-2N

Safety Department

St. Paul, MN 55101

L. L. Turner

Transportation Branch, U.S. Dept. of Energy

Savannah River Operations office

Box A

Aiken, SC 29801

U.S. Department of Energy

R. B. Chitwood, Chief

Transportation Branch

Division of Transportation and Fuel Storage

Mail Stop B107

Washington, DC 20545 
No. of

Copies

U.S. Department of Transportation

J. C. Allen

Office of Hazardous Materials Operations

Standards Division

DMT -213

2100 2nd Street, SW

Washington, DC 20590

W. W. Waggett

Rice University, Hazardous

Materials Section

P.0. Box 1892

Houston, TX 77001

V. Wingert

Federal Emergency Management Agency

609 Donohoe Building

550 C Street SW

Washington, DC 20472

J. J. Yezzi

U.S. Environmental Protection Agency

MERL, Ci

Edison, NJ 08817
No. of

Copies

ONSITE

2 Rockwell Hanford Operation

T. D. Cooper

J. V. Panesko

34 Pacific Northwest Laboratory

D. W. Dragnich

C. E. Elderkin

R. K. Hadlock

R. L. Bunnel

L. A. Franklin

S. F. Liebetrau

C. G. Lindsey (10)

B. W. Mercer

J. Mishima (10)

Publishing Coordination (2)

Technical Information VG (5) 


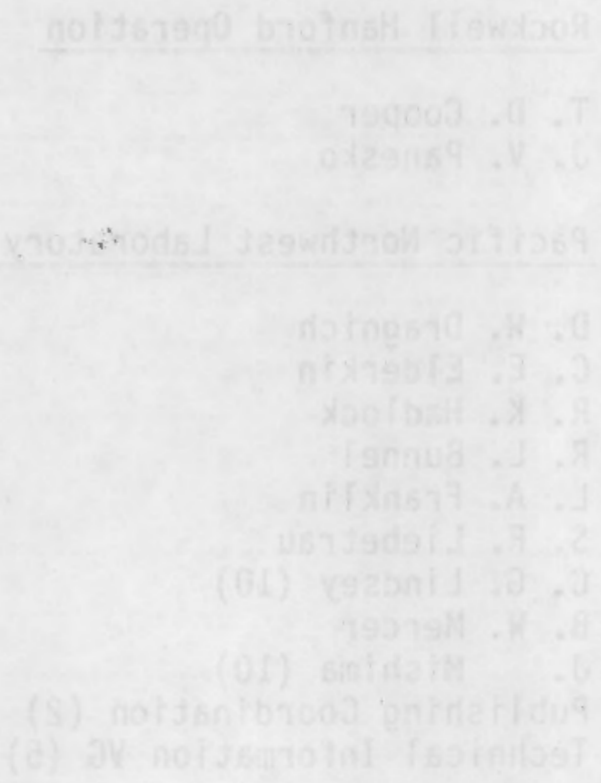

.

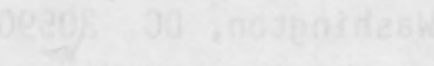

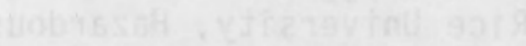

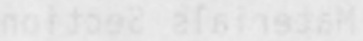

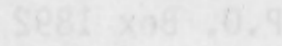

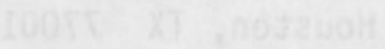

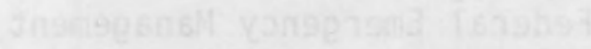

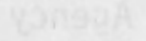

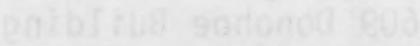

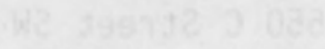

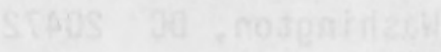

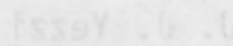

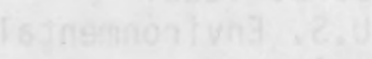
xangan

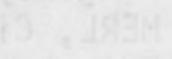

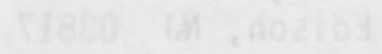




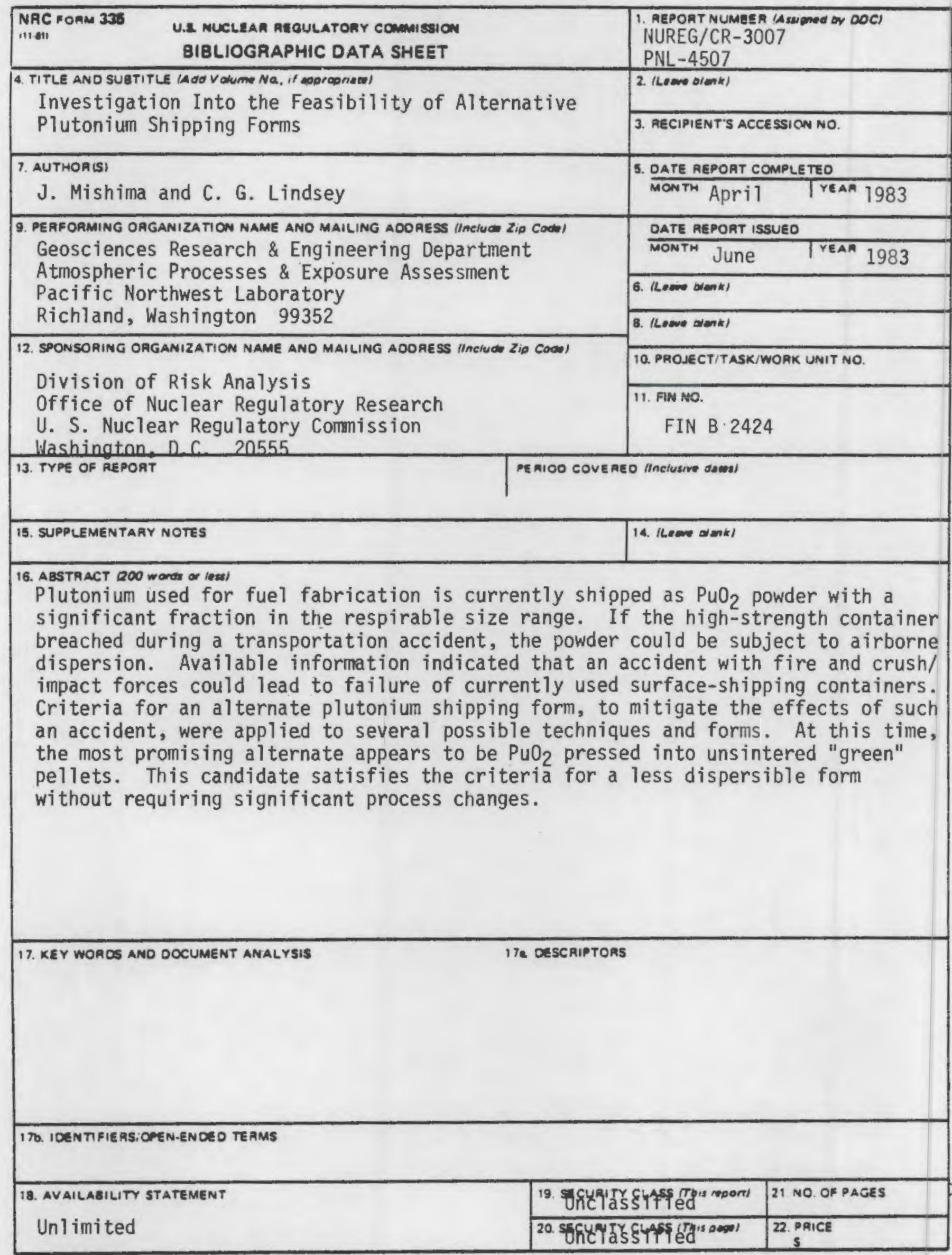




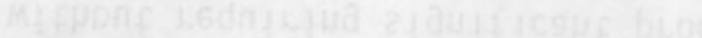

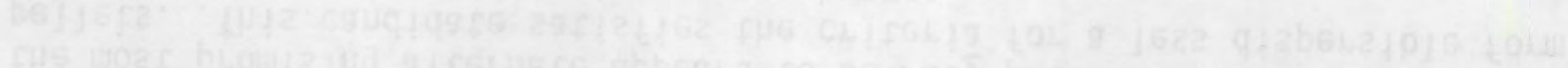

Whathen

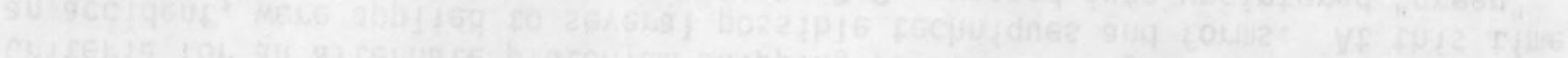

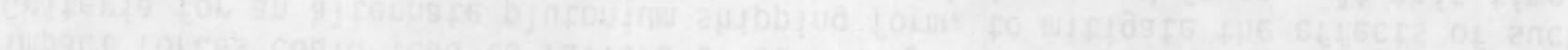

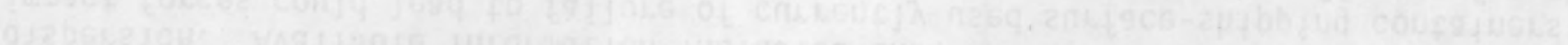

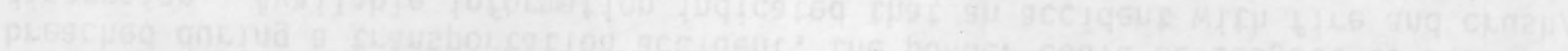

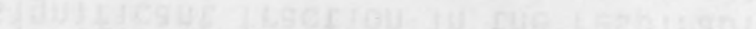

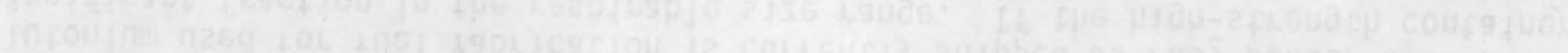

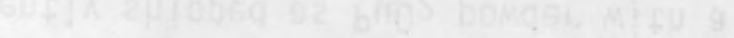

